Florida International University FIU Digital Commons

3-21-2002

\title{
Damage assessment of various structures by hurricane Andrew using aerial photographs
}

Sondwip Dhar

Florida International University

DOI: $10.25148 /$ etd.FI14062262

Follow this and additional works at: https://digitalcommons.fiu.edu/etd

Part of the Civil and Environmental Engineering Commons

\section{Recommended Citation}

Dhar, Sondwip, "Damage assessment of various structures by hurricane Andrew using aerial photographs" (2002). FIU Electronic Theses and Dissertations. 2792.

https://digitalcommons.fiu.edu/etd/2792 
FLORIDA INTERNATIONAL UNIVERSITY

Miami, Florida

DAMAGE ASSESSMENT OF VARIOUS STRUCTURES BY HURRICANE

ANDREW USING AERIAL PHOTOGRAPHS

A thesis submitted in partial fulfillment of the

requirements for the degree of

MASTER OF SCIENCE

in

ENVIRONMENTAL ENGINEERING

by

Sondwip Dhar

2002 
To: Dean Vish Prasad

College of Engineering

This thesis, written by Sondwip Dhar, and entitled Damage Assessment of Various Structures by Hurricane Andrew Using Aerial Photographs, having been approved in respect to style and intellectual content, is referred to you for judgment.

We have read this thesis and recommend that it be approved.

Hector R. Fuentes

Irtishad U. Ahmad

Walter Z. Tang; Major Professor

Date of Defense: May 21, 2002

The thesis of Sondwip Dhar is approved.

Dean Vish Prasad College of Engineering

Dean Douglas Wartzok University Graduate School

Florida International University, 2002 


\section{DEDICATION}

I dedicate this thesis to my wonderful parents. Without their understanding, support, and most of all love, the completion of this would not have been possible. 


\section{ACKNOWLEDGMENTS}

I am greatly appreciative to my major professor, Dr. Walter Z. Tang, for providing a significant opportunity to work on this project. I thank Dr. Tang for his wisdom, guidance, encouragement, understanding and patience throughout the duration of my graduate studies at FIU. His suggestions and support will always be cherished. I would also thank Dr. Stephen Leatherman, Director of International Hurricane Center, and Dr. Shahid Hamid at the Department of Finance for financial support throughout my M.S. program. I would like to express my appreciation to my committee members Irtishad U. Ahmad and Dr. Hector R. Fuentes for their valuable cooperation and priceless time. 


\section{ABSTRACT OF THE THESIS \\ DAMAGE ASSESSMENT OF VARIOUS STRUCTURES BY HURRICANE}

ANDREW USING AERIAL PHOTOGRAPHS

by

Sondwip Dhar

Florida International University, 2002

Miami, Florida

Professor Walter Z. Tang, Major Professor

The objective of this research was to assess the damage of various structures that were affected during Hurricane Andrew using aerial photographs. Different damage mechanisms were demonstrated. Quantitative damage assessment data was obtained by interpretation of aerial photographs. The damage data have been statistically analyzed. Various types of structures were studied and their typical damages were examined using the statistical analysis with respect to wind speed and zip codes. Illustrations of damages in different communities, damages to different roofs, and their possible failure mechanisms were also discussed. The damage data generated in this study can be used to predict damage during a hurricane after they are statistically correlated with the wind speed. 


\section{TABLE OF CONTENTS}

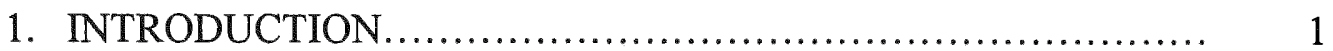

1.1. Types of Damage/Failure..................................... 2

1.1.1. Roofs............................................... 5

1.1.2. Cladding Selection and Attachment..................... 7

1.1.3. Roof Sheathing and Attachment....................... 9

1.1.4. Damage to Walls......................................... 11

1.1.5. Damage to Doors and windows......................... 15

1.1.6. Foundation damage.................................. 16

1.2. Causes of Damage/Failure.................................... 17

1.2.1. Roof Cladding Damage............................... 17

1.2.2. Sheathing Damage ................................... 18

1.2.3. Truss damage........................................ 18

1.2.4. Gable-end Damage................................. 18

2. FUNDAMENTALS OF AERIAL PHOTOGRAPHY................ 19

2.1. Photographic-Detailed Evaluation........................... 19

2.2. Photographic Resolution................................... 19

2.3. Photo reading.......................................... $\quad 20$

2.4. Photo Analysis............................................ 21

2.5. Photo Interpretation..................................... 21

3. WIND BEHAVIOR ON STRUCTURES .......................... 23

3.1. Suction Force ........................................... 23

3.2. Wind-borne debris....................................... 24

3.3. Hip Roof versus Gable Roof.............................. 28

3.4. Airflow Around the building............................... 29

3.5. Second Story Structure .................................. 37 
4. METHODOLOGY............................................... 38

4.1. Damage Assessment....................................... $\quad 38$

4.2. Saffir/Simpson's Scale....................................... $\quad 39$

4.3. Assumptions ............................................. $\quad 42$

4.4. Statistical Analysis.......................................... 43

4.5. Limitations.................................................. 44

5. DAMAGE MECHANISM...................................... 65

5.1. Effect of Immediate Surroundings........................... 65

5.2. Effect of Windborne Debris...................................... 65

5.3. Effect of Upstream Terrain................................... 66

5.4. Effect of Geometrical Parameters............................. 67

5.5. Effect of Wind Direction and Building Orientation.............. 67

5.6. Effect of Building Arrangement and Spacing..................... 68

5.6.1. Drag and Lift........................................ 69

5.6.2. Overturning Moments................................. 69

5.6.3. Tortional Moments.................................. 71

5.7. Interference Mechanism.................................... $\quad 72$

6. DAMAGE FACTORS......................................... 73

6.1. Shape Factor......................................... $\quad 73$

6.1.1. Forces on Basic Shapes.............................. 73

6.1.2. Aspect Ratio..................................... 74

6.2. Building Height....................................... $\quad 75$

7.2.1 Tall Buildings..................................... 78

7.2.2 Long Low Buildings.............................. 78

7. RESULT AND DISCUSSION ................................ 81

7.1 Residential buildings................................... 82

7.1.1 Single Family Houses................................ 82 
7.1.2 Single Family Duplex Houses.......................... 84

7.1.3 Mobile Homes......................................... 86

7.1.4 High Rise Residential Structures....................... 88

7.1.5 Town Houses........................................ 90

7.2 Public Buildings............................................. 92

7.2.1. School Buildings................................... 92

7.2.2. Shopping Centers................................... 94

7.3 Commercial Structures........................................ 96

7.4 Industrial Buildings......................................... 98

7.5 Concrete Structures........................................ 100

7.6 Ware Houses............................................ 102

7.7 Farm Structures.............................................. 104

7.8 Transportation Vehicles.................................... 106

7.9 Communication Towers.................................. 108

8. CONCLUSION ................................................ 110

9. RECOMMENDATIONS ...................................... 112

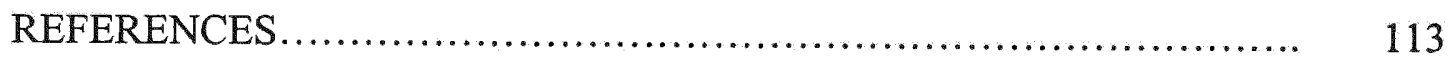

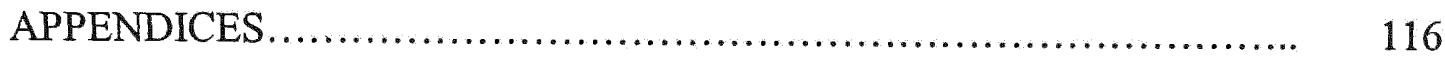




\section{LIST OF FIGURES}

FIGURE

PAGE

Figure 1.1. Wind perpendicular to the gable-end........................ 6

Figure 1.2. Typical Gable-end Details................................. 8

Figure 1.3. Wind effect on sheathing................................. 10

Figure 1.4. The windward wall experiences a positive pressure and the leeward wall experiences a negative pressure on roof...................... 12

Figure 1.5. Wind effect on gable-end ............................... 13

Figure 1.6. View of the windward and leeward wall..................... 14

Figure 3.1. Analysis of wind forces on roof............................ 25

Figure 3.2. Analysis of wind forces on side walls....................... 26

Figure 3.3. Openings on different sides of the building and the effect of such

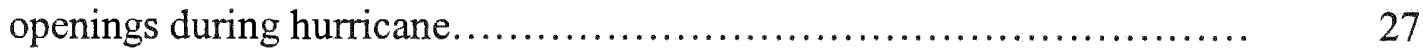

Figure 3.4. Overall wind direction surrounding a house................... 30

Figure 3.5. Flow pattern on the centerline of one, two, and three low buildings..................................................... 31

Figure 3.6. Average maximum suctions of roofs of different pitches....... 32

Figure 3.7. Pressure distribution for $20^{\circ}$ pitched roofs.................. 33

Figure 3.8. Pressure distribution for $20^{\circ}$ pitched roofs.................. 34

Figure 3.9. Pressure distribution for $15^{\circ}$ pitched roofs.................. 35

Figure 3.10. Pressure distribution for $30^{\circ}$ pitched roofs................. 36

Figure 4.1. Assumed distribution of \%damage during sever wind event... 43

Figure 4.2. Roof cover, Sheathing, Trusses, Gable-end and Overall Damage

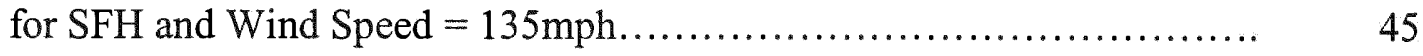

Figure 4.3. Probability Distribution Curve for SFH and Wind Speed $=$

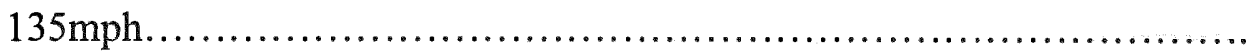

Figure 4.4. Roof cover, Sheathing, Trusses, Gable-end and Overall Damage

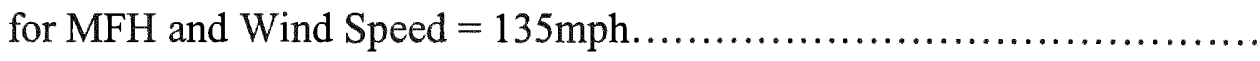

Figure 4.5. Probability Distribution Curve for MFH and Wind Speed $=135 \mathrm{mph}$. 
Figure 4.6. Roof cover, Sheathing, Trusses, Gable-end and Overall Damage

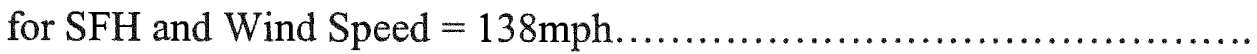

Figure 4.7. Probability Distribution Curve for SFH and Wind Speed $=$ $138 \mathrm{mph}$

Figure 4.8. Roof cover, Sheathing, Trusses, Gable-end and Overall Damage for $\mathrm{MFH}$ and Wind Speed $=138 \mathrm{mph}$

Figure 4.9. Probability Distribution Curve for MFH and Wind Speed $=138 \mathrm{mph}$.

Figure 4.10. Roof cover, Sheathing, Trusses, Gable-end and Overall Damage for SFH and Wind Speed $=140 \mathrm{mph}$.

Figure 4.11. Probability Distribution Curve for SFH and Wind Speed $=140 \mathrm{mph}$.

Figure 4.12. Roof cover, Sheathing, Trusses, Gable-end and Overall Damage for SFH and Wind Speed $=143 \mathrm{mph}$

Figure 4.13. Probability Distribution Curve for SFH and Wind Speed $=143 \mathrm{mph}$.

Figure 4.14. Roof cover, Sheathing, Trusses, Gable-end and Overall

Damage for SFH and Wind Speed $=143 \mathrm{mph}$

Figure 4.15. Probability Distribution Curve for SFH and Wind Speed $=135 \mathrm{mph}$.

Figure 4.16. Roof cover, Sheathing, Trusses, Gable-end and Overall

Damage for SFH and Wind Speed $=147 \mathrm{mph}$

Figure 4.17. Probability Distribution Curve for SFH and Wind Speed $=47 \mathrm{mph}$.

Figure 4.18. Roof cover, Sheathing, Trusses, Gable-end and Overall

Damage for SFH and Wind Speed $=147 \mathrm{mph}$

Figure 4.19. Probability Distribution Curve for SFH and Wind Speed $=147 \mathrm{mph}$.

Figure 4.20. Roof cover, Sheathing, Trusses, Gable-end and Overall Damage for SFH and Wind Speed $=147 \mathrm{mph}$ 
Figure 4.21. Probability Distribution Curve for SFH and Wind Speed $=147 \mathrm{mph}$.....

Figure 5.1. Drag coefficient of bodies at various Reynolds numbers........ 70

Figure 6.1. Pressure distribution on front centerline of tall building........ 76

Figure 6.2. Flow field around a large building........................... 79

Figure 7.1.1.1. Failure of wood framing system....................... 83

Figure 7.1.2.1. Elevated homes prone to roof damage.................... 85

Figure 7.1.3.1. Inadequately designed foundation....................... 87

Figure 7.1.4.1. Major cracks developed in the concrete slab.............. 89

Figure 7.1.5.1. Displacement of trusses............................. 91

Figure 8.2.1.1. Roof cover and sheathing damage..................... 93

Figure 8.2.2.1. Concrete roof damage................................. 95

Figure 7.3.1. Partially damaged low profile hip roof..................... 97

Figure 7.4.1. Installation and design shortcomings..................... 99

Figure 7.5.1. Insufficient reinforcement............................. 101

Figure 7.6.1. Weak wall foundation.................................. 103

Figure 7.7.1. Lack of adequate bracing support....................... 105

Figure 7.8.2. Displacing of heavy weight vehicles..................... 107

Figure 7.9.1. Weak pylon foundation................................ 109 


\section{INTRODUCTION}

On August 24, 1992, Southern Florida received a direct hit from hurricane Andrew, which came ashore with sustained winds of $145 \mathrm{mph}$ and gust up to $175 \mathrm{mph}$. Andrew first became a tropical depression and the first tropical storm of the season on August 16. The storm moved rapidly west and northwest during the next few days and reached hurricane strength on August 22.

In this study a quantitative damage assessment study was made on the building roof, sheathing, truss and gable end. Aerial photography was used for effective interpretation and detail s tudy w as c onducted with an approximate s cale of $1: 3000$ and w ithin $10 \%$ accuracy. One of the most common, versatile and economical forms of remote sensing is aerial photography. It's a science of deriving information about an object area or phenomena from a distance. The most common means of o btaining information is by measuring electromagnetic energy emanating or reflecting from the object of interest. The two basic processes involved are "data acquisition" and "data analysis". Aerial photographs are among the most important, widely available and commonly utilized kinds of remote sensed images.

Various types of damaged buildings were selected such as single-family homes, singlefamily d uplex houses, town h ouses, industrial a reas, the destruction w as a ssessed and their likely cause was determined. High winds were a major factor in majority of structural damages. Wind-borne debris caused missile impacts on the walls and roofs. 
Penetration of the building envelope by wind-borne debris was directly responsible for many catastrophic failures of the roof system. Failure of doors and windows due to wind and airborne debris breached the building envelope, which resulted in uncontrolled buildup of internal pressure that resulted in partial or complete blowouts of the major structural systems such as walls and roofs.

\subsection{Types of Damage/Failures}

Typical failures observed include complete collapse of roofing system in most of the dwellings and semi-engineered buildings, tiles and plywood sheets, failure of connections, failure of gable walls and progressive collapse of roof steel trusses. The hurricane had caused complete collapse of non-engineered buildings and heavy damage to a number of industrial structures, storage godowns, chimneys, cluster of housing, cinema halls, institutional/school buildings and factory buildings (Shanmugasundaram, et al., 2000).

During the Hurricane Andrew, majority of houses with RCC roofs have not been damaged severely. This is attributed to heavy static weight of the roof system, which will effectively resist the excessive uplift forces caused by the cyclone. RCC roofs can effectively resist potential damage initiation by wind-borne debris.

Wood accounts for more than $95 \%$ of the material used in framing residential structures in the United States. It is also used for a large part of small commercial and light weight 
industrial building frames. Due to the high suction forces, the plywood sheet roofing suffered heavy damage. Blowing-off of metal sheets has also been observed during Hurricane Andrew. While excessive wind forces and weak connections caused most of the failures of buildings/structures during hurricane, they could also be due to impact of wind-borne debris, inadequate design, and detailing and poor construction (Calfee and Murchison, 1998).

When houses are exposed to hurricane forces, roofs are most susceptible to damage, followed by walls and openings, and then foundations. Building failure during Andrew was primarily a result of negative pressure and/or induced internal pressure overloading the building envelope. The wood-frame gable ends of roofs were especially failureprone. In addition, many houses had been built with the plywood roof sheathing acting as the sole stiffener of the roof diaphragm and lateral support for the trusses. Once sheathing was blown away from the roof, nothing prevented the roof trusses from collapsing. Failure to properly attach the roof sheathing to the top chord of the roof truss and omission of gable end and roof truss bracing left roofs highly susceptible to loss of structural integrity (Oliver and Hanson, 1994). Because the roof sheathing provided the only stiffening of the roof diaphragm, the attachment to the sheathing became critical to the successful performance of the building envelope. No truss failures were cited as a primary cause of general roof or building failure, and no trusses failed because of the loads imposed. In fact, properly anchored, trusses transmitted wind loads to the rest of the structure satisfactorily (Riba et al., 1994). Roof sheathing is identified as a critical component that locks all other roof members together to form a structural system. Loss 
of roof sheathing led to instability and subsequent failure of the wood-frame gable ends and trusses.

One of the most damaging classes of failure in economic terms was the loss of gypsum wallboard ceilings (Keith, 1994). This form of damage affected most houses in the path of Andrew to some degree. Where roof failure did not lead to total structural failure, roof failure allowed rain, often heavy, to penetrate to the interior of the home. This not only resulted in damage to furnishings, but also further weakened the structure when rainsoaked ceilings collapsed, reducing reinforcement of the ceiling joists. The rain accompanying and following the passage of Andrew w as driven in through gable-end vents and roof turbines, through the joints between roof sheathing panels after roofing was blown off, and directly into the attic space of failed roof systems. Rain quickly saturated the insulation and the ceiling. The loss of ceiling strength due to water saturation, and the increased weight of the wet insulation, caused widespread collapse of ceilings. The loss of the ceiling a lso c ontributed to gable-end w all failures d ue to the diminished lateral support at the base of the gable-end walls.

It was observed that the most common type of structural damage from Hurricane Andrew in Florida, was loss of gable-end walls because over $80 \%$ of houses have gable roofs (Crandell et al., 1994),. Further the loss of the gable-ends was usually accompanied by loss of between four and twelve feet of roof sheathing immediately next to the gable-end wall. Once the roof sheathing was blown off, the gable-end truss and adjacent trusses collapsed in domino fashion. 
Typically, the gable-end popped out due to suction on the leeward side of the building and the loss of sheathing, or to a combination of suction and increased pressure resulting from breached openings in the shell. When the gable-end was on the windward side of the building, collapse was caused by the withdrawal of the fasteners connecting the sheathing to the gable end top chord. This caused the gable-end overhang to peel up, causing a cascading loss of additional sheathing downwind. This led to more sheathing loss and the eventual toppling of the adjoining trusses. Diagonal cross bracing of end trusses was rarely present in roofs that failed in this manner. Gable-end trusses were often only attached to the top plate of the end walls by infrequent toenailing.

\subsubsection{Roofs}

When homes exposed to hurricane-force winds, the order of failure is usually roofs, openings, and foundation (Perry, 1995). Roof systems are exposed to higher loading than any other building element (Smith and McDonald, 1991). Once the roof of a home was breached, failure of other building elements usually followed. Roof failure followed the following scenario. Once sheathing was lost, the building envelope was effectively breached. Wind pressure was now exerted against the inside of the gable end-wall, leading to its possible failure, and against the underside of the remaining sections of the roof, increasing the likelihood that the reminder of the roof would be lost. If the roof became detached, gables collapsed, and the remainder of the structure, now much weakened, often failed. 
The damage mechanisms to a Gable-end wall can be illustrated as follows: The wind is perpendicular to the Gable-end. This creates a positive pressure and on the other side it creates a negative pressure (suction). Similarly with the sides of the building due to formation of boundary layer there produces a suction force on the sidewalls.

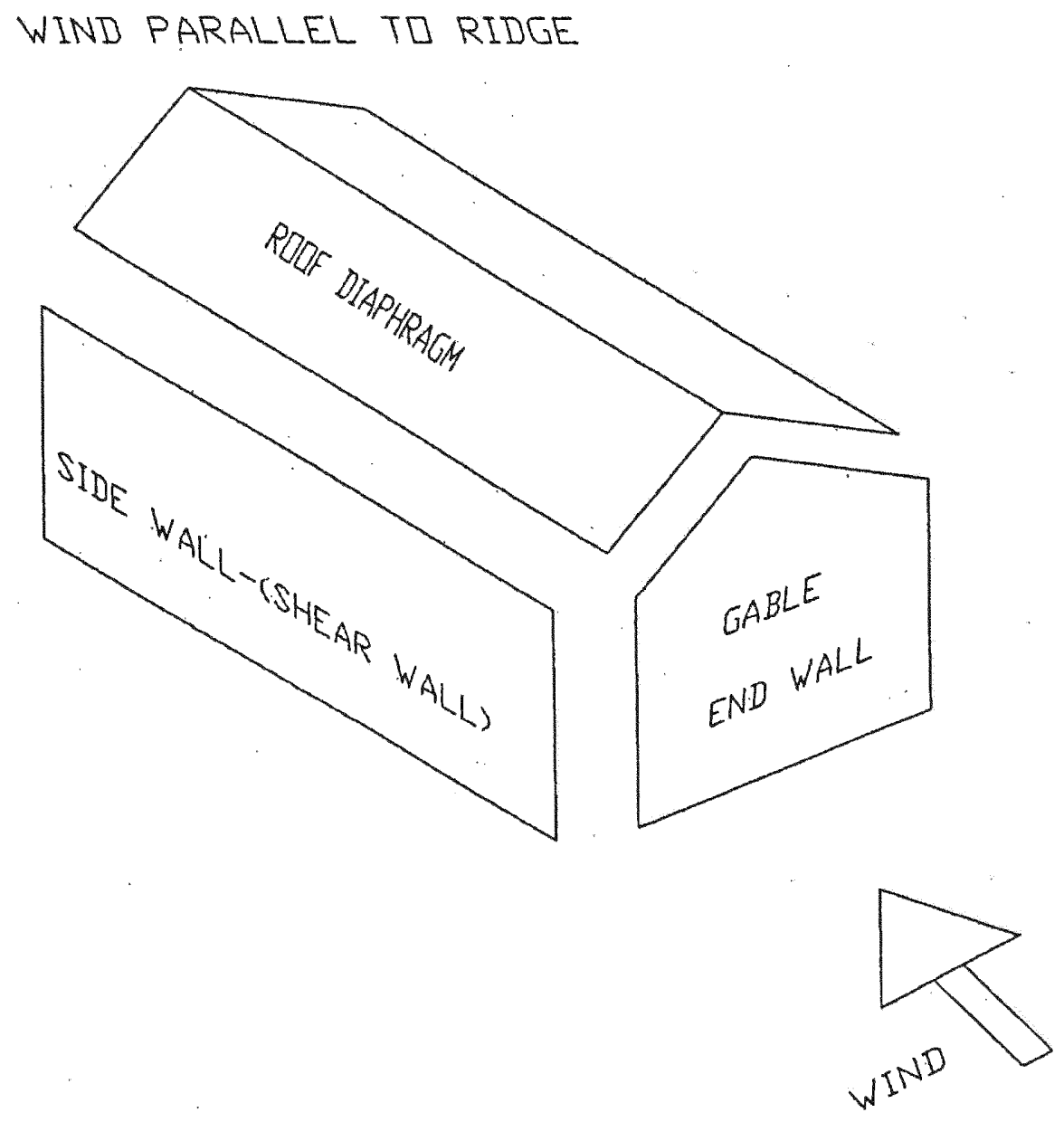

Figure 1.1. Wind perpendicular to the gable-end. 
Roofs are subjected to wind forces from many directions. Direct wind pressure can loosen shingles and tiles. Suction forces on the surface of the roof and vortices on the roof corners can lift both roof cladding and sheathing. Internal pressure generated when windows, doors, or sections of the roof itself are breached can lift and separate the roof from the rest of the structure. A properly designed and constructed hurricane-resistant roof must be able to withstand all these forces.

\subsubsection{Cladding Selections and Attachment}

In hurricane-damaged areas, both asphalt composition shingle and clay, and concrete tile, are common roofing materials. Both of them have proven problematic when exposed to hurricane-force winds. Shingles were attached to roofs using pneumatic staple guns in many cases. Once the wind managed to lift one layer of shingle tabs, the shingles acted as a sail, bending at the attachment and tearing it away.

Although popular for their appearance and their longevity in high-humidity tropical areas, clay and concrete tile roofs did not perform well in hurricanes Andrew. The primary and most serious problem was failure of the bond between the mortar and tile. A secondary problem was the low ductility of roofing tile. An extensive amount of clay and concrete tile damage during Andrew was caused by flying debris, which included roof tiles among other types of debris. As a tile broke or became dislodged and injected into the wind stream, causing a cascading failure. 


\section{RDOF SHEATHING}

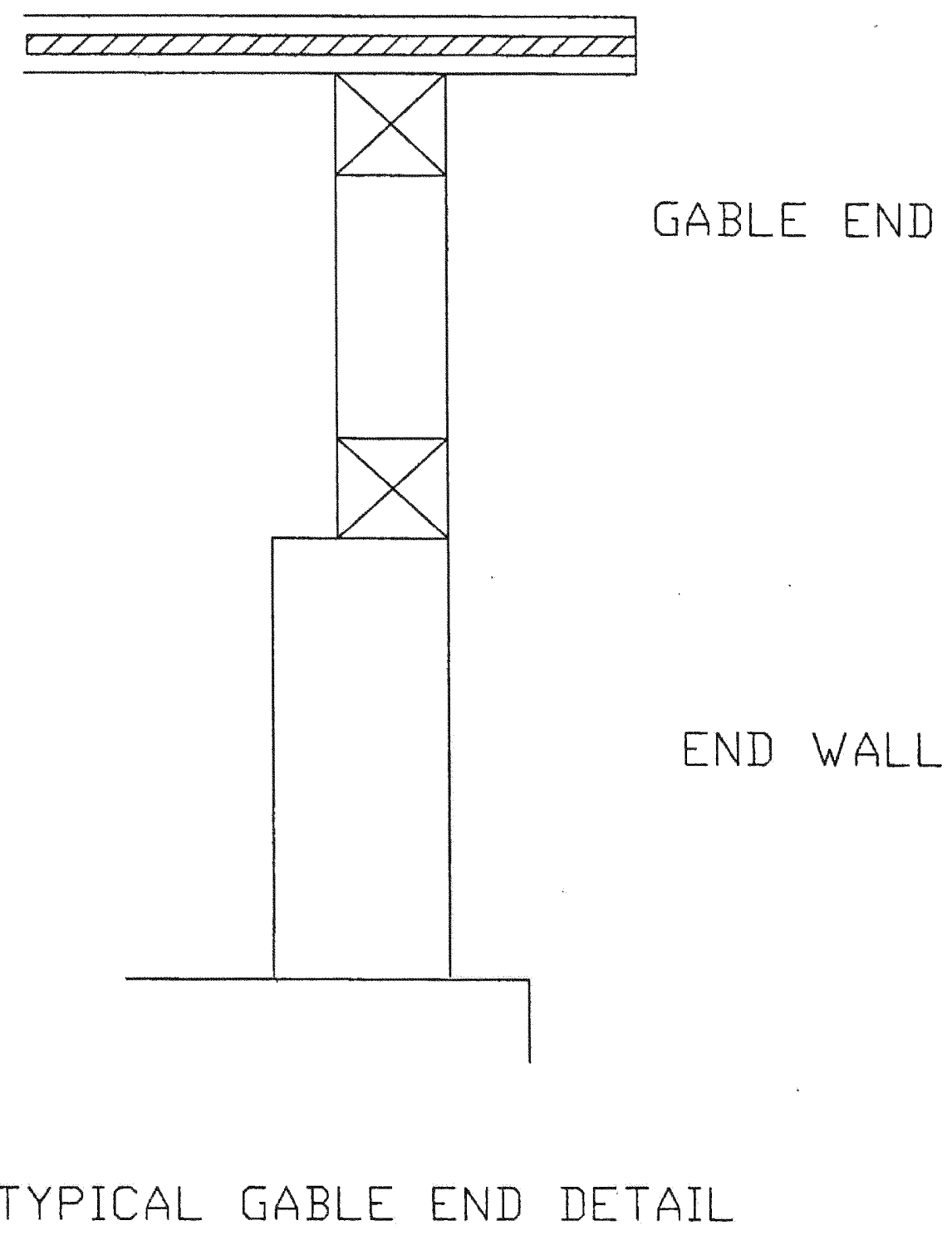

Figure 1.2. Typical Gable-end Details. 
Because roof tiles (and attaching mortar) are so brittle and easily damaged, use of roof tiles in hurricane areas should be avoided. Instead, metal panels that simulate tile could be used, or tiles could be developed with higher ductility for use in hurricane areas.

\subsubsection{Roof Sheathing and Attachment}

Roof sheathing is a critical component that locks all other roof members together to form a structural system. Roof sheathing failure was a common problem during hurricanes Andrew. During Andrew, almost $25 \%$ of houses had loss or damage to one or more panels of r oof s heathing, c ommonly s tarting in the $g$ able end (HUD, 1993). It is a lso observed that roof sheathing commonly failed in the region of the gable-end walls, and in all cases repeated failures was due to improper fastenings.

The SFBC (South Florida Building Code) requires nail spacing of between 6 inches on center and 12 inches on center, depending on the location of the sheathing panel. However, in sheathing that $\mathrm{w}$ as $\mathrm{b}$ lown off, $\mathrm{n}$ ails w ere s paced $\mathrm{m}$ uch farther a part, and fastening patterns were often erratic, ranging from 10 inches to 48 inches on center Further, it was common to find that staples and nails had been positioned to miss the underlying framing member completely. Figure 1.2 shows typical section of a gable-end and the effect of wind on the gable-end is shown in Figure 1.3. This is the pictorial representation of how the sheathing gets blown away due to strong wind force. 


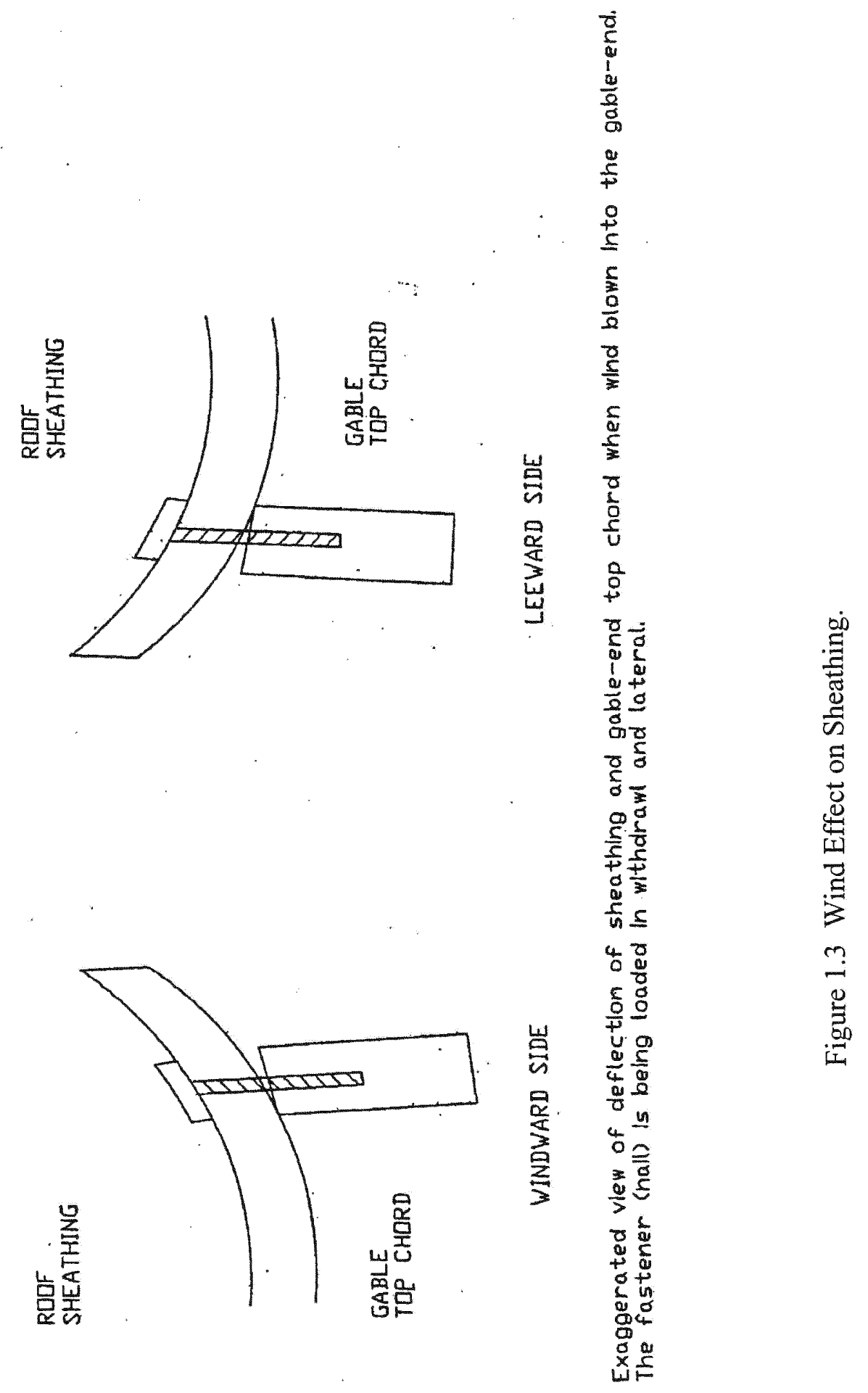


When sheathing failure did occur, a common reason was inadequate or improper fastening (Cunningham and Keith 1994). When staples were used, cases were observed in which o ne leg of the staple m issed the underlying truss or $r$ after. This r educed the strength of the connection by at least $50 \%$. Some staples showed evidence that the staple was driven through the sheathing with excessive force, leaving only a partial thickness of the sheathing to resist the wind.

\subsubsection{Damage to Walls}

Damage from flying debris was not a significant factor, although there were cases where debris penetrated walls. Wall failures were caused mainly by poor connections to the roof (Sanders, 1994). Failures of wall construction were observed when the reinforcing bars were omitted at wall intersections or comers. When this deficiency existed in combination with the failure of the tie beam to roof connection, the wall collapsed. In general, when the tie beam to roof connection failed, or was not present, the tie beam was then subjected to lateral stresses for which it was not designed (Sanders, 1994). Many total failures of CBS houses were the result of lack of tie down for the tie beam. Once uplift forces on the roof overcame the mass of the roof and tie beam, there was only the tension strength of the mortar to prevent total building collapse (Reardon and Meecham, 1994). Where failures of did occur, the primary reason was lack of vertical wall $\mathrm{r}$ einforcing. The lower $\mathrm{r}$ ate of $\mathrm{m}$ asonry $\mathrm{w}$ all failure $\mathrm{w}$ as a ttributed to the heavier mass of the masonry wall, and the tendency of a continuously 


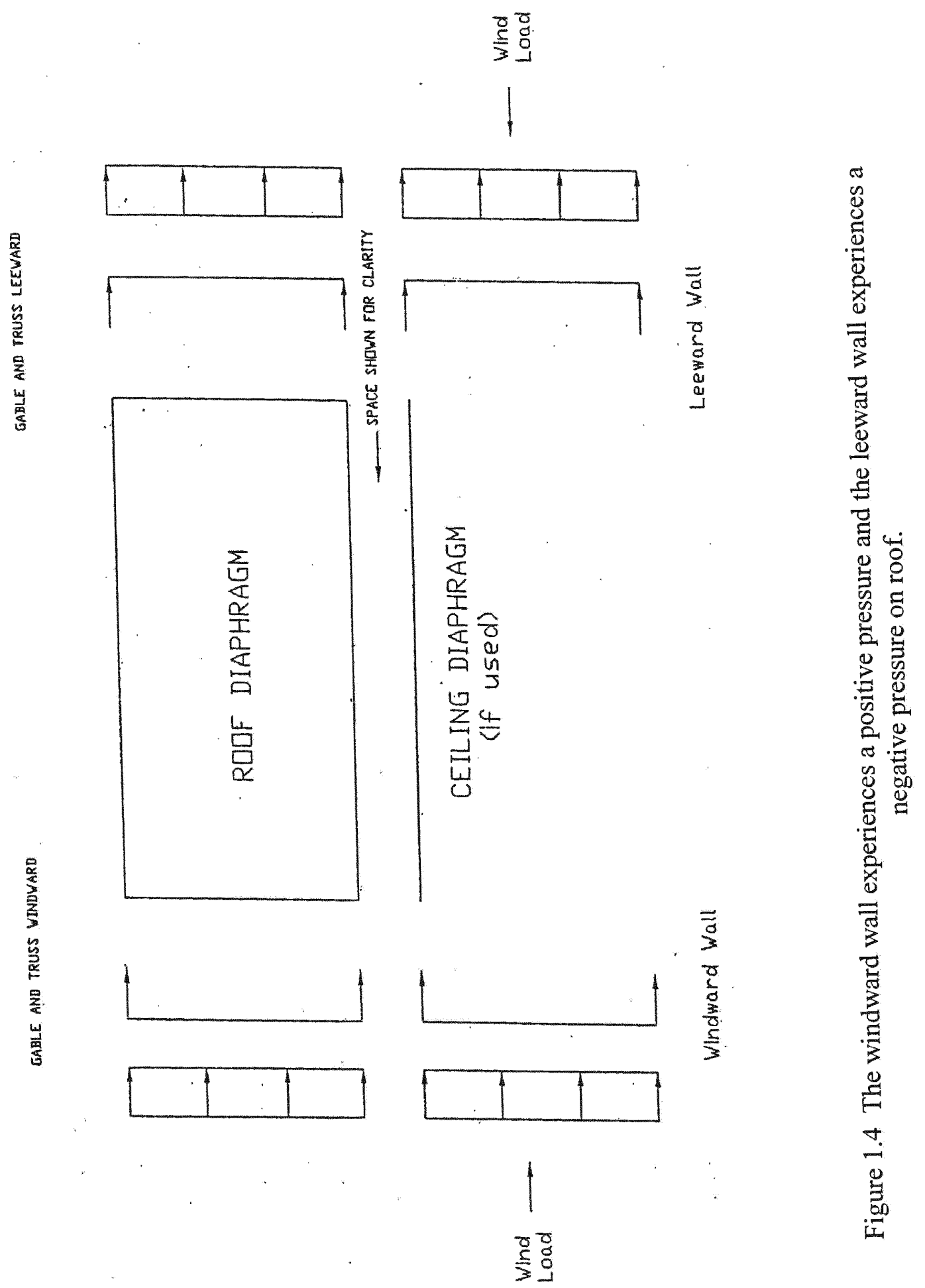



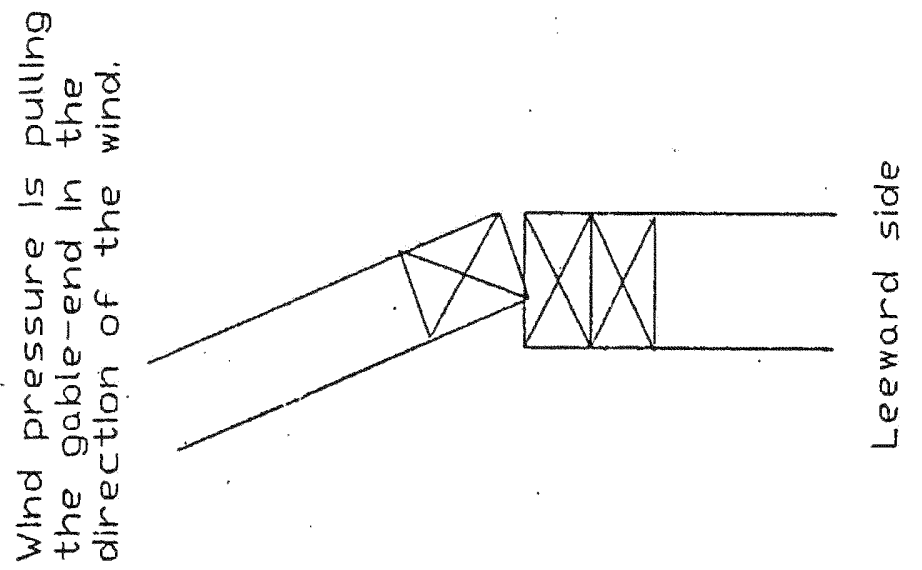

4
0
$ㅇ$
+

$\frac{Q}{4}$

$\gamma$ vi

¿

$\gamma$

10

บ

$\varepsilon \underline{0}$

능

$+0$

० के

案产

组 1

${ }_{0} 4$

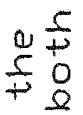

पे

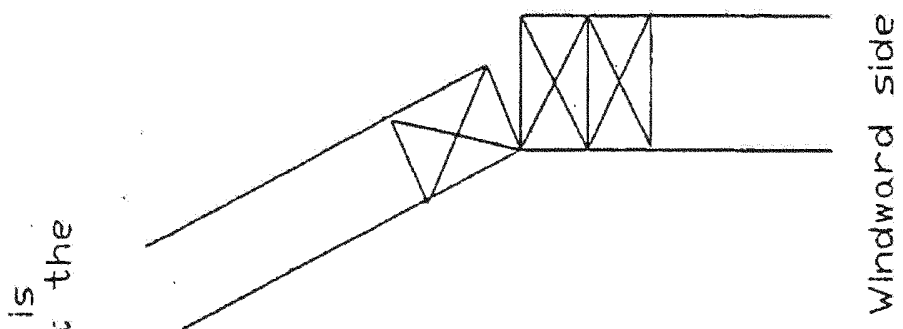

5

잉

U。

$\frac{0}{4} \frac{1}{0}$

ชั n

I

०

3 in

$\frac{0}{5} 4$

Q in

$\frac{1}{3} \frac{5}{6}$

n 0

no

कव

a ।

0 응

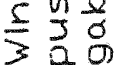

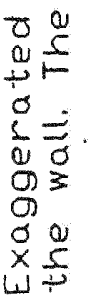




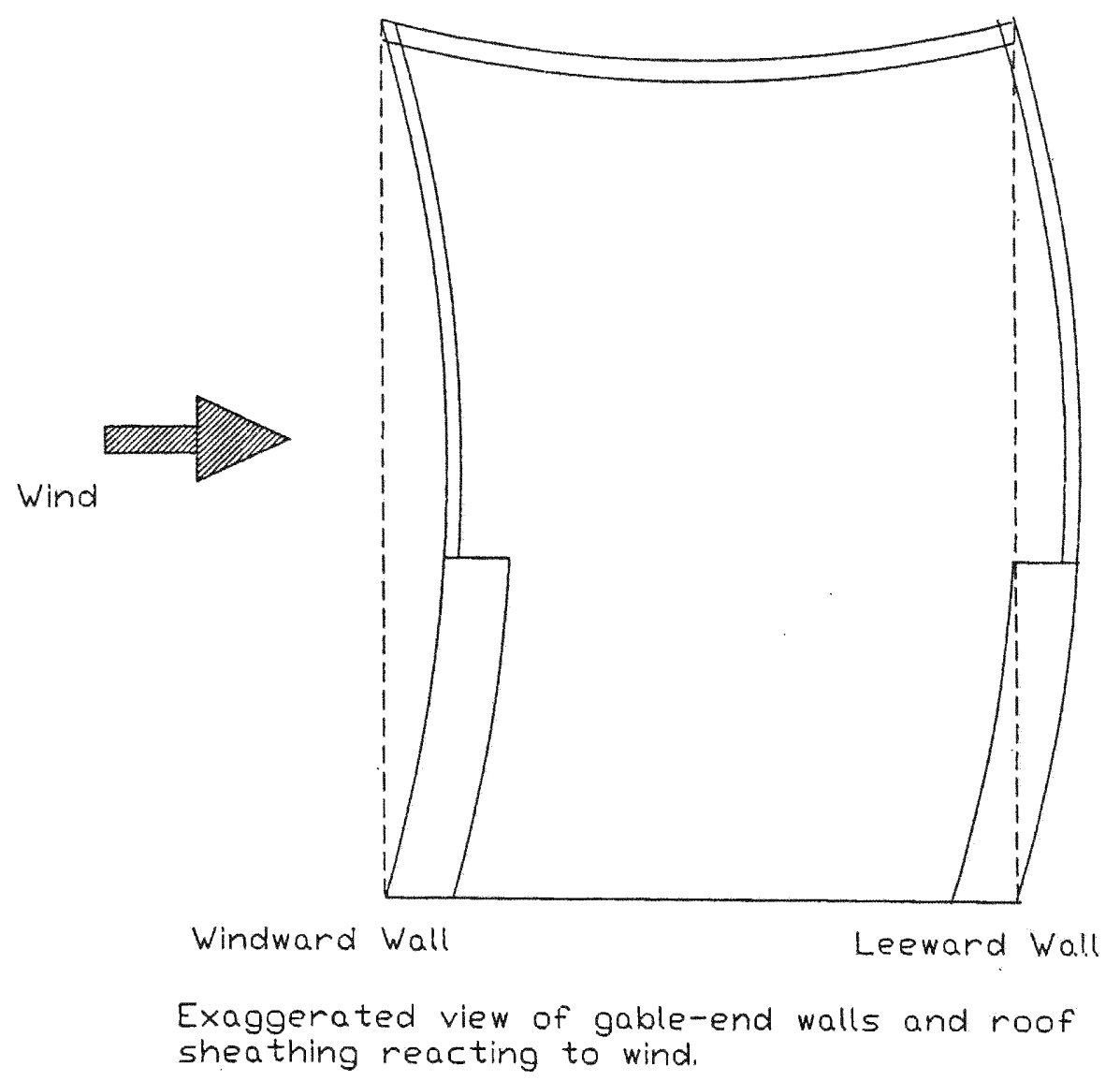

Figure 1.6 View of the windward and leeward wall. 
constructed system to be less prone to failure. Failures mechanism of a wall are as follows: poor mortar joints between walls and slab; lack of tie beams, horizontal reinforcing, tie columns, and tie anchors; and misplaced or missing hurricane straps between walls and roof were observed as shown in Figure 1.6. In some cases of failure where block walls collapsed completely because of inadequate anchorage to resist uplift and lateral forces as shown in Figure 1.4 and 1.5. In these cases, the deficiencies (and code violations) were common and included lack of tie downs, tie downs in unfilled cells, missing hooks from tie downs to the tie beams and foundation, and lack of corner bars. Wood frame walls suffered few component failures, except damage from missile impact. When failures did occur, connectors were usually the cause.

\subsubsection{Damage to Doors and Windows}

When window and door loss occurs, interior damage from wind and rain intrusion can be substantial. Although the main structural system was intact and damage appeared minimal from the outside (Murden, 1991). Windows, especially sliding glass doors, were very susceptible to failure from wind pressure and debris impact. Frame systems were usually found intact. The breaching of the building envelope by failure of openings (doors, windows) due to debris impact was a significant factor. Window protection such as shutters and pre-cut plywood performed well. Structures with adequate roof ventilation were observed to have performed better due to the ability of the ventilation to relieve induced internal pressure. Garage door failure was a significant cause of damage during Andrew. The most common failure was deflection of the garage door from wind pressure until the tracks rotated and the door rollers separated from the tracks. Loss of 
doors resulted in envelope breach and a sudden increase in internal pressure. Sometimes, loss of windows and doors caused roof loss. Many anchored roofs failed because of loss of windows and sliding glass doors.

Entry doors, especially french doors, and wood and metal double doors, were prone to failure. Observed failures included either pullout of the center pins, or shattering of the door leafs at the location of the center pin. Metal doors tended to deflect until the center pin pulled out, while wooden doors resisted the deflection but shattered at the pin instead.

\subsubsection{Foundation Damage}

Foundations are subject to damage from water and wind. Foundations are especially at risk from hurricane-driven water. Wave action can scour support from beneath a foundation or batter a foundation with the lateral force of the waves.

The piers were also susceptible to failure from water forces. The greatest weakness of the columns proved to be the shallow embedment. Major structural damage occurred when the footings were undermined by as little as two feet of erosion under the buildings. The vast majority of these foundations were in non-engineered buildings (i.e., residential structures). Under-house cross-bracing also proved to be unreliable. Wooden crossbracing frequently broke, particularly when parallel with the shoreline. Even steel rods were ineffective. Rods with diameters up to $1 / 2$ inch were bent and loosened by waves 
and debris. The bracings stiffen the foundation only when under tension. Once loosened, they have no beneficial effect.

Non-elevated structures fared even worse. Slab-on-grade foundations and other low foundations were extensively damaged or destroyed. Single-family homes occasionally floated off the foundation, but were more often demolished into small pieces and carried away by the waves (Rogers, 1991). Wind pressure against the walls of an elevated house produce enormous strain on the superstructure-to-foundation connection. Further, poorly embedded pile-and-pier foundations are subject to racking (horizontal sheer force); lateral wind and water forces horizontally displace the superstructure from the foundation to a point at which the foundation "folds" beneath the superstructure.

\subsection{Causes of Damage/Failures}

The following describes how each roof damage was quantitatively assessed using aerial photographs:

\subsubsection{Roof Cladding}

This was determined by the relative amount of cover missing (i.e. the area of cladding missing divided by the area of the whole roof resulted in a percentage value). Almost all residential buildings of the area suffered some degree of roof cladding damage from both wind and airborne debris (FEMA, 92). The percentage of damage is obtained by using the damaged area divided by the total area. The following damage percentage values are also obtained by the same approach. 


\subsubsection{Sheathing Damage}

This feature was also evaluated by the relative amount of sheathing missing. By aerial photograph inspection it was clear where the sheathing tablets were missing. Missing or damaged sheathing can be correlated to interior damage of the residences. The area of sheathing missing was divided by the area of the roof and the result was a value, which is representative of the amount of sheathing damage.

\subsubsection{Truss Damage}

The truss damage was evaluated by taking into consideration the amount of truss skeleton exposed to the outside. The truss exposure caused higher vulnerability of the roof structure.

\subsubsection{Gable-ends Damage}

The value given to the damage for each residential homes to the gable-end depended on various aspects. If the houses did not contain gable-ends the damage value was zero. However, if it did contain gable-ends, they were evaluated depending on the condition of the gable-end. The damage value was dependent upon the observed tilt of the gable-end. If the degree of tilt of the end was big the damage value was big. 


\section{FUNDAMENTALS OF AERIAL PHOTOGRAPHY}

\subsection{Photographic-Detail Evaluation}

The visual examination of aerial prints and negatives to obtain wide information about the homes that were destroyed or partly destroyed due to Hurricane Andrew is c alled photographic-detailed evaluation. There are several examination techniques for providing this information. They may be described from simplest to most complex as "photo reading", photo analysis" and "photo interpretation". All these methods are commonly called "photo interpretation". Actually there are separate techniques, which supply practical information in proportion to their increasing difficulty (Lueder, 1959).

\subsection{Photographic Resolution}

Spatial resolution is an expression of the optical quality of an image produced by a particular camera system. Resolution is influenced by a host of parameters, such as the resolving power of the film and camera lens used to obtain an image, any uncompensated image motion during exposure the conditions of film processing and so on. Some of these elements are quantifiable. 
The analysis of regional hurricanes and risk must consist of the following:

- Building a historically and statistically based database on the characteristics and effect of past hurricanes.

- Modeling the occurrence, wind speeds, wind duration and wind steadiness of a hurricane.

- Evaluating effects of these modeled predictors on engineered and non-engineered structures.

- Estimating damages and losses in the affected region.

- Continuously storing new data into database for the verification and calibration of the models (Lueder, 1959).

\subsection{Photo Reading}

The technique of photo reading is concerned mainly with the recognition and respective positions of man-made features and equipment, animal life and common terrain features. It is interested in the photographic appearance (in plan) of such things as buildings, bridges, artillery pieces, cultivated fields, hills, streams, rock strata, beaches, woodlands roads etc. As the map-reader is aquatinted with the conventional symbols appearance upon a map, so the photo reader can distinguish between various objects registered upon on aerial photographs. 
Basically, the photo reader considers and uses the aerial photograph as an exceptionally detailed base map or map supplement. Photo reading is the simplest of the evaluative techniques. It is the method used by majority of "interpreters" in the lower echelons of the military services, professional geologists and photogrammetrists (Lueder, 1959).

\subsection{Photo Analysis}

"Analysis" is defined as "the process of separating anything into its constituents parts or elements, or the examination of anything to distinguish its components parts separately or in their relation to the whole". Photo analysis is concerned with such an operation, applying it to various features of the photograph. It includes all the aspects of photo reading, but adds to them an evaluation of the numeric and interrelationship of photofeatures. The areas of fields may be determined and classified as to size, position and use (Lueder, 1959).

\subsection{Photo Interpretation}

Finally there is a photo interpretation. It includes all the characteristics assigned to photo reading and photo analysis. A complete understanding of the implications inherent in these statements is necessary for a proper appreciation of photo interpretation.

A stereoscopic or three-dimensional view is essential to photo interpretation. Effective interpretation cannot be made without it. In order to obtain the stereoscopic effect, it is 
necessary to regulate the frequency at which aerial exposures are made so that each picture overlaps the previous one by $60 \%$. Thus each object on the ground will appear on at least two consecutive photographs and will be seen in three dimensions when the two pictures are viewed stereoscopically (Lueder, 1959). 


\section{WIND BEHAVIOUR ON STRUCTURES}

Flowing wind exerts pressure on a structure and its component parts. The horizontal pressure on the front wall and horizontal suction on the rear wall cause an overturning effect. Also, these wind pressures can slide the structure off its foundation (Wilson, 1993). Since the wind speeds up as it flows over the roof, it tends to suck the roof upward and off; this is also called negative pressure. Internal pressures also changes, especially if wind enters the building through broken windows or failed doors. With an opening in the windward wall, internal pressure increases; if an opening occurs in a side or leeward wall, internal pressure decreases. The elevation above grade of the roof of the house is a particularly important parameter in determining wind uplift forces. As the roof height increases, there is an increased uplift force on the rafter connections and related components down through the foundations.

A storm surge creates wave actions that pound away at the structures. Tall buildings can shake or even collapse. The drastic barometric pressure difference in a hurricane can make well-enclosed structures explode and the negative pressure or suction can lift up roofs and the entire buildings.

\subsection{Suction Force}

Fluctuating p ressures a cting on low-rise building roofs $\mathrm{c}$ an $\mathrm{c}$ reate $\mathrm{s}$ tress reversals and may lead to the failure of fasteners or cladding, which is growing concern in low-rise 
building industry. Local pressure fluctuations govern the design of cladding as well as fasteners. Therefore it appears that the actual characteristics of pressure fluctuations on various types of buildings under diverse conditions are required to provide generalized guidelines for the betterment of building design. As shown in Figure 3.1 an analysis has been done to predict the behavior of walls due to wind force.

\subsection{Wind-borne Debris}

The primary causes are the uplift suction forces, poor connection details and impact of wind-borne debris. In the present study, the cyclonic effect of wind has completely damaged the total plywood sheet roof cladding of many of the industrial, storage and poultry sheds (Shanmugasundaram, et al, 2000).

Windborne projectiles are a major factor in home damage and destruction during a hurricane. Penetration of the building envelope by windborne debris was directly responsible for many catastrophic failures of roof systems during Andrew because such penetration allowed the uncontrolled buildup of internal air pressure (Minor and Behr, 1994; Mitrani et al., 1995). An opening on the windward wall of a building of only $5 \%$ is enough to allow full internal pressurization and effectively doubles the pressures acting to lift the roof and push the side walls outward (Behr, 1994). The loss of doors 

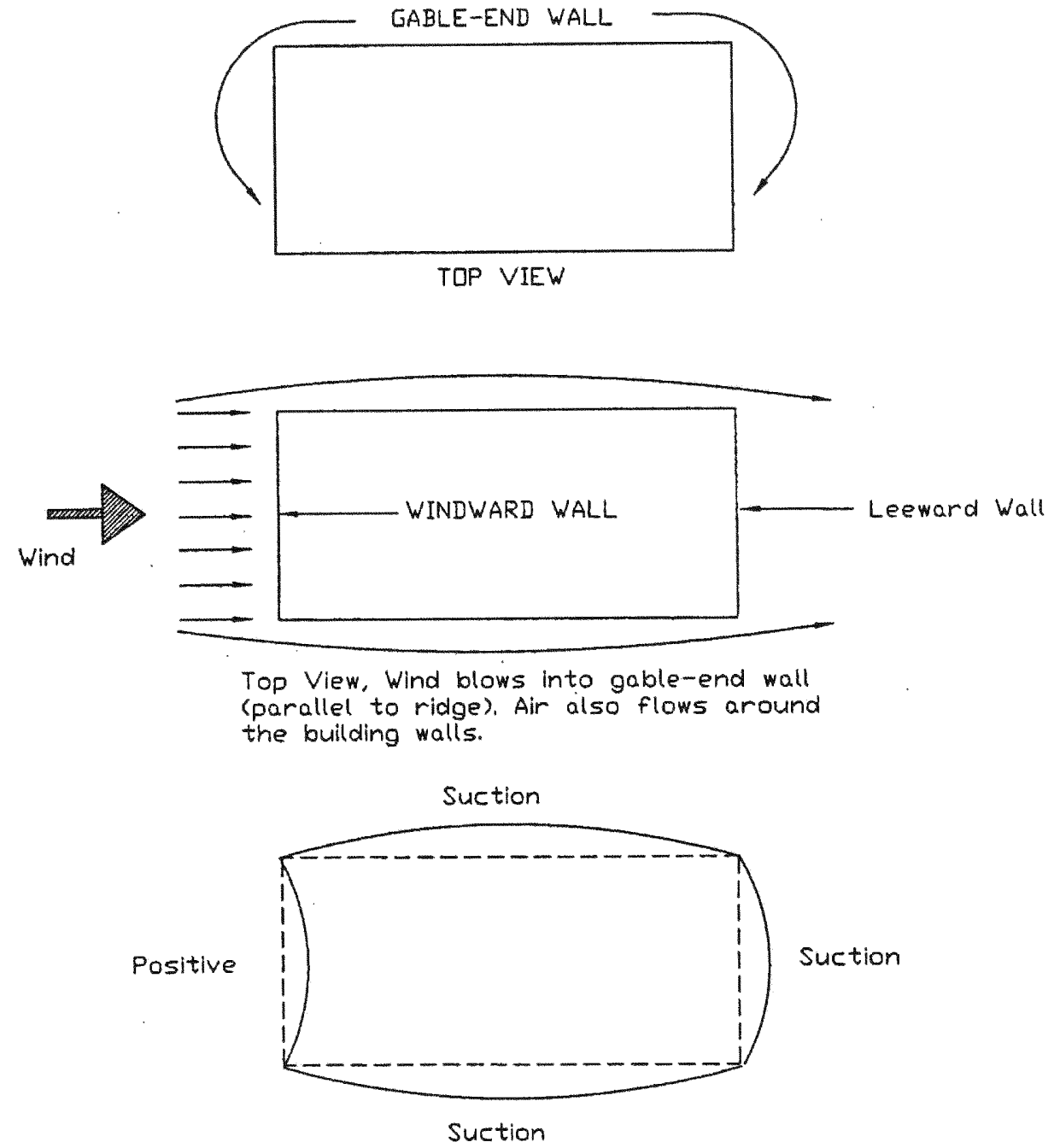

Top view. Reaction (deflection) of walls to the dynamic forces. Dotted line denotes undeflected surface. Solid line denotes surface reacting to the force from the wind flow around the object: Positive pressure exerts a force towards the surface. Suction exerts a force pulling away from a surface.

Figure 3.1 Analysis of wind forces on roof. 


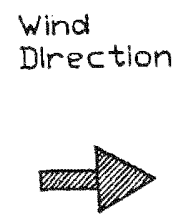

Windward

Gable-end Wall

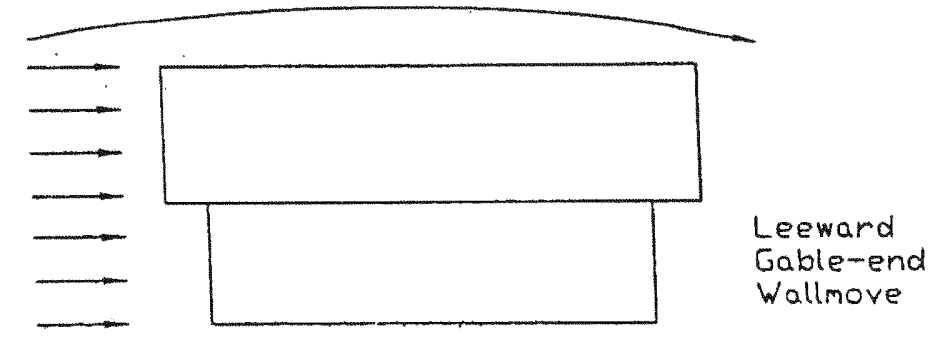

Side view, Air flows into the gable-end woll. Wind is parallel to ridge.

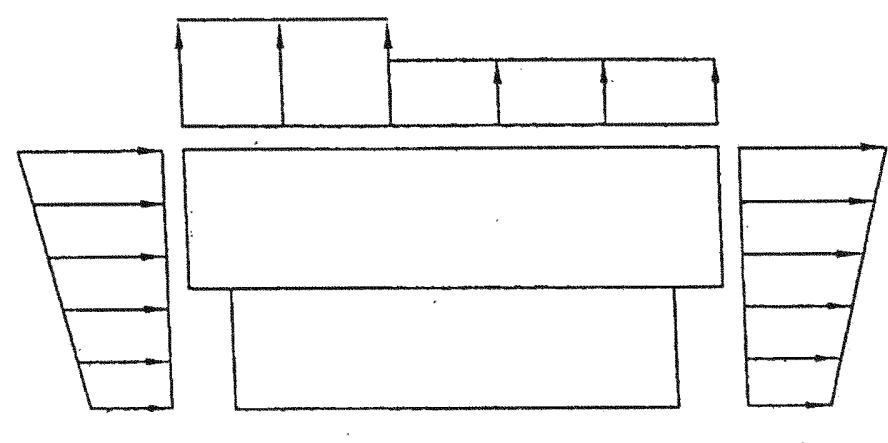

Side view, Direction of loads (forces) on bullding with wind into gable-end.

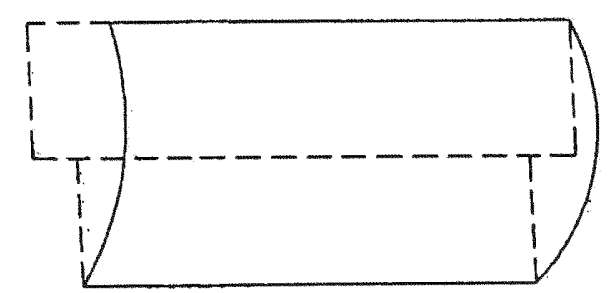

Side view of deflection of side wall and roof to this wind flow into the face of the gable-end wall.

Figure 3.2 Analysis of wind forces on side walls. 

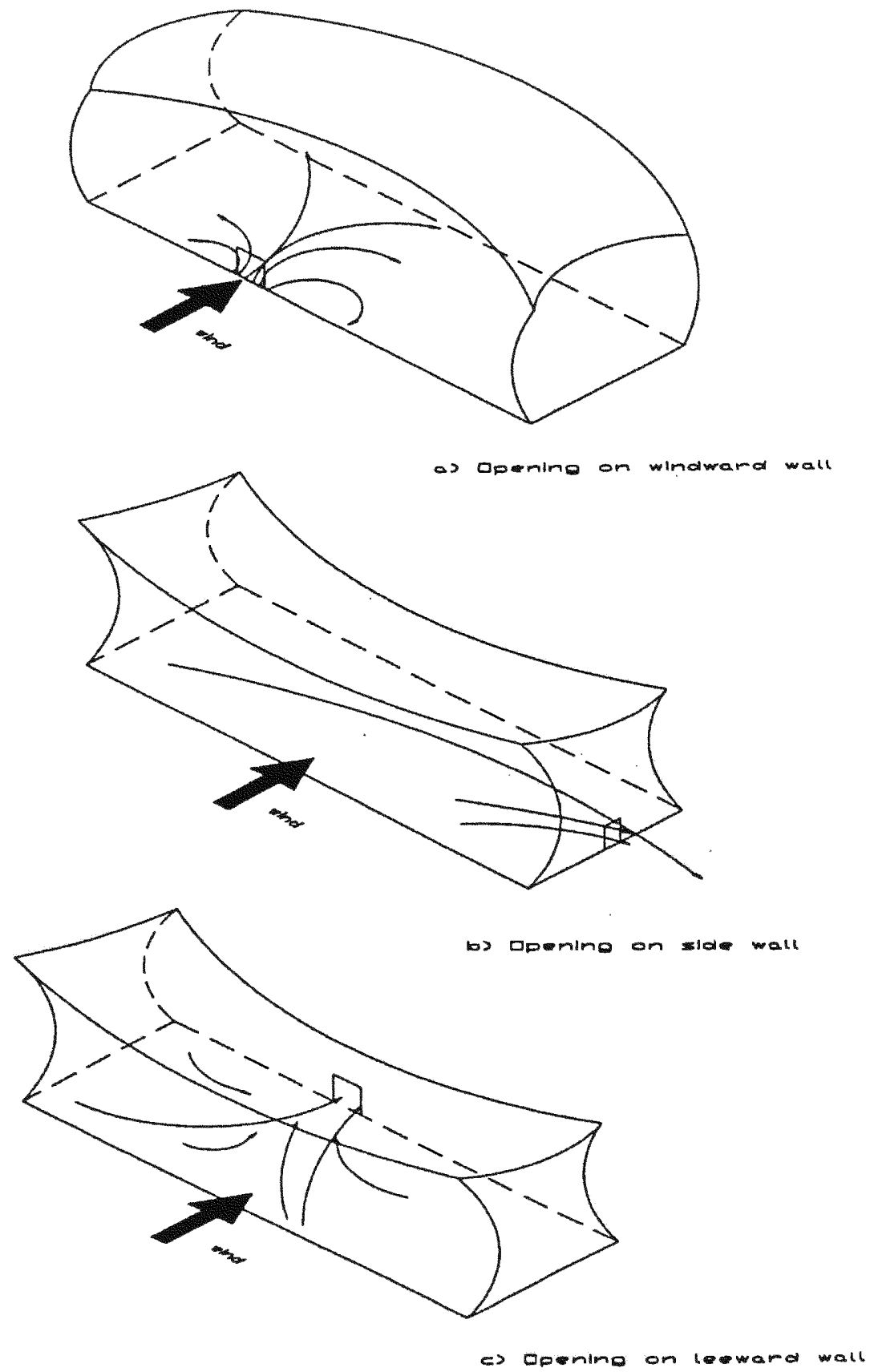

Figure 3.3 Openings on different sides of the building and the effect of such openings during hurricane. 
(primarily garage and sliding glass doors) and windows was the second most important and costly aspect of the storm. Wind-borne debris (particularly from roofing materials) contributed to a significant portion of this damage and an opening in the wall creates pressurization and depressurization of the building envelope as shown in Figure 3.3.

The pool of potential projectiles that can be picked up by hurricane-force winds and turned into wind-borne debris includes roofing materials such as shingles, tiles, and gravel; inadequately attached cladding components such as sheathing and siding; and rocks and tree limbs (HUD, 1993). Wind-borne debris from Andrew included tree limbs, fences, dislodged rooftop antennas, and components from failed buildings. The failure of metal-clad buildings and mobile homes generated considerable wind-borne debris during Andrew.

\subsection{Hip Roof versus Gable Roof}

Hipped roofs have survived better than gabled roofs in the hurricane affected regions. There is evidence that the highest local suction pressures on the gabled roof can be roughly $50 \%$ higher than those on hipped roof. Thus hipped roofs are to be preferred for hurricane-prone regions.

The hip roof appears to be instrumental in reducing the amplitudes of suction and translating "hot spots" of negative pressures further downstream, thereby reducing the lever arm from the axis about which the roof is overturning (Surry, 1990). 
The key difference identifiable in Figure 7.1.1.1 (Single-Family Houses) is the distribution of the high suction relative to the structural framing. Particularly, for the wind along the ridgeline. There is a little global difference between the hip and gable geometry for $4: 12$ roof slopes, but the hip roof has significant advantage for larger slopes, so long as the building envelope remains intact (Case and Isyumov, 1998).

\subsection{Airflow around the Building}

Airflow around buildings is dependent on the approach wind velocity gradient, and the arrangement of neighboring buildings. The velocity gradient is determined by the surface "roughness" and by the local topography. As the velocity increases with height the static pressure increases and provides a pressure gradient down the building surface. The resultant, secondary flow may combine with eddies from the adjacent buildings to produce high street-level winds and similar secondary flow in the reverse direction occurs on the leeward side of the building. Pressure distribution is dependent on the velocity profile. As shown in Figure 3.4 which is a 3-D view of the airflow around a single building. Further it has been observed that in an area there can be many buildings and when wind blows between two buildings an eddy is formed behind the first building which acts as a positive pressure for the second building. When the velocity distribution is introduced the pressure distribution on the front face is proportional to the dynamic head $\left(\mathrm{v}^{2} / 2 \mathrm{~g}\right)$, the suctions on the side and rear are uniform and the suction on the roof is half that in case of a uniform air stream. (Sachs, 1978). 


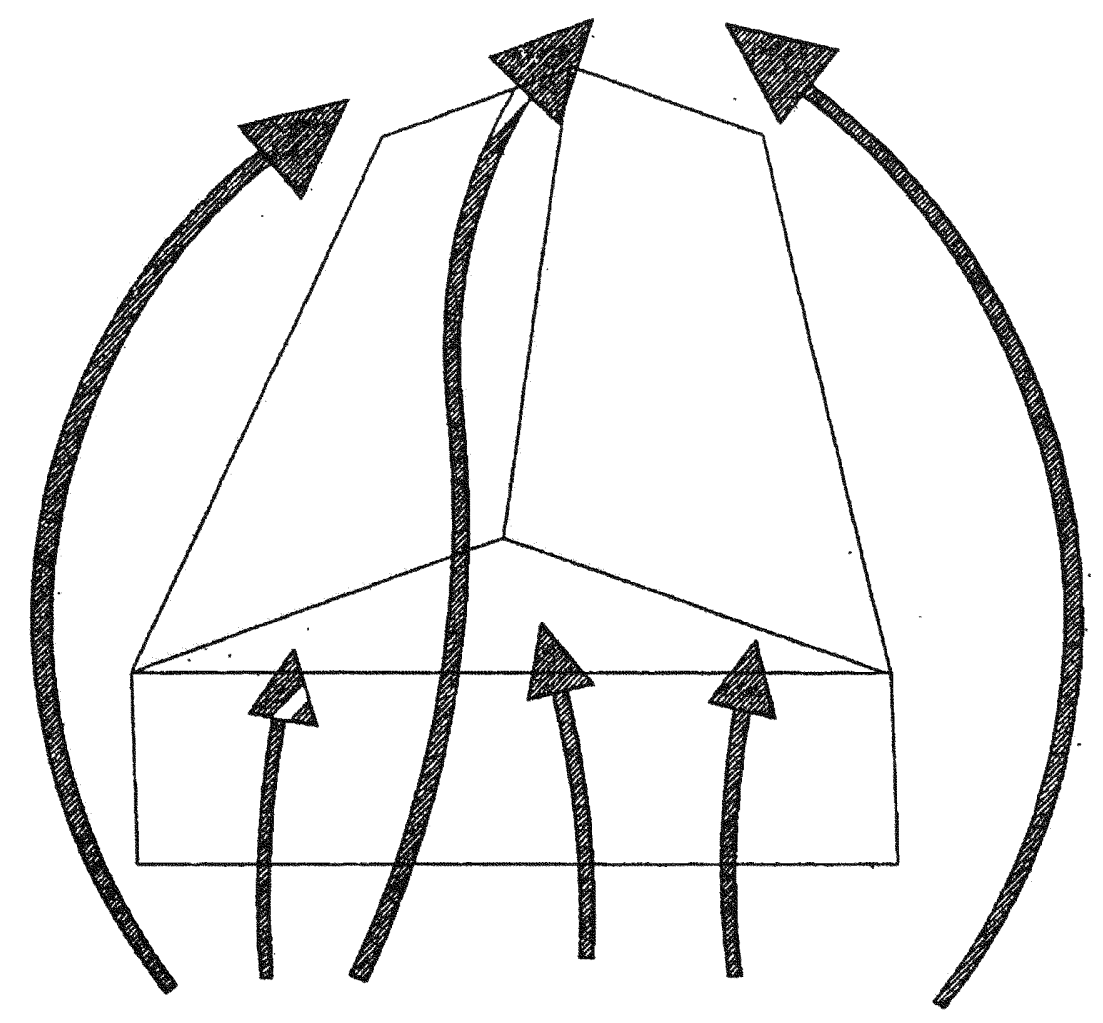

3-D of Airflow when wind direction is into gable end wall

Figure 3.4 Overall wind direction surrounding a house. 


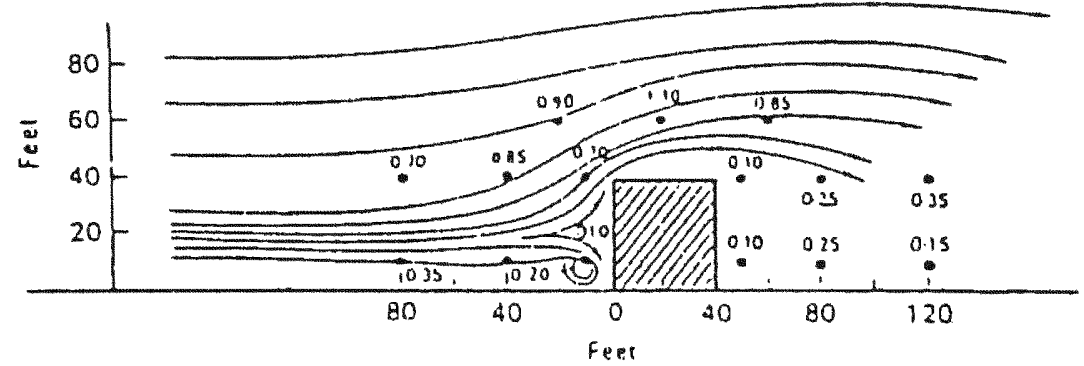

(a) Single low building

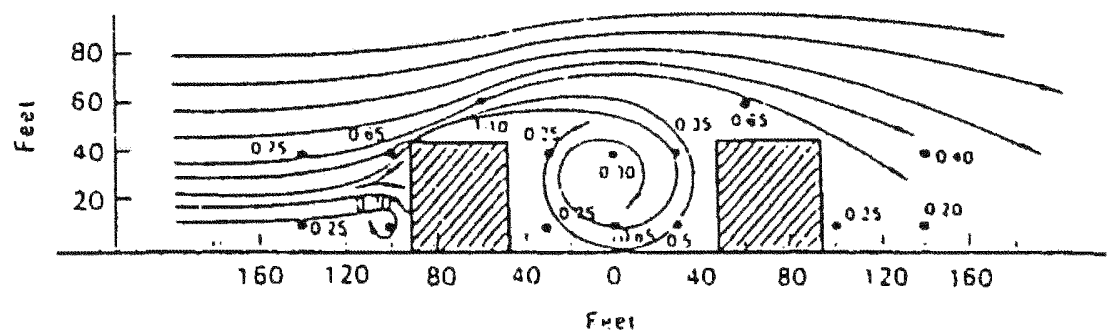

(b) Two low buildings

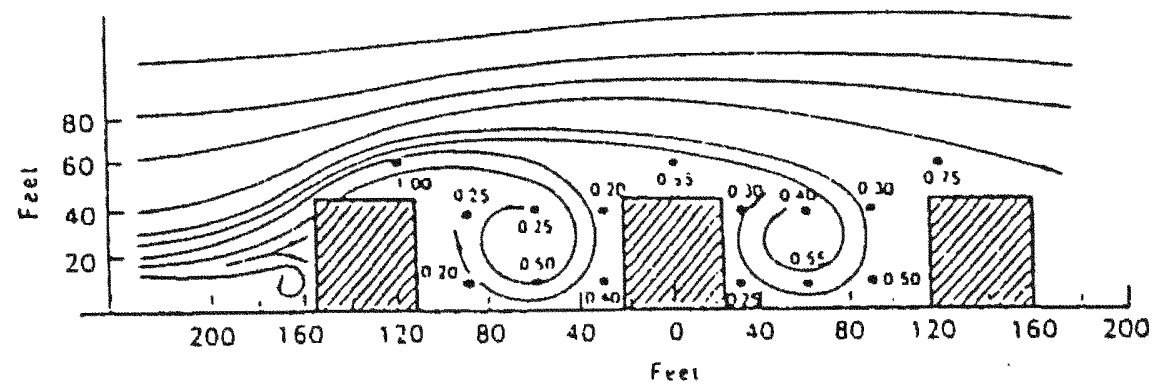

(c) Three low buildings

Figure 3.5 Flow pattern on the centerline of one, two, and three low buildings. (Velocity $=1.0$ at roof level, away from buildings).

Adapted from: "Wind Forces in Engineering" by Peter Sachs, M.A., C. Eng., M.I. Mech.E. 1978, page 241. 

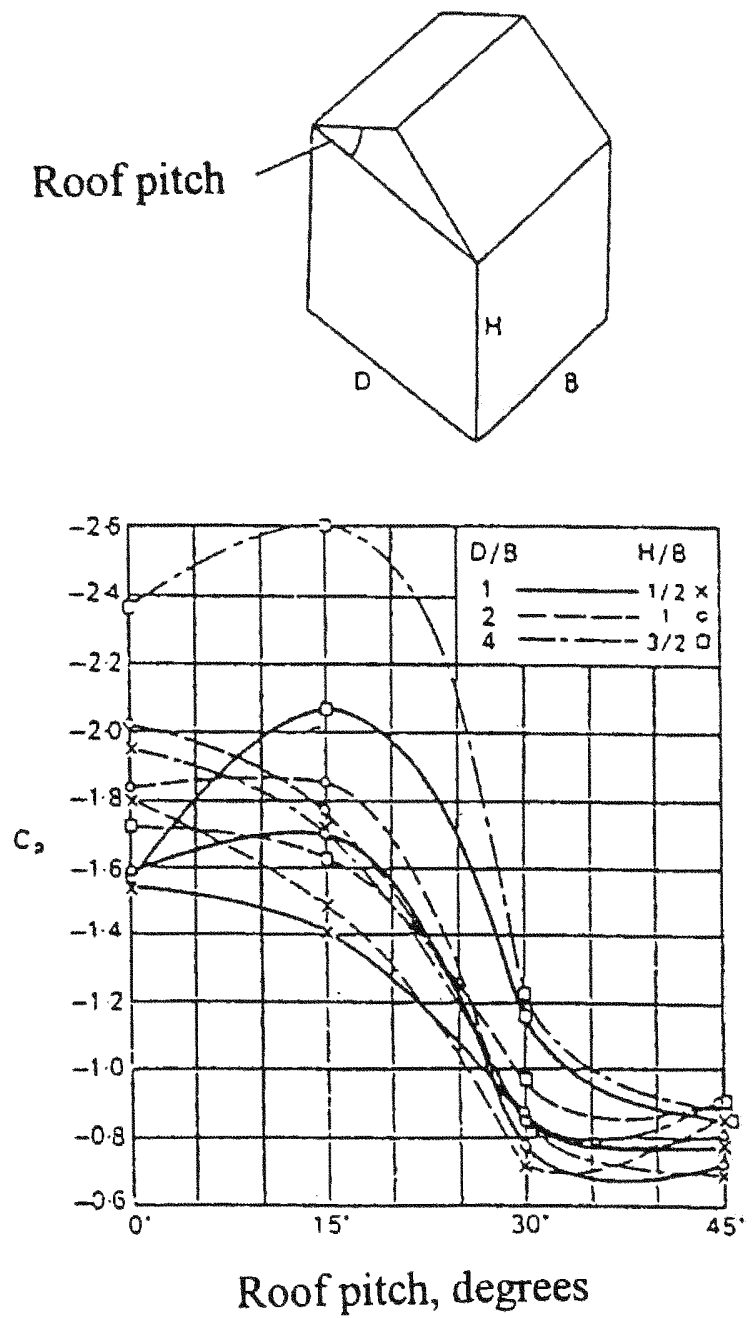

Figure 3.6 Average maximum suctions of roofs of different pitches.

Adapted from: "Wind Forces in Engineering" by Peter Sachs, M.A., C. Eng., M.I. Mech.E. 1978, page 224. 

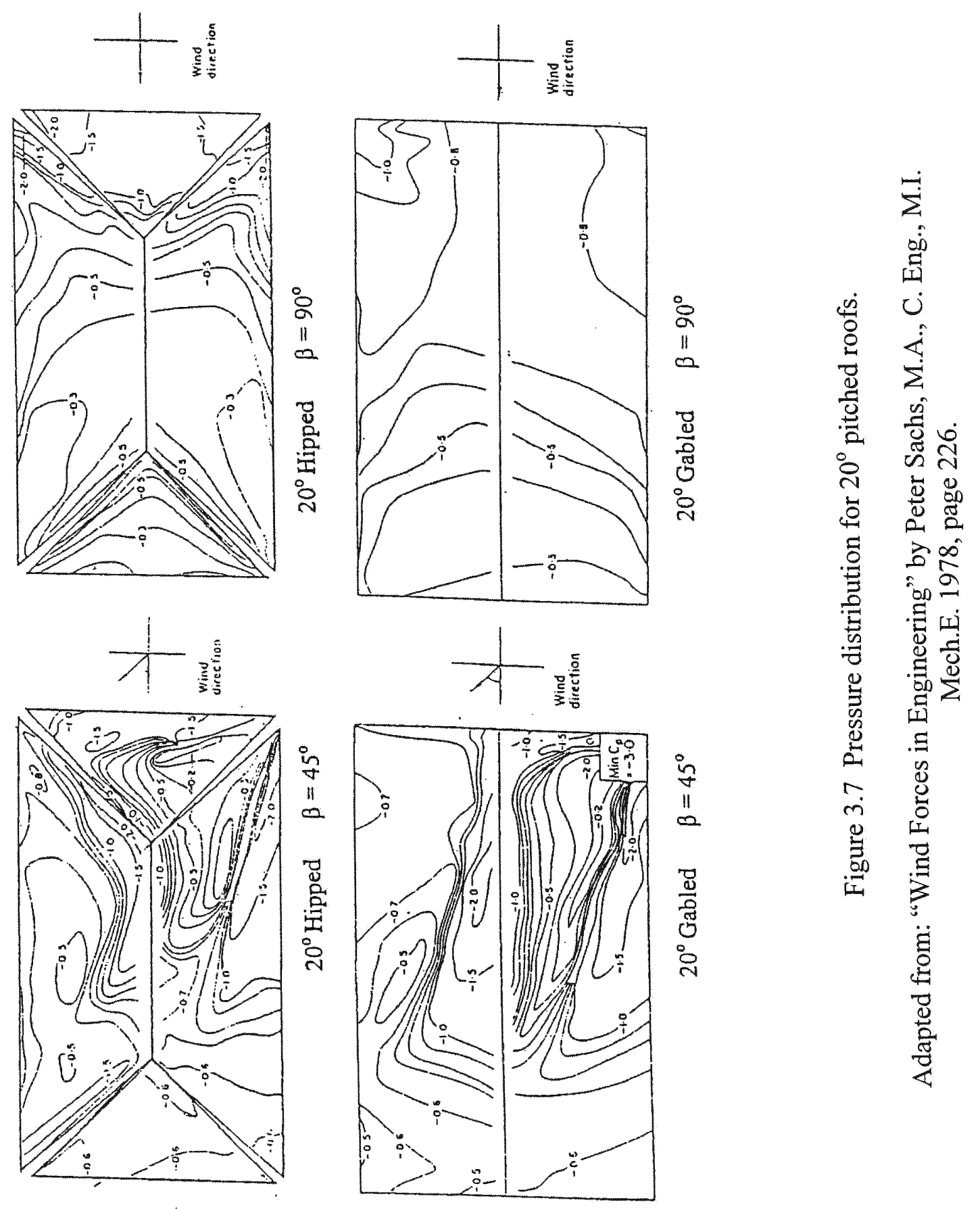


\section{†i}
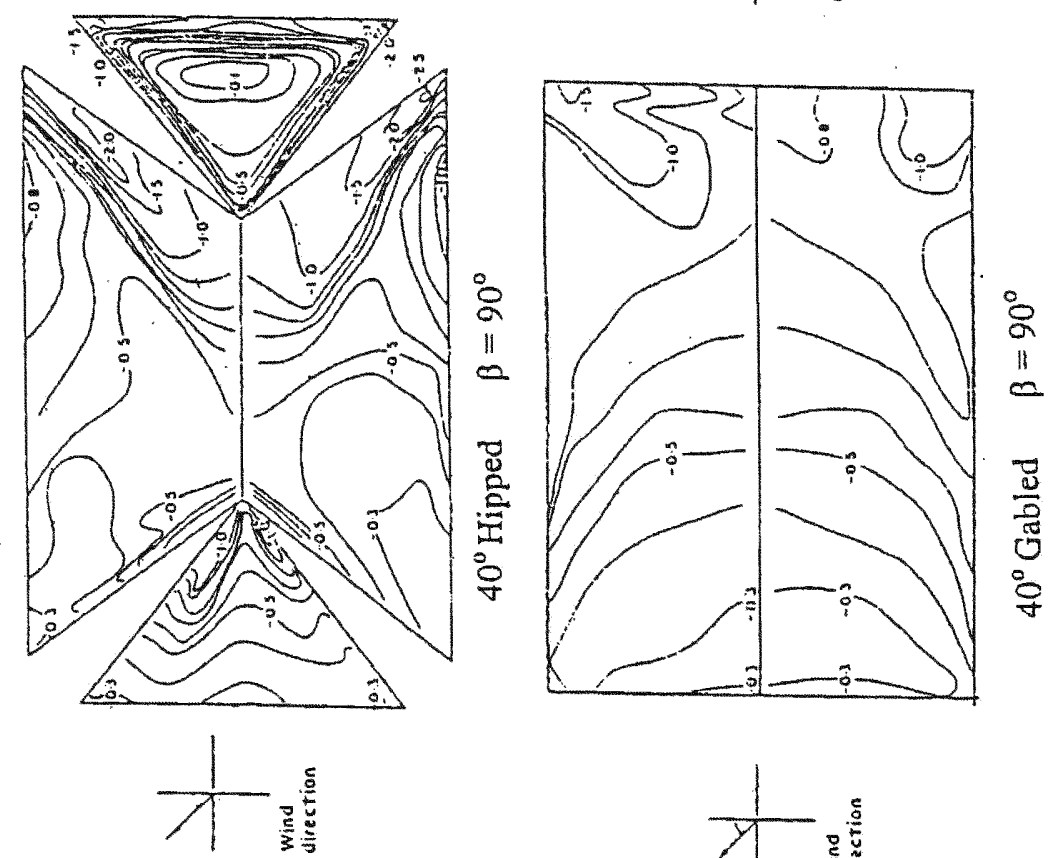

+ t!
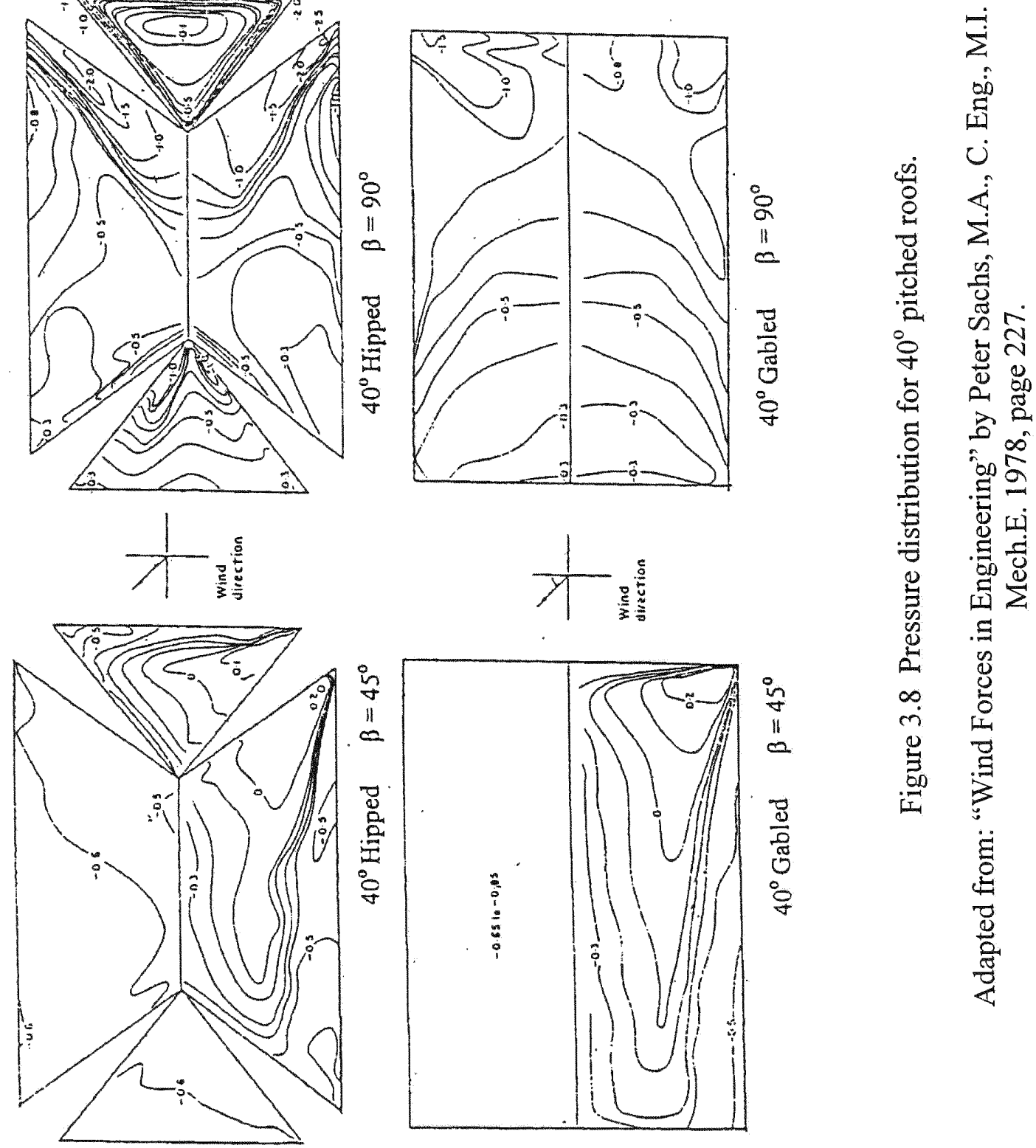

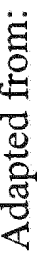



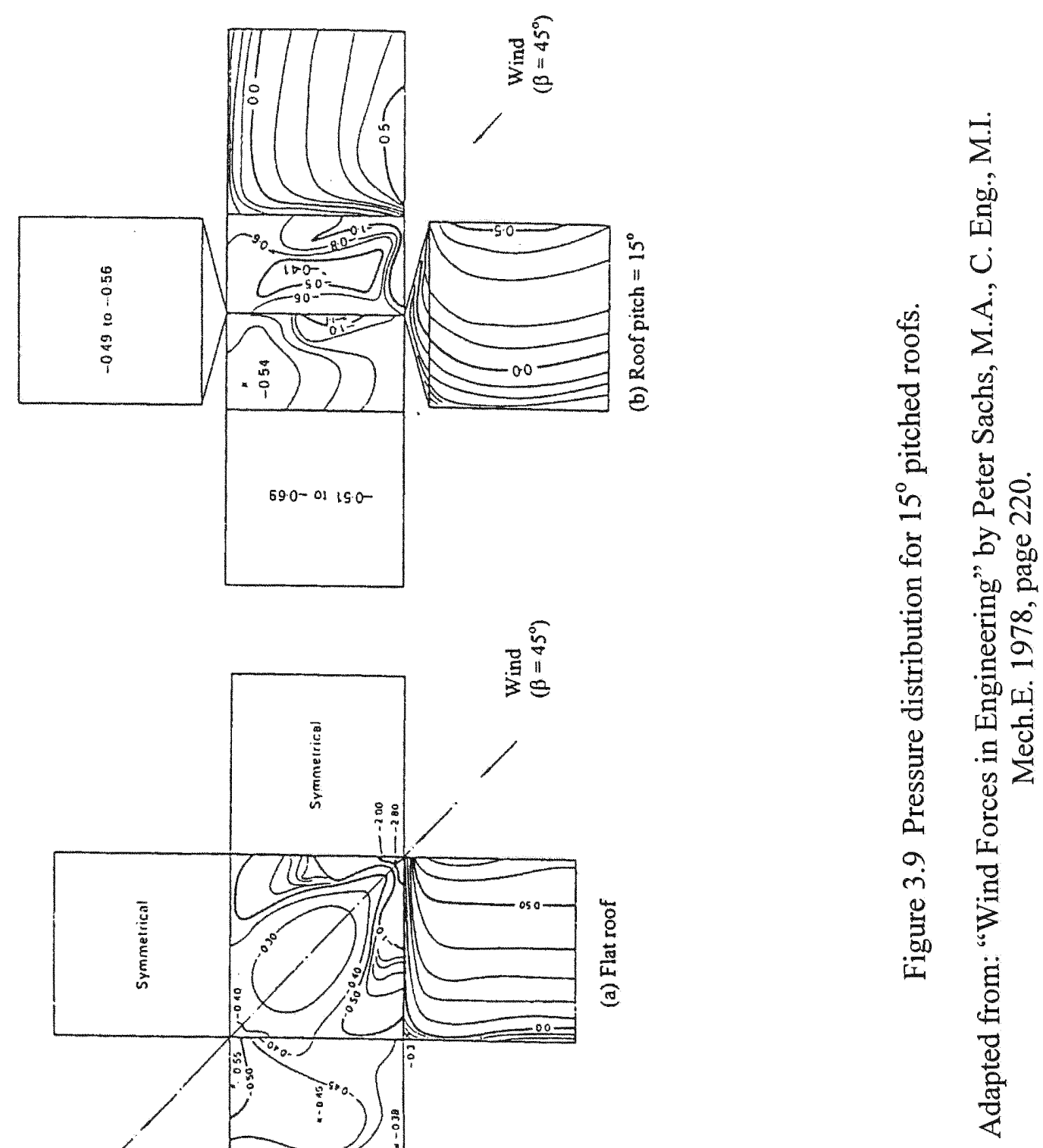


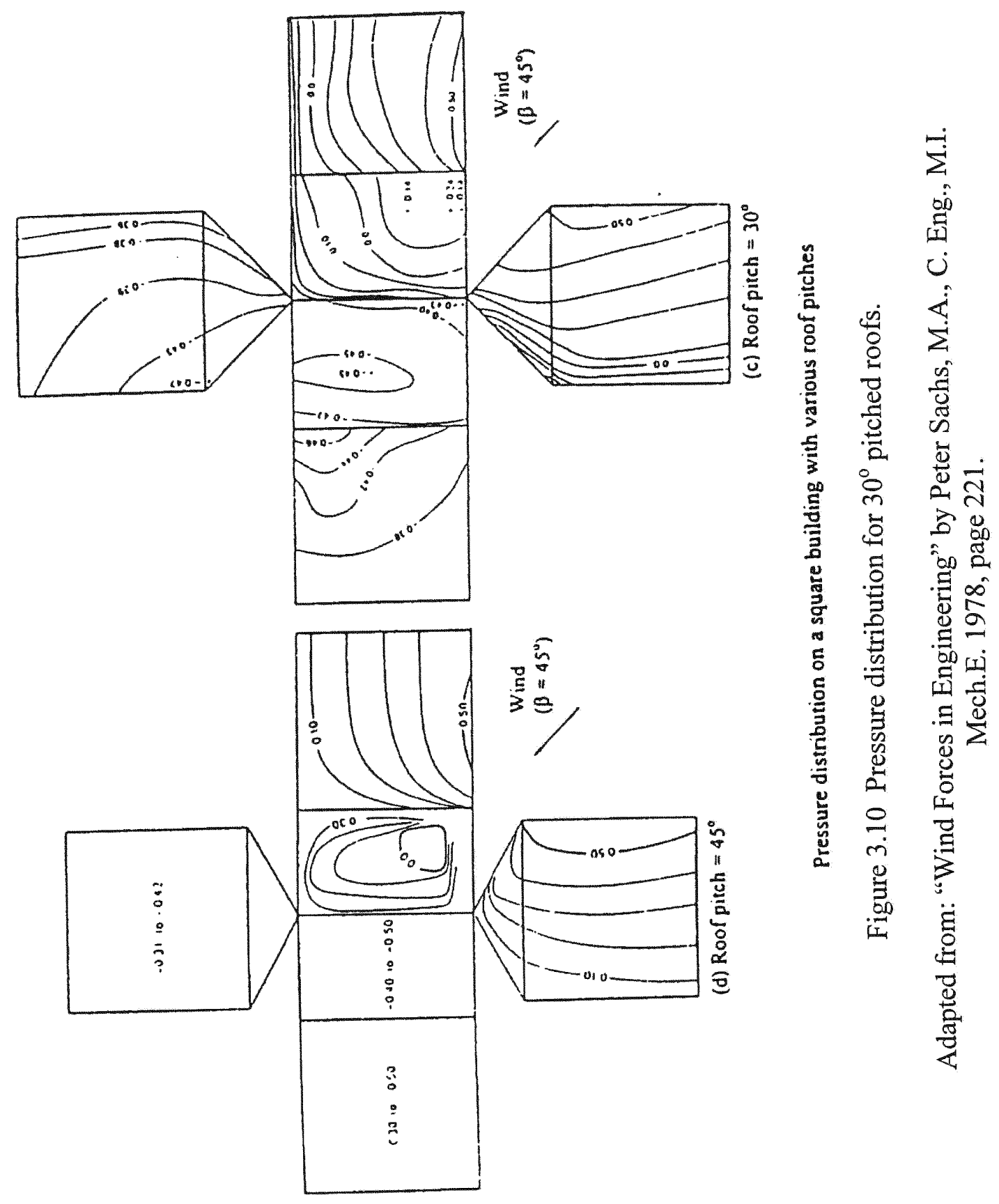




\subsection{Second Story Structure}

A proposed mechanism for collapses is that the second story and roof of the upwind houses are pushed by the wind blowing across the house so that the upper part of the house moves downwind. The movement affects various components of the first story in different ways. The studs in walls running across the house rack so that stud cavities that used to be rectangles become parallelograms. Stud walls without sheathing offer little resistance to racking. Studs of sheathing walls are restrained from racking by the sheathing, which is commonly secured to the studs with nails. Stud walls are often constructed by nailing through the top and bottom plates into the end wood of the studs with two $82 \mathrm{~mm}$ nails. Lateral forces across the house would be resisted in part by the shear walls running across the house (Dorton, and Lombardy, 1986).

Figure 3.6 shows a graphical r epresentation of a verage m aximum s uction p ressure on roofs of different pitches. This graph has been explained using the plan view of the roof depending on the pitches. Figure 3.7 shows pressure distribution for $20^{\circ}$ gable-end pitched roof. Similarly Figure 3.8 shows the pressure distribution for $40^{\circ}$ gable-end pitched roof. The pressures on the different pitches of roof clearly indicates that as the degree of inclination reduces the pressure is more on the ridge and when the inclination is higher for example $40^{\circ}$ the pressure reduces at the ridge. The same figures also compares the pressure difference between two different degrees of hipped roof. This case is opposite to the gable-end roof. More the inclination higher is the suction force on the ridge. 


\section{METHODOLOGY}

Performance $\mathrm{c}$ haracteristics of houses in $\mathrm{H}$ urricane A ndrew have been a nalyzed $\mathrm{u}$ sing the statistical sampling technique with respect to zip codes and wind speed. Post-disaster evaluations were made based on a sample data of 16200 structures and building a query from the data that was helpful to statistically present the overall damage with respect to zip codes and wind speeds. Various kinds of structures were studied with respect to specific zip code and their damage trend was determined for the particular zip code by plotting a graph between percentage overall damage versus cumulative damage percentage.

\subsection{Damage Assessment}

Roof cover, sheathing, trusses, gable-end and overall were five categories evaluated for damage. The percentage damage to the structure and to the structural components was estimated by careful examination of the aerial photographs. The aerial photographs were taken in $3,600 \mathrm{ft}$ to $7,000 \mathrm{ft}$ flight altitude, with negative scale $\left(1 "=600^{\prime}\right)$. The following is an example of the criteria that was used to differentiate the different degrees of overall roof structure damage (Tang et al., 1997). 


\begin{tabular}{|l|l|}
\hline Level of Overall & Criteria \\
\hline $0 \%$ & $\begin{array}{l}\text { Less than } 10 \% \text { of roof cover was missing, sheathing } \\
\text { appeared intact, the structural integrity of the building } \\
\text { appeared secure. }\end{array}$ \\
\hline $10 \%$ & $\begin{array}{l}\text { Less than } 50 \% \text { of the sheathing was missing or damaged, } \\
\text { less than } 10 \% \text { of truss was damaged, the structural } \\
\text { integrity of the building appeared secure. }\end{array}$ \\
\hline $30 \%$ & $\begin{array}{l}\text { Less than } 30 \% \text { of the truss was damaged, no noticeable } \\
\text { gable-end damage. }\end{array}$ \\
\hline $50 \%$ & $\begin{array}{l}\text { Less than } 50 \% \text { of the truss was damaged, less than } 30 \% \\
\text { of the gable-end was damaged or collapsed. }\end{array}$ \\
\hline $100 \%$ & $\begin{array}{l}\text { Less than } 80 \% \text { of the truss was damaged, less than } 70 \% \\
\text { of the gable-end was damaged or collapsed. }\end{array}$ \\
\hline
\end{tabular}

\subsection{Saffir/Simpson's Scale}

The severity of hurricanes is rated using Saffir/Simpson's Scale. The scale assigns a storm to one of the five categories based on the wind speed. The scale is as follows: 
Category One Hurricane: (Winds 74-95 mph or 119-153kph)

- Storm surge generally $4-5 \mathrm{ft}$ above normal.

- No real damage to building structures.

- Some damage to poorly constructed signs.

Category Two Hurricane: (Winds $96-110 \mathrm{mph}$ or $154-177 \mathrm{kph}$ )

- Storm surge generally $6-8$ feet above normal.

- Some roofing material, door and window damage of buildings.

- Considerable damage to mobile homes, and poorly constructed signs.

- Small craft in unprotected anchorage break moorings.

Category Three Hurricane: (Winds $111-130 \mathrm{mph}$ or 178-120kph)

- Storm surge generally $9-12 \mathrm{ft}$ above normal.

- Some structural damage to small residence and utility buildings with minor amount of wall failure.

- Damage to shrubbery and trees with foliage blown off trees and large trees blown down.

Category Four Hurricane: (Winds $131-155 \mathrm{mph}$ or $210-249 \mathrm{kph}$ )

- Storm surge generally $13-18 \mathrm{ft}$ above normal.

- More extensive wall failure with some complete roof structure failures on small residence. 
- Shrubs, trees, and all signs are blown down.

- Complete destruction of mobile homes.

- Extensive damage to doors and windows.

- Major damage to lower floors of structures near the shore.

Category Four Hurricane: (Winds $131-155 \mathrm{mph}$ or 210 - 249kph)

- Storm surge generally greater than $18 \mathrm{ft}$ above normal.

- Complete roof failure on many residences and industrial buildings.

- Some complete building failure with small utility buildings blown over or away.

- All shrubs, trees, and signs blown down.

- Complete destruction of mobile homes.

- Sever and extensive damage to doors and windows.

- Major damage to lower floors of all structures located less than $15 \mathrm{ft}$ above sea level and within 500 yards of the shoreline. 


\subsection{Assumptions}

To evaluate roof structure damage, the following assumptions are necessary: For any group of structures, it can be assumed that even if they all were built to the same building code, some would resist the wind better than others. There are many reasons for this, the building shape, the building contractor, the workmanship, the material used, the building inspector, the building location, and others.

In addition, even if all the buildings in a small group were built with the intention that they could withstand a $50 \mathrm{~m} / \mathrm{s}$ windstorm, some would fail at values below this speed and some would not be damaged even at speeds well above this. Only the roofs were evaluated for structural damage based on the damage to the roof truss skeleton.

Consequently, a simple distribution of buildings can be proposed, ranked according to their resistance to the wind load in a storm. It is assumed that the majority of buildings exhibit a "typical" resistance, and by calibration with the data of Friedman (1984), it can be determined that for the low-rise structures considered here, this speed is between 40 and $50 \mathrm{~m} / \mathrm{s}(90-110 \mathrm{mph})$, or approximately building code design values. To make calculation straightforward, a simple symmetrical triangular distribution as shown in the figure below with wind load (L) as shown. For this arrangement, the probability that a structure would suffer damage is given by the fraction of the area or $A(A+B+C)$. The statistical analysis has the similar kind of graphical representation with respect to the graphs shown below. 


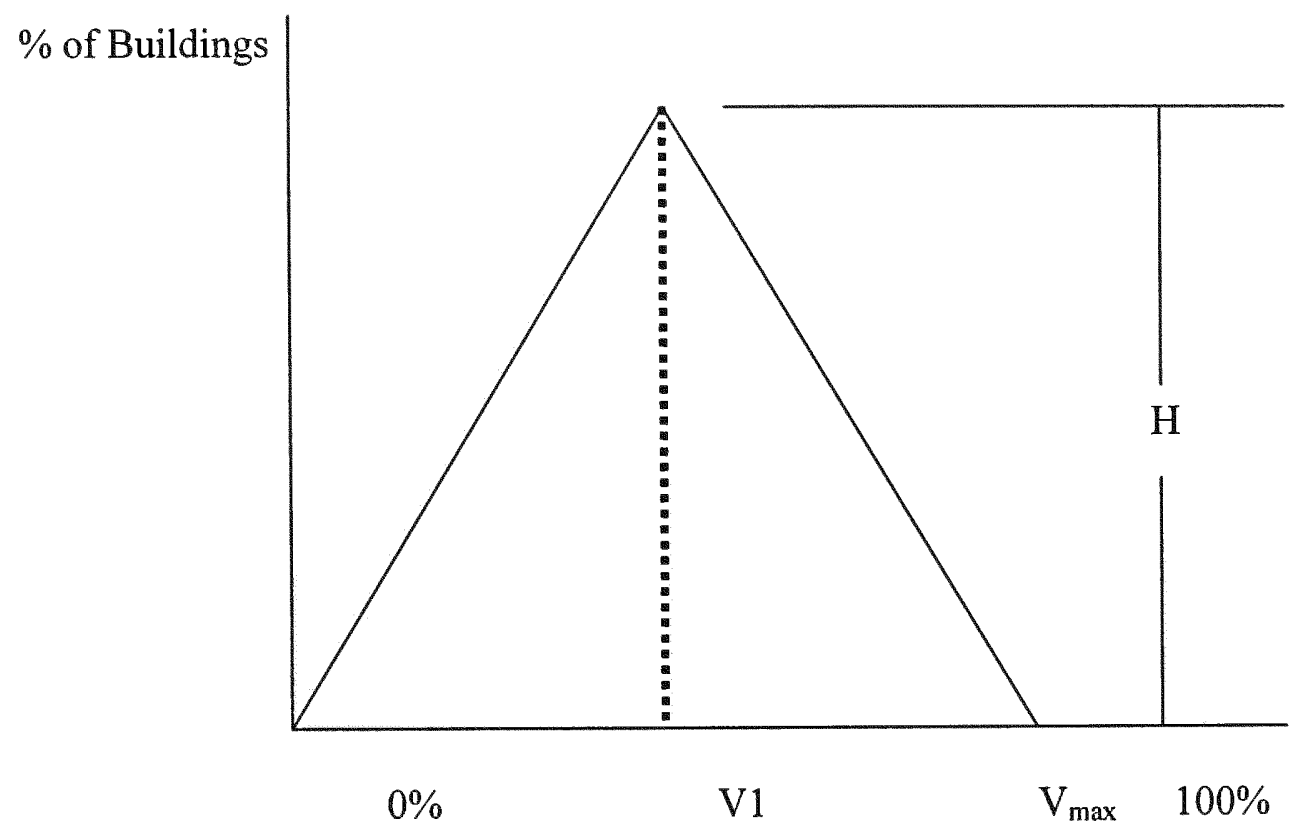

Figure 4.1. Assumed Distribution of \% Damage due to Severe Wind Event.

\subsection{Statistical Analysis}

In order to compare the damage data all damage assessment data was counted by building a QUERY in the Microsoft Access by having some variables and constants. In this case all the five categories of damage that is roof cover, sheathing, gable-end, trusses and overall were kept constant and wind speed and zip code was the variable for different kinds of structures. Based on the constants and variables damage functional curves and cumulative percentage curves were constructed using the Microsoft EXCEL Table. 


\subsection{Limitations}

This project deals with the after effect of the Hurricane Andrew and it is a predictive model for future hurricanes. But one of the limitations for this model is it was based on the buildings codes that were used ten years back when the Hurricane Andrew took place. Now with the change of building codes and provisions and with the strict enforcement of the same this model may not be accurate when dealing with the damages during a hurricane. The area hit by the hurricane may not have been covered by any building code at the time the structure was built. A review of hurricane destruction reveals that the adequacy of building codes and the level of local compliance played a key role in determining the amount of damage. Damage to residential structures occurred particularly to the non-engineered and semi-engineered family dwellings. The construction was considered to be in a traditional form, in which roofs are connected to the walls by "toe nailing," have generally proved incapable of resisting hurricane force winds. 
Figure 4.2 Roof Cover, Sheathing, Trusses, Gable-End and Overall Damage for SFH and Wind Speed $=135 \mathrm{mph}$.

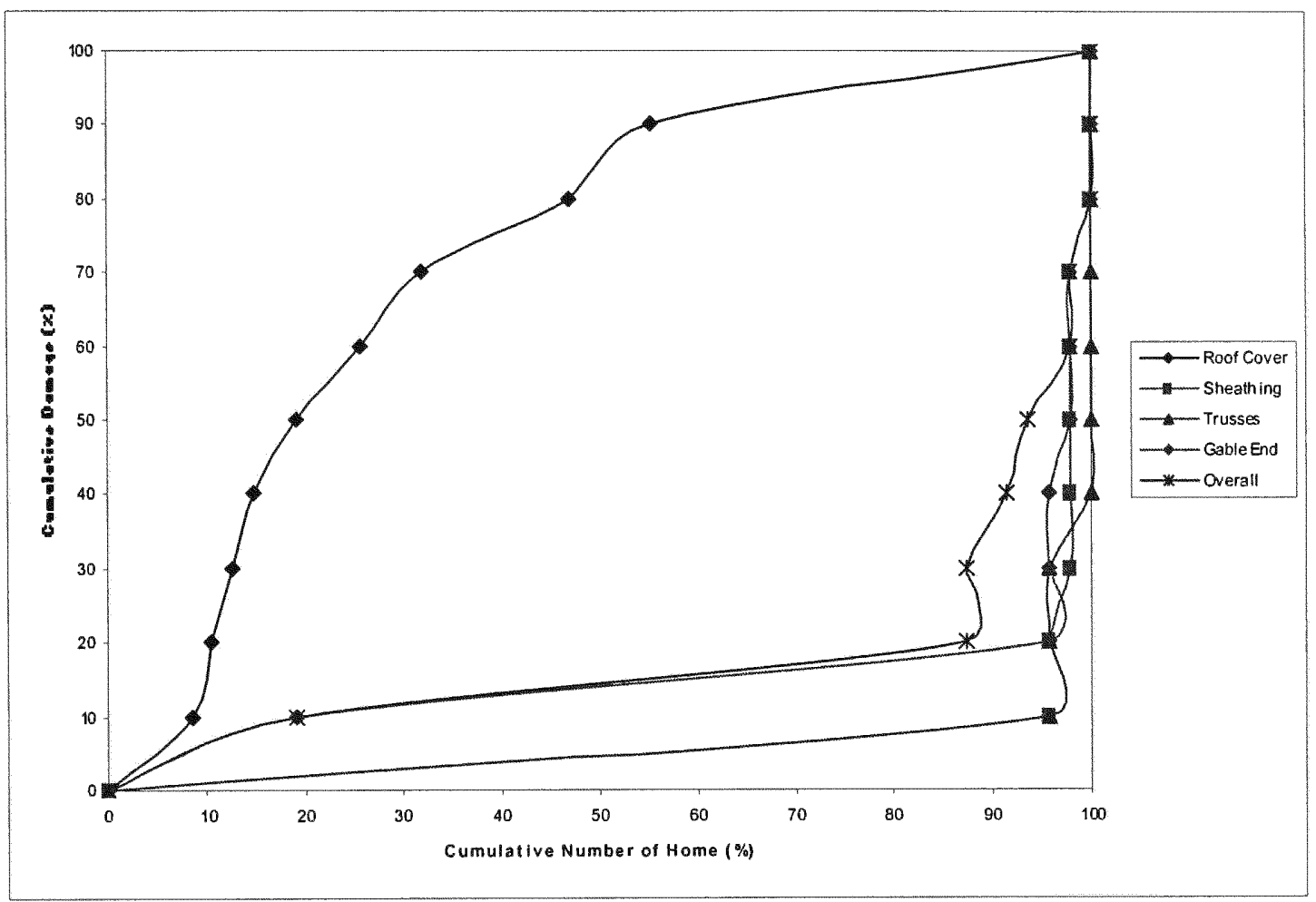

The above graph represents various structural damages for SFH type of structures for the wind speed of $135 \mathrm{mph}$. It represents that roof cover for $50 \%$ of the houses had more than $85 \%$ damage. In case of the overall $90 \%$ of the houses had more than $30 \%$ overall damage. The damage levels for gable-end, trusses and sheathing was more or less similar. The cumulative data for MFH community damage assessment is shown in Table 1 (Appendix A). 
Figure 4.3 Probability Distribution Curve for SFH and Wind Speed $=135 \mathrm{mph}$.

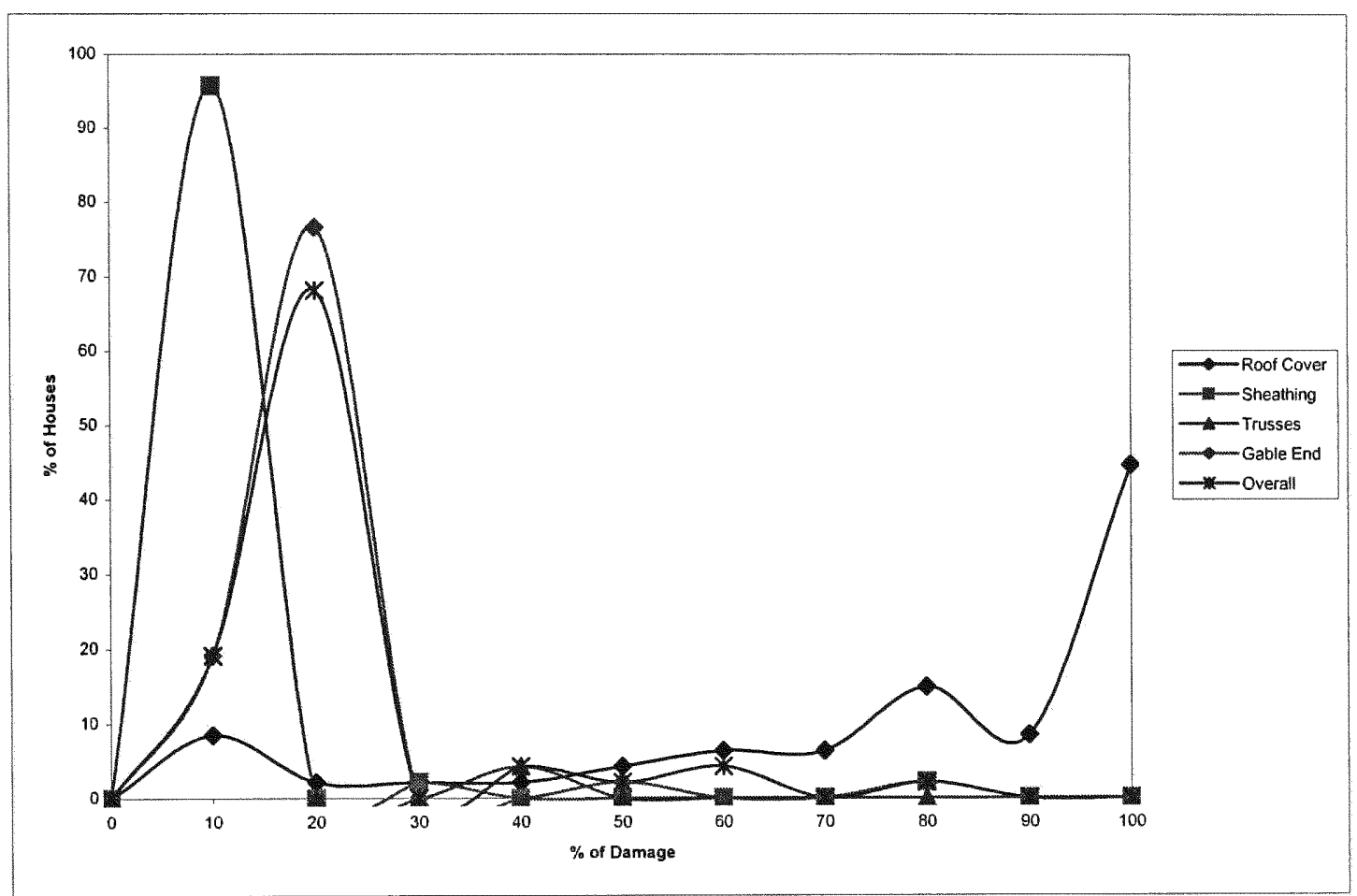

The probability distribution curve shows that for SFH structures trusses and sheathing had a maximum damage of $10 \%$ for more than $90 \%$ of the houses, following gable-end damage, which has more than $75 \%$ of the houses had $20 \%$ damage. In case of overall the peak damage is $20 \%$ for more than $65 \%$ of the houses. The probability data for SFH community damage assessment is shown in Table 1 (Appendix A). 
Figure 4.4 Roof Cover, Sheathing, Trusses, Gable-End and Overall Damage for

MFH and Wind Speed $=135 \mathrm{mph}$.

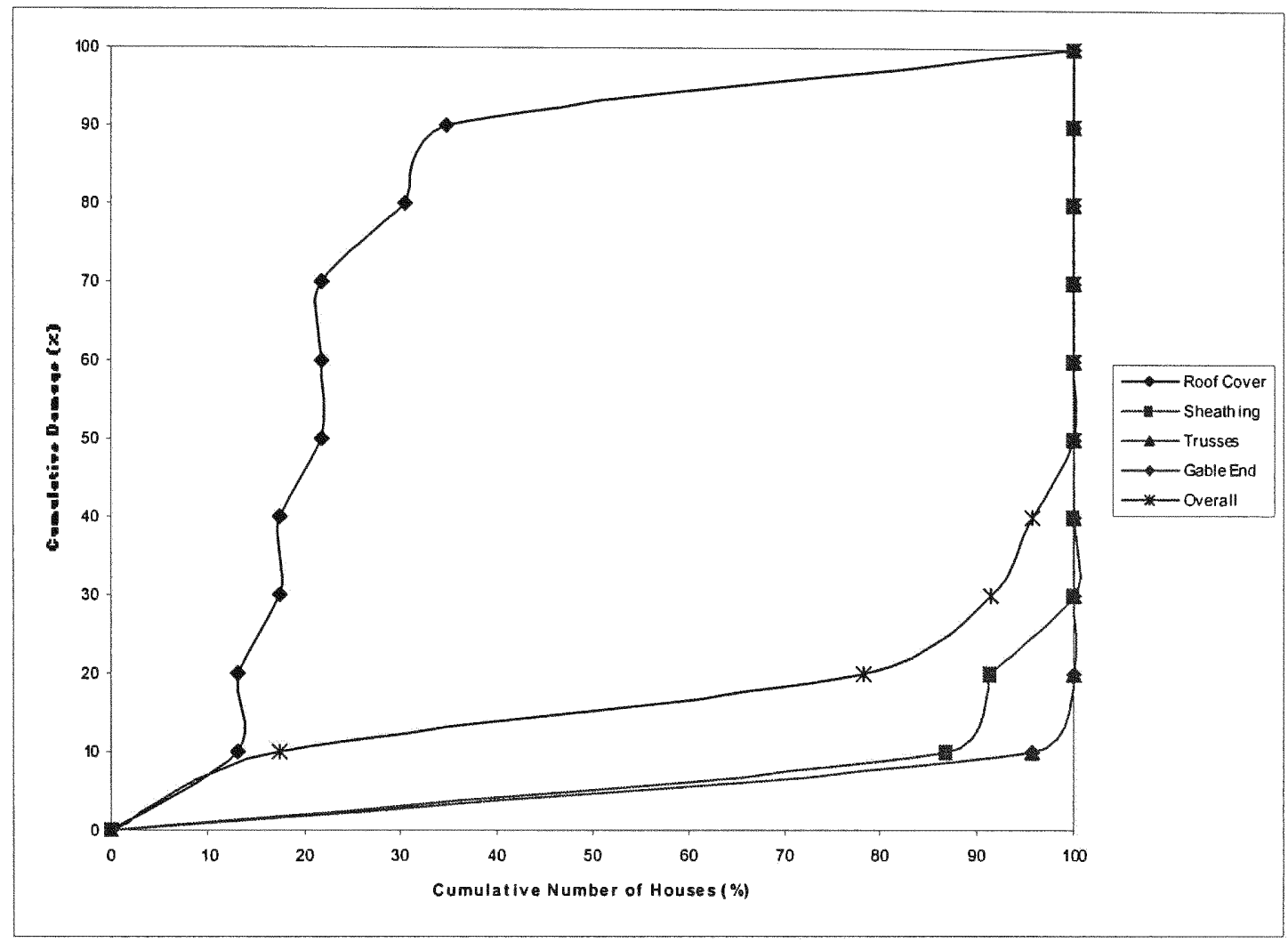

The above graph represents various structural damages for MFH structures for the wind speed of $135 \mathrm{mph}$. It represents that roof cover for $50 \%$ of the houses had more than $90 \%$ damage. In this MFH community it has different damaged levels. The cumulative data for MFH community damage assessment is shown in Table 2 (Appendix A). 
Figure 4.5 Probability Distribution Curve for MFH and Wind Speed $=135 \mathrm{mph}$.

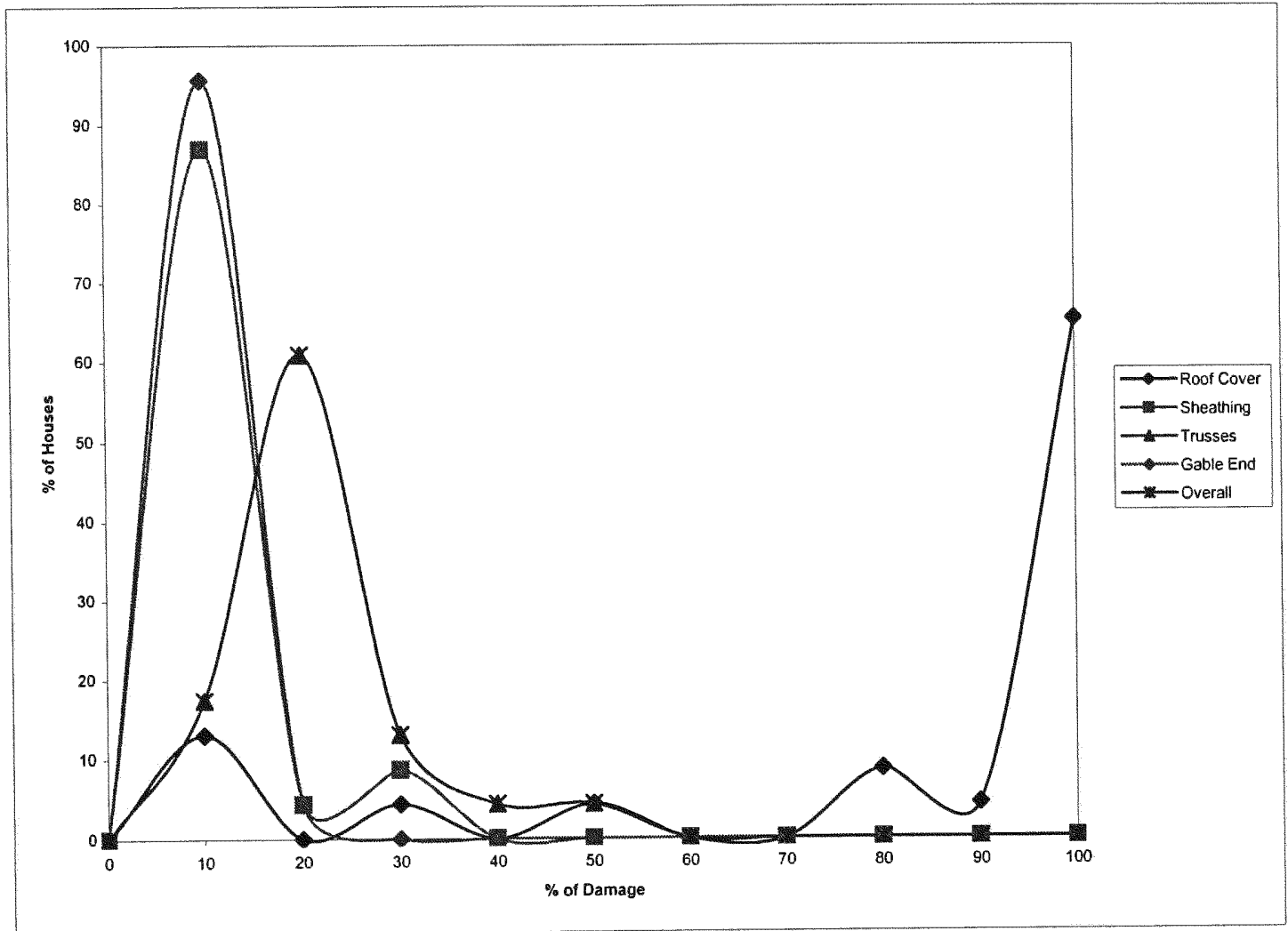

The figure represents that more than $90 \%$ of the houses have $10 \% \mathrm{~g}$ able end damage followed by $80 \%$ of the house have sheathing damage. The overall damage of MFH community is $20 \%$ for $60 \%$ of the houses. In case of roof cover it is observed that $100 \%$ damage has been cause to more than $65 \%$ of the houses. The probability data for MFH community damage assessment is shown in Table 2 (Appendix A). 
Figure 4.6 Roof Cover, Sheathing, Trusses, Gable-End and Overall Damage for

SFH and Wind Speed $=138 \mathrm{mph}$.

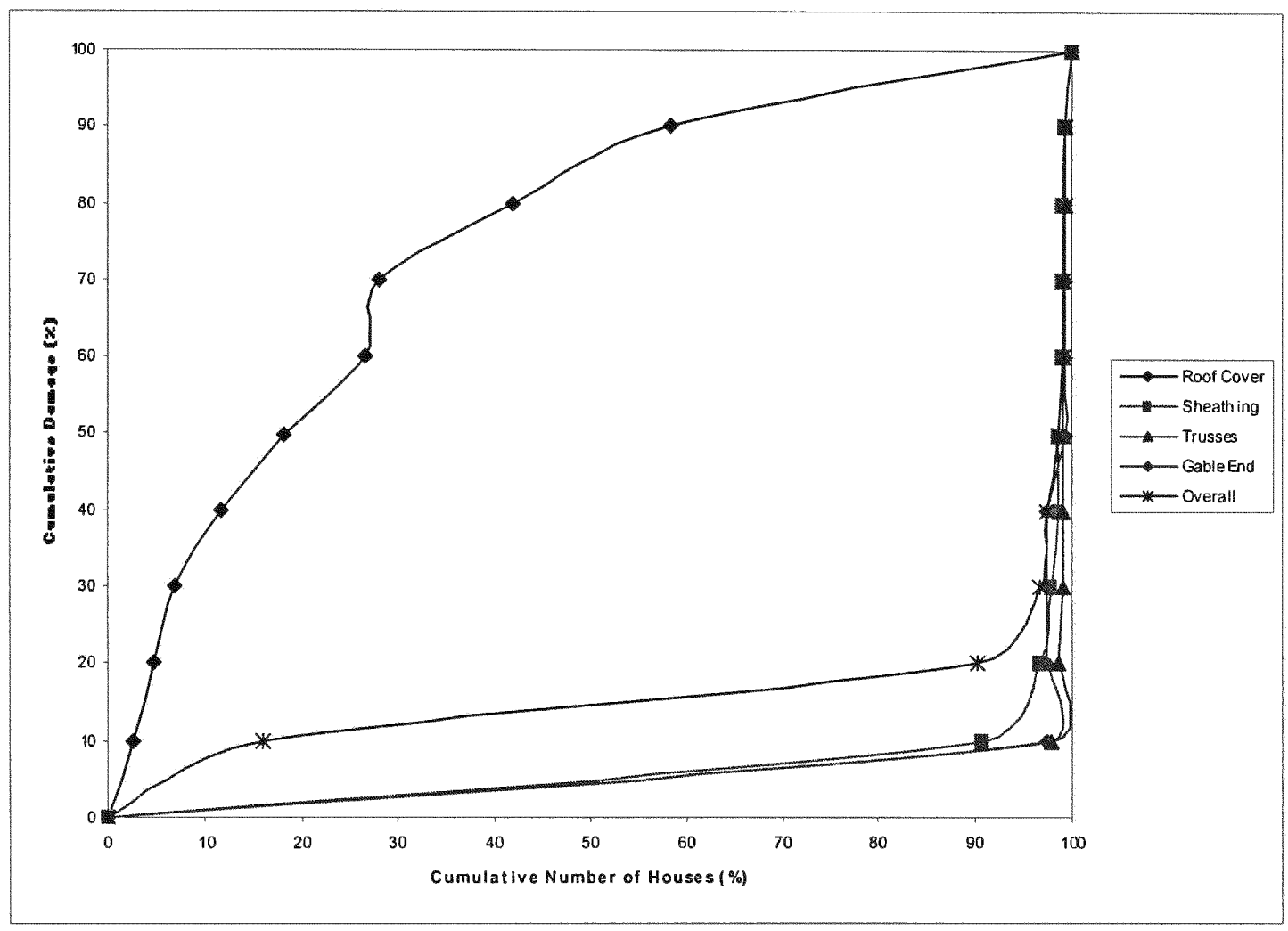

The above graph points out maximum roof cover damage for $50 \%$ of the houses, which has more than $80 \%$ of damage. These SFH structures tolerated a wind speed of $138 \mathrm{mph}$. Other structural damages at this wind speed had similar curves and for $50 \%$ of the number of houses the overall damage was more than $10 \%$. The cumulative data for SFH community damage assessment is shown in Table 3 (Appendix A). 
Figure 4.7 Probability Distribution Curve for SFH and Wind Speed $=138 \mathrm{mph}$.

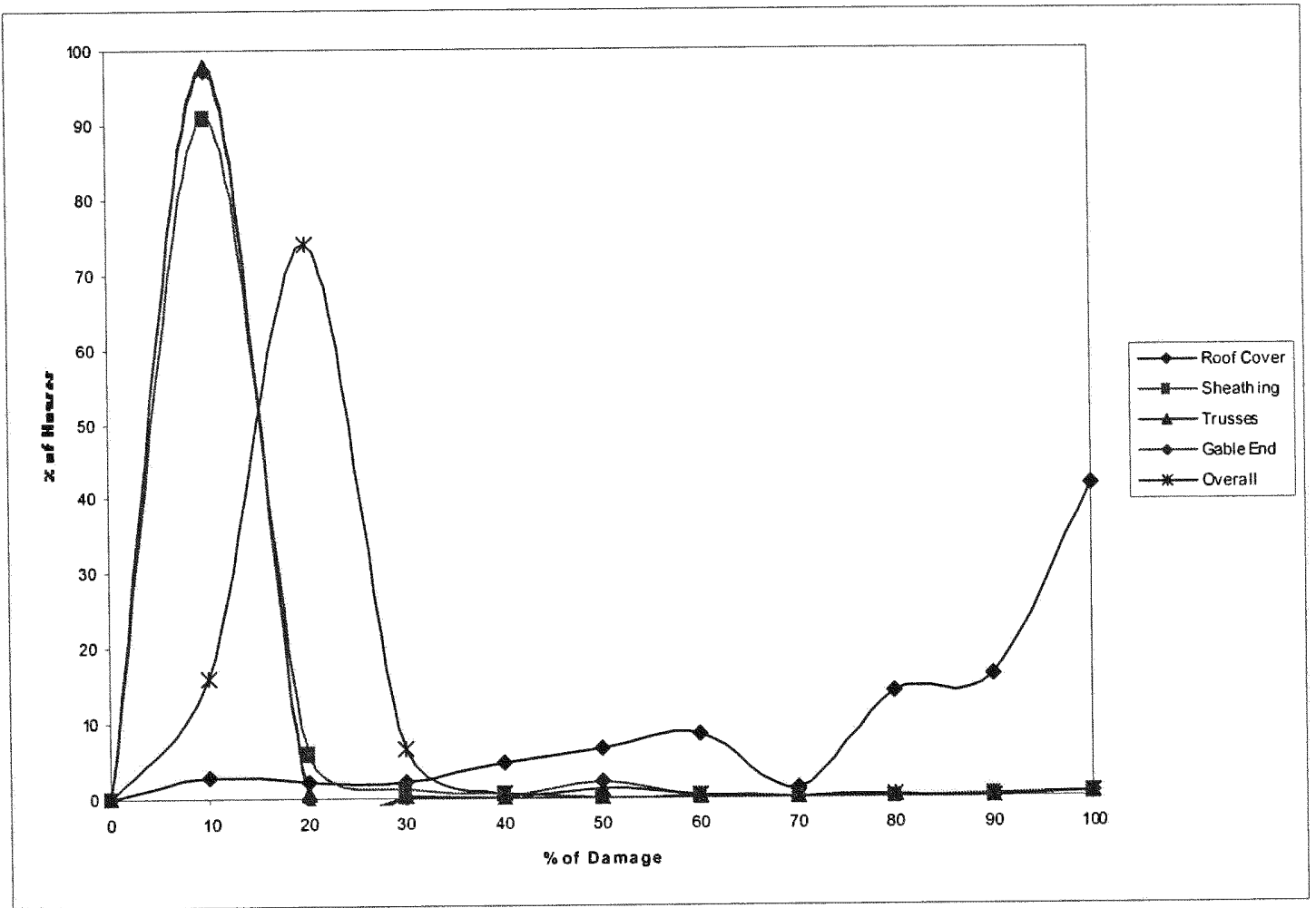

The figure represents that more than $95 \%$ of the houses had high probability damage at $10 \%$ for truss and gable-end. The overall damage of more than $70 \%$ of the houses had peak percentage damage at $20 \%$ for SFH type of structures. The probability data for SFH community damage assessment is shown in Table 3 (Appendix A). 
Figure 4.8 Roof Cover, Sheathing, Trusses, Gable-End and Overall Damage for

MFH and Wind Speed $=138 \mathrm{mph}$.

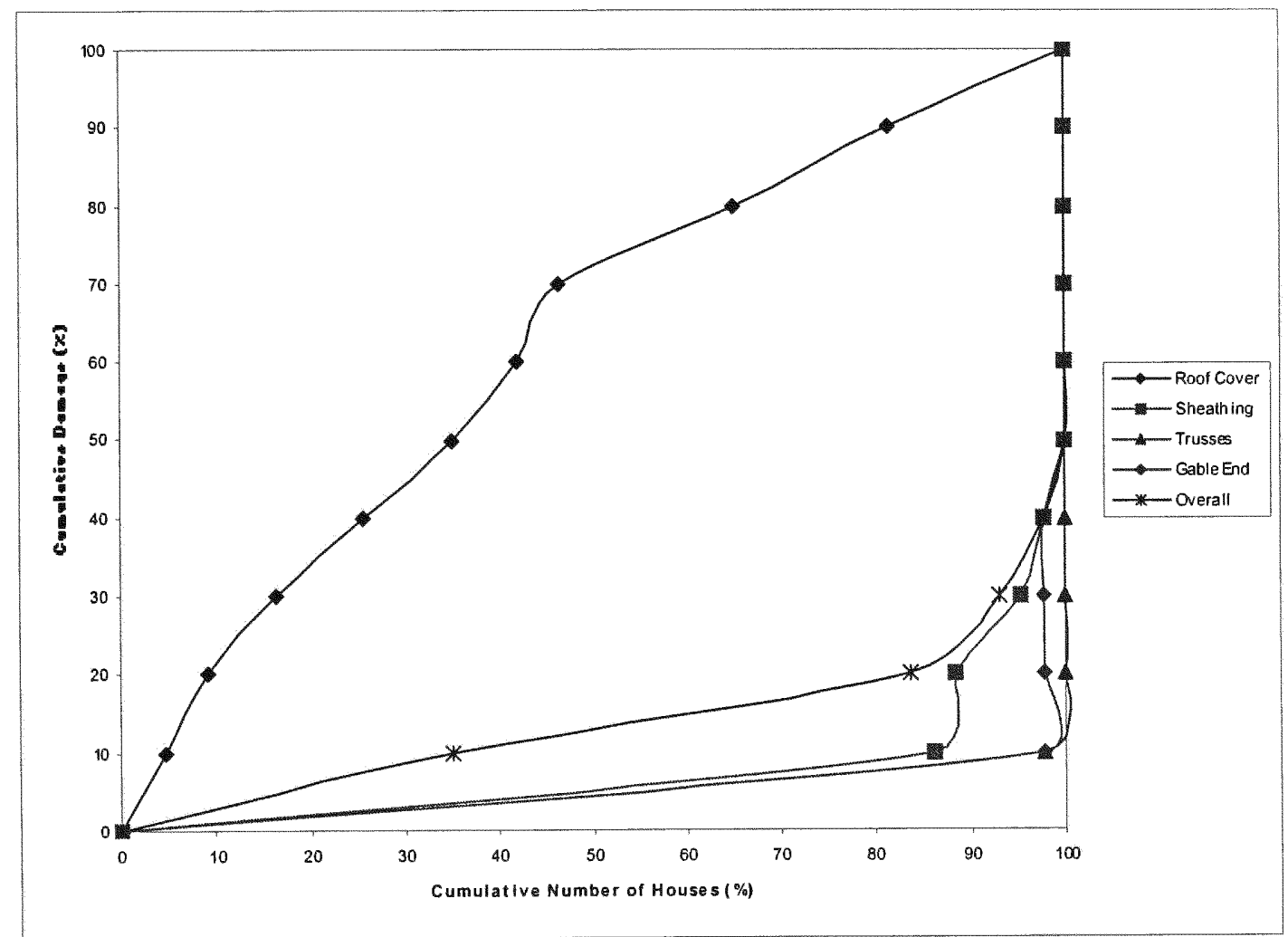

The figure shows maximum damage has been occurred in case of roof cover for MFH type of structures at a given wind speed of $138 \mathrm{mph}$. The graph shows that $50 \%$ of the houses had more than $70 \%$ of roof cover damage. The cumulative data for MFH community damage assessment is shown in Table 4 (Appendix A). 
Figure 4.9 Probability Distribution Curve for MFH and Wind Speed $=138 \mathrm{mph}$.

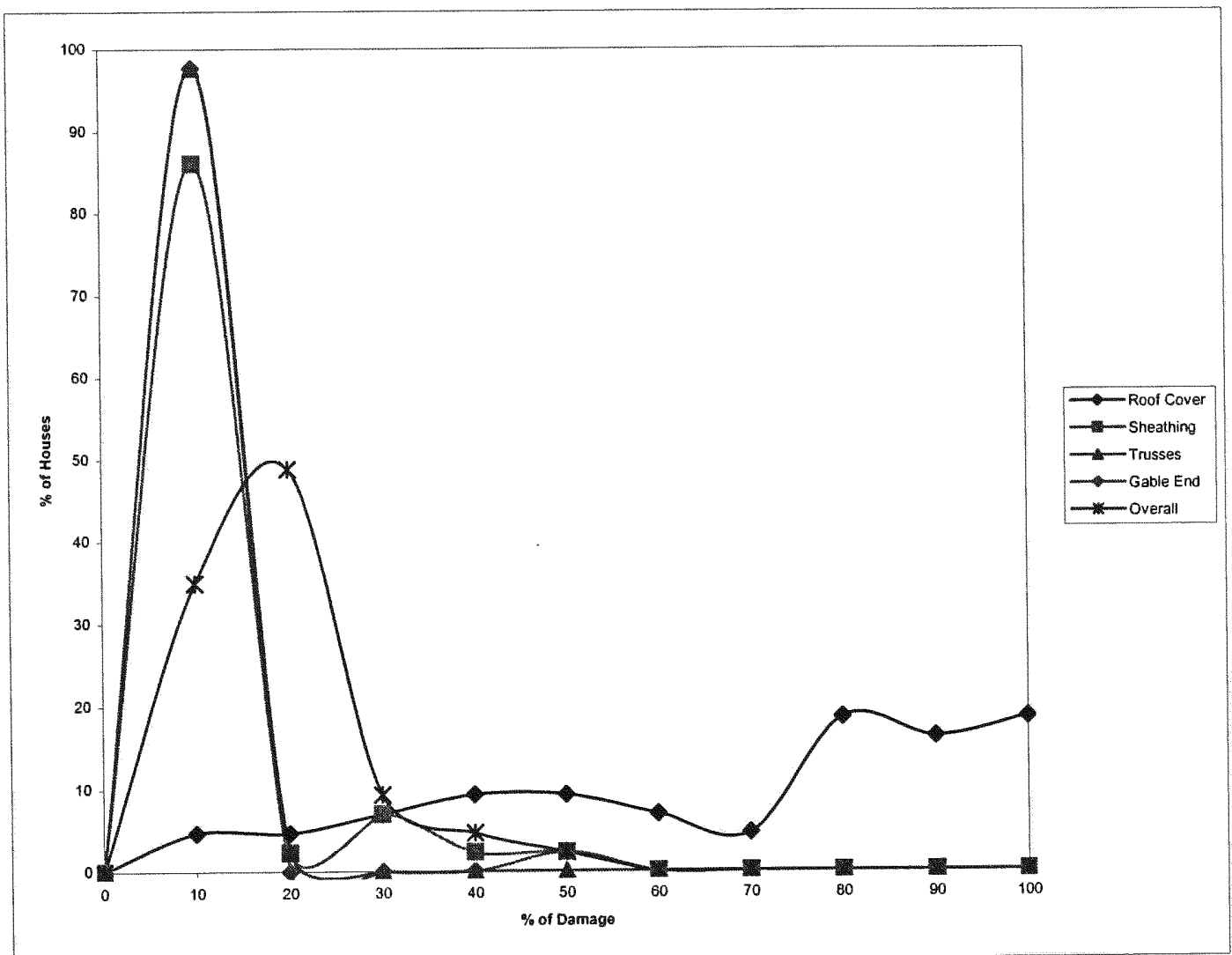

The probability distribution curve shows a maximum of $10 \%$ damage for gable-end, trusses and sheathing of more than $90 \%, 90 \%$ and $80 \%$ respectively. In case of overall damage it is $20 \%$ for $50 \%$ of the houses. The probability data for MFH community damage is shown in Table 4 (Appendix A). 
Figure 4.10 Roof Cover, Sheathing, Trusses, Gable-End and Overall Damage for

SFH and Wind Speed $=140 \mathrm{mph}$.

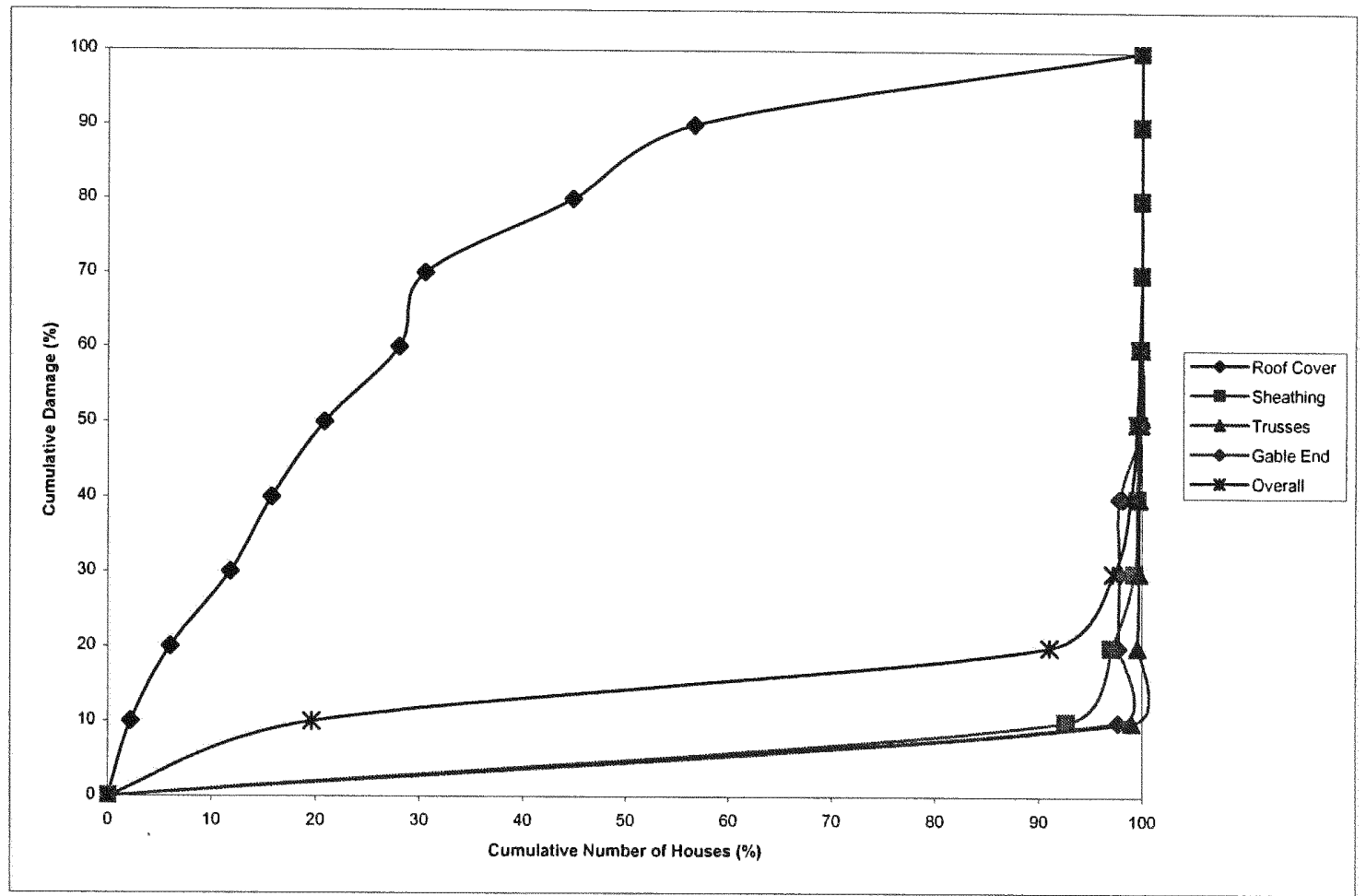

The above graph represents various structural damages for SFH type of structures for the wind speed of $140 \mathrm{mph}$. It represents that roof cover for $50 \%$ of the houses had more than $85 \%$ damage. The damage levels for gable-end, trusses and sheathing was more or less similar. The cumulative data for SFH community damage assessment is shown in Table 5 (Appendix A). 
Figure 4.11 Probability Distribution Curve for SFH and Wind Speed $=140 \mathrm{mph}$.

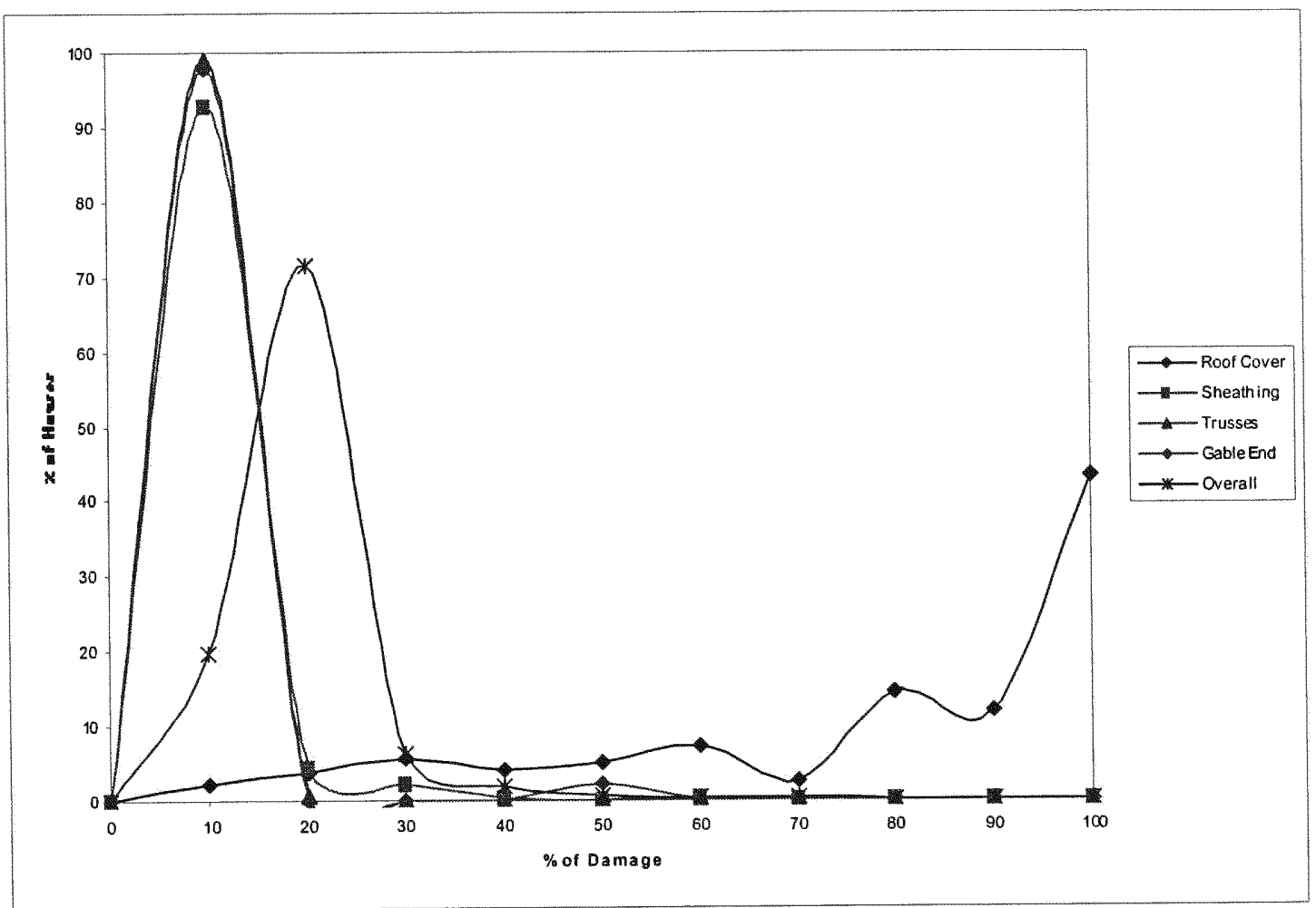

The figure represents that more than $90 \%$ of the houses had high probability damage at $10 \%$ for sheathing, trusses and gable-end. The overall damage was approximately $70 \%$ of the houses had a peak percentage damage of $20 \%$ for SFH structures. The probability data for SFH community damage assessment is shown in Table 5 (Appendix A). 
Figure 4.12 Roof Cover, Sheathing, Trusses, Gable-End and Overall Damage for SFH and Wind Speed $=143 \mathrm{mph}$.

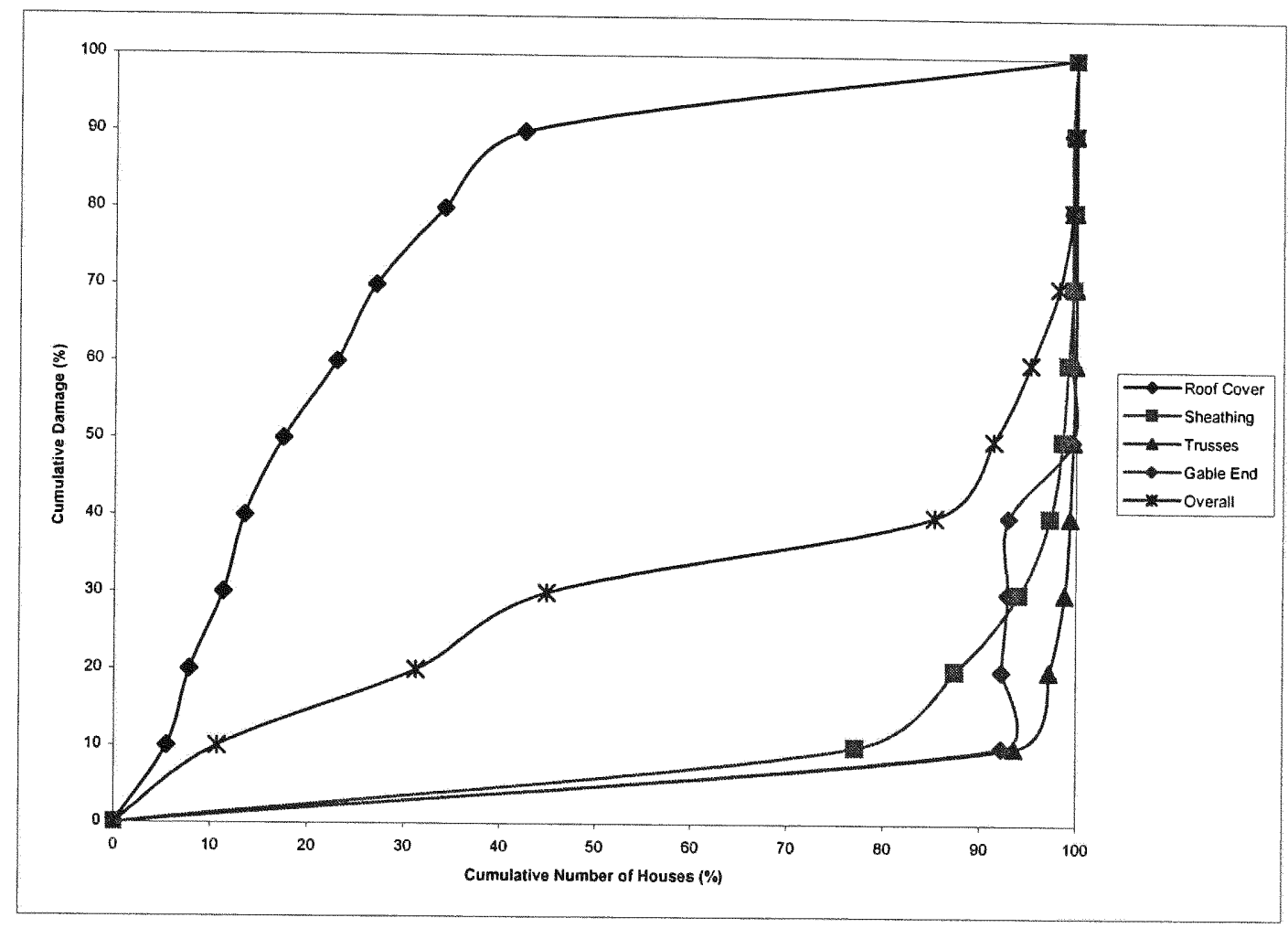

The figure represents that $50 \%$ of the houses had cumulative damage of $90 \%$ for SFH structures with a wind speed of $143 \mathrm{mph}$. The overall for such community of structures was more than $30 \%$ for $50 \%$ of the houses. There were various damage levels as observed from the above graph. The cumulative data for SFH community damage assessment is shown in Table 6 (Appendix A). 
Figure 4.13 Probability Distribution Curve for SFH and Wind Speed $=143 \mathrm{mph}$.

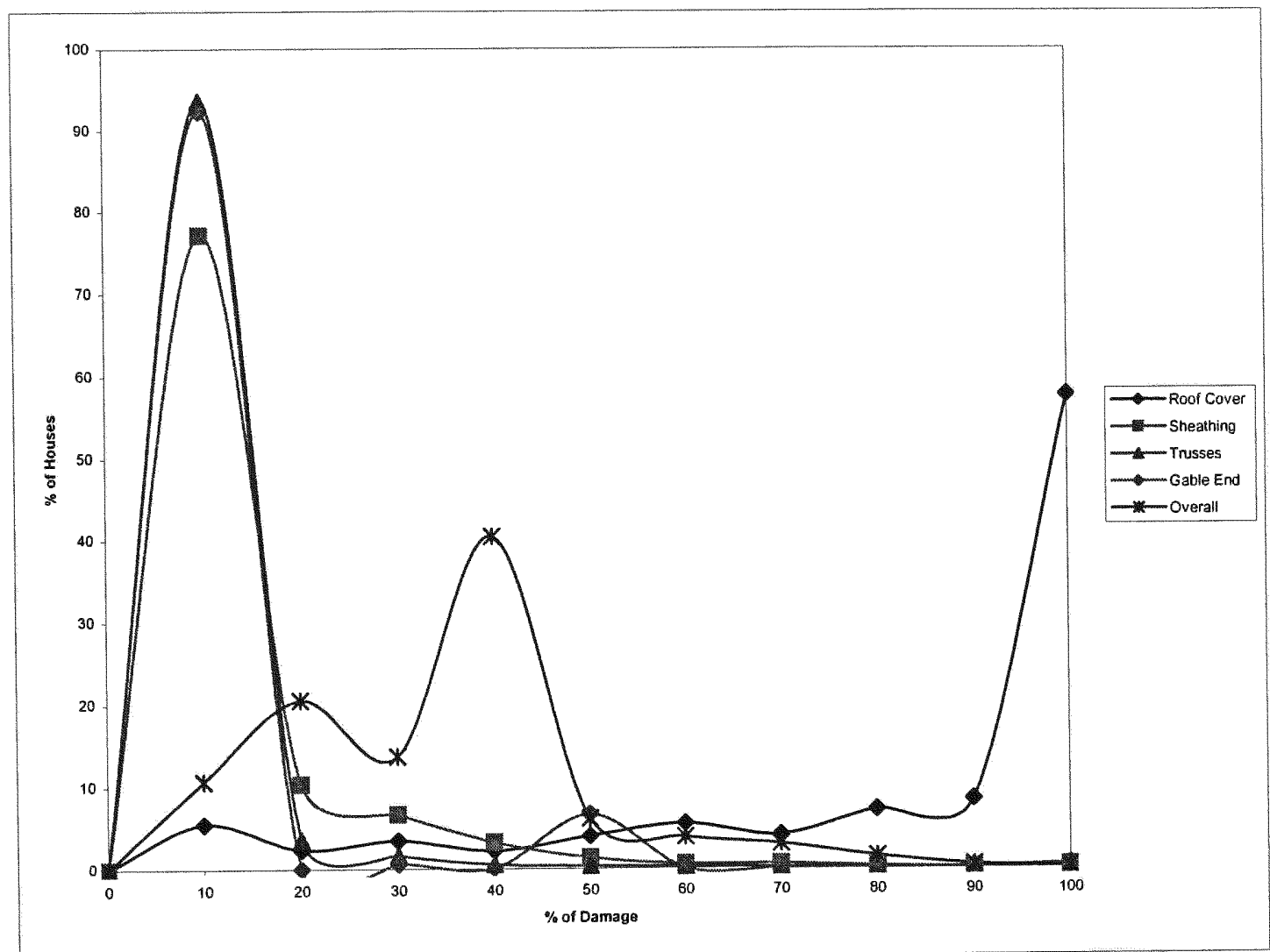

In terms of probability distribution for SFH structures trusses and gable-end had $10 \%$ damage for more than $90 \%$ of the houses, following sheathing damage, which has more than $75 \%$ of the damage. In case of overall the peak damage is $40 \%$ for $40 \%$ of the houses. The probability data for SFH community damage assessment is shown in Table 6 (Appendix A). 
Figure 4.14 Roof Cover, Sheathing, Trusses, Gable-End and Overall Damage for MFH and Wind Speed $=143 \mathrm{mph}$.

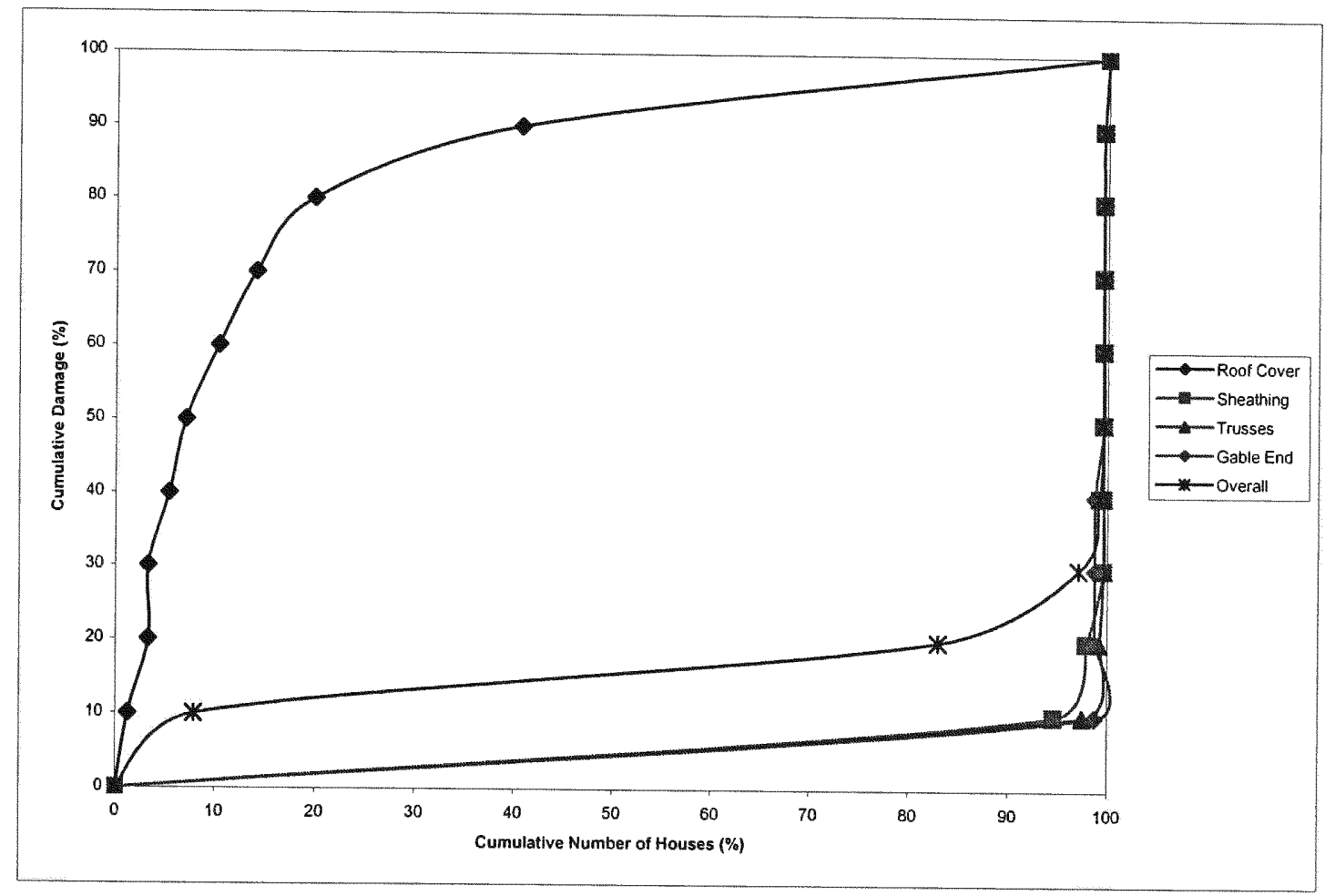

In terms of cumulative percentage for MFH type of structures and for wind speed of 143 505 of the houses had roof cover damage of more than $90 \%$. The curves showing the damage for sheathing, trusses and gable-end is approximately similar that is all of them have same percentage of damage. Whereas when overall is considered $50 \%$ of the houses had more than $10 \%$ of various structural damages. The cumulative data for MFH community of damage assessment is shown in Table 7 (Appendix A). 
Figure 4.15 Probability Distribution Curve for MFH and Wind Speed $=143 \mathrm{mph}$.

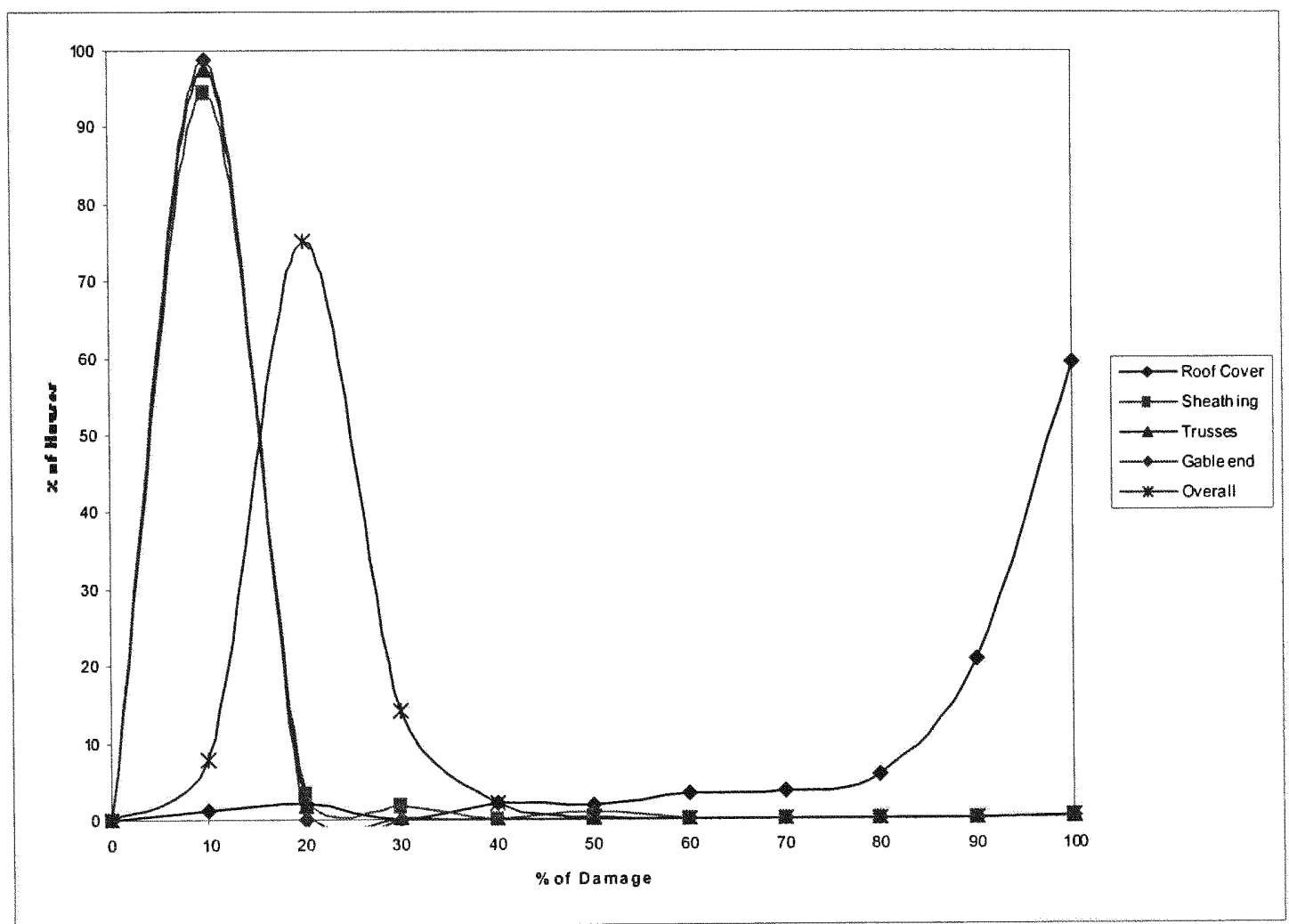

The above figure represents maximum percentage of houses having a gable-end damage of $10 \%$. Sheathing and trusses also share a high damage level of $10 \%$ for more than $90 \%$ of the houses. The overall having a maximum of $20 \%$ has more than $70 \%$ of the damages. The probability data for MFH community damage assessment is shown in Table 7 (Appendix A). 
Figure 4.16 Roof Cover, Sheathing, Trusses, Gable-End and Overall Damage for

SFH and Wind Speed $=147 \mathrm{mph}$.

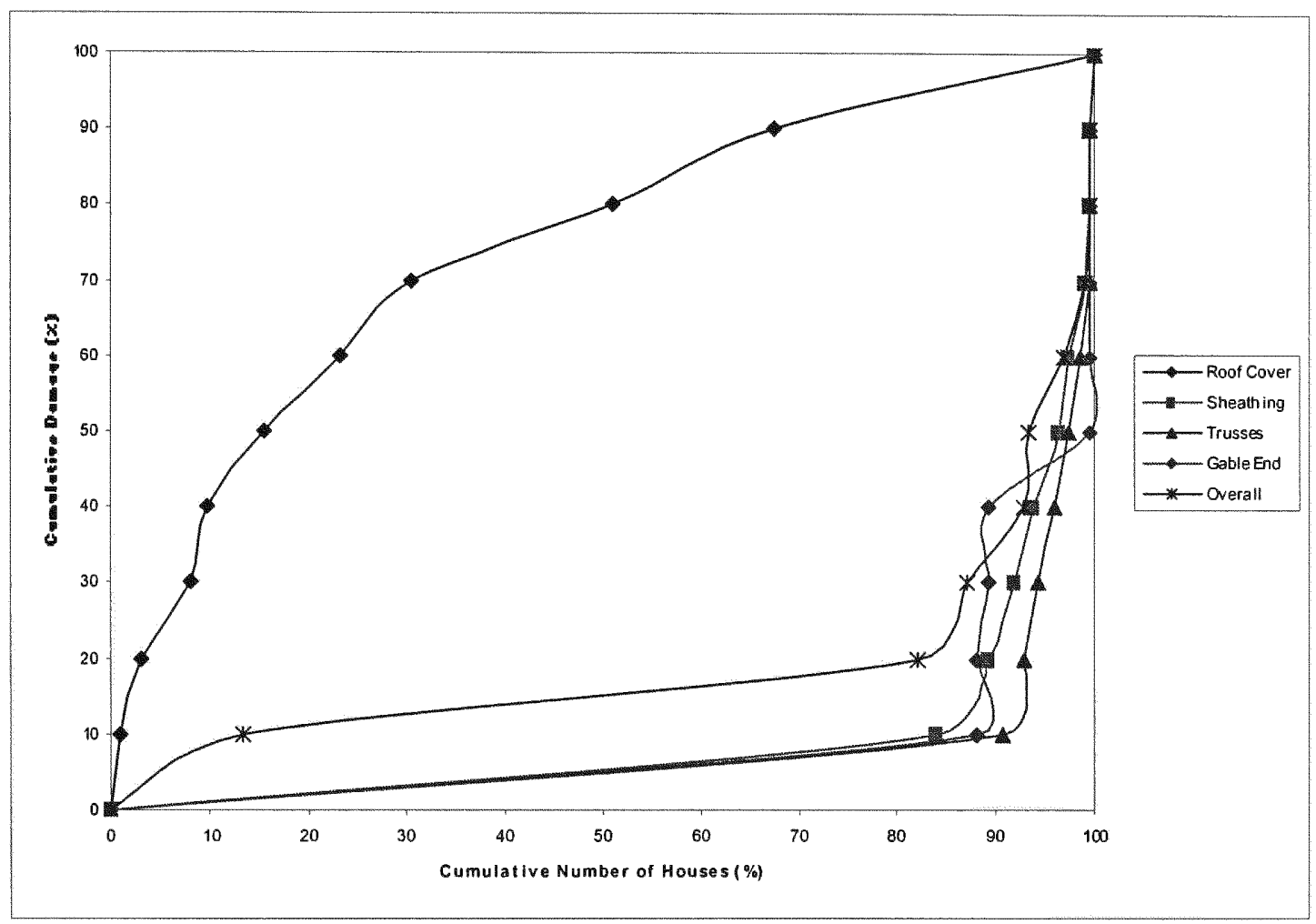

The above graph points out maximum roof cover damage for $50 \%$ of the houses, which has an approximate damage of $80 \%$. These SFH structures tolerated a wind speed of 147 mph. The overall damage was more than $10 \%$ for $50 \%$ of the houses. The cumulative data for SFH community damage assessment is shown in Table 8 (Appendix A). 
Figure 4.17 Probability Distribution Curve for SFH and Wind Speed $=147 \mathrm{mph}$.

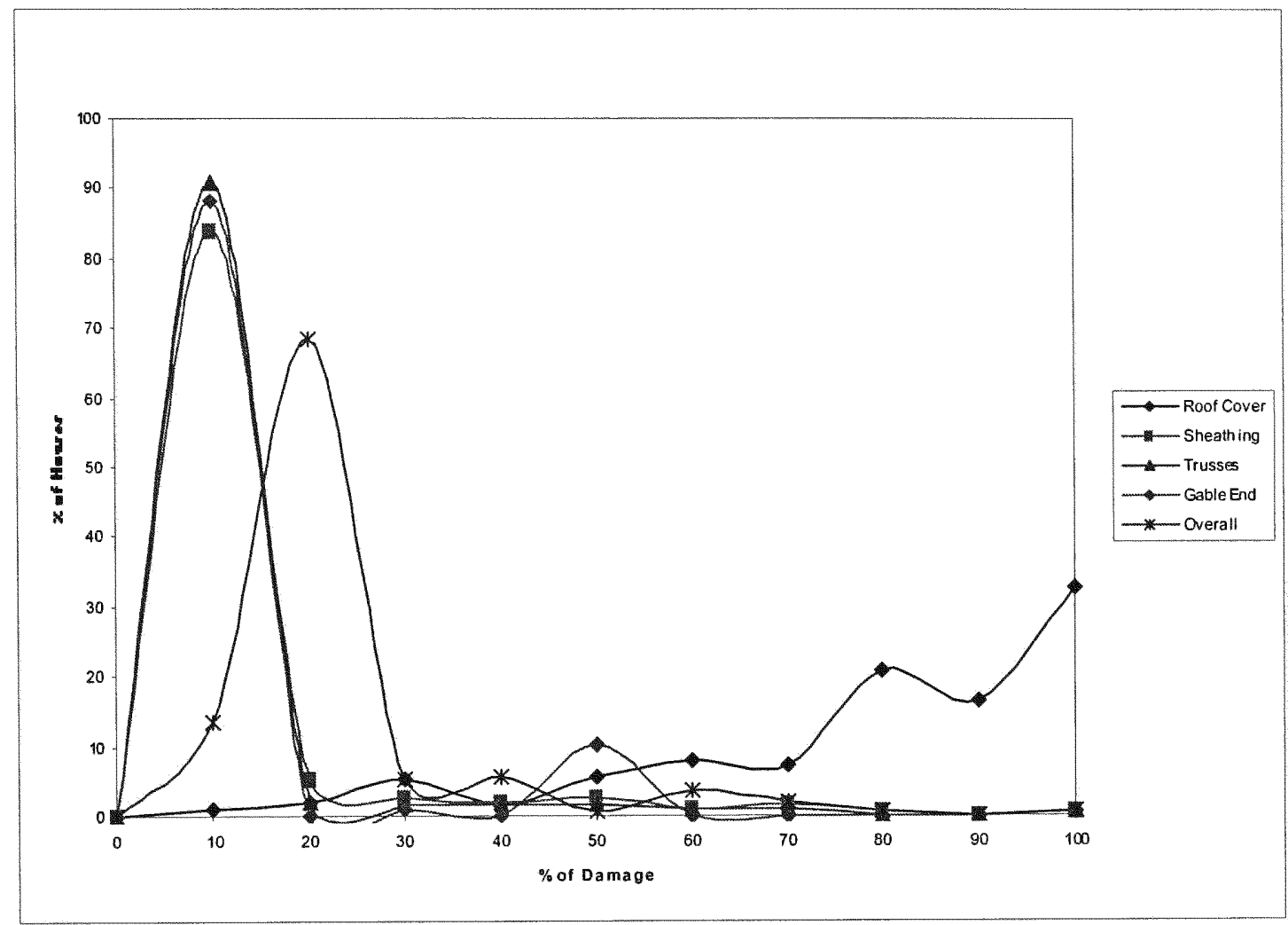

The figure represents that approximately $90 \%$ of the houses had high probability damage at $10 \%$ for sheathing, trusses and gable-end. The overall damage of more than $65 \%$ of the houses had a peak percentage damage of $20 \%$ for SFH structures. The probability data for SFH community damage assessment is shown in Table 8 (Appendix A). 
Figure 4.18 Roof Cover, Sheathing, Trusses, Gable-End and Overall Damage for

MFH and Wind Speed $=147 \mathrm{mph}$.

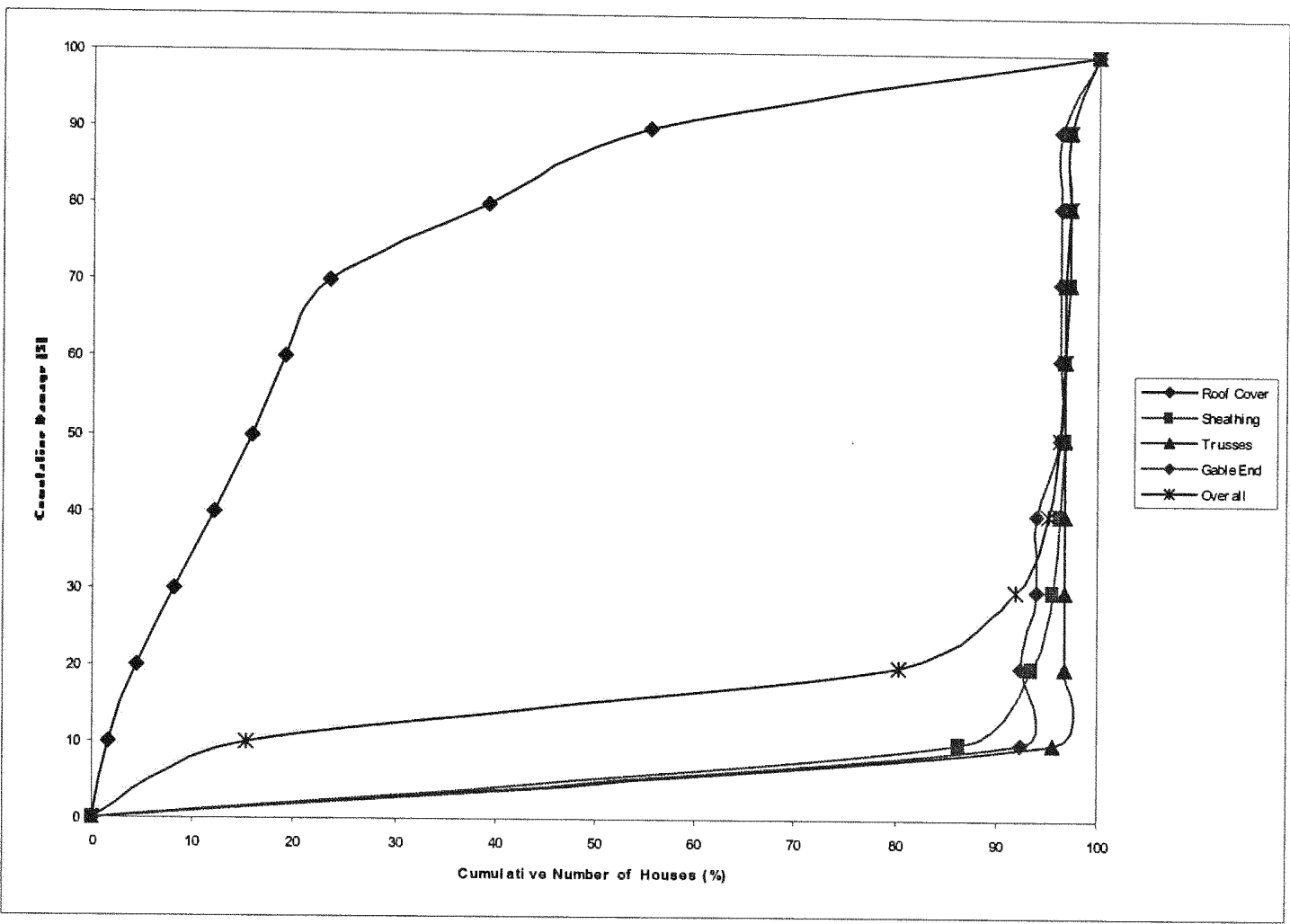

The above graph represents various structural damages for MFH type of structures for the wind speed of $147 \mathrm{mph}$. It represents that roof cover for $50 \%$ of the houses had more than $85 \%$ damage. The damage levels for gable-end, trusses and sheathing was more or less similar. The cumulative data for MFH community damage assessment is shown in Table 9 (Appendix A). 
Figure 4.19 Probability Distribution Curve for MFH and Wind Speed $=147 \mathrm{mph}$.

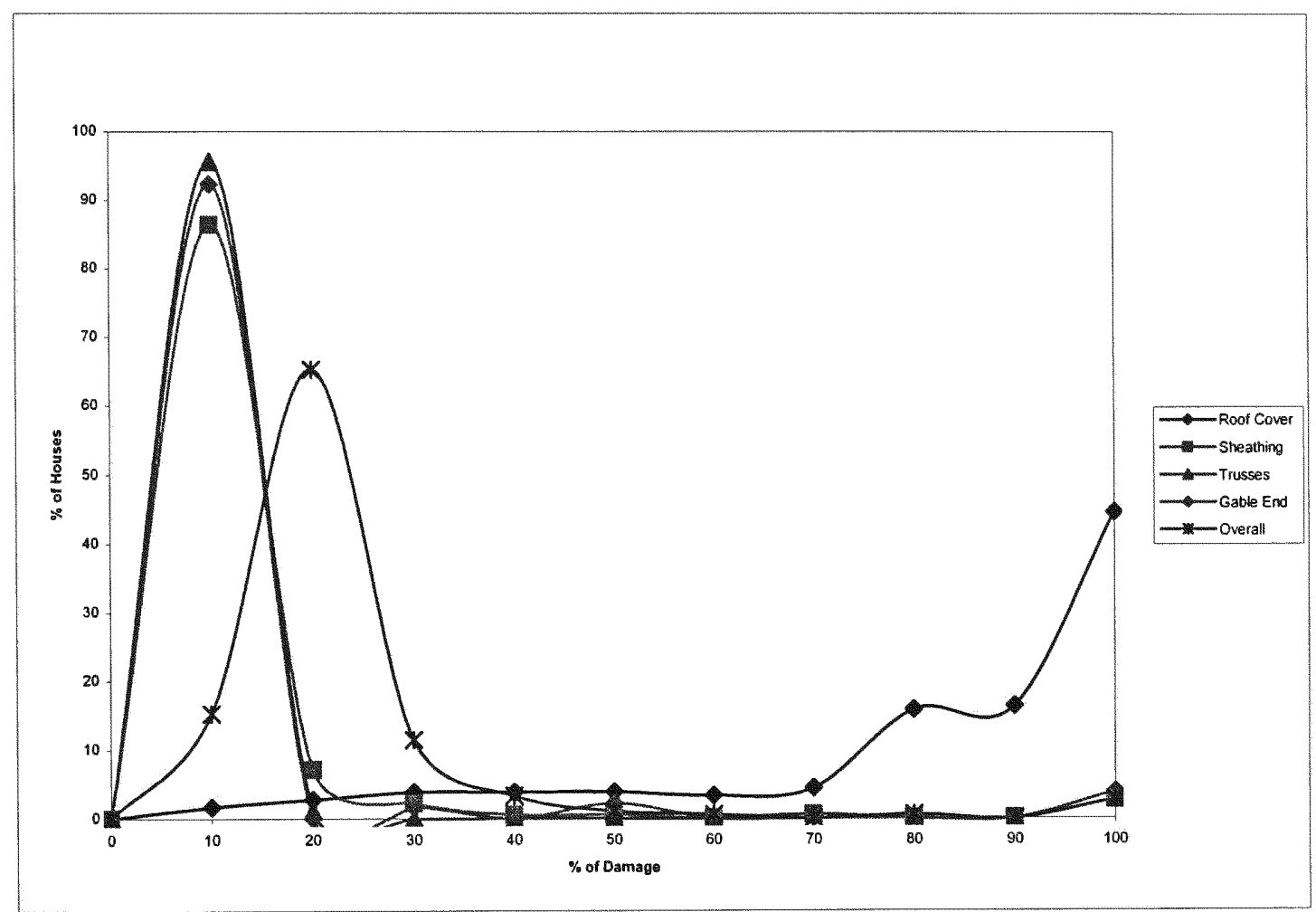

The figure represents that more than $95 \%$ of the houses has the probability of truss damage of $10 \%$. The overall damage of MFH community is $20 \%$ for more than $60 \%$ of the houses. The probability data for MFH community damage assessment is shown in Table 9 (Appendix A). 
Figure 4.20 Roof Cover, Sheathing, Trusses, Gable-End and Overall Damage for

MH and Wind Speed $=147 \mathrm{mph}$.

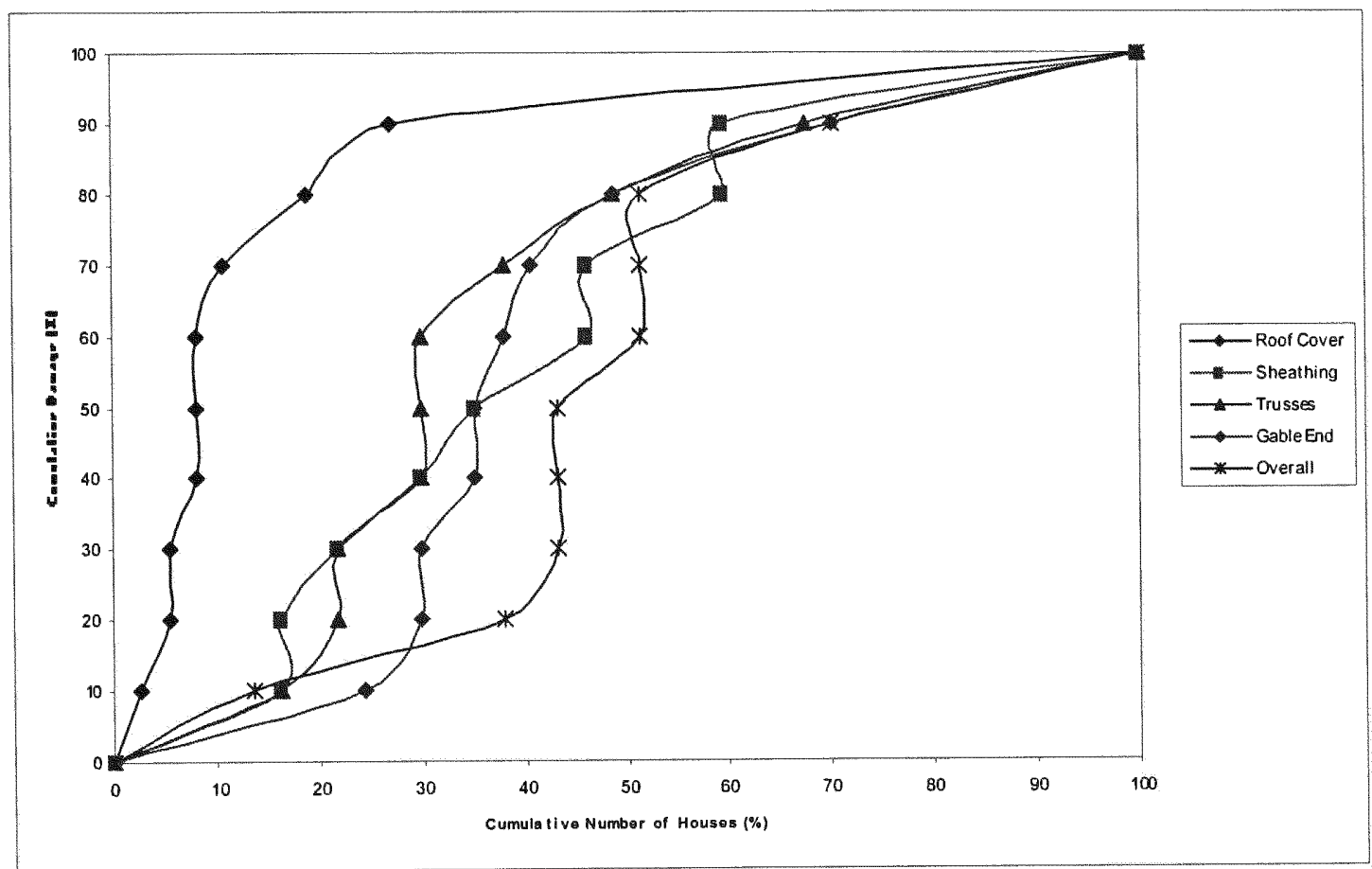

The above figure indicates that various structural damage of $\mathrm{MH}$ type of structures at given wind speed of $147 \mathrm{mph}$. The various levels of damages in case of MH were quite high for example at $50 \%$ of the number of houses more than $70 \%$ damage was observed. The cumulative data for $\mathrm{MH}$ community damage assessment is shown in Table 10 (Appendix A). 
Figure 4.21 Probability Distribution Curve for $M H$ and Wind Speed $=147 \mathrm{mph}$.

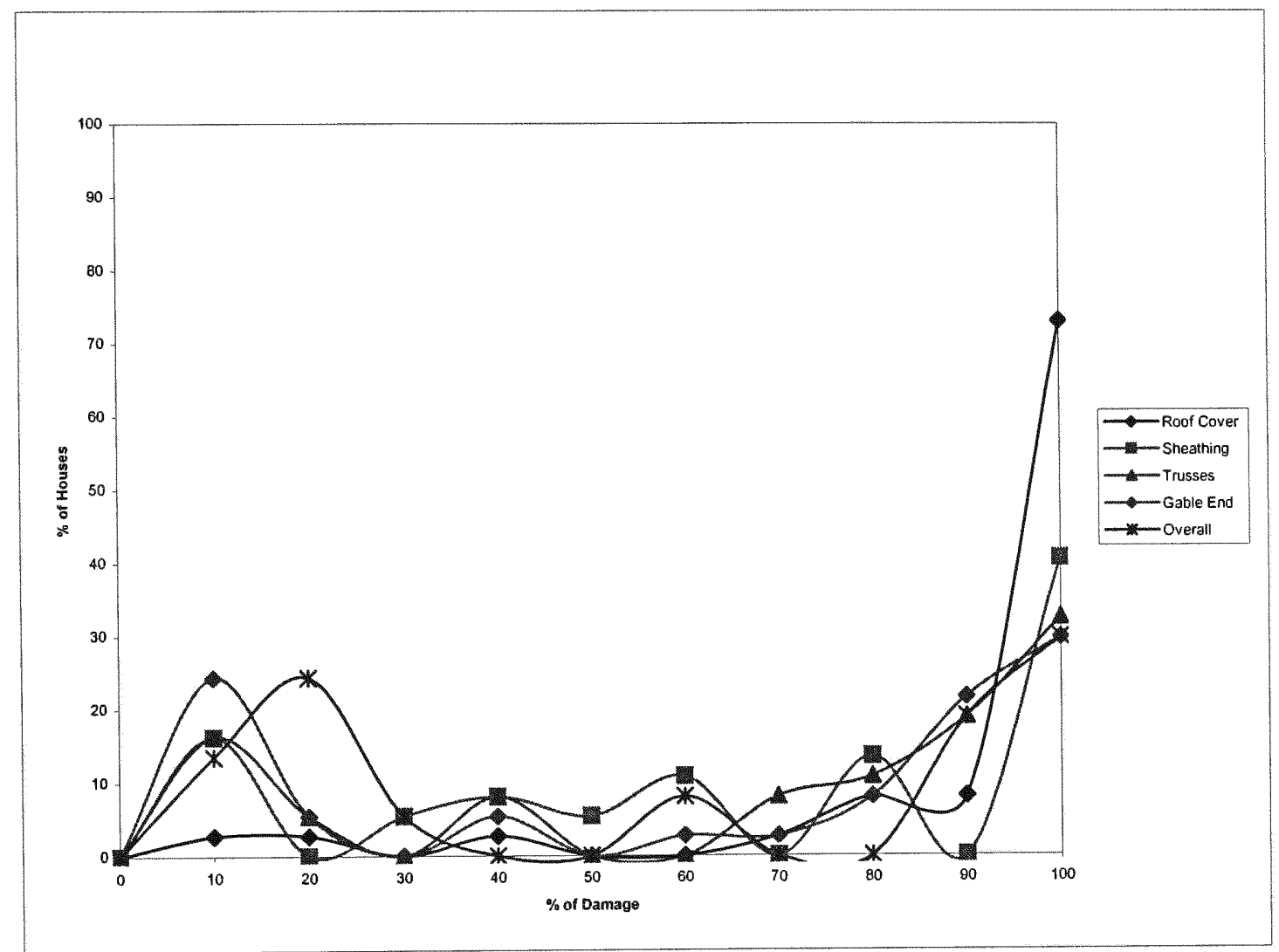

Observation of the above probability distribution curve, the peak percentage of damage for overall MH type of structures was $20 \%$ for more than $20 \%$ of the houses. Around $100 \%$ roof cover damage was observed for more than $70 \%$ of the structures. The probability data for $\mathrm{MH}$ community damage assessment in Table 10 (Appendix A). 


\section{DAMAGE MECHANISM}

\subsection{Effect of Immediate Surroundings}

High pressures or suctions are often reduced in complex surroundings, the lower loads increases. The reduction of mean loads and increase of dynamic loads due to increased turbulence in the cluttered environment result in an increase of lower peak loads. For high peak loads, the decreased mean component dominates, yielding reduced peaks. The net effect is a less distinct variation of wind loads with direction in complex surroundings compared with that for an i solated building. A lso, the environment with similar-sized buildings can lower the ambient pressure for the region below the general building height (Surry, and Davenport, 1991). Some examples related to the effect of immediate surroundings are Figures 1.3, 1.4 and, 1.5.

\subsection{Effect of Windborne debris}

The impact of windborne debris is the primary cause of breach in buildings and residential structures during a storm and concurrently the fluctuating pressures are the cause of the failure of components and claddings. One of the main causes of the failure of the structure during a storm is the failure of windward wall leading to an increase in internal pressures, which in some instances becomes almost double, thus leading to the collapse of leeward wall and loss of the roof. Windborne gravel is one of the main components in the failure of windows, since they impact the windows at speeds up to $36-$ 
$40 \mathrm{ft} / \mathrm{s}$ causing cracks and allowing the increase in internal pressurization. The breakage from impact by windborne materials is most common cause of the failure of windows.

The problem of having an intact building during a storm is dependent on the building envelope's r esistance a gainst two factors namely: the impact of w indborne debris and fluctuating pressures on the structure during a storm. The fluctuating pressure during a hurricane must also be taken into account while considering the design of the building envelope. (Surry and Davenport, 1991). Some examples related to the effect of windborne debris are Figures 1.16, and 1.19.

\subsection{Effect of Upstream Terrain}

It is well known that wind pressures on buildings are affected by terrain roughness. In the case of an isolated building, with increased surrounding obstructions the mean wind pressures acting on the building decreases while the unsteady pressure increase. Similarly, the magnitude of increase in wind loads due to adjacent buildings is strongly dependent on the upstream terrain.

Due to the lower degree of turbulence associated with open-country exposure, fluctuations in the wake of an upstream building are well-correlated and therefore cause enhanced wind loads on the downstream building. On the other hand, a more turbulent urban exposure works to dampen the strength of such a wake, thereby reducing the 
overall wind loads on the downstream buildings (Surry and Davenport, 1991). Some examples related to the effect of upstream terrain are Figures 12.6 and 12.13.

\subsection{Effect of Geometrical Parameters}

Wind loads on buildings increase with increasing height of buildings. It was observed that increasing the height of the upstream building due to shielding but dynamics loads increased reduced mean along-wind loads. The mean forces decreases with an increase in size of the upstream building due to shielding provided by the large upstream building. It has been suggested that since large buildings upstream shed large vortices, which increases the fluctuating velocity of the flow, the along-wind fluctuating forces and response have a tendency to increase with the size of the upstream building.

It was observed that adverse effects could be encountered depending on the relative placement of structures in the approaching wind. Introducing variations in building geometries may decrease these effects (Surry and Davenport, 1991). Some examples related to the effect of geometrical parameters are Figures 12.9 and, 12.11.

\subsection{Effect of Wind Direction and Building Orientation}

Wind effects on buildings depend not only on the magnitude of wind speeds, but on the associated wind direction as well. Since in actual situations the direction of wind is always changing, it is important to study the effect of wind direction on interference 
effects. In the case of an isolated building with a square cross-section, the maximum drag force is registered when the wind strikes the building normal to one face i.e. at a $0^{\circ}$ angle of attack. The maximum mean torque however would be for wind direction at an angle of attack of about $75^{\circ}$ to a face of the building. With two or more close-by adjacent buildings, this scenario is expected to change.

The wind pressure on adjacent buildings varies with wind direction. However, detailed measurements on the effect of angle of attack of wind on interaction between adjacent buildings show that the critical wind direction may vary, depending upon the building geometries and their relative arrangement (Surry and Davenport, 1991). Some examples related to the effect of wind direction and building orientation are Figures 7.2, and 7.20.

\subsection{Effect of Building Arrangement and Spacing}

The spacing between adjacent buildings and their relative arrangement are the most important factors governing interference effects. Interference effects between two buildings should decrease by increasing the separation distance, such that beyond a certain spacing buildings behave as isolated under the action of wind. It should be noted however that in case of tall buildings, interference effects in terms of dynamic loads can be significant up to a distance of $1 \mathrm{~km}$. downstream.

It was concluded that if a medium sized building near a waterfront or other clear fetch area has similar or taller buildings built upstream at critical locations, the downstream 
building will suffer significant increases in peak loads and serious dynamic effects (Surry and Davenport, 1991). Some examples related to the effect of building arrangement and spacing are Figures 6.1, and 7.1.

\subsubsection{Drag and Lift}

For flows about symmetrical shapes, a drag force may be identified acting in the mean wind direction and a lift force at right angles to it. These aerodynamic forces are expressed in terms of non-dimensional drag and lift coefficients: their magnitude depends upon building geometry. As expected, the closer the two buildings the higher is the level of shielding. At a distance of about twice the building width, there is practically no drag force on the building and still lower spacing, a negative shielding (suction) is experienced by the downstream building. This is because the negative pressure on the leeward face of the downstream model is small as compared to that on the windward face since the separated shear layers from the upstream model reattach on the sides, of the downstream model and become weak by the time they reach the leeward end (Surry and Davenport, 1991). Some examples related to the effect of drag and lifts. 


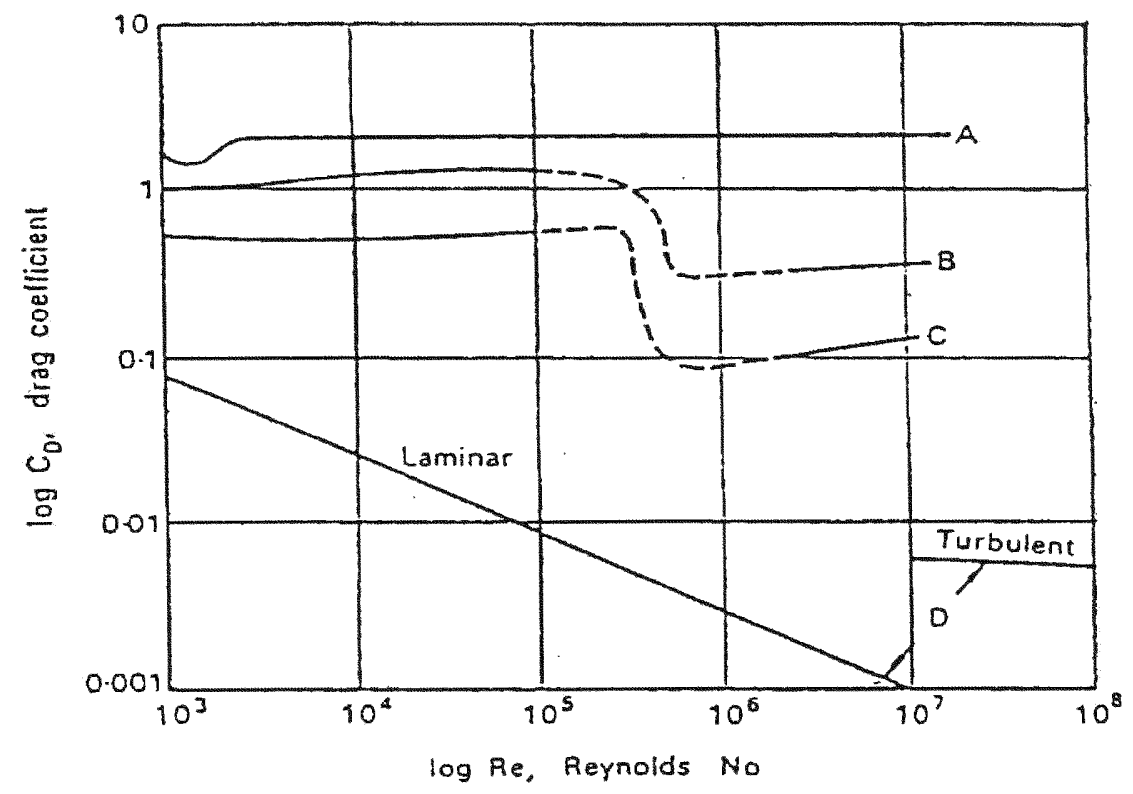

Drag coefficients of bodies at various Reynolds numbers.

A-upright, infinitely long plate.

B-infinitely long cylinder

C-Sphere

D-Flat Plate

Figure 5.1 Drag coefficient of bodies at various Reynolds numbers.
A - Upright, infinitely long plate.
B - Infinitely long cylinder.
C - Sphere.
D - Flat Plate.

Adapted from: "Wind Forces in Engineering" by Peter Sachs, M.A., C. Eng., M.I. Mech.E. 1978, page 60. 


\subsubsection{Overturning Moments}

The dead load of a building tends to resist the overturning or toppling effect of wind. Overturning moments may be problematic for the whole building especially in the case of relatively tall and slender structures. Base overturning moments are generally expressed about axes normal to the building faces.

The dynamic wind loads due to interference follow a different trend from that of the mean loads and the effects are much more severe. In the case of buildings with symmetric geometries, torsional moments may be caused by non-uniformities in the wind flow due to adjacent structures. This effect may further be accentuated if a building is not geometrically symmetric (Surry and Davenport, 1991). Some examples related to the effect of overturning moments are Figures 13.3, and 14.1.

\subsubsection{Tortional Moments}

Wind-induced pressure distribution on an isolated building may create a significant torsional moment, if the distance between the elastic center of the building (or its geometrical shear center, if it is rigid) and its aerodynamic center or point of application of the resultant wind force is large.

Wind flow is, in general, unsteady, incompressible and slightly viscous. Viscous effects are practically restricted in a thin layer of air around the rigid surface of the structure 
known as boundary layer. Thus wind flow field around a structure can be considered to consist of the in viscid and irrotational far field (potential flow) and the near field of the rotational and turbulent boundary layer (Bazeos and Beskos, 1996). Some examples related to the effect of tortional moments is Figure 10.2.

\subsection{Interference Mechanism:}

Interference effects due to a large group of low-rise buildings are major factors. There are many parameters, which affect the manner in which one building modifies the forces on another building in its vicinity. These are: size and shape of the building, wind velocity and direction, type of approach terrain and above all, the location and proximity

of neighboring buildings. In case of wind flow around an isolated building, the windward walls are subjected to positive pressure, due to the direct impact on wind. Negative pressure (suction) is generated on the other three walls and roof, due to separation of flow around the edges of the building (Khanduri, et al. 1998).

With the inclusion of another building in the vicinity, the loading pattern becomes quite complex. The buildings may experience increased or reduced wind loads depending upon their geometries, spacing as well as the characteristics of wind flow and upstream terrain. The arrangement of buildings their relative size and the direction of wind determine the extent of interaction. 


\section{DAMAGE FACTORS}

\subsection{Shape Factors:}

The evaluation of the shape factor for a structure is complementary to the determination of wind velocities.

$$
\text { Force }=\mathrm{C}_{\mathrm{F}} \mathrm{Aq}
$$

Where $A$ is the structure's area, $C_{F}$ is a non-dimensional shape factor, and $q=1 / 2 \rho V^{2}$

$\mathrm{q}$ is called the dynamic head of the wind. Although the shape factor is defined by equation. (6.1.1) It should not be inferred that $C_{F}$ remains constant when $A$ or $q$ change. Evidently $\mathrm{C}_{\mathrm{F}}$ will be different for a cylinder with frontal area $\mathrm{A}$ and a flat plate with the same area, but the basis of all work on wind forces is that remains $\mathrm{C}_{\mathrm{F}}$ constant for shapes with different sizes but similar geometry, under certain conditions. It may be assumed that $C_{F}$ is independent of the wind turbulence, but not entirely independent of velocity (Sachs, 1978).

\subsubsection{Forces on Basic Shapes}

Wind forces on open structures can usually be estimated by adding together calculated forces on individual members. Sharp-edged members are independent of scale (Re effects) but semi-aerodynamic shapes have drag coefficients varying with wind velocity, 
although m embers of 1 ess than 3 inches in diameter d o n ot r each the supercritical Re region. Suitable account should be taken of the angle of the wind, nearby frameworks or structures and the aspect ratio of each member (Sachs, 1978).

\subsubsection{Aspect Ratio}

If a member is infinitely long, it has the same pattern of airflow around it at every crosssection. More usually, the member has one or two ends and air then escapes around these ends and reduces the average drag per unit length. This reduction is a function of the length/diameter or aspect ratio $\lambda$, which is therefore defined

$$
\lambda=\mathrm{L} / \mathrm{D}
$$

Where one end of the member is sitting on a flat surface in a uniform wind stream the surface has a mirror effect so that the aspect ratio is defined as

$$
\lambda=2 \mathrm{~L} / \mathrm{D}
$$

Correction factors are common to member's shapes and are given in table below. Correction factors multiply the appropriate shape factor $\mathrm{C}_{\mathrm{F}}$. 


\section{Correction Factors for Aspect Ratio}

\begin{tabular}{|c|c|}
\hline Aspect ratio, $\lambda$ & Correction factor, A \\
\hline $0-4$ & $0-6$ \\
$4-8$ & $0-7$ \\
$8-40$ & $0-8$ \\
Above 40 & $1-0$ \\
\hline
\end{tabular}

It is not necessary to use any aspect ratio correction on structural members coming to a gusset plate or a cross-member, as these prevent flow of air round the ends of the members. A similar effect is obtained in wind-tunnel work by putting end plates on the members under test (Sachs, 1978).

\subsection{Building Height:}

In general buildings may be defined as structures utilized by people for living, working or storage. In this context, the wind has two main effects;

i. It exerts forces and moments on the structure and its cladding and

ii. It distributes the air in and around the building. 


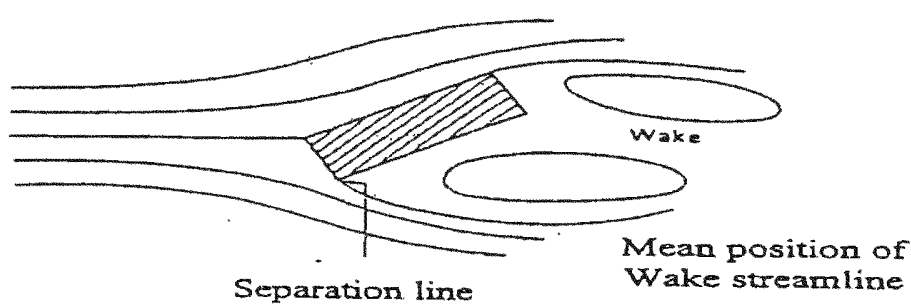

Separation line

Wake streamline

Plan

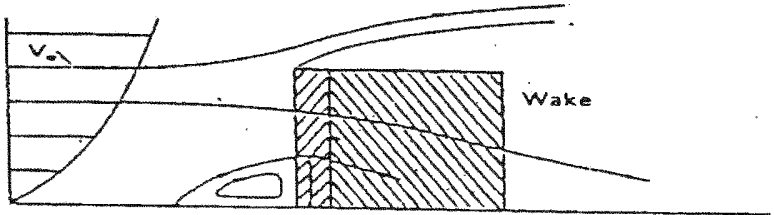

Elevation

Characteristics of wind flow over a building

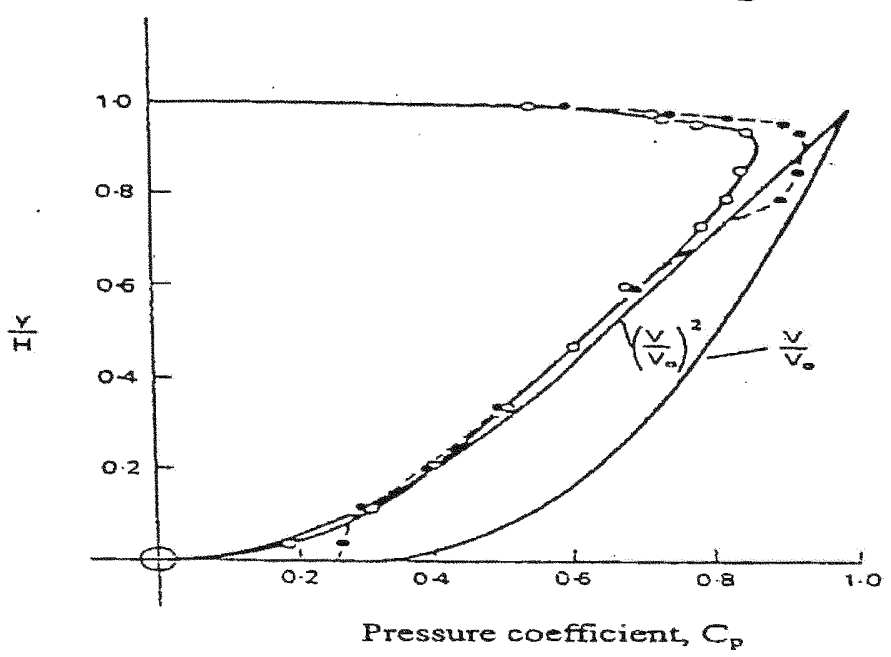

Figure 6.1 Pressure distribution on front center line of tall building. Wind angle $\beta=0$

$\circ$ Calculated $=\left[\Delta / 1 / 2 \rho V_{0}^{2}\right]\left(V / V_{0}\right)^{2}\left(V_{0}=\right.$ reference velocity $)$

- Measured (model immersed in boundary layer)

Adapted from: "Wind Forces in Engineering" by Peter Sachs, M.A., C. Eng., M.I. Mech.E. 1978, page 213. 
This air can carry rain, snow or chimney smoke and can upset the internal ventilation system when it passes into the building. For these reasons the study of air-flow is becoming integral with planning a building and its environment.

Roofing and cladding are not always carefully designed, and localized wind pressures and suctions are receiving more attention. It is undoubtedly in the private sector that most damage has occurred, for two reasons: building codes do not incorporate the expected maximum wind speed for the life of the building and secondly they do not consider the high local suction which cause the first damage (Sachs, 1978).

\section{Observations}

i. Roofs of all pitches were liable to damage at corners from a quartering wind, and at gable roof edges from a side wind onto the gable end.

ii. High-pitched tiled roofs $\left(>35^{\circ}\right)$ also suffered on the leeward side of the ridge and due to the presence of chimneys.

iii. Low-pitched tiled roofs suffered worse damage than high-pitched ones in the same areas, as forecast by wind-tunnel tests.

iv Gable walls fell outwards due to large suctions caused by frontal wind eddies or by winds funneled between houses. These usually occurred when the wall cavity ties were no longer effective.

In general the response of medium and small buildings to wind gusts is static, rather dynamic as their construction is usually very stiff compared to larger structures. They 
therefore react to all long-and short-term wind speeds so that their design should be to static peak gust conditions.

\subsubsection{Tall Buildings}

Typical wind flows around a tall building (in a velocity gradient) are shown in Figure 7.1.4.1 (High Rise Residential Structures). For the lower three-quarters of height the flow separates laterally, leaving a point of no flow and maximum static pressure on the centerline, in frontal flow. As the velocity increases with height the static pressure increases and provides a pressure gradient down the building surface. The resultant, secondary, flow may combine with eddies from adjacent buildings to produce high street-level winds and similar secondary flow in the reverse direction occurs on the leeward side of the building (Sachs, 1978).

\subsubsection{Long Low Buildings}

The wind-flow around a long low building such as a factory has similar characteristics to that over a long flat plate. A small eddy is attached to the lower windward side and a larger eddy remains "stationary" on the leeward side, caused by separation at sharp building edges. The windward pressure therefore approaches the dynamic head and the leeward suction coefficient ranges from -0.5 to -0.9 , for broader and narrower impermeable buildings. Higher suction occurs when the wind approaches at an angle to the building, and can reach values of -1.0 just behind the separation edge. Sidewall 

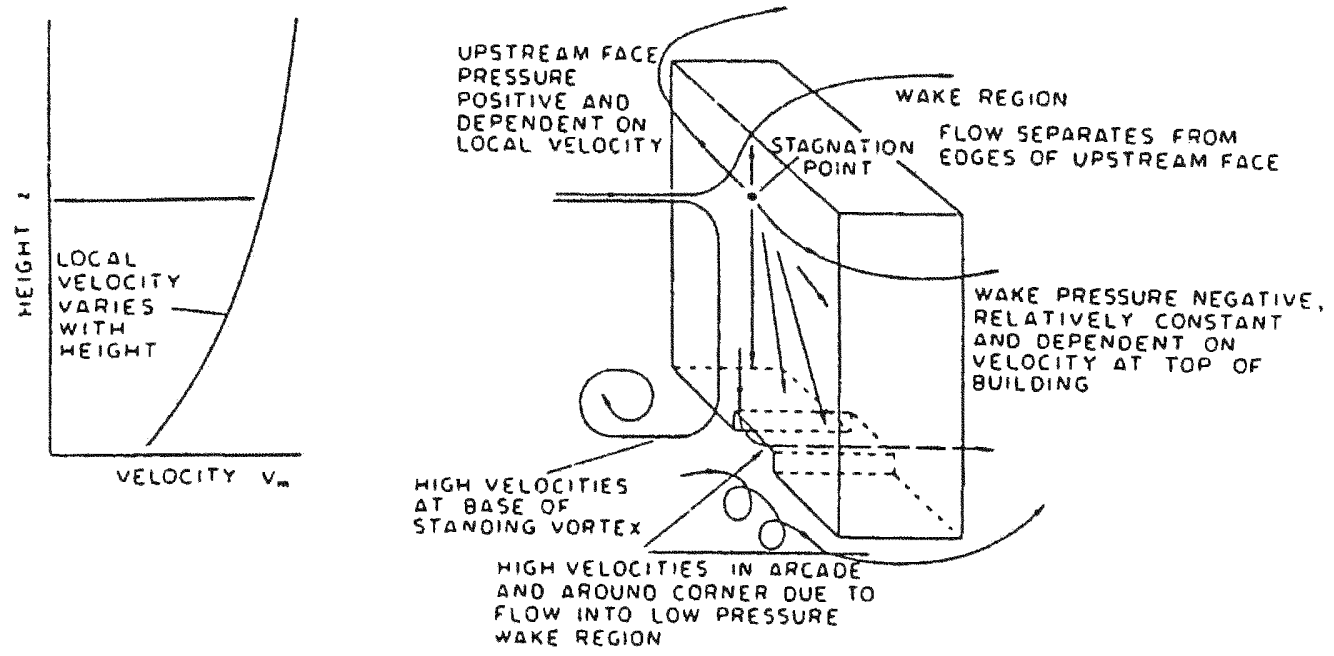

Figure 6.2 Flow field around a large building

Adapted from: "Wind Forces in Engineering" by Peter Sachs, M.A., C. Eng., M.I. Mech.E. 1978, page 242. 
suctions can reach -1.5 . By far the most serious suction occurs on the roof. These are caused by intense e ddies a fter high v elocity s eparation on the w indward e dge ( Sachs, 1978). 


\section{RESULTS AND DISCUSSION}

Various factors were used to determine the damage mechanism on building structures. The most important factor considered for the damage mechanism was the magnitude of the wind speed and its direction. Some of the other factors considered for this mechanism were aspect ratio, shape of the building, building height, effect of surrounding structures, wind borne debris, building orientation and spacing between buildings. Several case studies were studied and their damages were examined and possible cause of failure mechanism was estimated.

Mobile homes are treated separately from other case of residential structures. The damage includes a stability failure mechanism (overturning and sliding off its foundations) that is not treated for other buildings. Dynamic objects like trailers, trucks and air planes were also considered for the case studies to determine the direction of the wind speed and also possible cause of damage on the structures due to such objects. Similarly pylons were also considered to determine the damage on adjacent structures and suitable recommendations mitigation measures were made based on such damages. 


\subsection{RESIDENTIAL BUILDINGS}

\subsubsection{SINGLE FAMILY HOUSES}

Single Family Houses includes small individual single storied houses with or without a boundary. It comprises of gable-end and hip roof structures. Hip roofs are more efficient aerodynamically and therefore introduce lesser loads to the structure and its components. The framing geometry of hip roof roofs inherently braces the roof and end walls against lateral loads. Wood trusses, as individual components performed satisfactorily. However, the loss of few panels of roof sheathing often led to structural failure and collapse of the roof system. Gable-end trusses were left hanging by their hurricane straps or were severely stressed. Most observed failures in the roof systems (rafter and trusses) were attributed to installation and design shortcomings such as inadequate fastening of roof sheathing and insufficient anchoring at rake overhangs. There was also a notable lack of secondary bracing at gable ends. Nevertheless, in the few situations where well-designed lateral bracing was used at gable-ends, the roof structural framing was usually intact even though sheathing may have been lost. Secondary bracing appeared to be more important to taller roofs with larger gables. Lateral bracing was not an issue with hip roofs, which are inherently braced by their framing geometry. 


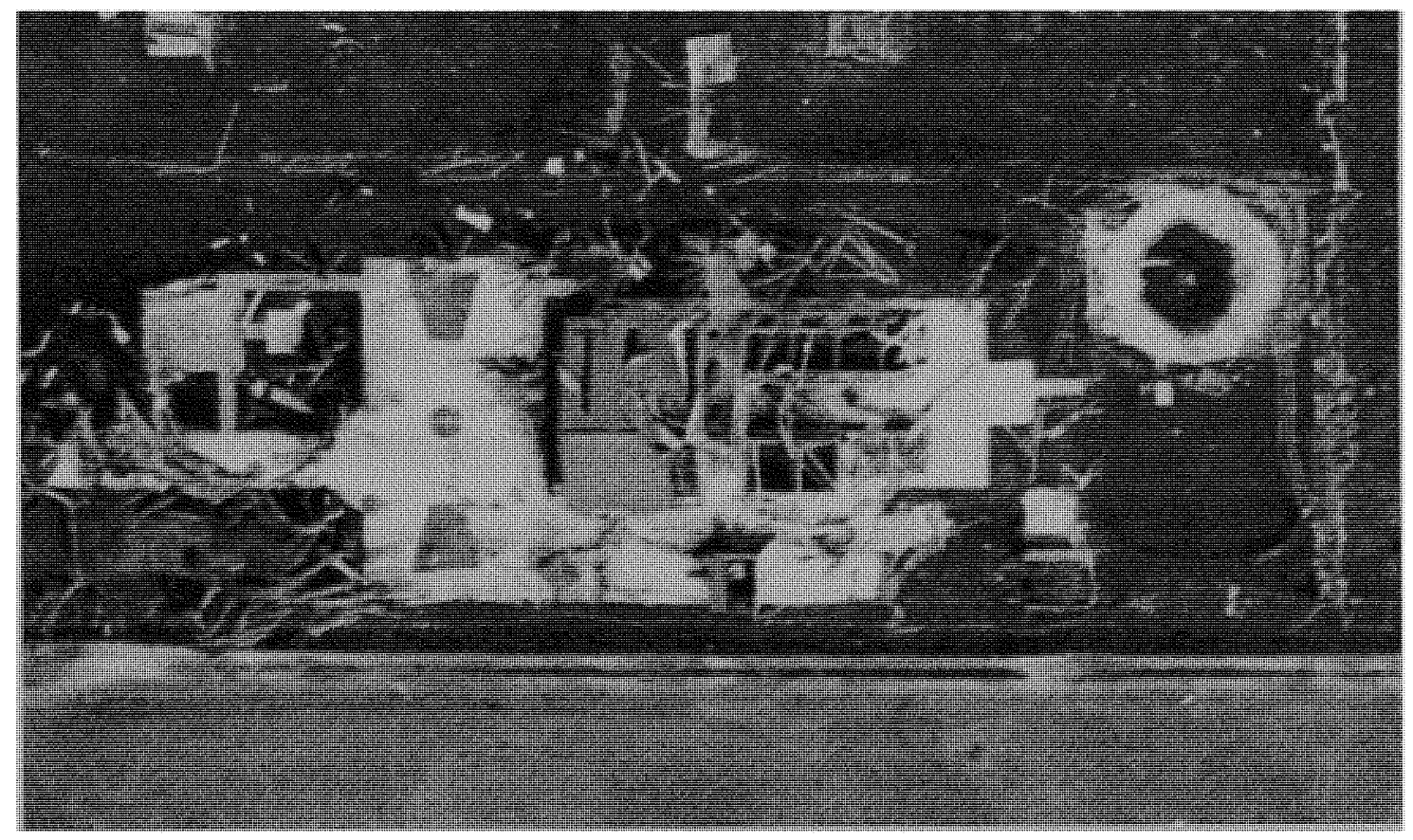

Figure 7.1.1.1 Failure of wood framing system.

This figure shows the roof has been partly damaged. The damaged portion is very clearly showing that there $\mathrm{w}$ as major s tructural truss $\mathrm{d}$ amage. The connection $\mathrm{w}$ as not s trong enough to resist the wind speed. The partly damaged portion shows a complete failure of the wood framing system, detached roof sheathing, collapsed gable end, and fallen drywall ceiling. It is also evident that the exterior walls are also racked from reduced lateral support from the tattered roof structure and inadequate shear wall construction. There are twenty two similar cases as shown in Appendix B. 


\subsubsection{SINGLE FAMILY DUPLEX HOUSES}

Various examples of Single Family Duplex Houses have been taken into consideration, which are situated near artificial lakes. Similar to single-family homes it comprises of gable-end and hip roof with the latter more efficient to resist the wind force. In some cases In some cases there are number of gable ends and the roof system has been badly damaged. The houses situated near artificial lakes, roof cover and sheathing damage was very prominent as the hurricane wind could directly strike the roof without any barriers such as trees or other houses. Improperly fastened roof sheets or tiles are the most common projectiles. Collapsing of roof structure was also visible due to suction force that can lift up the entire roof whenever the building envelope is breached. Two-story homes suffered more water damage as a result of a greater number and exposure of windows. Single Family Duplex Houses may suffer less projectile damage to the roof structure; conversely, they may be the prime contributor to projectiles that elevate the roof damage level of lower profile homes. 


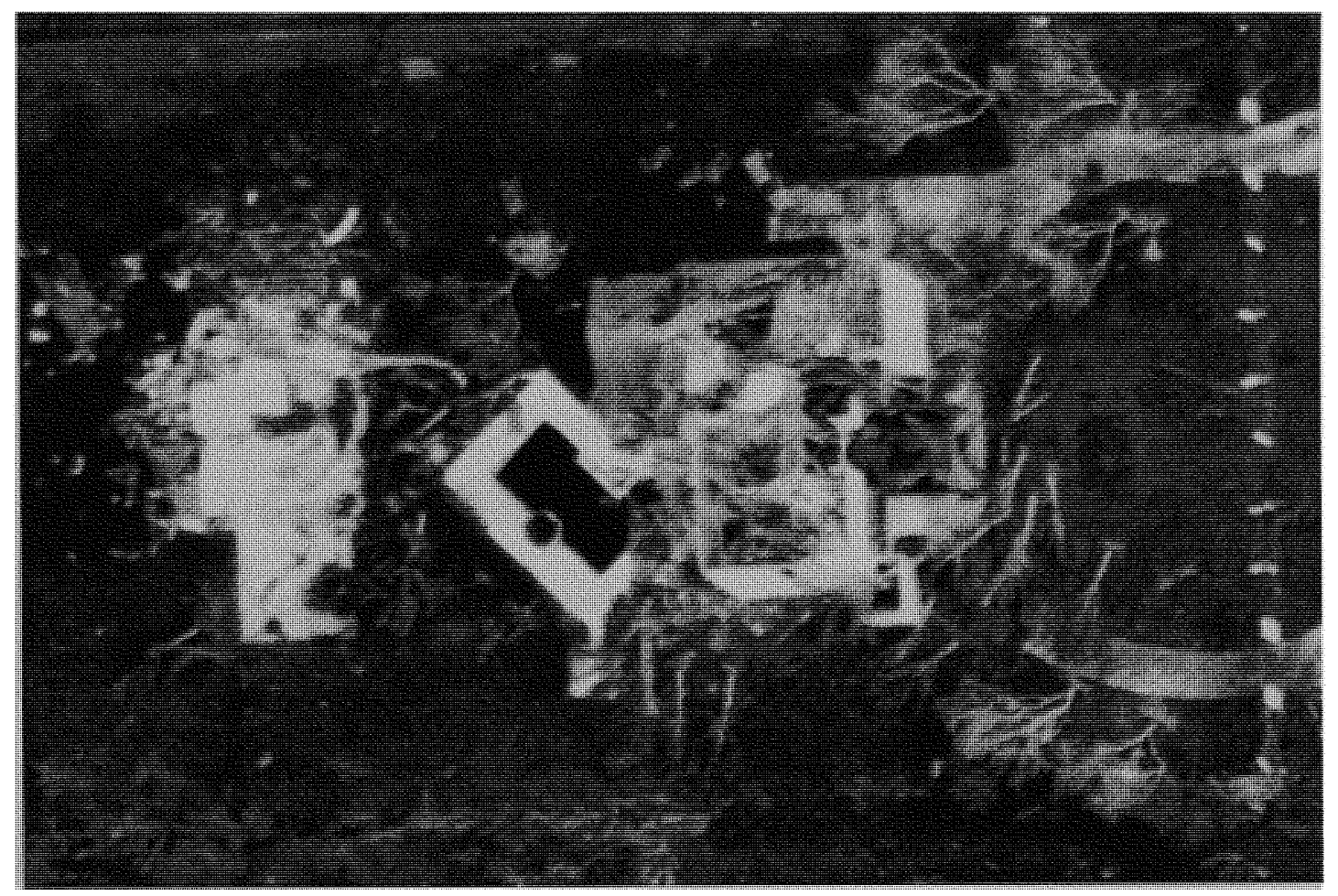

Figure 7.1.2.1. Elevated homes prone to roof damage.

The figure shows two single-family homes, which had a concrete ceiling and was destroyed by strong wind impact. The house on the left hand side was not damaged in comparison to the house on the right hand side, the reason being that the wind direction was from east to west and this house had a direct impact without experiencing any major barriers. There were no trees, which could obstruct the wind force. The speed of the wind was high enough to uproot small trees as seen in the picture. Debris were scattered all around the place. They debris were probably not wind borne debris. There are six similar cases as shown in Appendix B. 


\subsubsection{MOBILE HOMES}

There are various examples of mobile residential units, which are drastically by storm surge. Complete failure of wood framing system: shattered windows, failed porch overhang, detached roof sheathing, collapsed gable end and fallen drywall ceiling was visible in majority of the mobile homes. Exterior walls were severely racked from reduced lateral support from the tattered roof structure and inadequate shear wall construction. Overturning, uplift and sliding were observed due to inadequately designed, installed or maintained foundations with deficient lateral bracing or load paths to the superstructure and also due to lack of connections between house superstructure and foundation. Foundations must be capable not only of supporting the gravity load of the structure above them, but they must also be connected to the structure in a way that addresses flotation and horizontal loads, as well as transmission of those loads to the earth. 


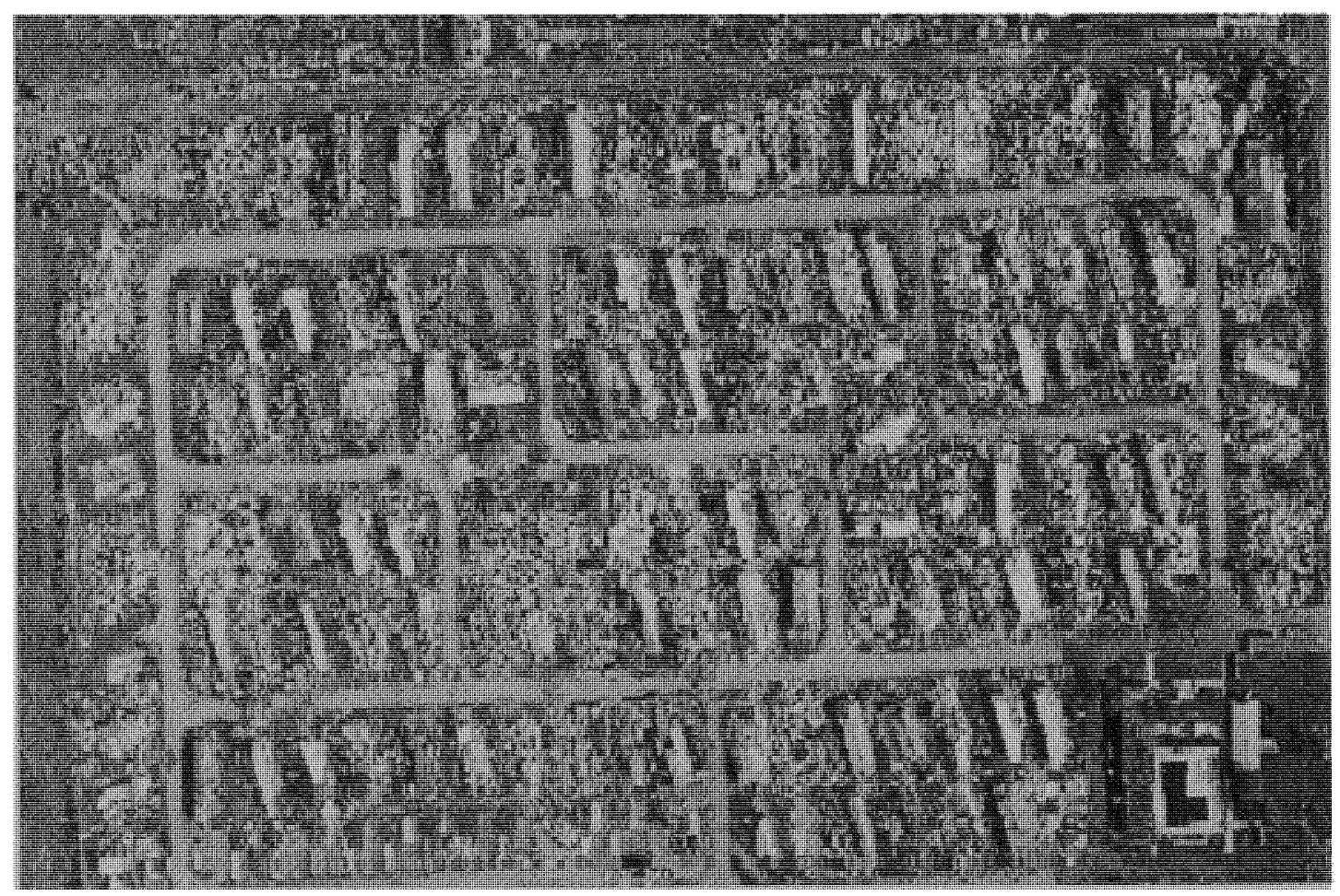

Figure 7.1.3.1. Inadequately designed foundation.

The figure shows an entire community of mobile homes, which has been drastically affected by storm surge. It's an overall view of the houses. Some of the houses have been badly damaged. Most observed failure in roof system (rafters and trusses), which might be due to installation and design shortcomings such as inadequate fastening of roof sheathing and insufficient anchoring at rake overhangs. There are three similar cases as shown in Appendix B. 


\subsubsection{HIGH RISE RESIDENTIAL STRUCTURES}

Few high-rise residential structures had minor roof damages mainly at their corners. Especially when these buildings stands next to some kind of artificial lake. Collapsing of roof structure was visible in one of the figures. Elevated roof trusses were more prone to hurricane damage. The top floor of the house was in bad shape as the roof, which was made of concrete, was severely damaged to the extent exposing the reinforcement. Other floors were comparatively safer than the top floor. 


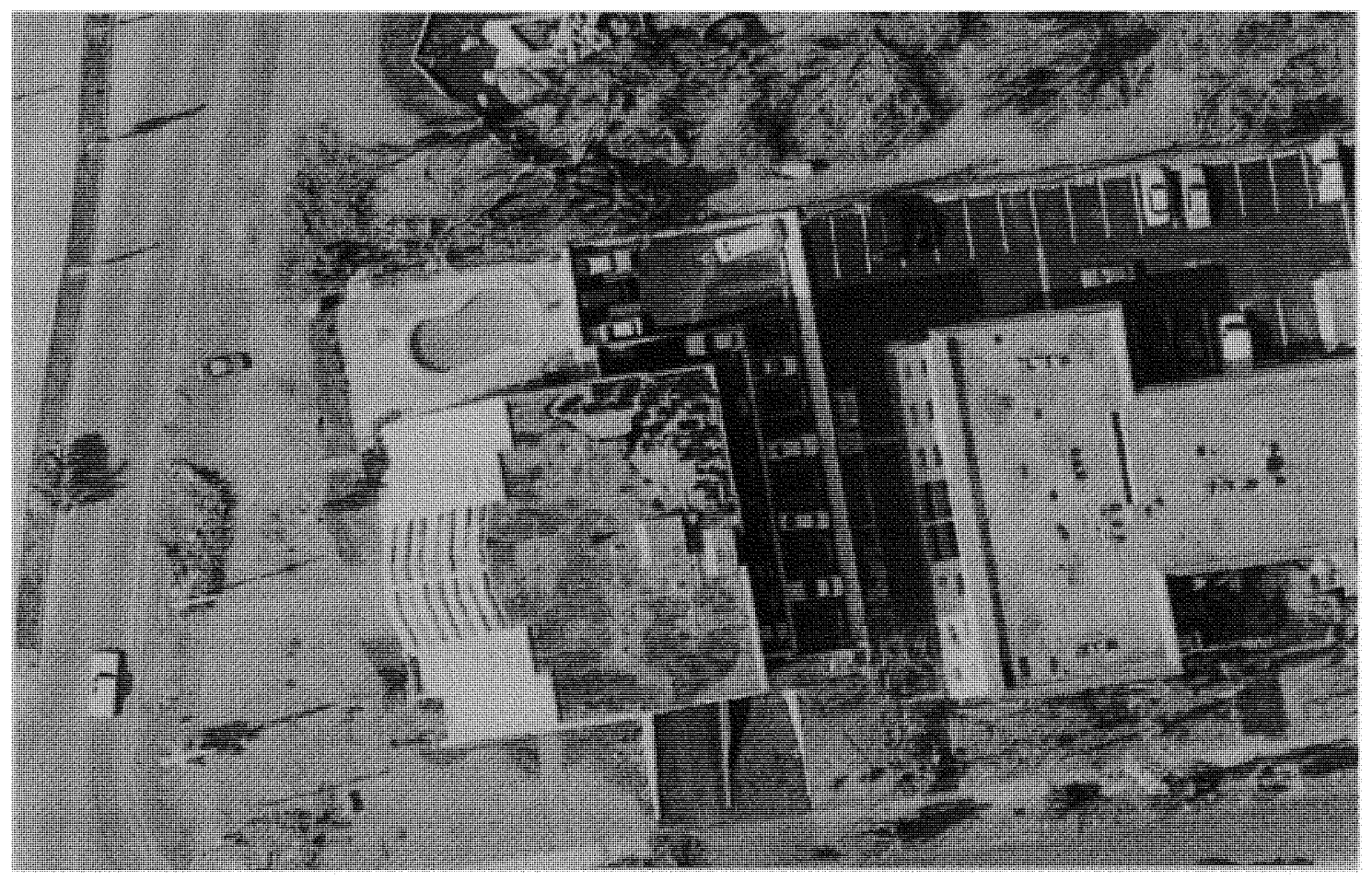

Figure 7.1.4.1. Major cracks developed in the concrete slab.

This figure shows a multistoried commercial building. The top corner portion the roof was damaged. The roof was made of concrete and the even concrete did not withstand the wind impact. Major cracks have been developed in the corner of the building. The wind direction can be predicted by this damage. The wind was blowing from north-east to south-west. The elevation of this particular building was higher than any other building hence there was no barrier to avoid such damages. There are two similar case as shown in Appendix B. 


\subsubsection{TOWN HOUSE}

Town House is generally series of single-family houses without individual boundaries. As seen in the following figures it can be noted that the corner houses are prone to damages. The damage depends on the location of the residential units, their orientation, adjacent $u$ nits e tc. R oof cover and sheathing failures a re o bserved to be m aximum. It might be due to window breakage or door failure on the windward side of the buildings caused most of the roof failures. Wind-borne projectiles are the major factor in home damage and d estruction d uring the hurricane. P enetration of the b uilding envelope $b y$ wind-borne debris was directly responsible for many catastrophic failures of the roof systems, because such penetration allowed the uncontrolled buildup of internal air pressure. The pool of potential projectiles that can be picked up by hurricane- force winds and turned into wind-borne debris include roofing materials such as shingles, tiles and gravel; inadequately attached cladding components such as sheathing and siding; and rocks and tree limbs. 


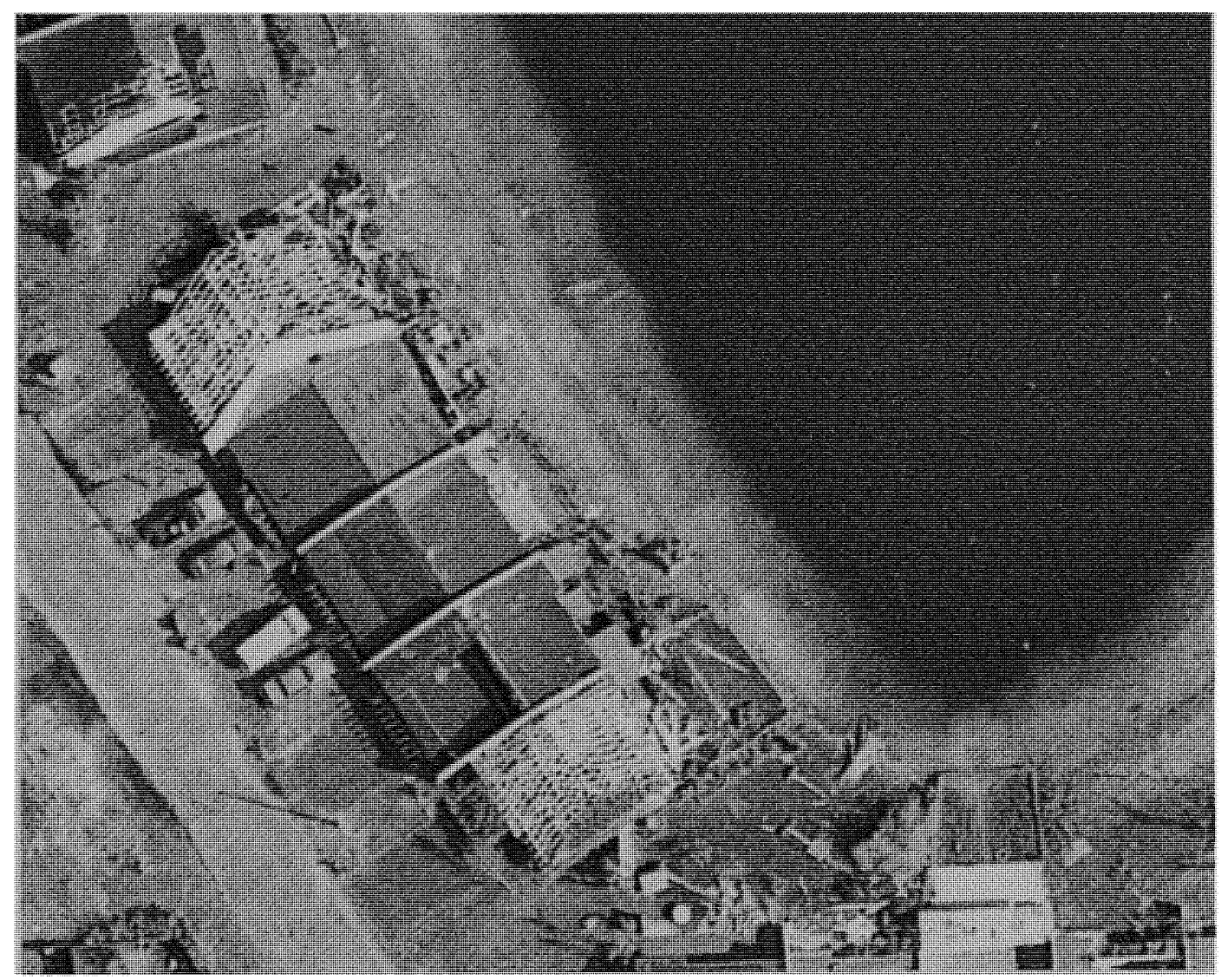

Figure 7.1.5.1. Displacement of trusses.

This figure shows damages to the corner houses. These single-family houses were situated beside a lake. The two-corner home has been severely damaged. The entire roof cover, sheathing and the gable end were missing. There has been major displacement of the trusses. Debris of the corner houses can be found scattered all around them. The wind direction can be very well predicted from the debris. The wind was blowing from southwest to north-east. The roof structure of the corner homes should be adequately braced, as these houses had no barriers to obstruct the wind force. There is one similar case as shown in Appendix B. 


\subsection{PUBLIC BUILDINGS}

\subsubsection{SCHOOL BUILDING}

Very few school building has visible roof cover damages. In one of the case where it had roof truss system the roof cover, sheathing and gable end was completely blown off exposing the truss skeleton. Structural damage was insignificant and overall damage was contributed to the roof cover damage. The probable cause of the damage may be sheathing was not properly nailed and were not holding the sheathing to the roof. The roof was low pitch which acted as a airfoil and had uplift pressure exerted on their windward side. In another example the school building had concrete roof and hence the damage was minimum. 


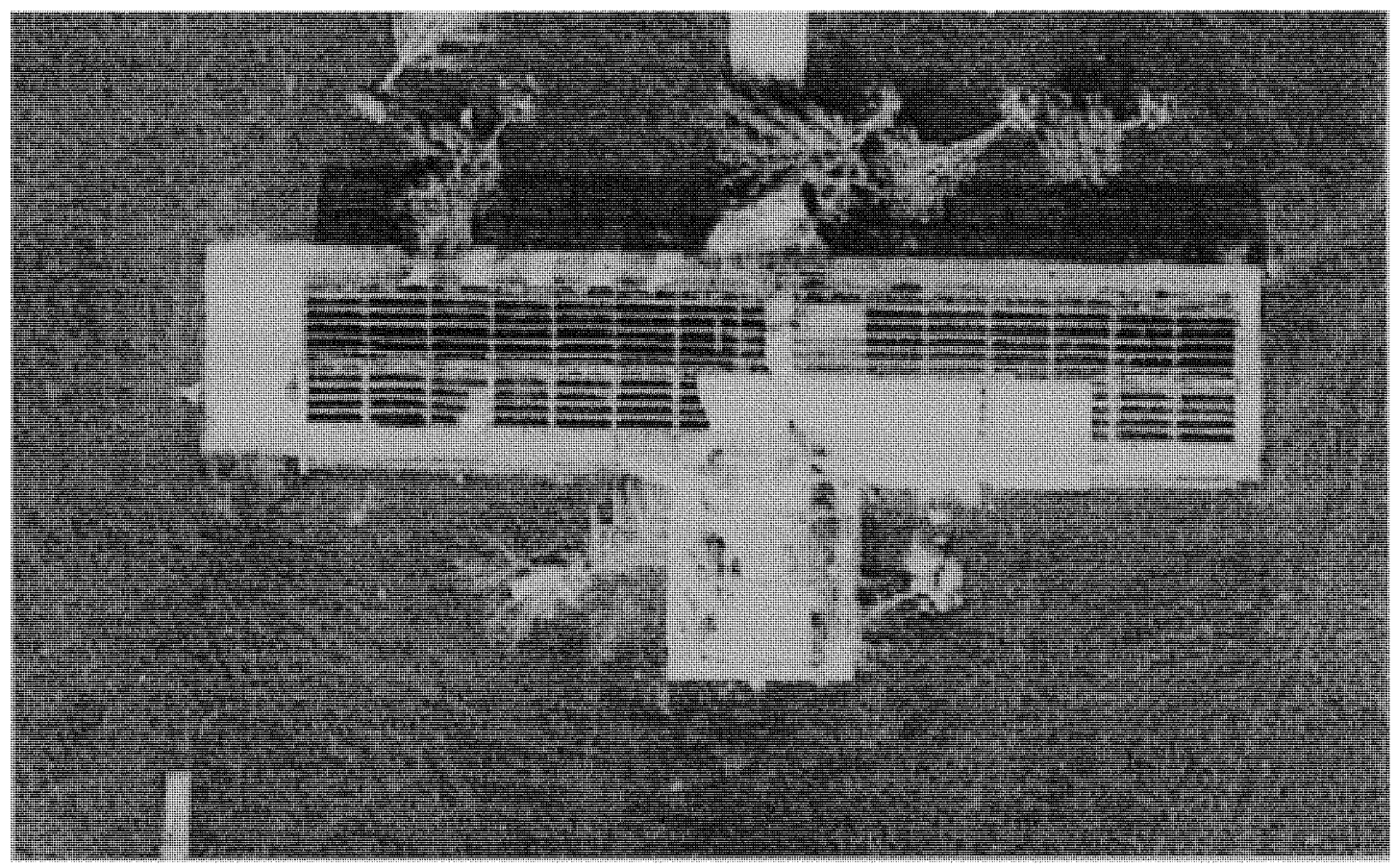

Figure 7.2.1.1. Roof cover and sheathing damage.

The figure appears to be a school building. The roof cover, the sheathing and the gable end have been completely damaged. There were few trees surrounding the house. One of the trees on the left hand side caused some minor damage to the exterior walls. Only a very small portion of the sheathing was intact. The wind direction cannot be predicted accurately. The canopy, made of concrete was also damaged. The structural stability of the trusses was strong enough to resist the wind force, and hence no major damage to the trusses. The truss connection was adequately strong enough and hence there was no major damage. There is one similar case as shown in Appendix B. 


\subsubsection{SHOPPING CENTERS}

Shopping Centers are huge structures with concrete roof or steel roof truss. When the span increases for concrete roof proper reinforcement and high grade concrete should be used as per building codes to sustain wind impacts during a hurricane. In case of truss system large sheets of roof covers should be securely fastened to the rafters. Often, rafters were attached by toenails to the top plate and in other cases hurricane clips attached to the rafters to only the top plate rather than to the wall studs. 


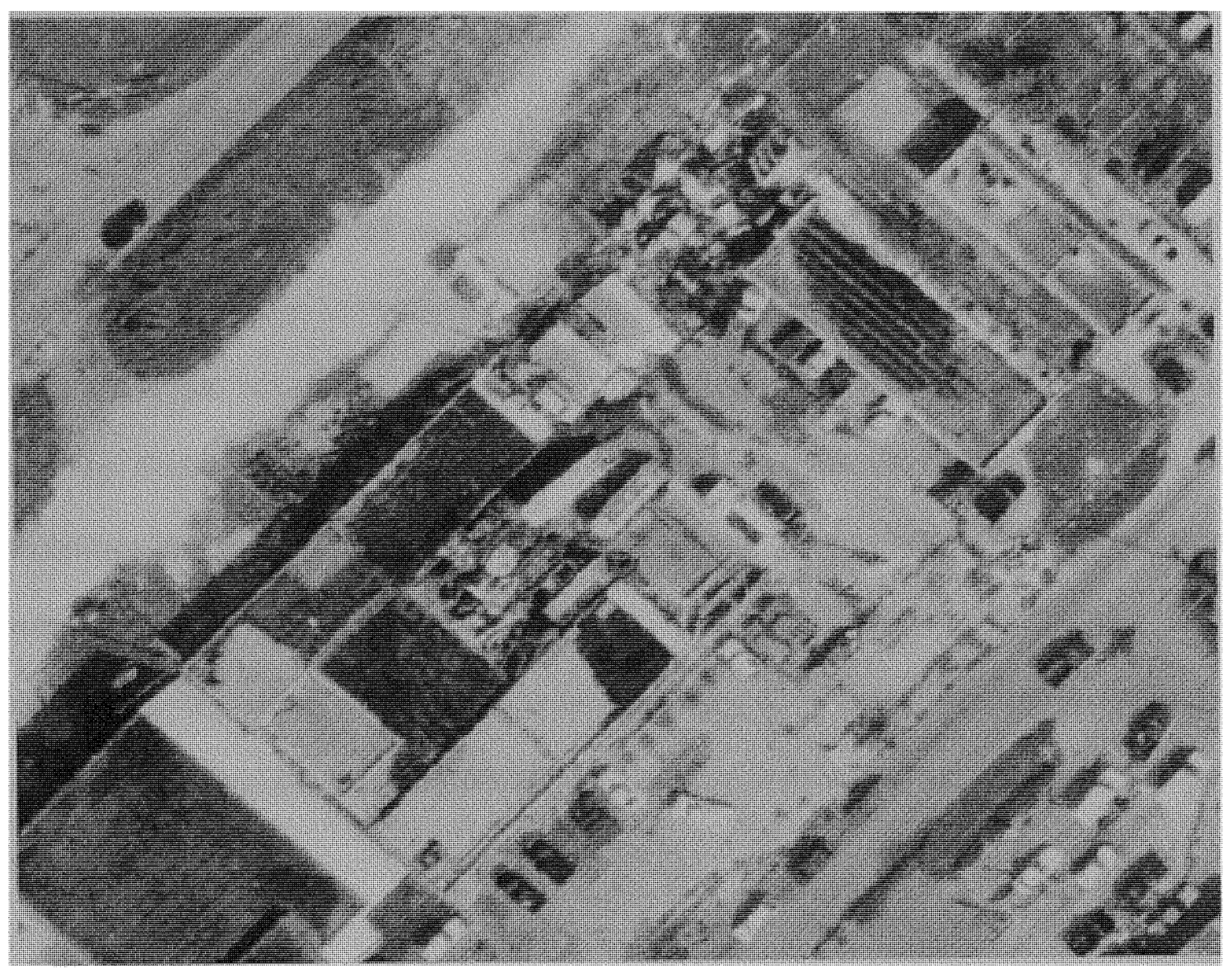

Figure 7.2.2.1. Concrete roof damage.

The above figure shows some kind of shopping malls. The mall had a concrete structure. Severe structural damage to concrete block and stucco CBS walls has taken place. Damage was usually associated with insufficient reinforcement for continuous load paths from the upper tie beam, through the wall, to the foundation. Similarly, there may be a case where there could be discontinuities in the reinforcement of concrete tie beams or insufficient overlap at the corner resulted in collapse of CBS walls. There is one similar case as shown in Appendix B. 


\subsection{COMMERCIAL STRUCTURES}

Commercial structures include hospitals, schools, warehouses, treatment plants, hangers, hotels, clubhouses and other commercial establishments. In majority of cases roof cover and sheathing damage has occurred exposing the trusses. Generally these structures have large spans and taller roofs, which may not resist the storm, surge striking with great velocity. Dislocation of trusses was also very common to such structures due to lack of secondary bracings. Sever loss of plywood sheathing and upliftment of the over hangs was also evident in these structures. There was no major damage to the exterior walls may be due to usage of proper construction system and foundation anchorage. Increased stiffness and strength of cantilevered roof systems provide added resistance to these structures. 


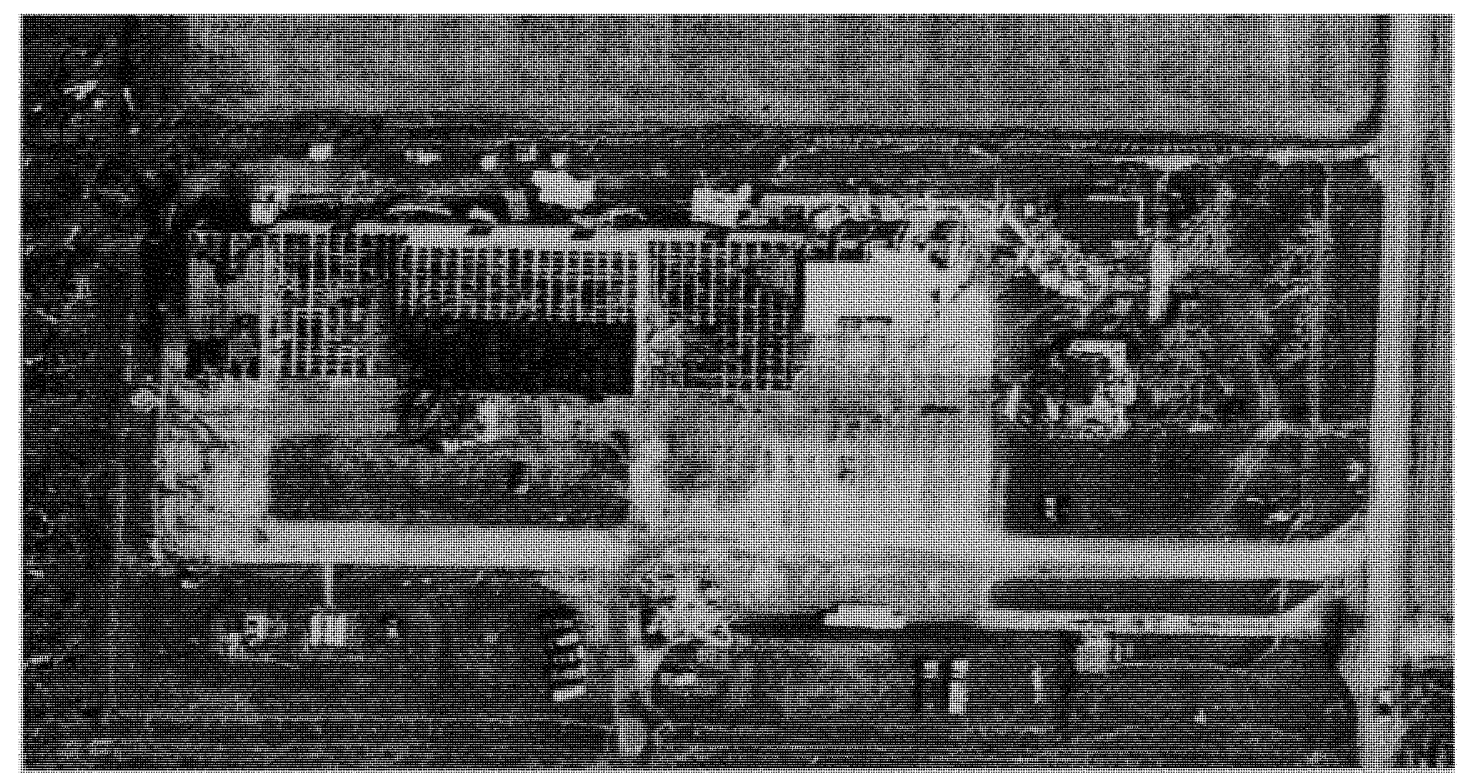

Figure 7.3.1. Partially damaged low profile hip roof.

The figure appears to be a hospital building. There has been major roof damage. Only a small portion of the roof is intact. The wind direction was not very clear. Lot of wind borne debris can be seen strewn all around the building. It might have a low profile hip roof so the overall damage was equally distributed. There has been no major structural damage as the trusses are intact and there is not even a slight displacement of it. This shows that the trusses were constructed structurally strong but not the roof covering and sheathings which got removed due to high wind speed. There are nineteen similar cases as shown in Appendix B. 


\subsection{INDUSTRIAL BUILDINGS}

Industrial buildings may consist of steel truss, wood-frame truss or concrete roof depending upon the type of industry and its usage. In one of the case it has been observed that the roof covering, which are in the form of long sheets, have been badly bend and twisted resulting $100 \%$ damage. R oof c overings, which w ere n ot a dequately attached, and the corner and eaves regions of the roof were frequently damaged. Roof failures occurred because of lack of proper connection between the roof and the exterior walls. With roof gone, walls lost the support provided by roof system and were subjected to collapse even when exposed to lesser winds. The structural failures of steel and wooden trusses may be due to design shortcomings such as inadequate fastening of $\mathrm{AC}$ sheets and insufficient anchoring. Wind-borne projectiles were also the major factors for many catastrophic failures of the roof systems. 


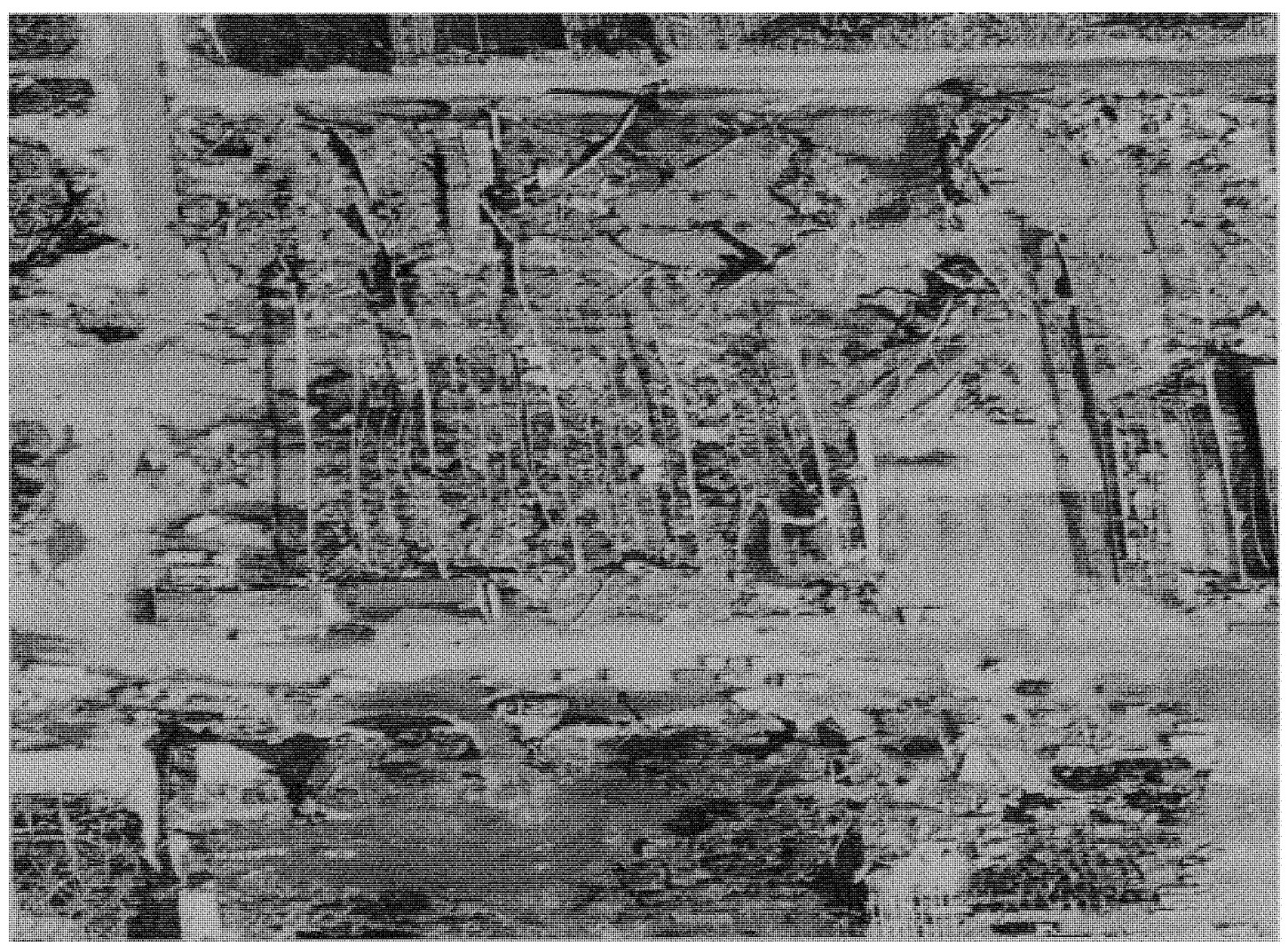

Figure 7.4.1. Installation and design shortcomings.

This figure shows looks like some kind of industrial area, which has been severely damaged, with the velocity of wind. The most common observed failure is roof system (rafter and trusses) was attributed to installation and design shortcomings such as inadequate fastening of roof sheathing and insufficient anchoring at rake overhangs. There was a notable lack of secondary bracing at gable ends; however, it cannot be overstated that secondary bracing will provide little benefit in limiting overall building damages without solving the primary problem associated with sheathing fastening. There are three similar cases as shown in Appendix B. 


\subsection{CONCRETE STRUCTURES}

During an hurricane or cyclone only concrete roofs have better resistance to damages. Even though concrete performed better than tiled roof in some cases it did not withstand the impact of wind. Concrete slabs were damaged with large cracks. Due to damage to the concrete slab the steels were exposed. A possibility of concrete slab failure was because high strength concrete was not used during the construction. Damage was usually associated with insufficient reinforcement for continuous load paths from the upper tie beam, through the wall to the foundation. The intersection in the slabs provides continuity of the tie beam reinforcement. When this deficiency exists in combination with failure of the tie beam to roof connection, the wall collapsed. Sometimes composite constructions such as concrete and timber construction are done depending upon the usage and importance. 


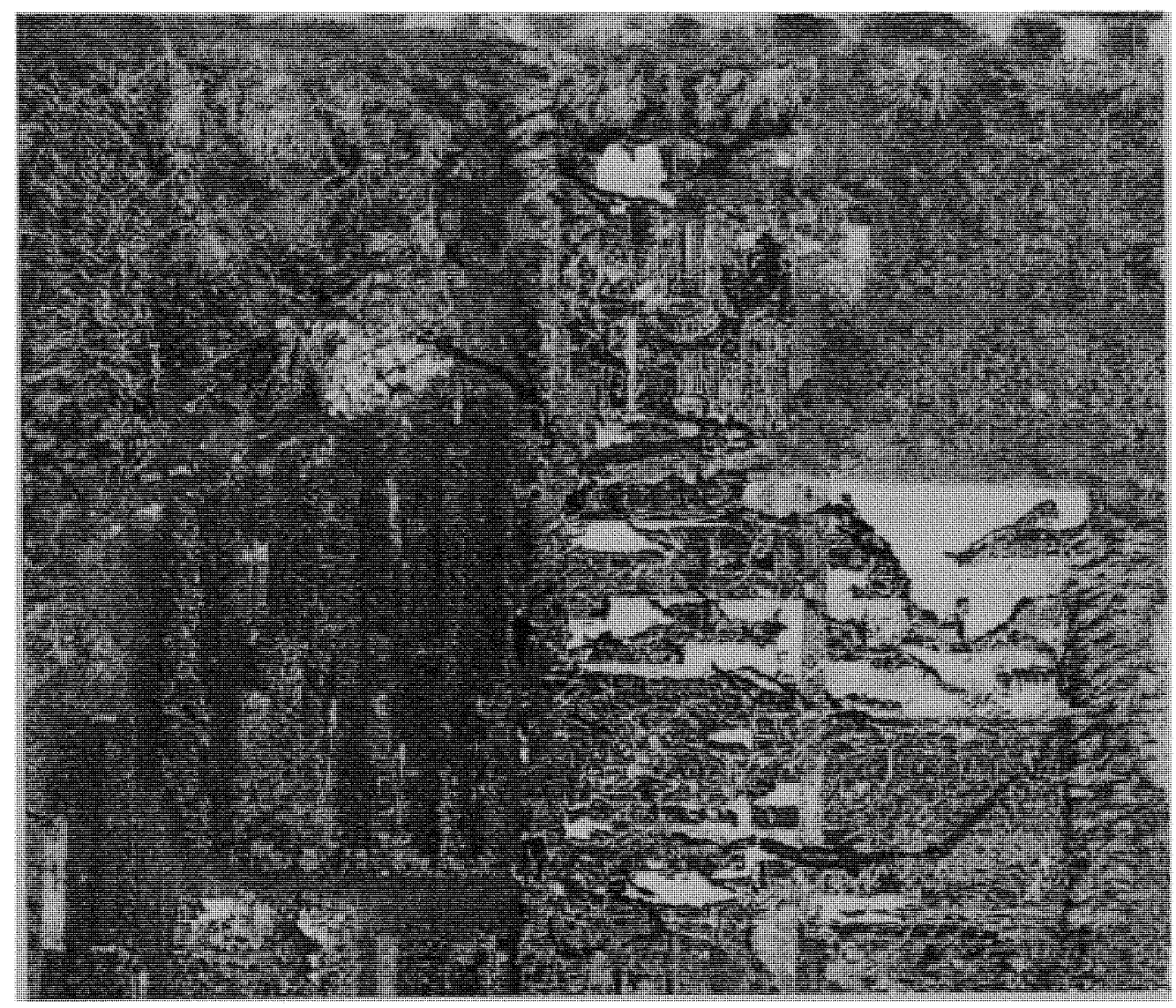

Figure 7.5.1. Insufficient reinforcement.

This figure shows a concrete structure, which could not withstand the impact of wind. Major portion of the concrete slab was damaged with large cracks that can be observed. Due to the damage of the concrete slab the steels were exposed. The wind direction cannot be a ccurately determined as there w ere no trees s urrounding the house. It w as evident that high strength concrete was not used during the construction of this home. Damage was usually associated with insufficient reinforcement for continuous load paths from the upper tie beam, through the wall to the foundation. There are six similar cases as shown in Appendix B. 


\subsection{WARE HOUSE}

There are various kinds of warehouse roof covers such as gable-end roof cover, flat roof cover, concrete ceiling etc. The roof frame may be of timber or steel. Generally for large structures steel is used and in case of small ware houses timber is used. Metal roof cover is used in case of steel structures, which are directly placed on the trusses with no sheathing below this cover. So when one of the sheets is uplifted large portion of the truss is exposed. Generally, composition shingle roofs appeared to withstand the wind's force better than the corrugated metal roofs. This is partly attributed to the fact that shingle roof systems were wood sheathed, which remained fastened better than the corrugated metal. In case of concrete roof covering it can withstand better wind impacts even though damage is observed may be due to lack of tie beam reinforcement at the corners and intersections. It may be due to poor mortar joints between the slabs. 


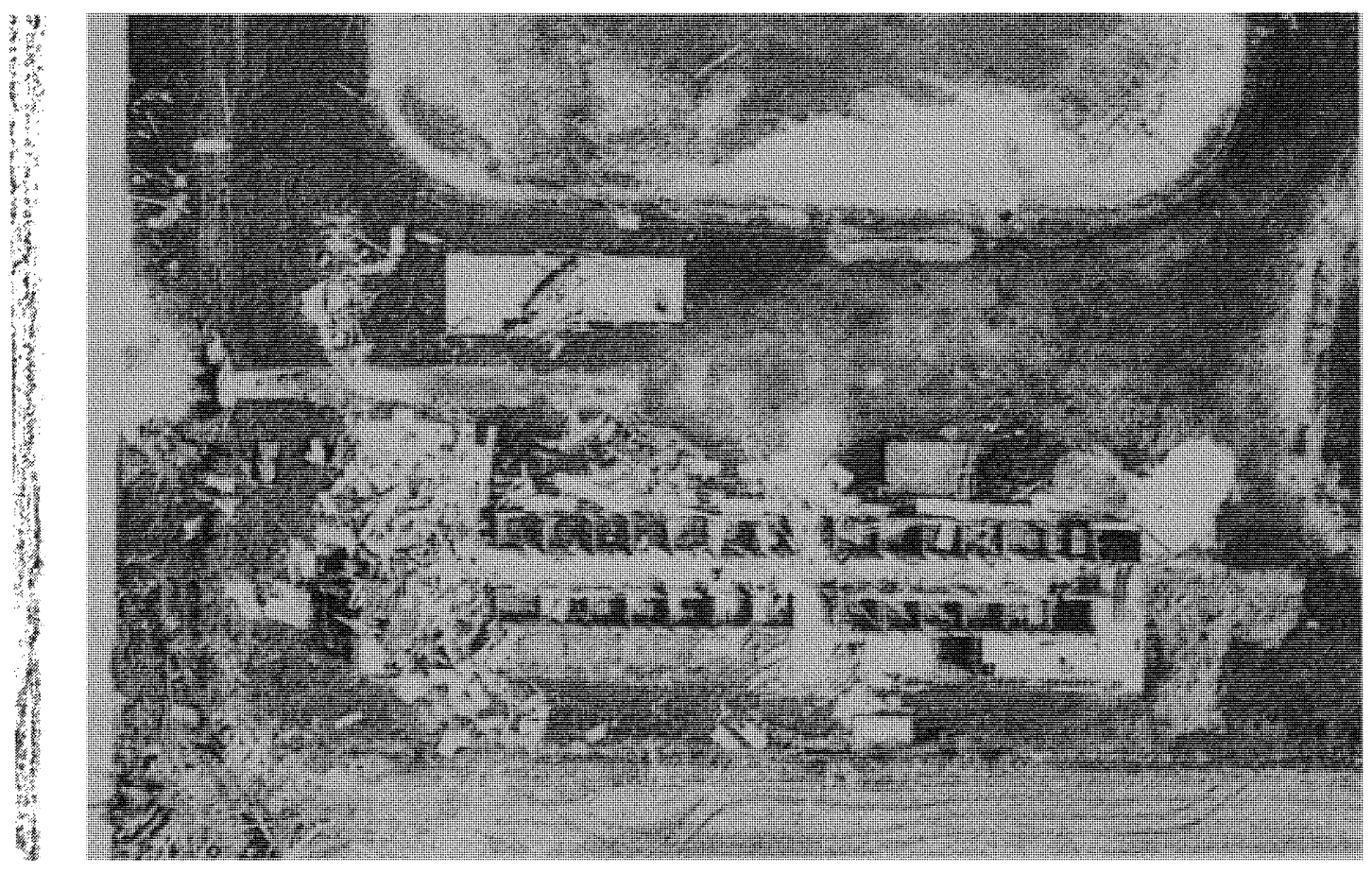

Figure 7.6.1. Weak wall foundation.

The figure shows some kind of warehouse, which has been completely destroyed by storm surge. The major damage occurred at the two ends of the long building. Gable end at both corners were completely destroyed. The roof cover and sheathing was completely destroyed. There was no sign of roof truss. The entire frame structure collapsed. Some portion of the dry wall has been destroyed as seen in the figure. The left side of the house has been badly dislocated along with debris and hence it was difficult to predict the exact damages. The destruction of the dry wall was due to the fact that the foundation of the walls may not have been adequately strong. There are three similar cases as shown in Appendix B. 


\subsection{FARM STRUCTURES}

Farm Structures include small or large houses in an isolated area. These houses lack any king of barrier such as trees or other houses. These houses have inefficiently designed roof trusses and foundations and hurricane accompanied with rain may completely damage the roof framing system. As rain quickly saturate the insulation and the ceiling and the loss of ceiling strength will occur due to increased weight of the wet insulation. The wind stream generates uplift as it divides and flows around the structure. Once the building envelope is breached may be due to small openings such as ventilation windows or doors, pressurization or depressurization of the building takes place. Pressurization pushes wall panels and sheathing out, while depressurization can pull ceiling down. Internal pressure coupled with external suction adds to the withdrawal force on sheathing fasteners. When the openings are on the leeward side of the building, the result is a pressure drop in the interior, which can pull ceiling material away from the framing. Also in some cases it is observed that the roof has been destroyed due to fallen trees. 


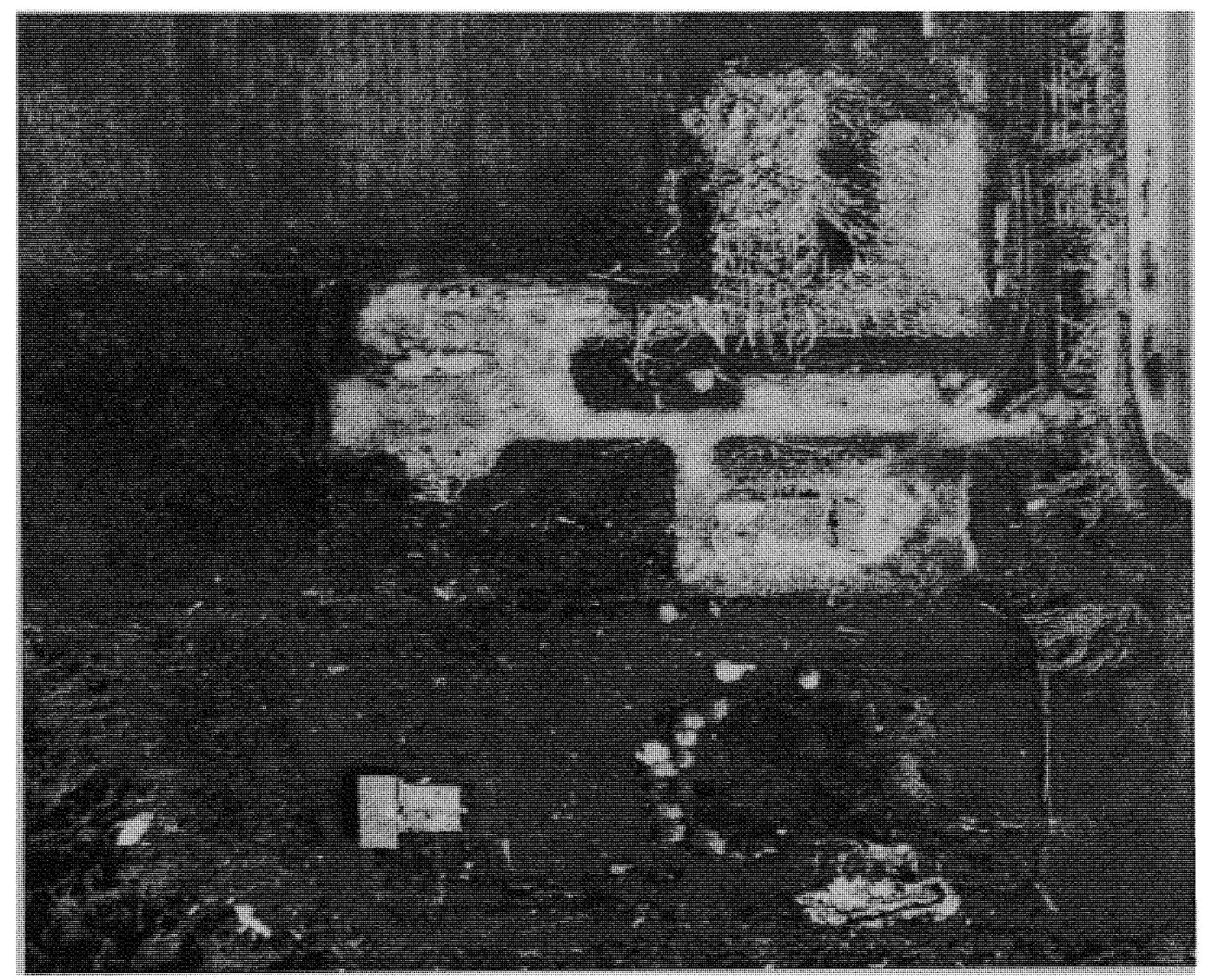

Figure 7.7.1. Lack of adequate bracing support.

This figure shows major roof damage. The roof cover and the sheathing have been completely missed. It appears that the wind direction was from north to south. It is evident from the fact that when the wind was blowing in this direction, the north side of the house has been damaged more than the southern part. The complete upliftment force was due to strong wind blowing in north south direction. In such cases the house should have adequate bracing support and the ridge should be strong enough to avoid structural failure. There are twelve similar cases as shown in Appendix B. 


\subsection{TRANSPORTATION VEHICLES}

Transportation Vehicles includes small family vehicles, trucks, trailers, buses, airplane, etc. The examples in the following figures such as grounding of airplanes can be concluded that any dynamic object present during the hurricane may not withstand the impact and can lead to accidents. The wind pressure was high enough to push the airplane down. Dynamic objects fall on property it can create massive destruction. Even heavy weight trailers are dislocated due to the wind force. 


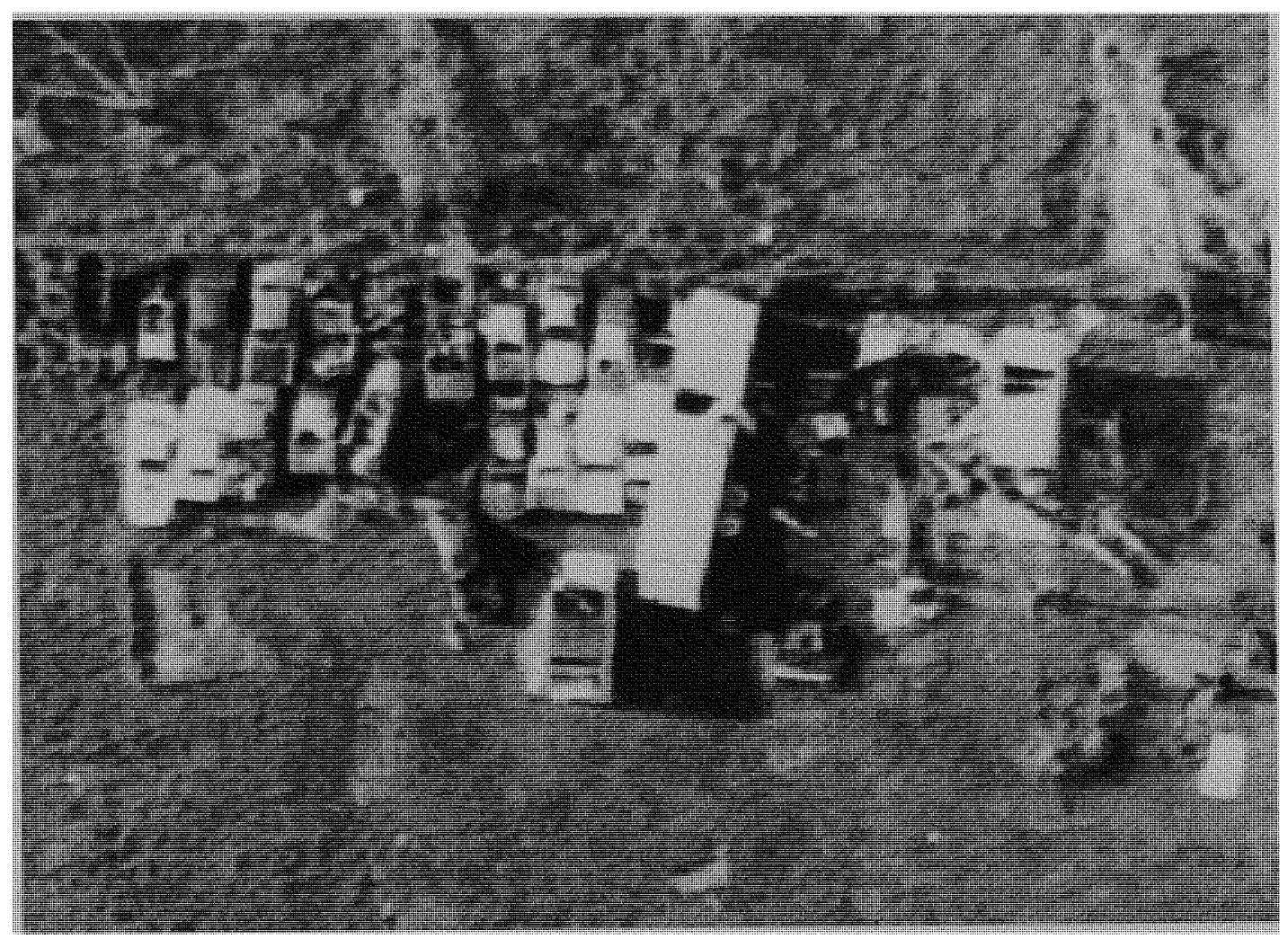

Figure 7.8.1. Displacing of heavy weight vehicles.

This figure shows a example of $d$ amaged $c$ aused to the $p$ arked $v$ ehicles. Even a big trailer could be seen displaced. The velocity of wind displaced the trailer and inturn other vehicles got damaged due to the movement of all adjacent vehicles and collided with each other. The vehicles were just pushed without causing major damage. Hence there were no debris that can be found surrounding the place. The wind direction was from right to left. There are three similar cases as shown in Appendix B. 


\subsection{COMMUNICATION TOWERS}

Communication towers are huge steel structures. Though they are designed to withstand to hurricane or earthquake sometimes due to weak foundation these communication towers may topple causing great destruction to life and property. In one of the example a pylon had fallen on the house nearby ripping it into two parts. The foundation might not be s o s trong to r esist the wind s peed. The s oil bearing $c$ apacity of the particular a rea should be estimated before placing the pylon and simultaneously wind pressure exerted on the pylon should be calculated. It should be noted that there should be no residential buildings around the radius of the tower, which is equal to the height of the tower to avoid major accidents. 


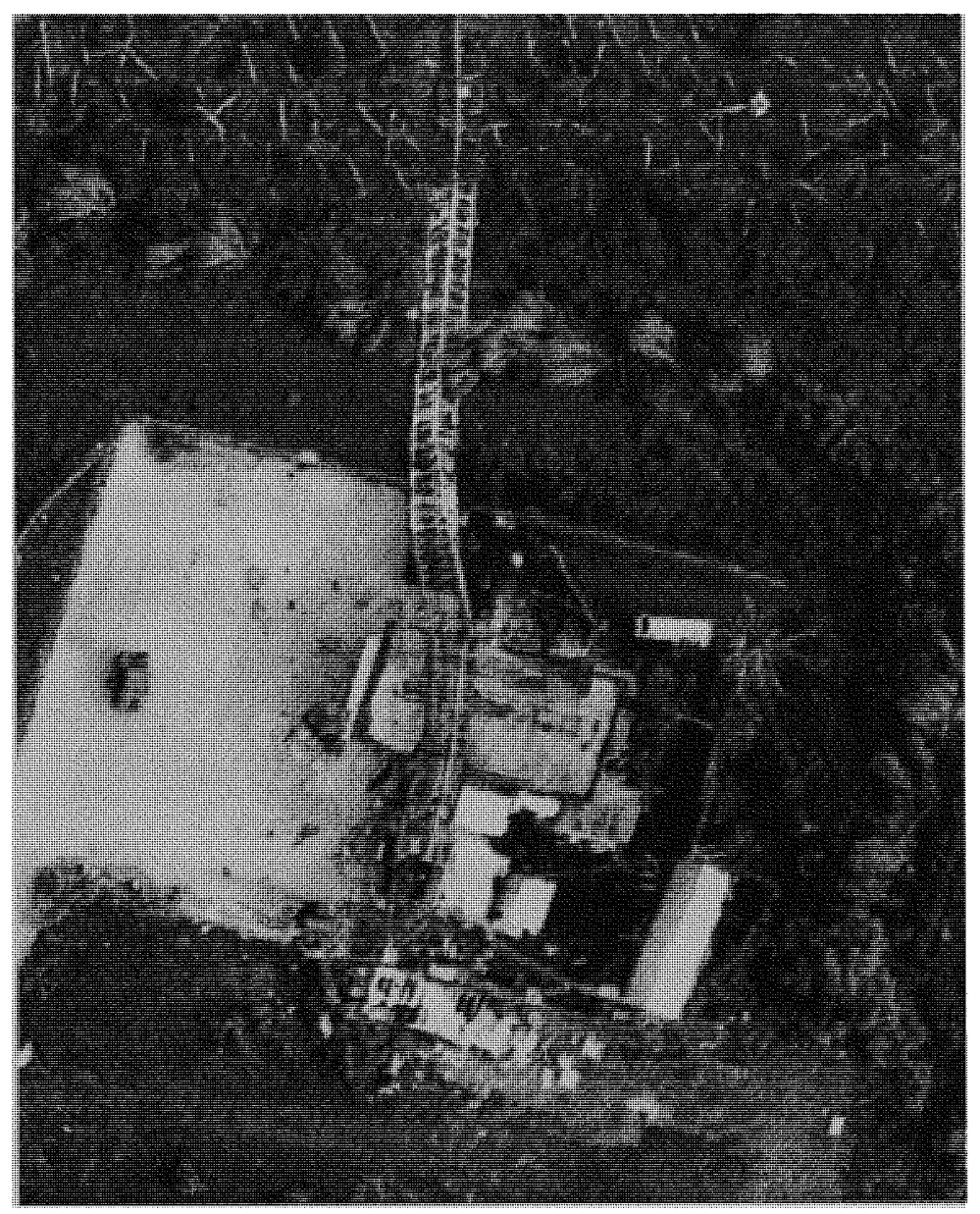

Figure 7.9.1. Weak pylon foundation.

The figure shows a pylon fallen on the house and ripping it in two parts. The foundation of the pylon might not have been strong enough to resist the wind speed. The wind direction was from east to west, which can be predicted from the movement of small trees around the house. It is, therefore, recommended that there should be no residential building around the radius of the tower, which is equal to the height of the tower to avoid major accidents and loss of life and property. There is one similar case as shown in Appendix B. 


\section{CONCLUSION}

Aerial Photography has long been used in the assessment of disasters. Housing performance at two extremes of hurricane events have been documented and presented in this research. Statistical data on housing performance provides a useful tool to quantify the frequency and importance of various forms and causes of damage. Statistical interference on the data are possible, such that associations with levels of damage and certain housing characteristics can be made in an objective, scientific manner.

The effect of the roof covering was a significant factor on the damage to a structure. The use of shingle roof material appears to affect the amount of exterior and the interior damage more significantly. The roofing material that has the most tenacity to stay on the roof is the asphalt and gravel. The asphalt and gravel roof coverings were less likely to be stripped from the roof, exposing the sheathing. The houses that had tile roofs were most likely to be uninhabitable and repairable. Interior regions had slightly less damage in relation to roof sheathing exposure, exterior and interior damage in comparison to the coastal zones. The amount of structural wind borne debris generated due to a hurricane in both urban and rural environments is dependent on both the location to the path and to the number of residences in the area. Roughly $20 \%$ of the houses had tile roofs, $70 \%$ had roof shingles and $10 \%$ had asphalt and gravel roofs. The residences had an average of $50 \%$ of the roof sheathing exposed from the hurricane winds. The exterior of the residence experienced $37 \%$ damage while the interior had $35 \%$ damage. The average wind speed was $140 \mathrm{mph}$. 
While it is seldom possible to prevent the occurrences of a hurricane, it is possible to mitigate the extent of damage caused to buildings and structures, by adopting improved design and construction techniques in cyclone-prone areas. Building frames and masonry walls are required to be designed to have adequate lateral strength to withstand cyclonic forces, in addition to having strength to resist vertically acting dead and live loads.

In the case of roof with tile cladding, it is preferably to provide concrete restraining strips over tiles, at a spacing of not greater than $1.5 \mathrm{~m}$ centers, to better resist uplift forces. It is desirable to provide suitable roof bracing to increase the integrity of the structure in resisting the cyclonic forces. Anchorage, bracing and continuity are the prime factors influencing the structural integrity and increasing the resistance to withstand wind forces. Further, these strips can anchor to the main rafters suitably. The lateral resistance of the wall in many of the low-rise industrial buildings can be improved by providing a continuous $\mathrm{RC}$ bond beam at the top. Provision of $\mathrm{RC}$ columns to support the roof trusses (instead of block pilasters) with infilled block work will help in preventing the progressive collapse of the roof truss system in the event of hurricane. 


\section{RECOMENDATIONS}

Recommended design wind speeds for American National Standards Institute sets buildings based on 50-years recurrence intervals. Although ANSI and the major codemaking b odies s et r ecommended standards, it is up to s tate and local governments to actually adopt a code with adequate provisions for wind resistance. Strict enforcement of building code and provisions should be practiced by each individual dwelling to avoid disasters during a hurricane. In a hurricane prone zone the building should be made of CBS blocks and the hurricane straps should be e mbedded while the concrete is being poured such that it attains the required strength after the concrete has been set. The roof truss is then anchored to these hurricane straps for adequate stability against strong wind force. In framed construction, the SFBC requires either board or plywood storm sheathing on all exterior stud walls. Location of the buildings plays an important role in determining the effect of wind pressure on the walls and on its component parts. Buildings located within a suburban upstream exposure experience lower loads than if located in an open country exposure. Furthermore, if a building becomes embedded within a regular array of similar buildings, the all important peak loads are reduced. Seepage of water from the roof is a major cause of the damage not only to the interior but due to saturation the dead load increases and collapses. All joints on the roof cover should be a dequately s ealed to a void p enetration of $w$ ater. C onstruction of residential dwellings should be avoided around any kind of transmission towers or pylons or at least it should not be in the radius equal to the length of the pylon. This helps to reduce the property loss to a great extent. 


\section{REFERENCES}

Baskaran, A. and Chen, Y. (1998). "Wind load cycle development for evaluating mechanically attached single-ply roofs". Journal of Wind Engineering and Industrial Aerodynamics. $77 \& 78$ 695-701.

Beste, F. and Cermak, E. Jack (1997) "Correlation of Internal and Area-averaged External Wind Pressure on Low-rise Buildings." Journal of Wind Engineering and Industrial Aerodynamics. 69-71, 557-566.

Ben L. Sill, and Ronald T. Koziowski. "Analysis of Storm-Damage Factor for Low-Rise Structures.

Case, P.C. and Isyumov, N. (1998). "Wind loads on low buildings with 4:12 gable end roofs in open country and suburban exposures". Journal of Wind Engineering and Industrial Aerodynamics. $77 \& 78$ 695-701.

Caillouette, D. (1992) "Developing a Tolerant Building. Creating a Hurricane Tolerant community-City of Venice." Planning Department.

Calfee, D.R. and Murchison, W.W. (1998). "Demystifying window and door selection for single-family homes in high-wind environments". Journal of Wind Engineering and Industrial Aerodynamics. 77 \& 78 695-701.

Crandell, J. H. (1998). "Statistical assessment of construction characteristics and performance of homes in Hurricane Andrew and Opal". Journal of Wind Engineering and Industrial Aerodynamics. 77 \& 78 695-701.

Carter, Lindsey E. and Nichols, Gary G. (1993) "Are Building Codes and/or Enforcement Adequate for Hurricane Protection?” Florida.

Dorton, R.A. and Lombardy, A. (1986) "Canadian Journal of Civil Engineering". The National Research Council of Canada.

Fedral Emergency Management Agency (FEMA). (1983) "Progress Report on a Study of Rapid Damage Assessment by Remote Sensing."

Fedral Emergency Management Agency (FEMA). (1992) "Building Performance: hurricane Andrew in Florida."

Guidelines for Disaster Prevention and Preparedness in Tropical Cyclone Areas. Prepares, the Economic and Social Commission for Asia and the Pacific, the World Meteorological Organization and the League of Red Cross Societies. Geneva/Bankok, 1997. 
Huang, Z., Rosowsky, D.V., and Sparks, P.R. (1992). "Hurricane simulation techniques for the evaluation of wind-speeds and expected insurance losses". Department of Civil Engineering, Clemson University.

Hsu, J. (1998). "Hurricane Damage Assessment of Residential Homes Using Aerial Photographs".

Khan, Mohammed S. and Wimal Suaris. (1992) "Design and Construction Deficiencies and Building Code Adherence." Florida

Kumar, S.K. and Stathopoules, T. (1997). "Computer Simulation of F luctuation Wind Pressures on Low Building Roofs". Journal of Wind Engineering and Industrial Aerodynamics 69-71.

Kumar, S.K. and Stathopoulos, T. (1998). "Fatigue analysis of roof cladding under simulated wind loading". Journal of Wind Engineering and Industrial Aerodynamics. 77 \& 78 695-701.

Lew, H.S. (1976) "Wind and Seismic Effect." US Department of Commerce.

Lillesand, M. Thomas and Kiefer, W. Ralph (1994) "Remote Sensing and Image Interpretation."

Lillesand, M. Thomas and Kiefer, W. Ralph (1994) "Remote Sensing and Image Interpretation." John Wiley and Sons, Canada. 1-350.

Mahendran, M. (1995) "Wind-resistant Low-rise Buildings in the Tropics." Journal of Performance of Constructed Facilities. 9(4), 330.

Marshall, T.P. (1985). "Performance of Structures During Hurricane Alicia and the Altus Tornado".

Molina, F. Bruce and Hallam, A. Cheryl (1999) "USGS Open Skies Aerial Photography of Selected Areas in Central America."

Sankaran, R. and Paterson, D.A. (1997). "Computational of Rainfall on a Tall Rectangular Building". Journal of Wind Engineering and Industrial Aerodynamics. 72. 127-136.

Seong, H. S. and Peterka A. J. (1997). "Computer Simulation of Non-Gaussian Multiple Wind Pressure Time Series". Journal of Wind Engineering and Industrial Aerodynamics, 72. 95-105. 
Shanmugasundaram, J., Arunachalam, S., Gomathinayagam, S., Lakshmanan, N. and Harikrishna, P. (2000) "Cyclone Damage to Buildings and Structures-A case study." Journal of Wind Engineering and Industrial Aerodynamics. 84, 369-380.

Suaris, W. and Khan, M.S. (1995) "Residential Construction Failures Caused by Hurricane Andrew." Journal of Urban Planning and Development.

Surviving the Storm. Building Codes, Compliance, and the Mitigation of hurricane Damage. All-industry Research Advisor Council in cooperation with the National committee on Property Insurance, December, 1989.

Surry, D. (1990). "Recent and Current Research into Wind Loading of Low Buildings at the University of Western Ontario". Journal of Wind Engineering and Industrial Aerodynamics, 36. 1319-1329.

Unanwa, C.O., McDonald, J.R., Metha, K.C., and Smith, D.A. "The Development of Wind Damage Bands for Buildings." Journal of Wind Engineering and Industrial Aerodynamics. 84, 119-149.

Ulrich, P . and B oissonnade, A. (1990). "How to B est U se Engineering R isk A nalysis Models and Georgraphic Information Systems to Assess Financial Risk from Hurricanes". 


\section{APPENDIX A}

Statistical Analysis based on Quantitative Damage Database. 


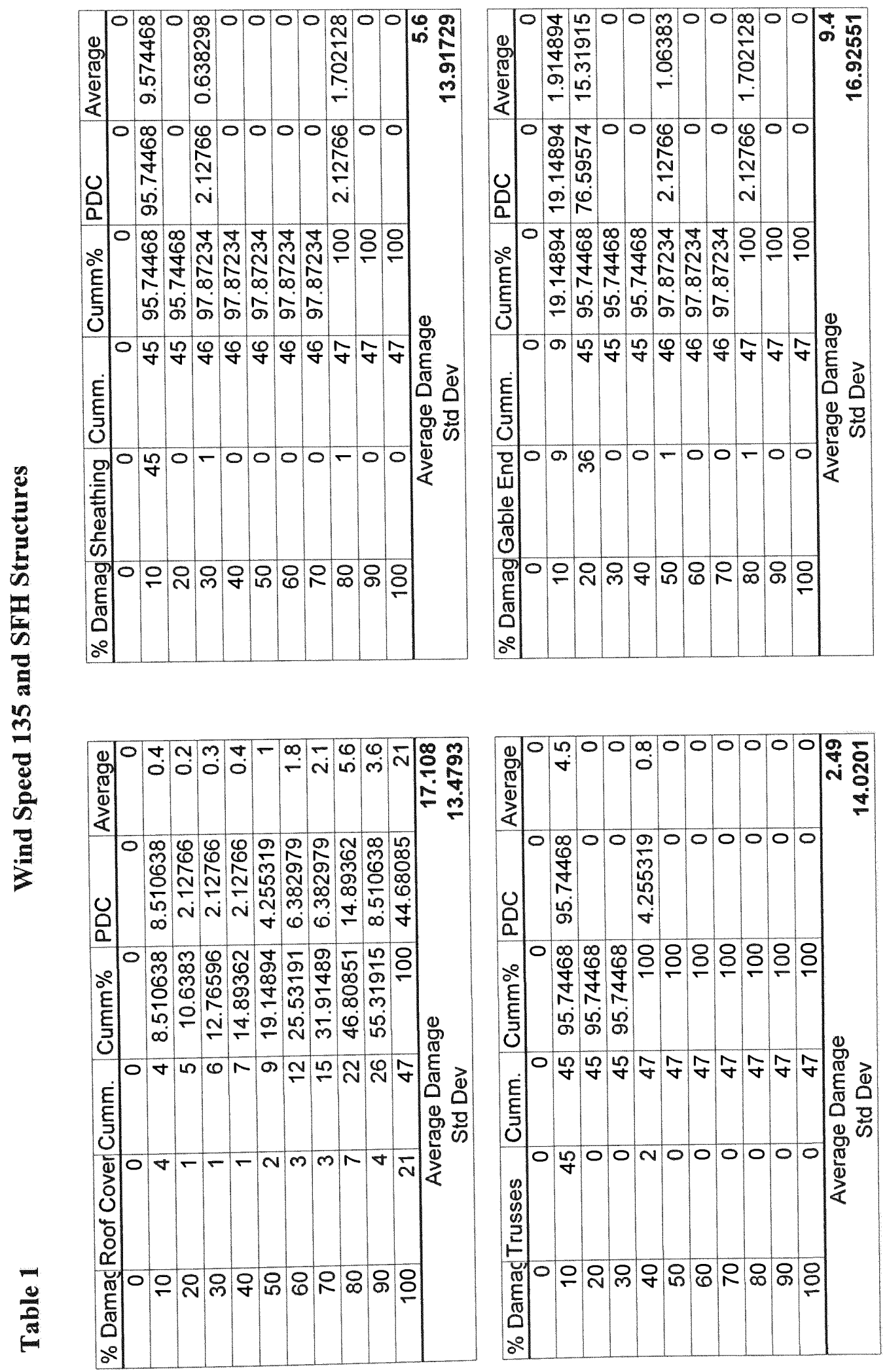




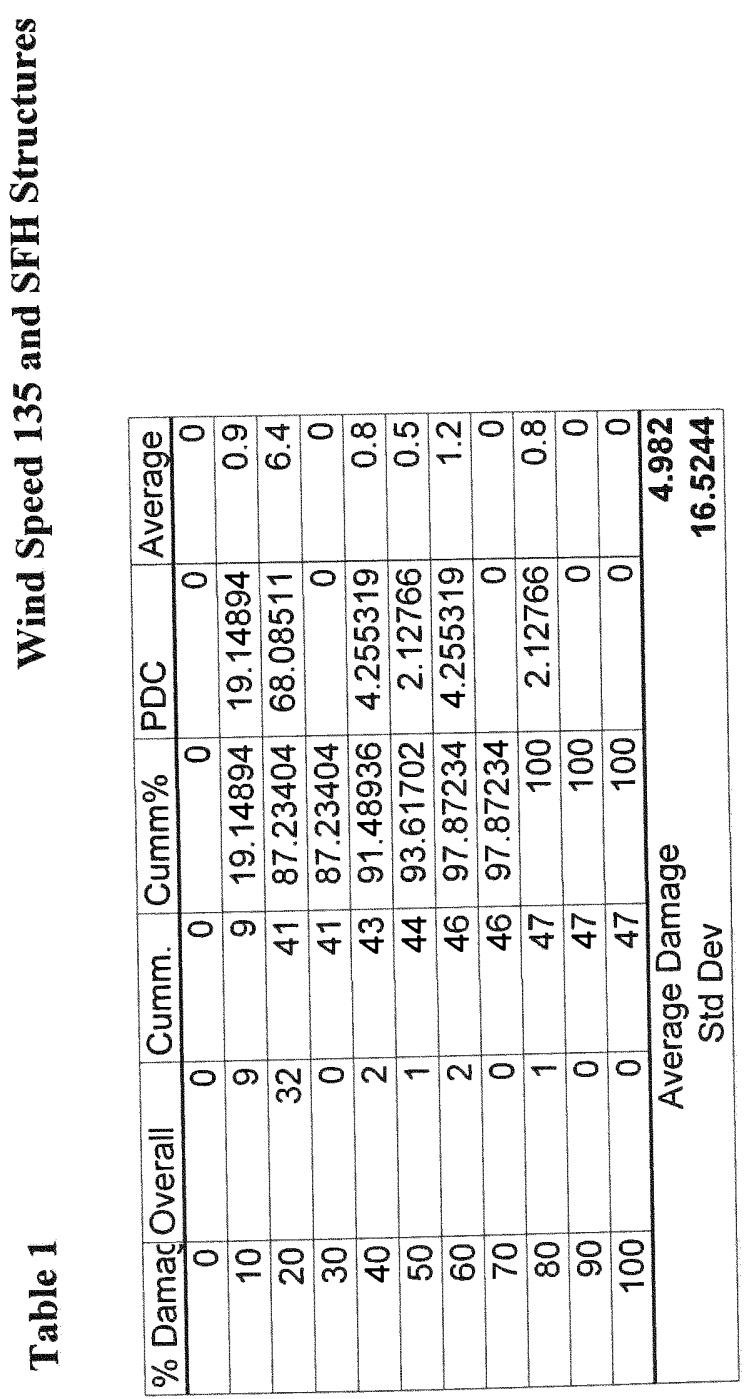



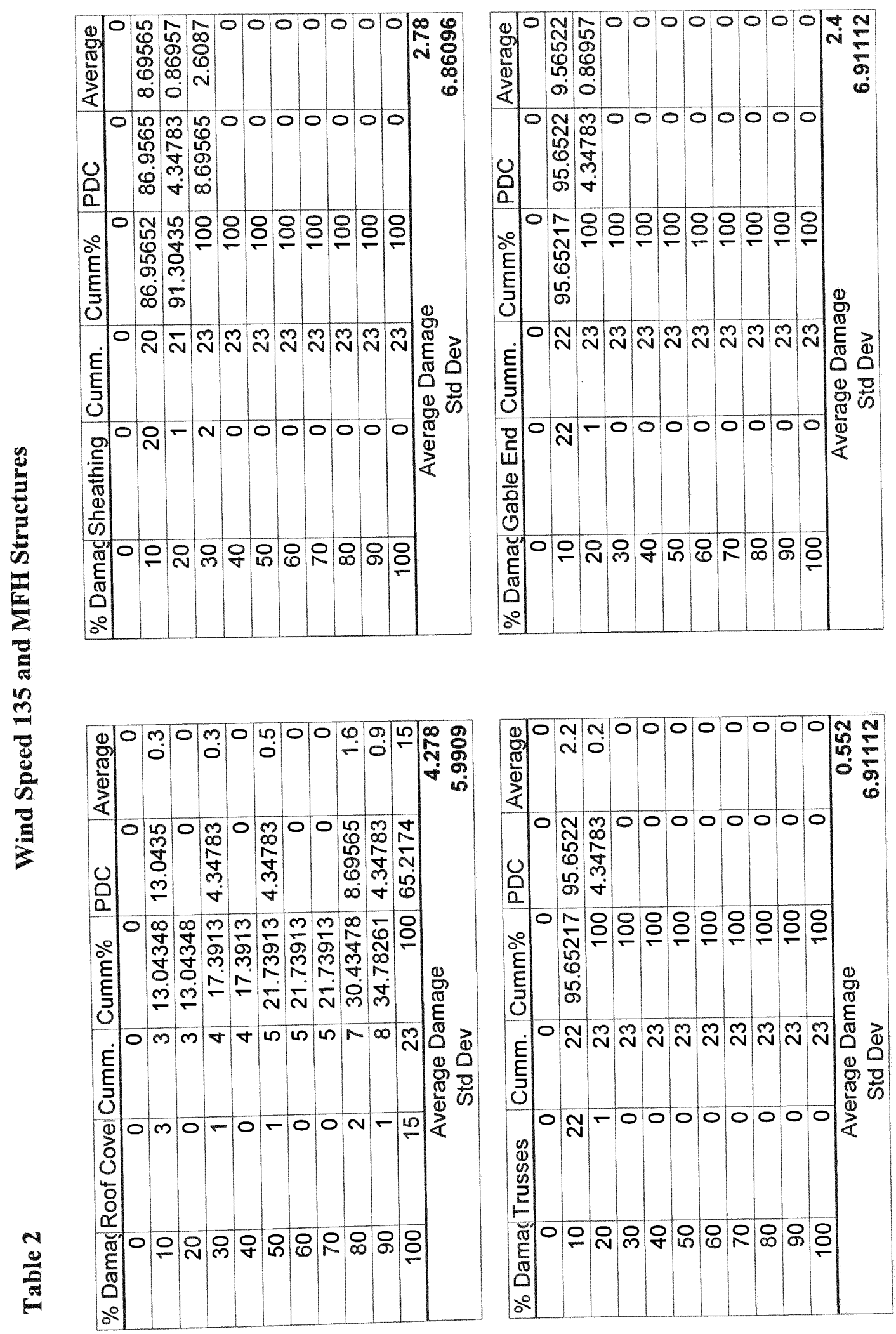


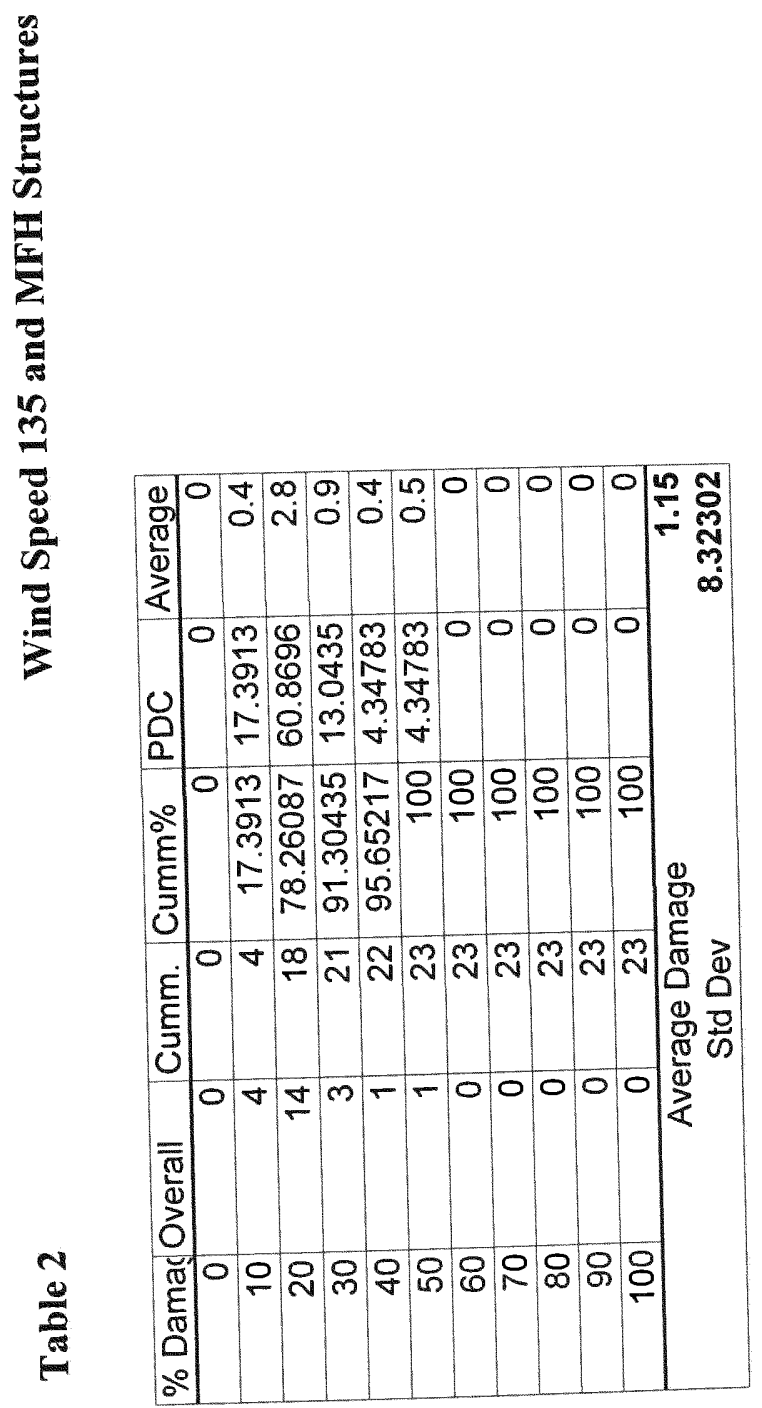



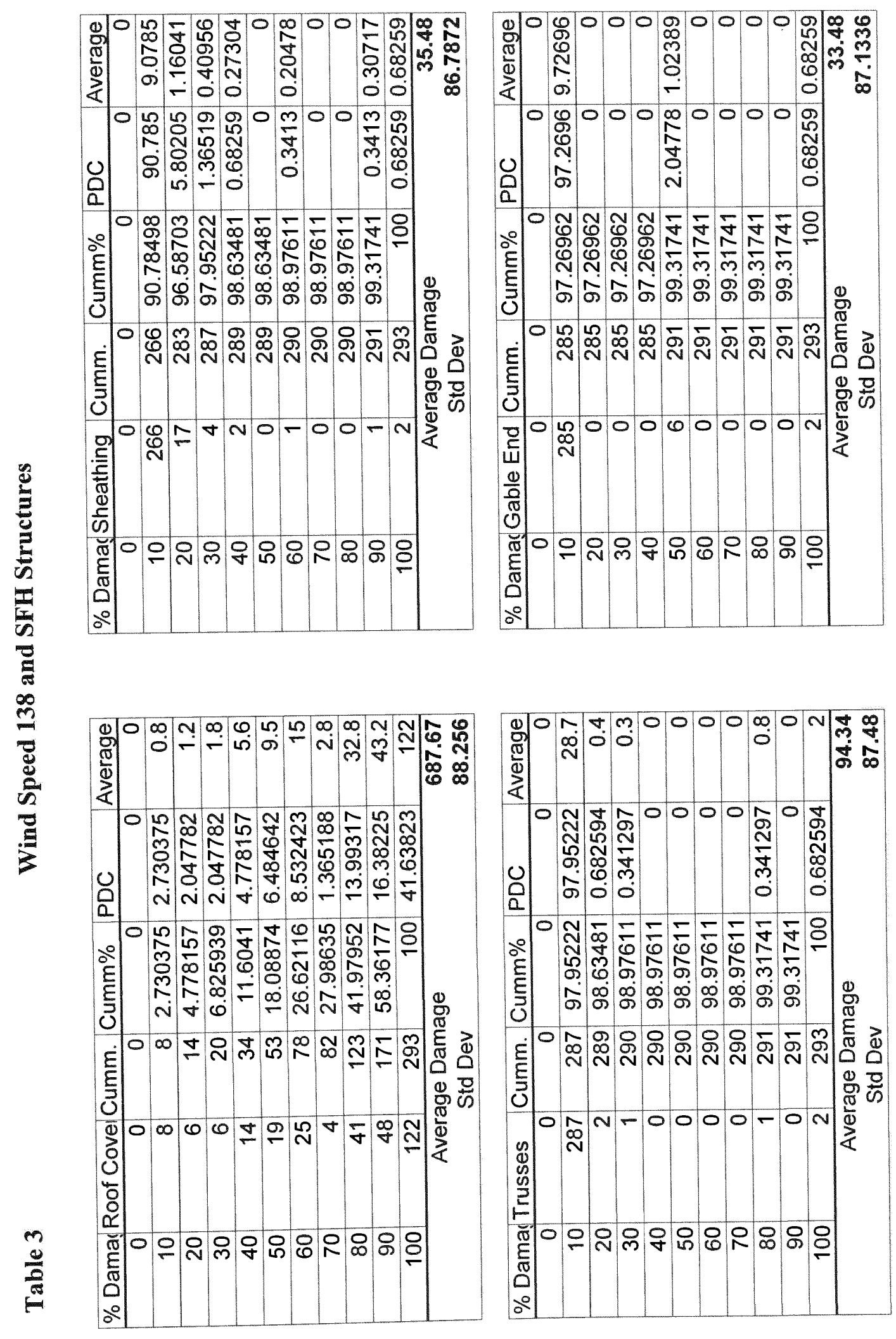


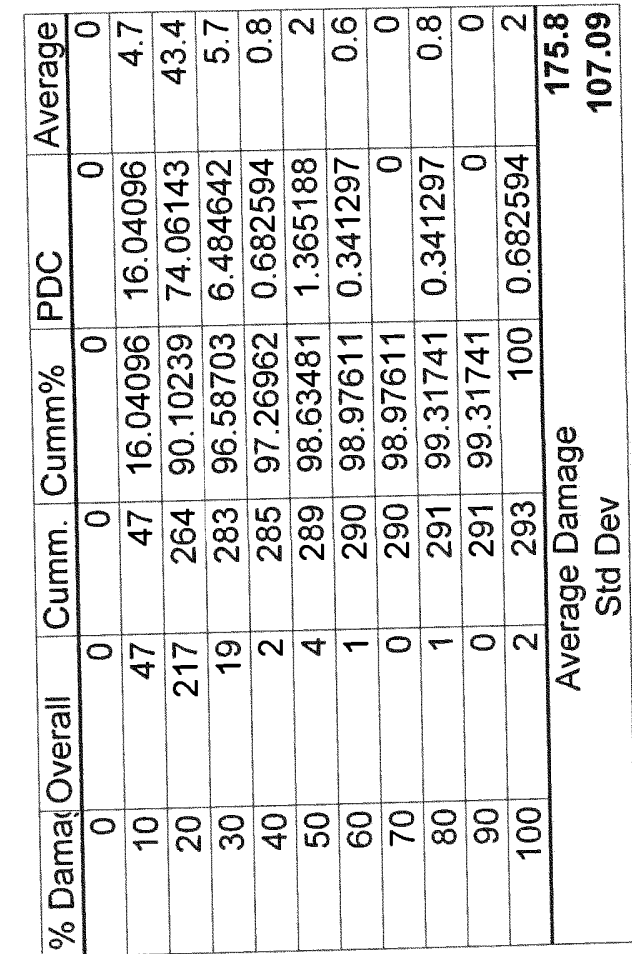




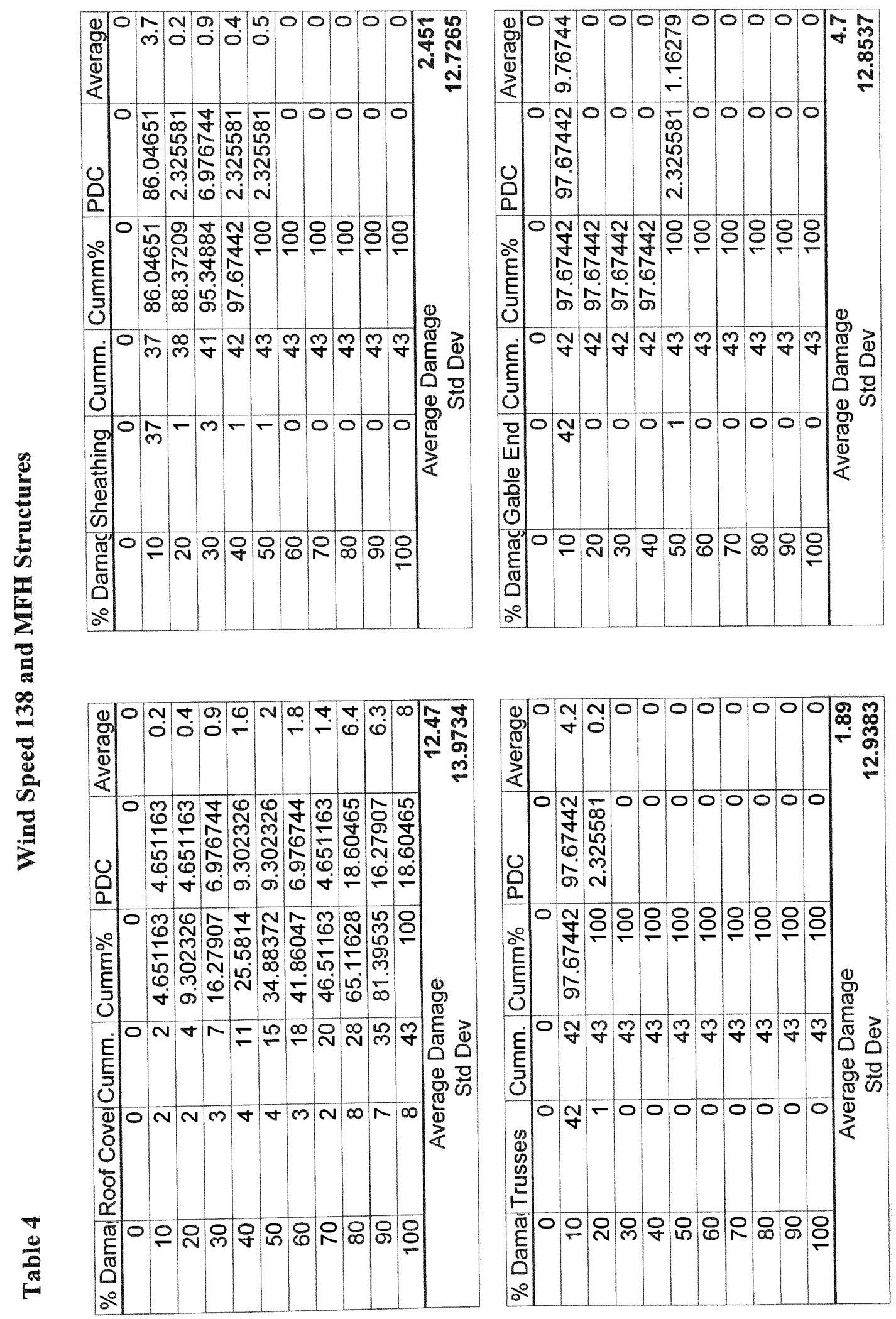



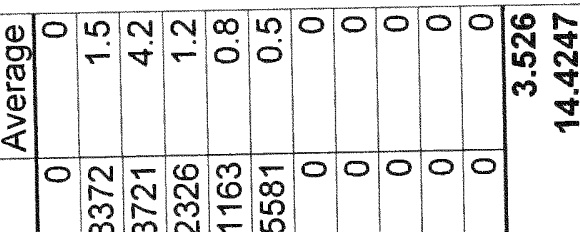
$m$ N $\infty M \div$

U)

- on m

m 0 m

m

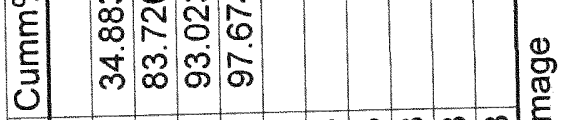

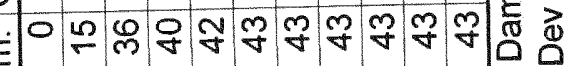

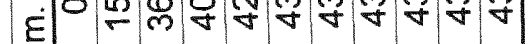

$\Phi$ 뭉

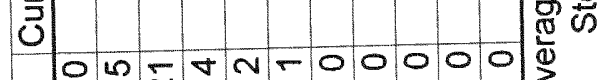

$\overline{\overline{0}}$

$\operatorname{lon} \pi n-00000$

\&

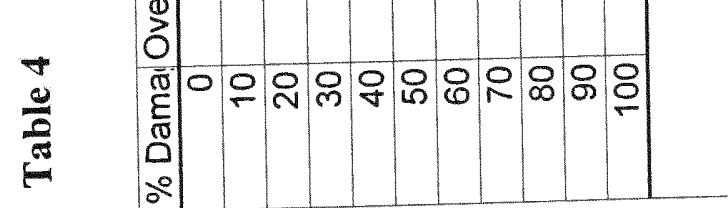




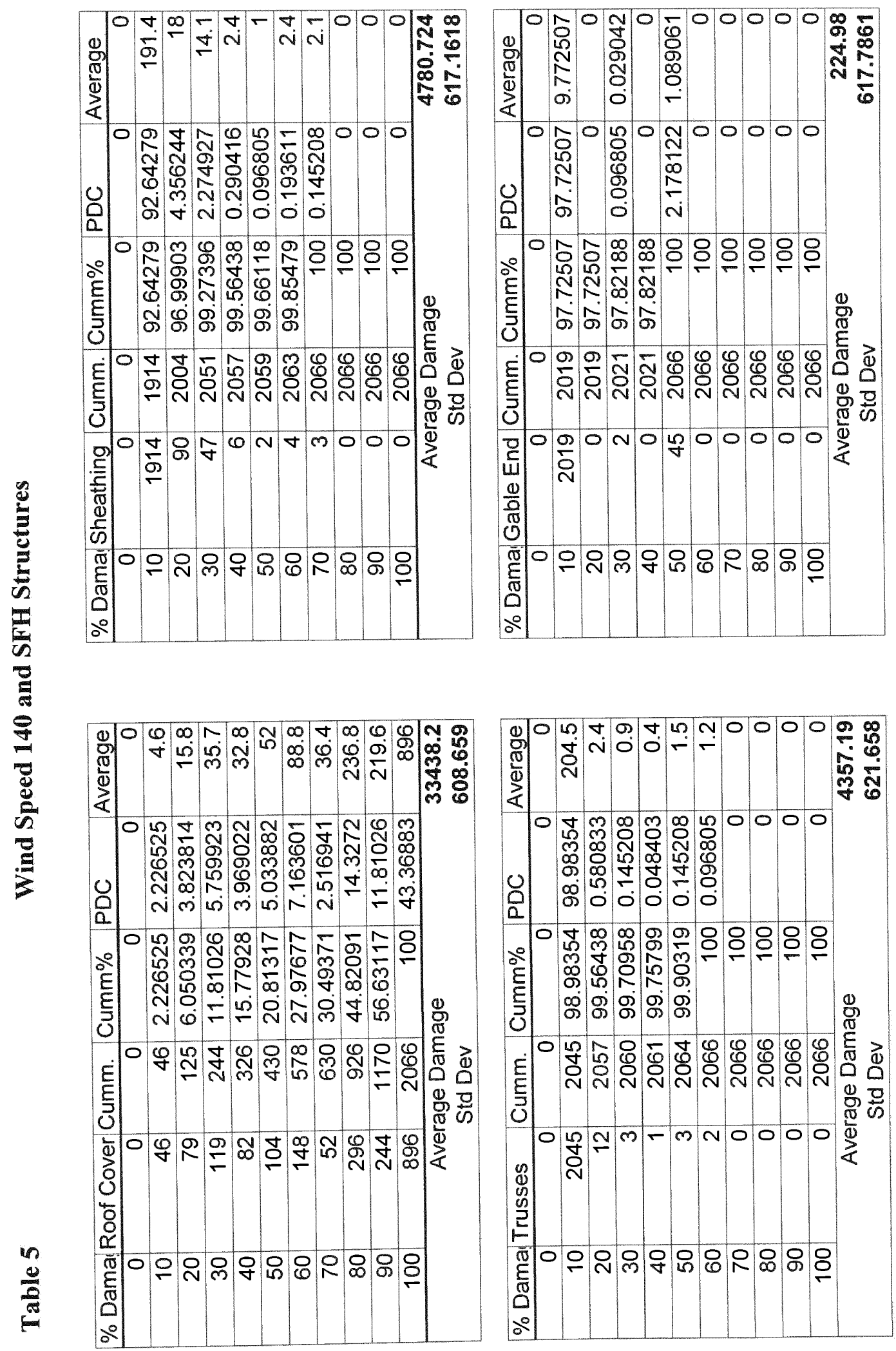


o m t idma mata ட

定

0)

0 ᄂ

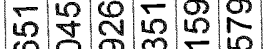

임ㄷㄴ

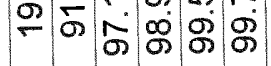

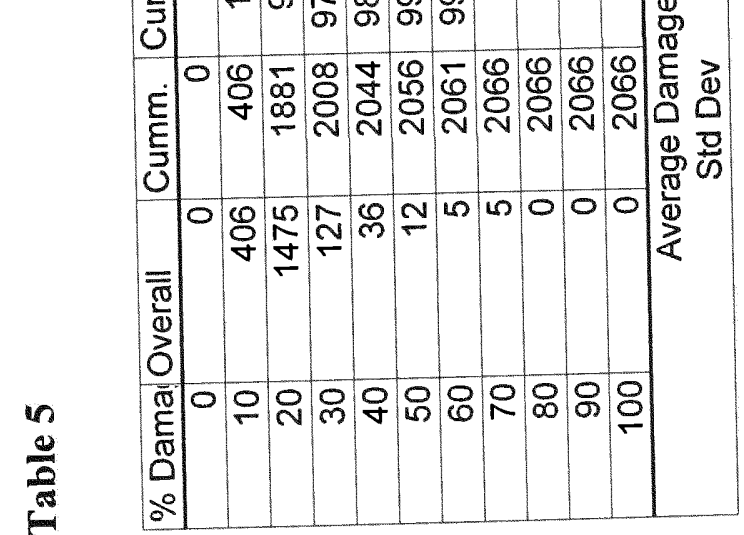



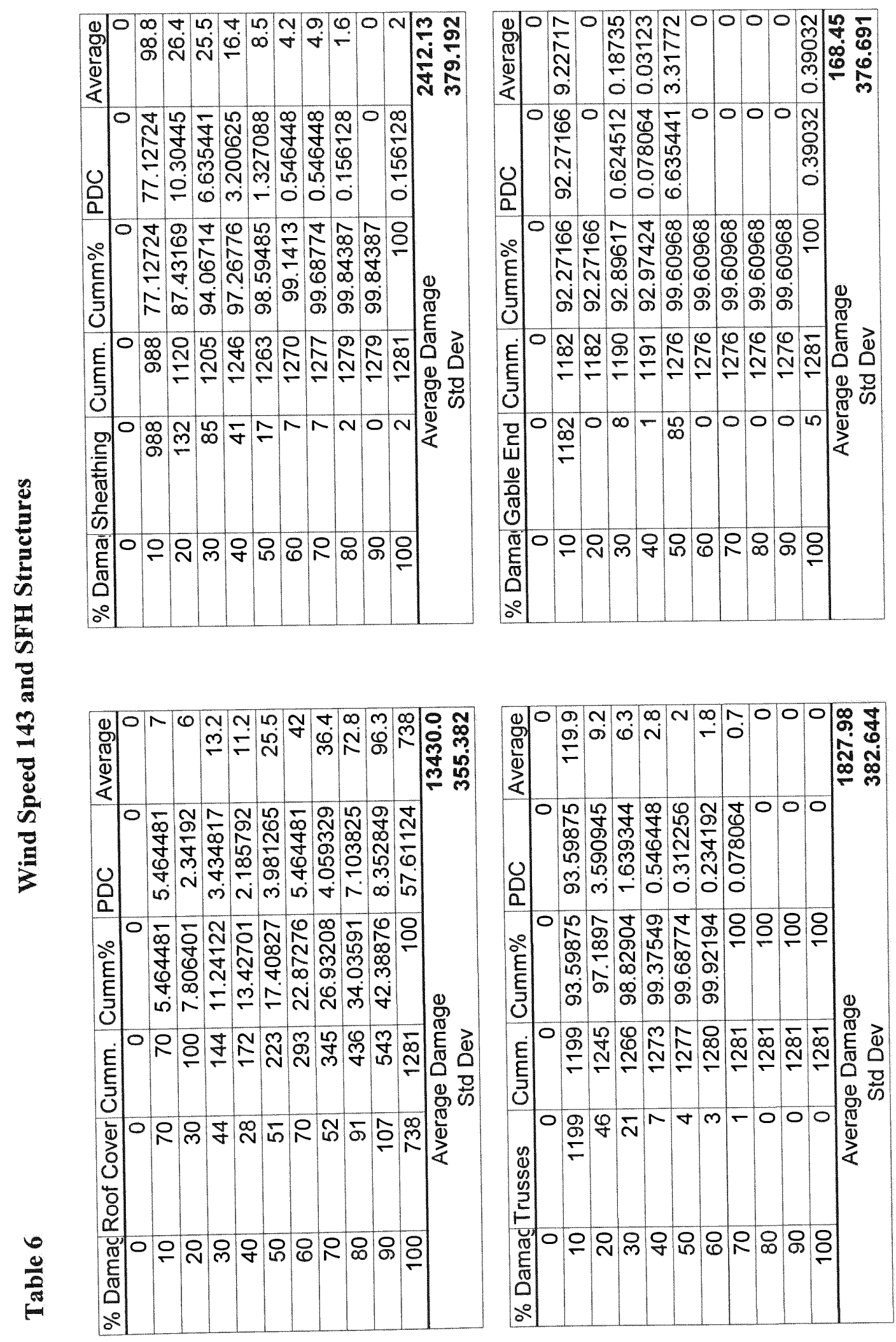
है

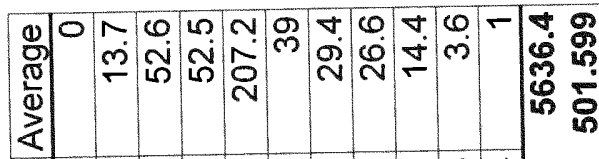

这

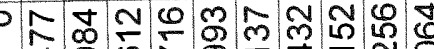
ษ गิ 10

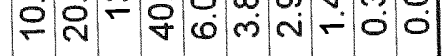

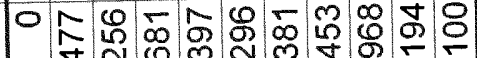
ง ำ 云 غ

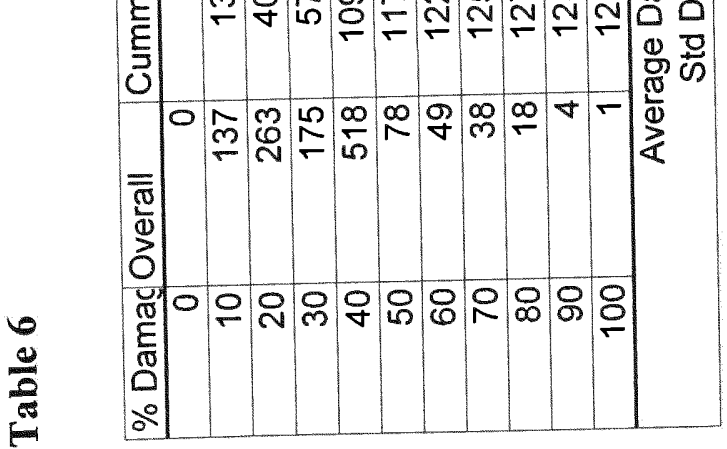




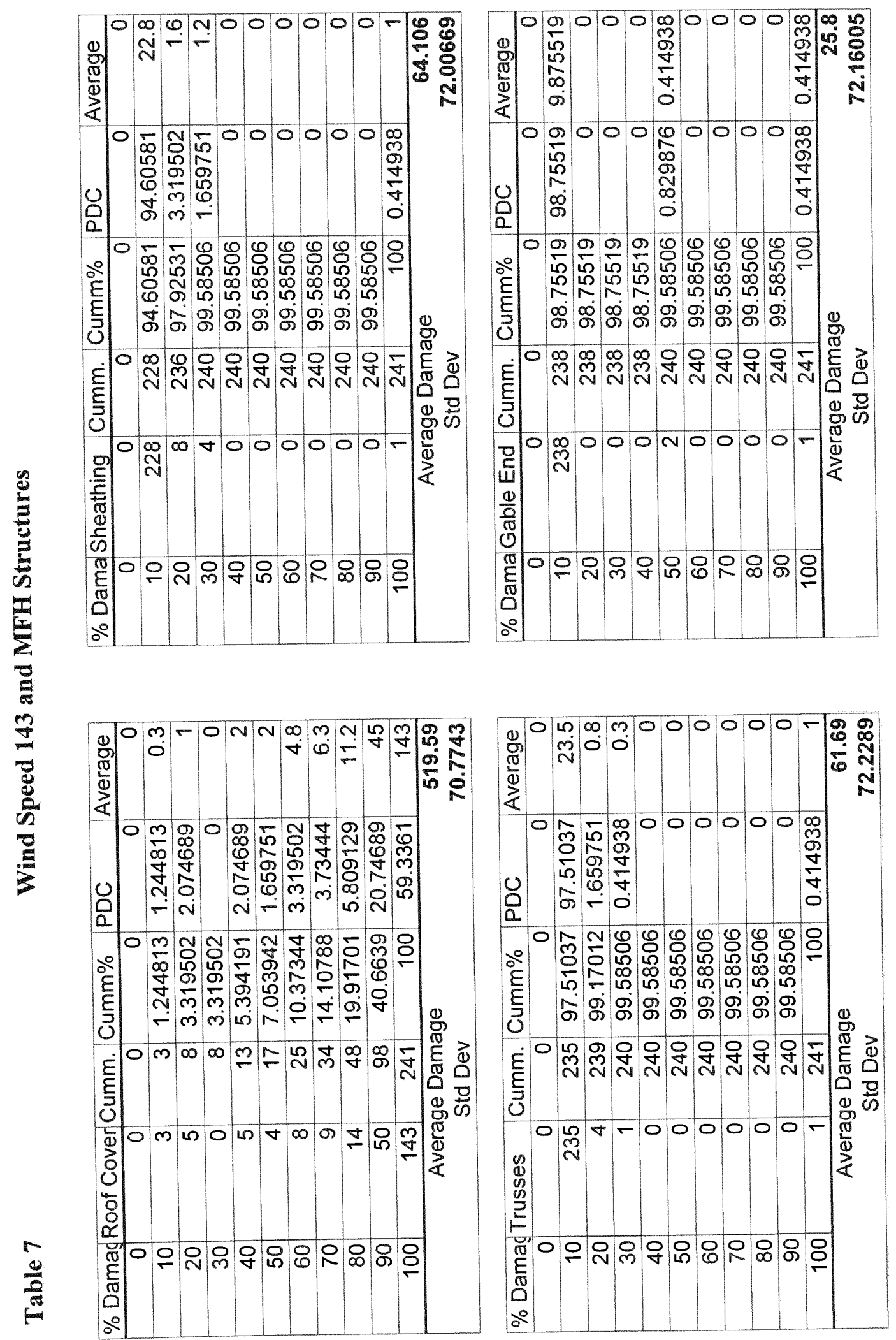


O

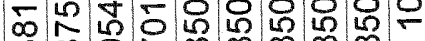

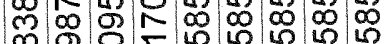
ヘ

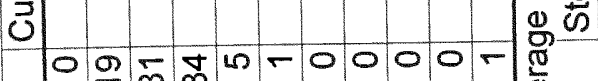

है

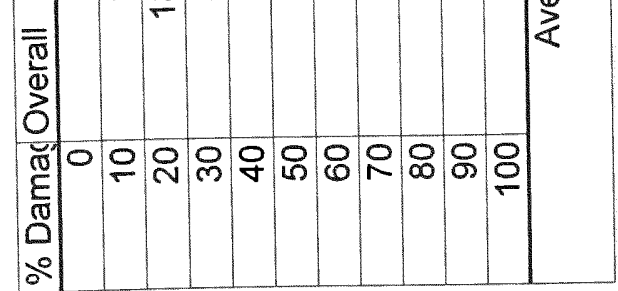




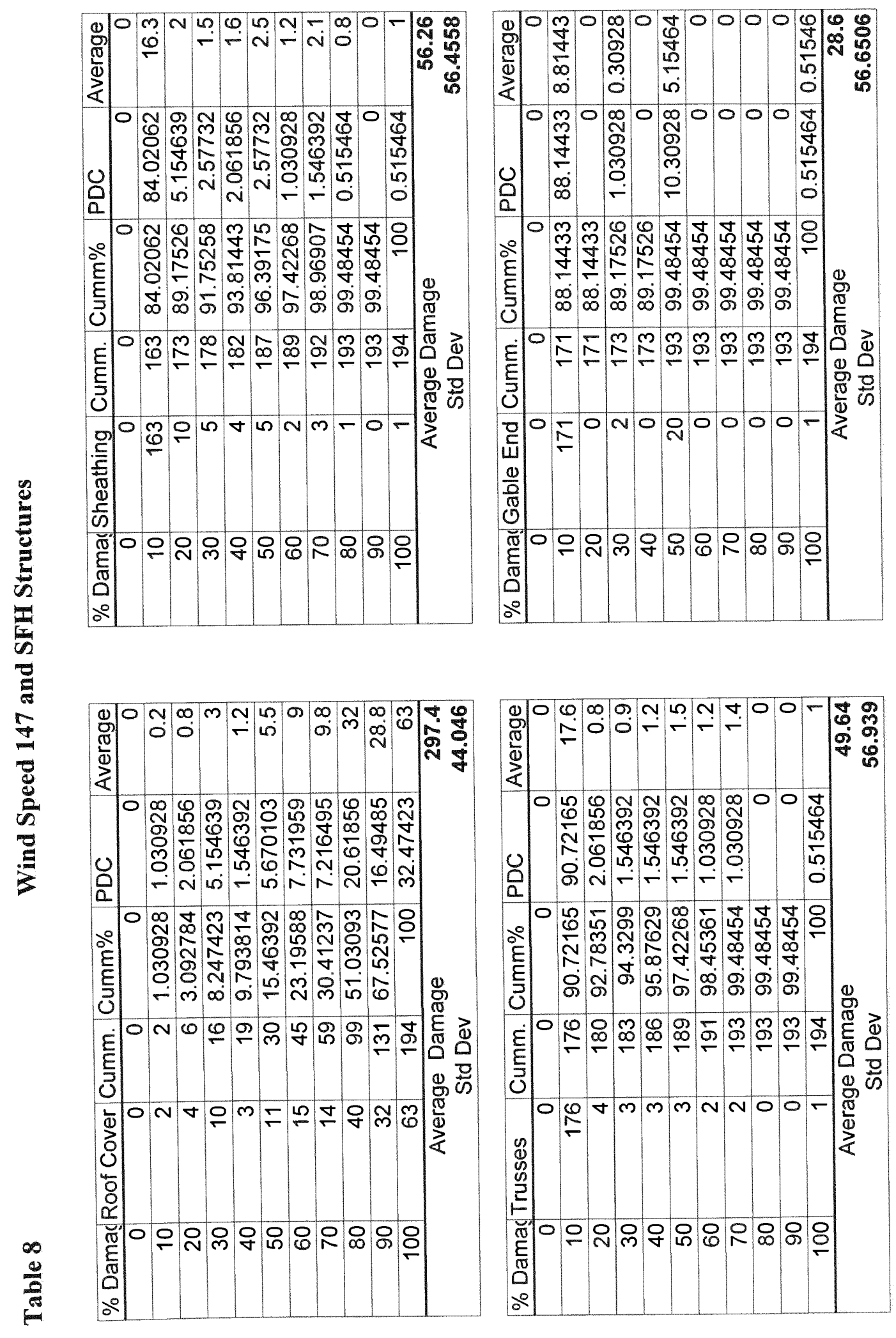


娄
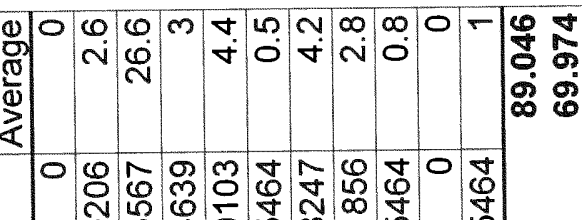

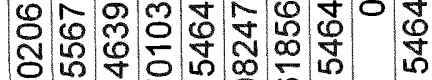

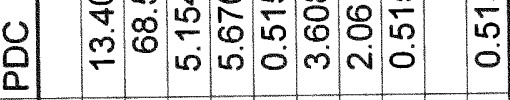

0 gீ

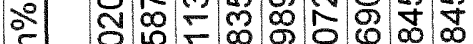

E ச

ஸ்

:

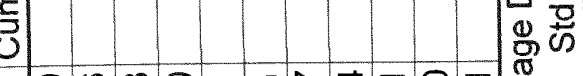

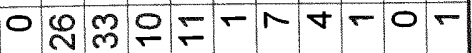

品

$=1010$

২

2

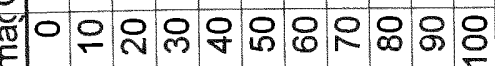

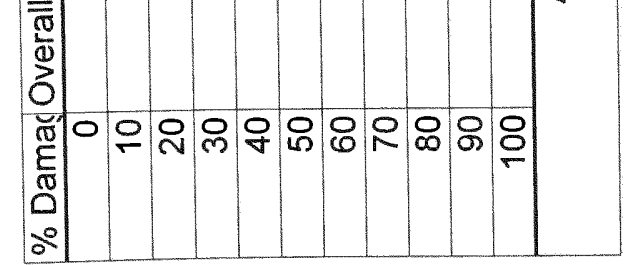



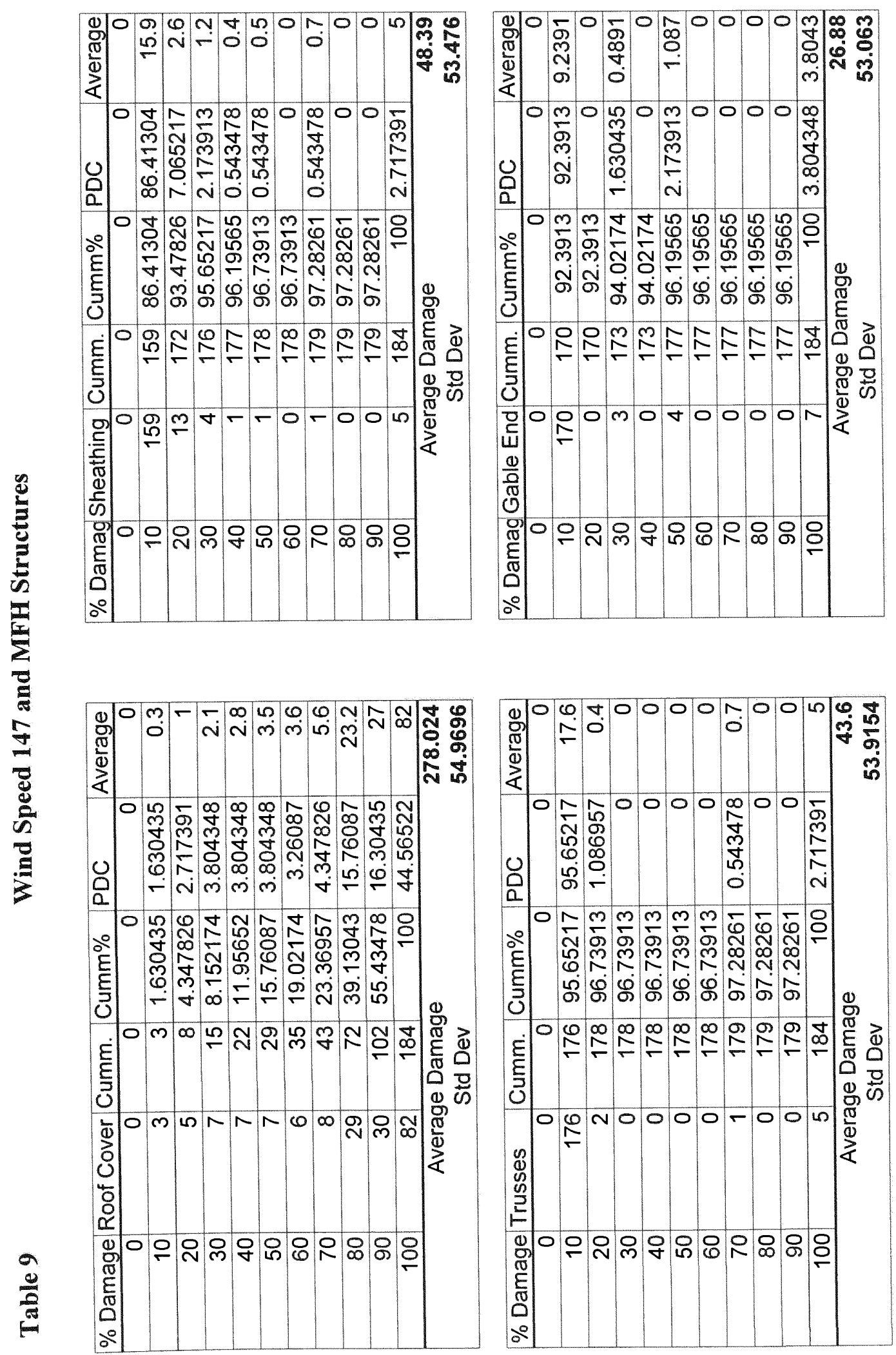


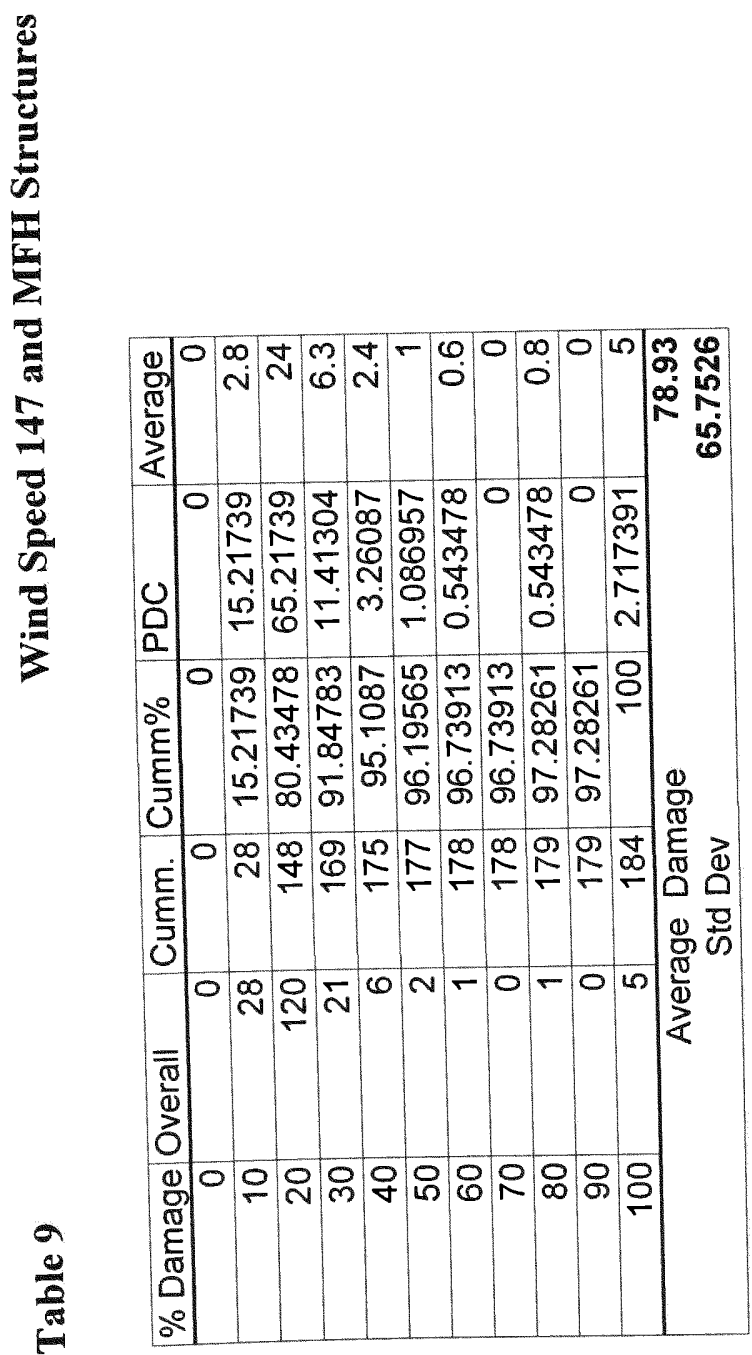




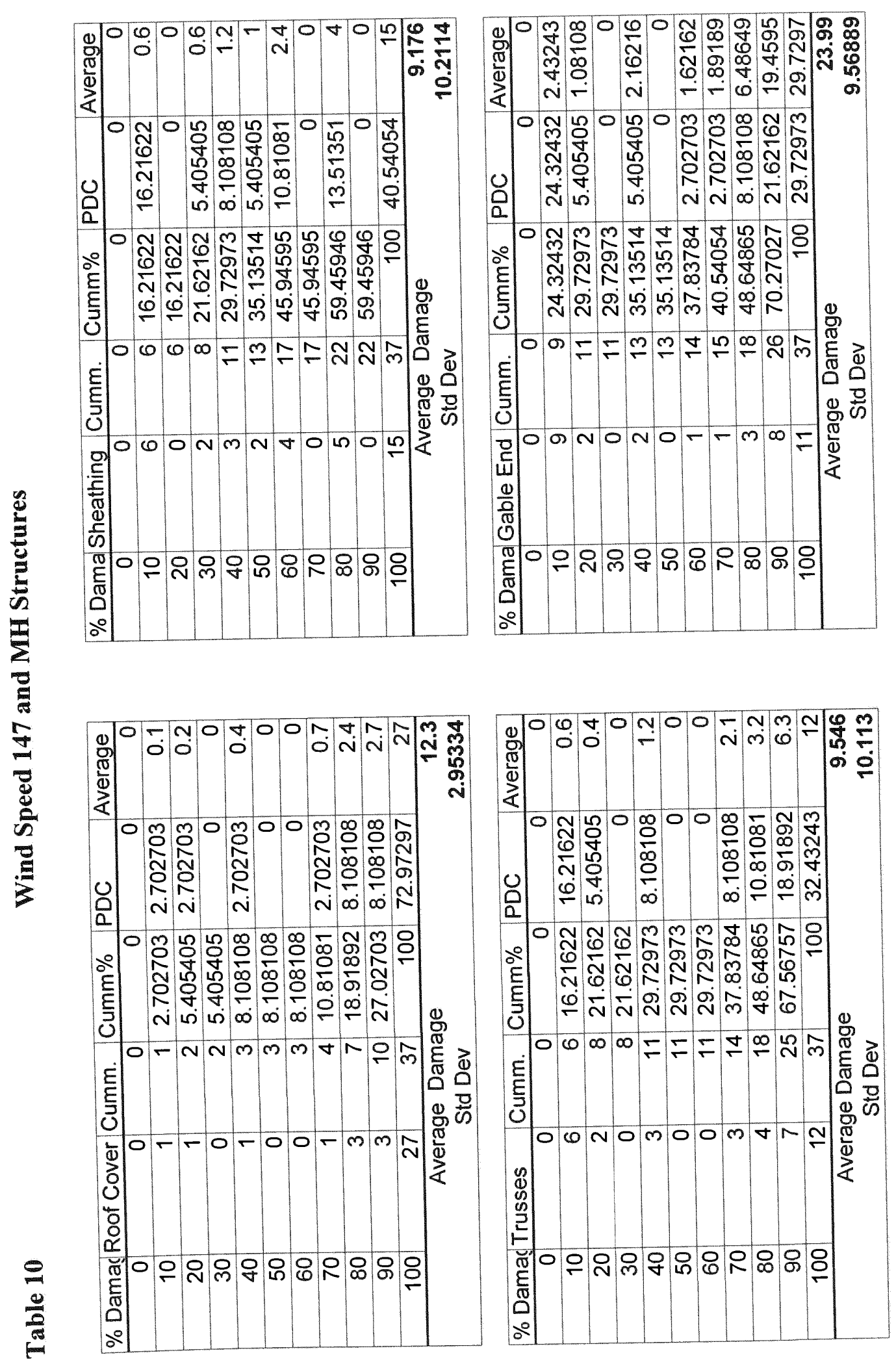




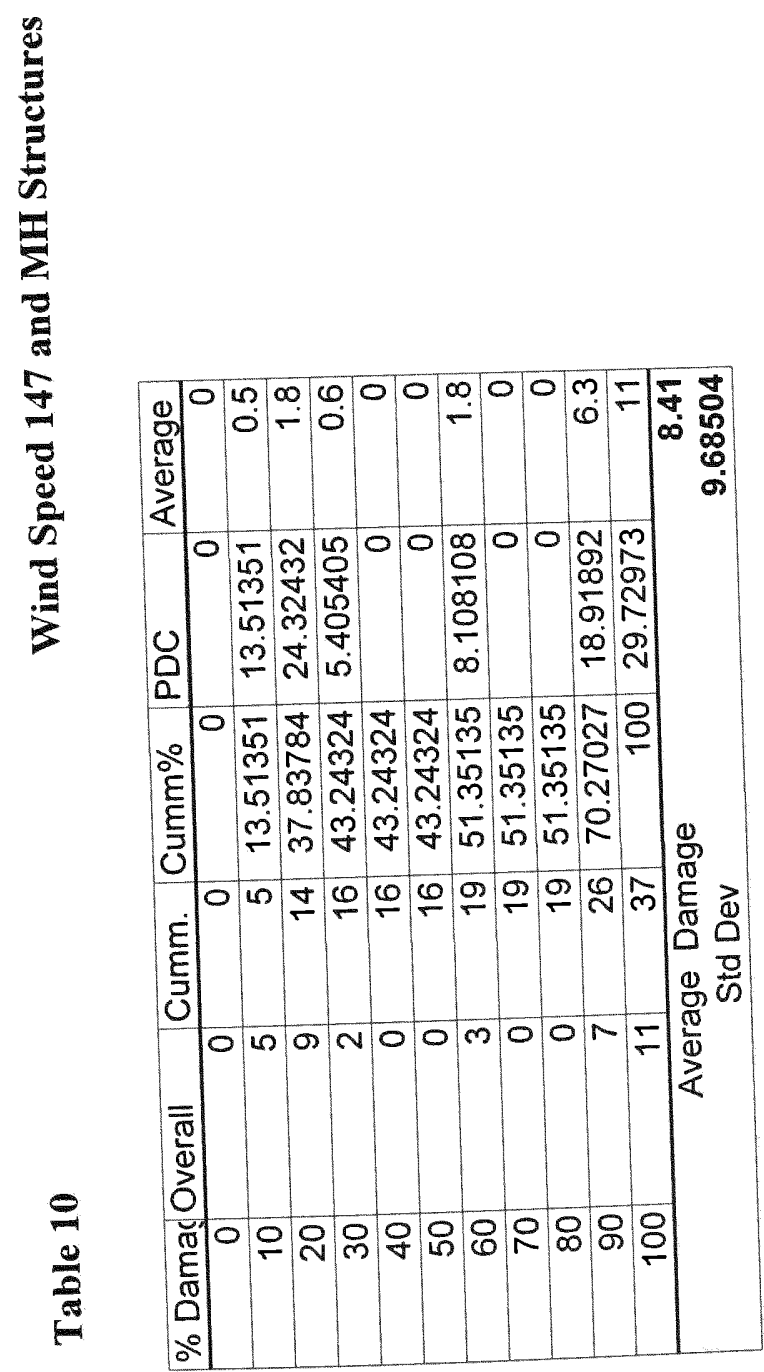




\section{APPENDIX B}

Case Studies of Various Structures Damaged due to Hurricane Andrew. 


\section{RESIDENTIAL BUILDINGS}

\section{SINGLE FAMILY HOUSES}




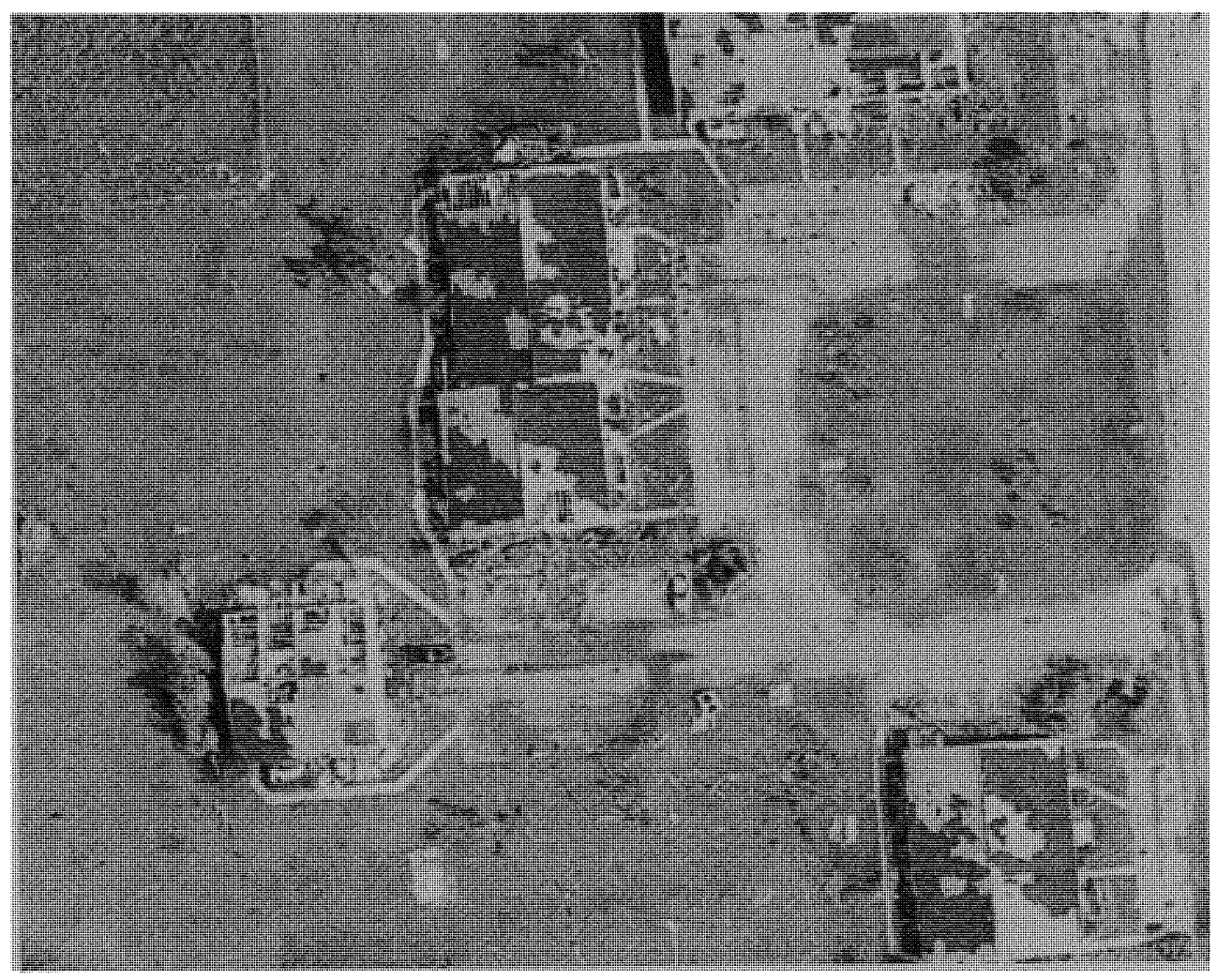

Figure 1.1. Damage to corner house.

The figure above shows extensive damage to single family homes. The corner house was severely damaged. Major portion of the roof cover and sheathing was blown off. Moreover since it was a corner house wind struck the house directly. The corner house had number of small trees, which could not create a barrier/obstruction to resist the damage caused in the corner houses. 


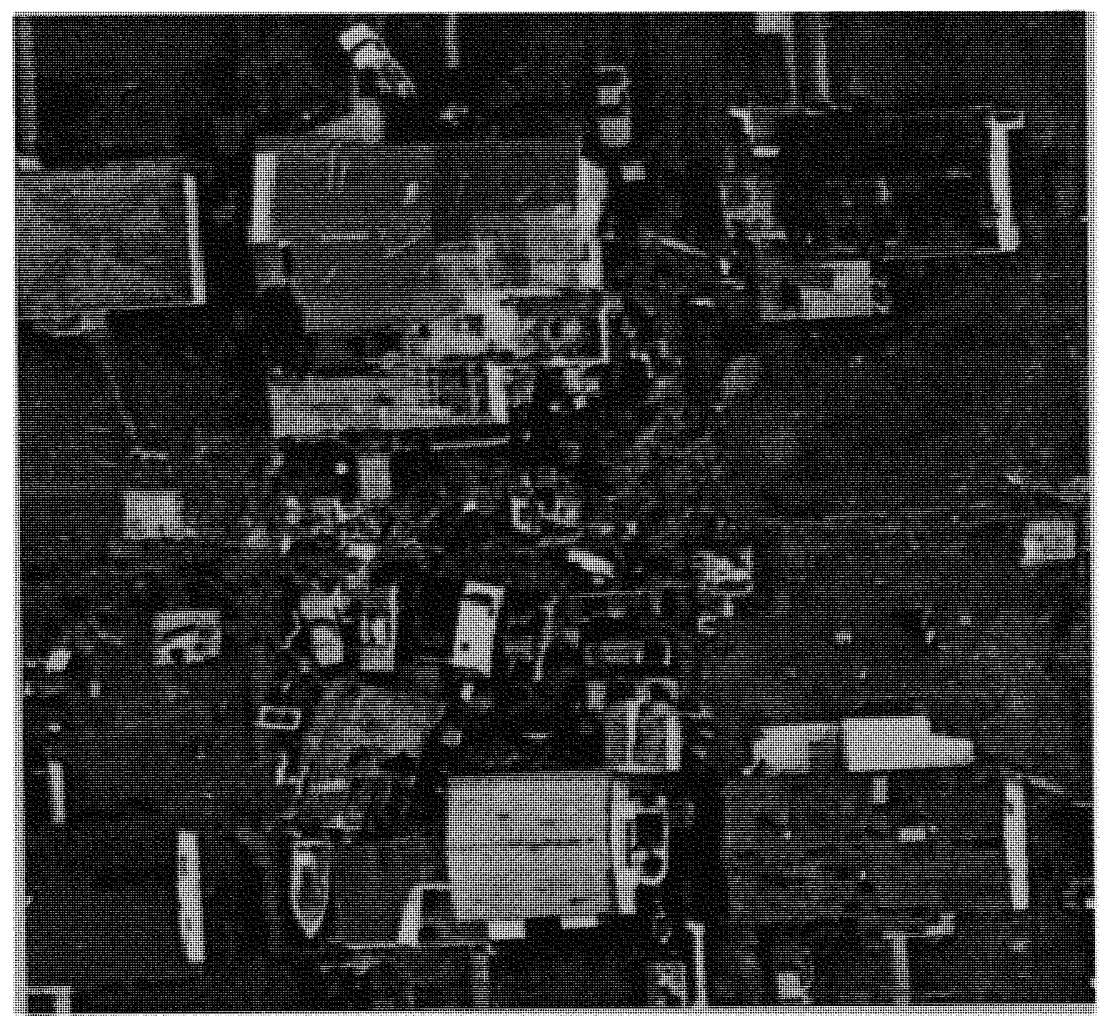

Figure 1.2. Damage due to wind-borne debris.

In this picture major damage was the roof cover damage. The velocity of the wind was adequately strong enough to blow off the roof covers of various houses, which means that roof cover material was not securely fastened together. The wind path was very clear in this picture. The wind takes a curved course from south-west to north-east direction. Wind borne debris can be seen all around the places. All the houses were structurally strong enough to resist the velocity of the wind hence major damages cannot be observed except for the roof cover damage. 


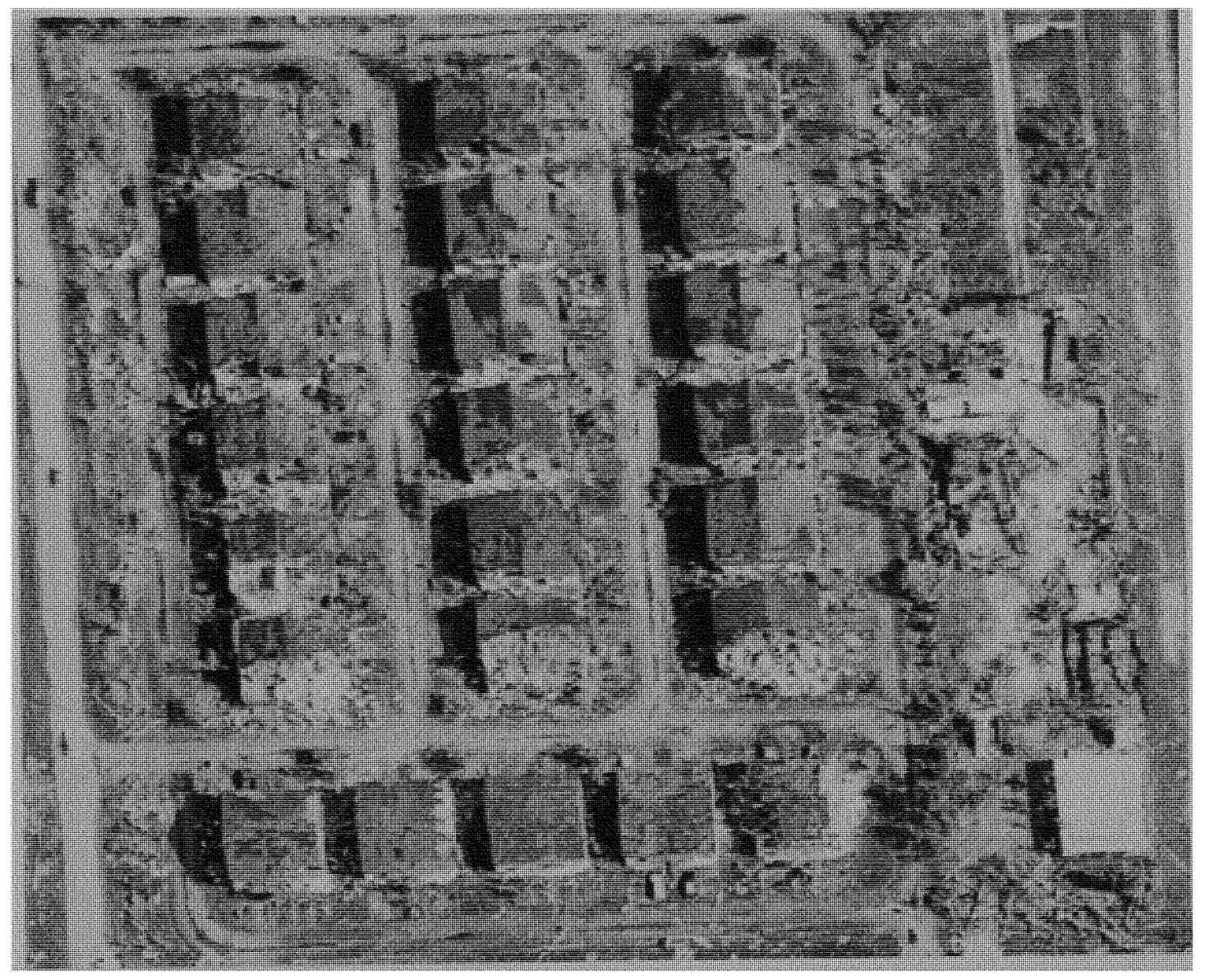

Figure 1.3. Progressive roof cover damage.

The figure shows a community of homes, which are closely spaced. They suffered major destruction. In some cases the dry wall has been completely destroyed. Most of the houses have roof cover and sheathing damage. Debris were scattered all around the individual houses. The wind direction can be predicted accurately by the extent of damage. The direction of wind was from south to north. It is seen that houses at front are damaged more than the houses at the back. The reason being that the houses in the front provided a barrier for the houses at the back. 


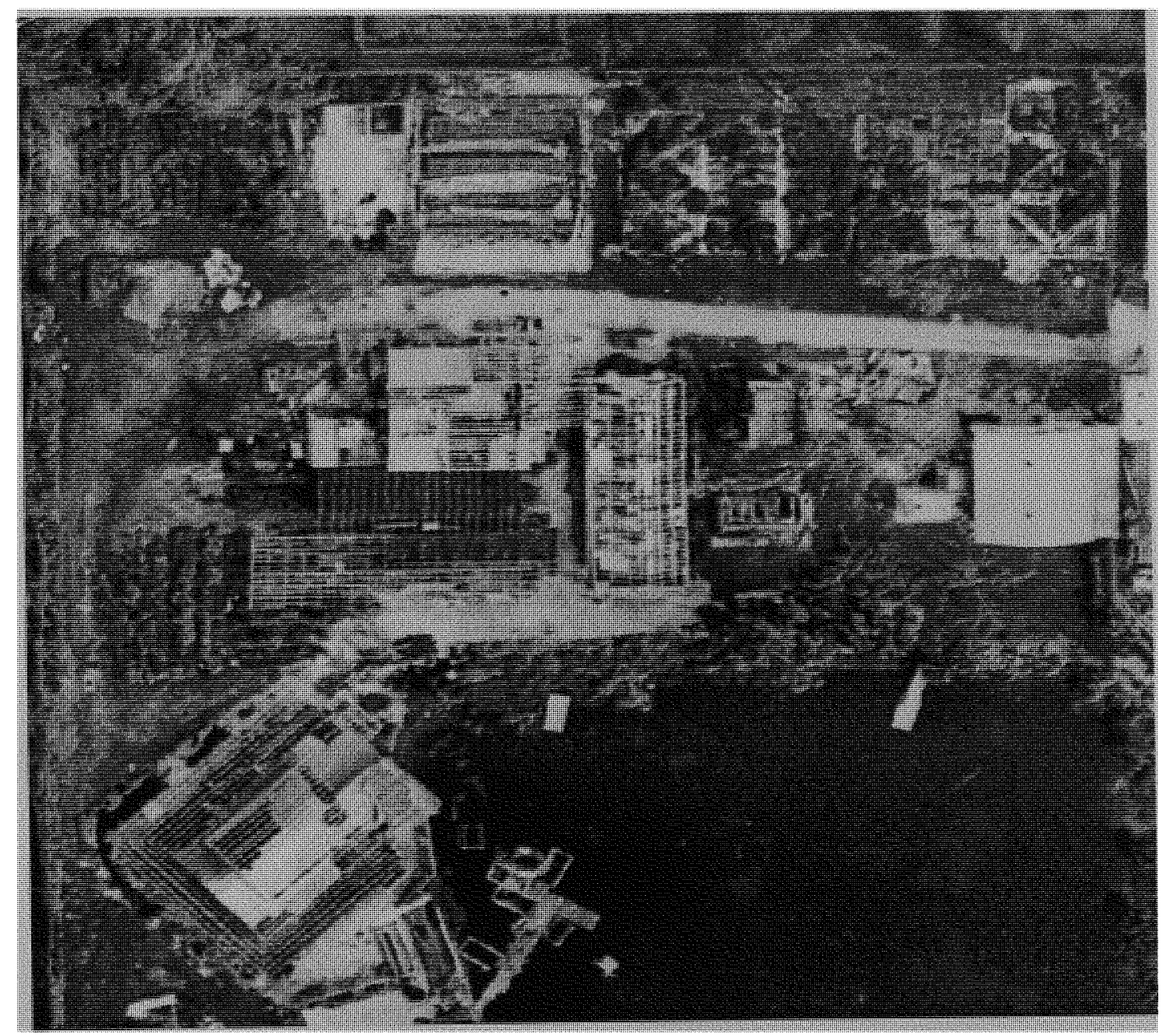

Figure 1.4. Roof cover, sheathing and gable-end damages.

The figure shows single-family homes, located around a lake, which has been extensively damaged by strong winds. The major damage is in the roof system. In most houses there were roof cover, sheathing and gable end damages. The structural component of the truss was intact without major damages. Debris can be found around the house. The wind direction cannot be easily predicted, as there are no trees either around the houses or surrounding the lake. 


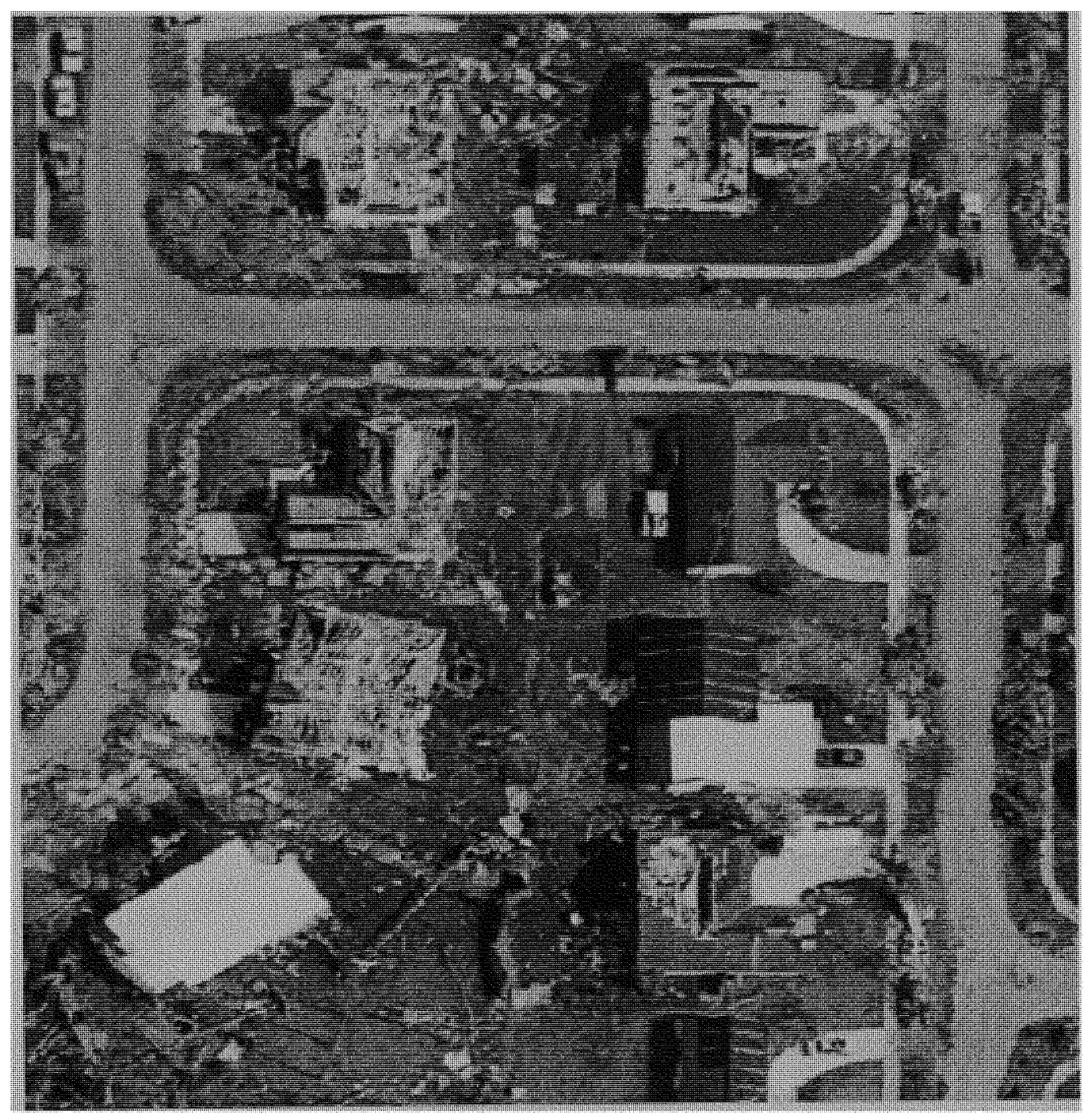

Figure 1.5. Dislocation of truss members due to strong wind force.

The figure shows few houses in a community where some houses have been badly damaged. Mostly the damage was in the roof system. In some cases the entire roof cover and the sheathing was missing with roof framing damaged completely. Wherever there was a roof framing damage the gable end was also completely damaged. So in these cases the frame was damaged due to inadequate fastening and due to weak bracing. The wind direction cannot be predicted accurately due to variable damages. 


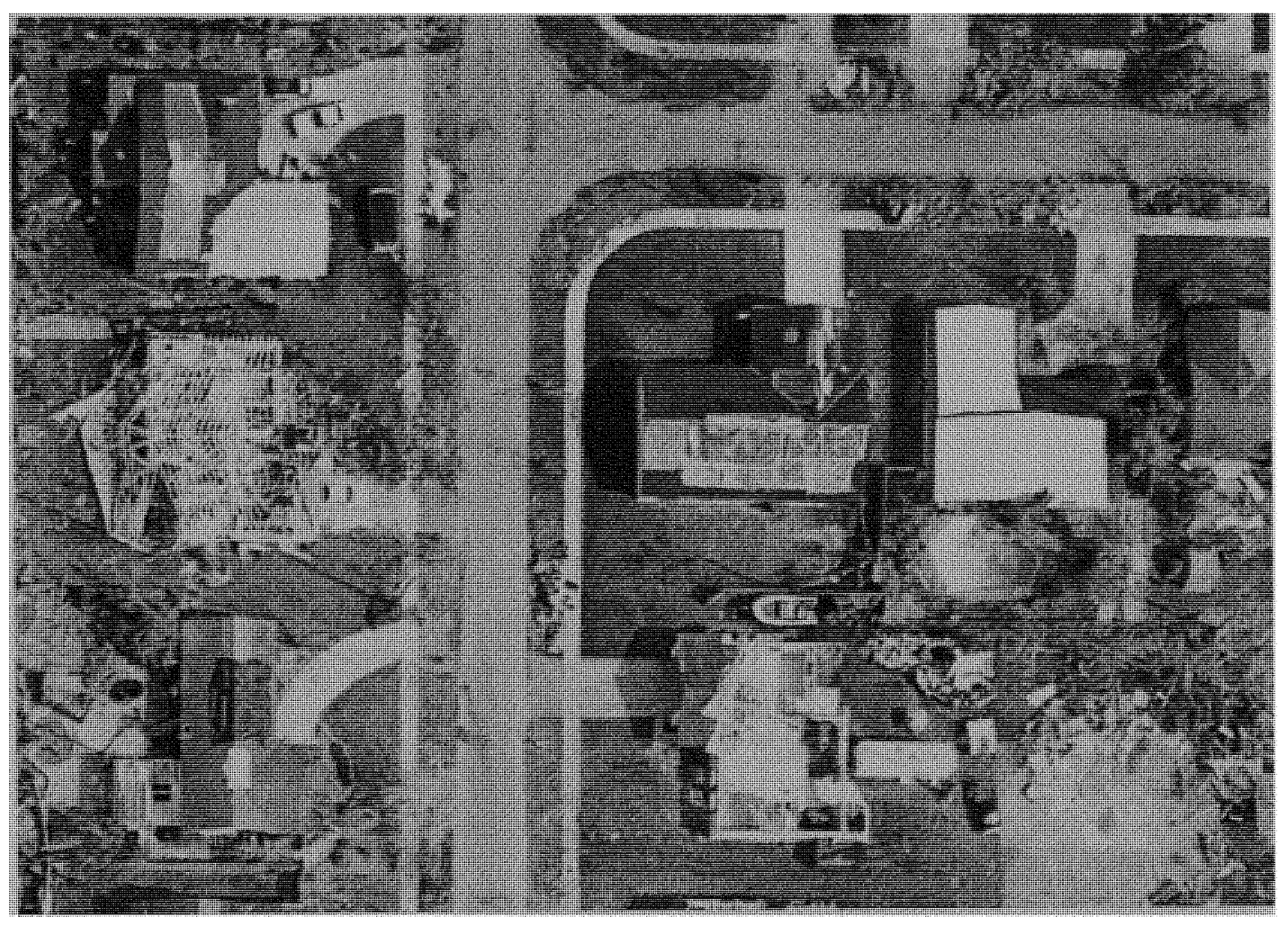

Figure 1.6. Variable roof system damage.

This figure shows some single-family homes. Some of them are highly damaged while others have minor damage. Minor damage includes only roof cover and sheathing while major damage includes roof truss and gable end damage. In case of the house, which has the roof truss, damage the wind might have blown perpendicular to the gable end. Those houses, which stood in the wind path, had minor damages to the roof cover and the sheathing. The wind direction was from east to west. 


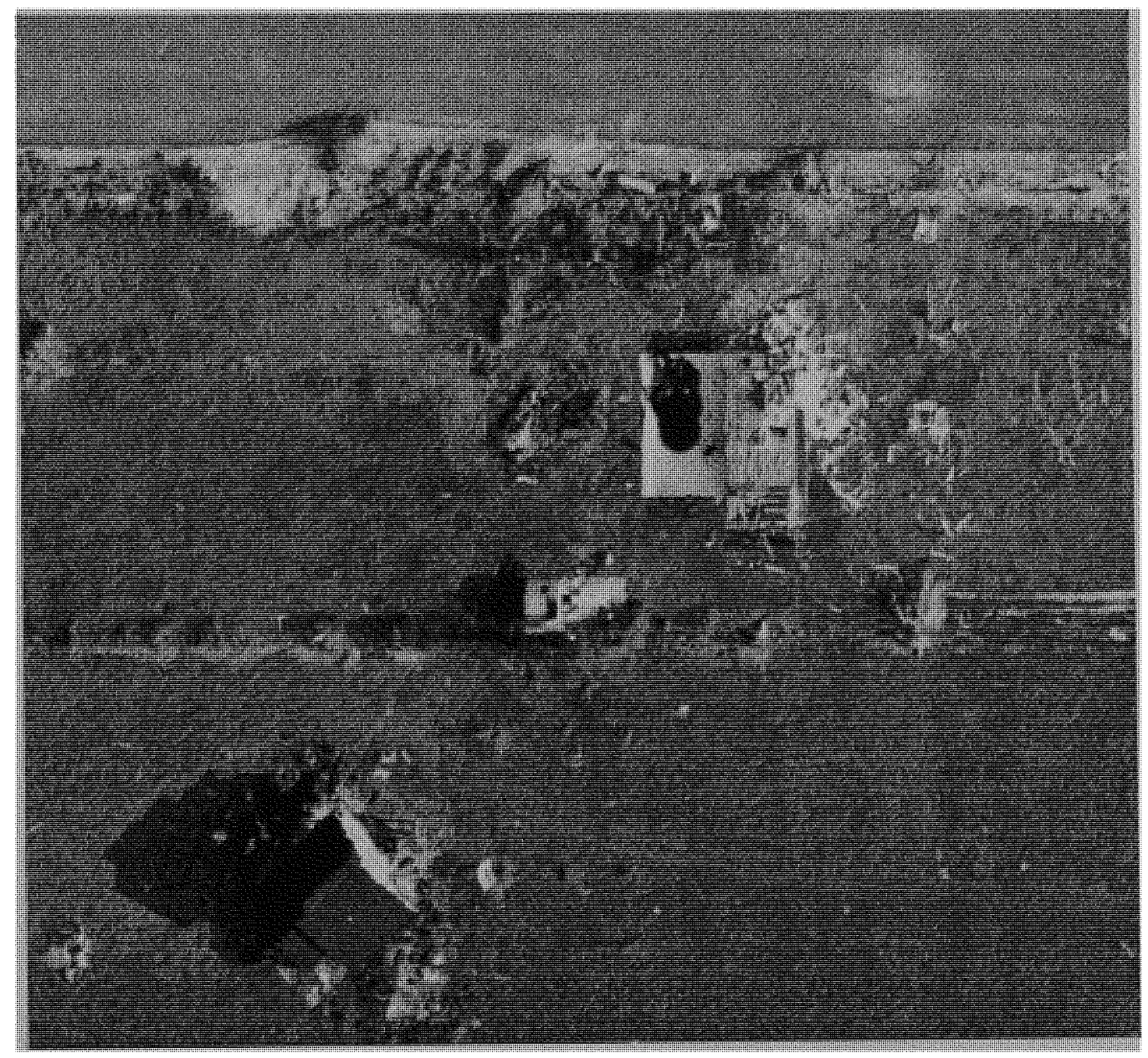

Figure 1.7. Comparison of damage between two isolated houses.

The figure shows two single-family houses. One was partly damaged and the other was badly damaged. The one that has been partly damaged has wind borne debris surrounding the house and debris might have been accumulate from the house that has been badly damaged. The house that has been severely damaged has major structural roof damage. The entire roof frame has been damaged including gable ends. The wind direction cannot be predicted from the damage and there are no major trees surrounding the houses to sustain the wind impact. Debris can be found all around the damage house. 


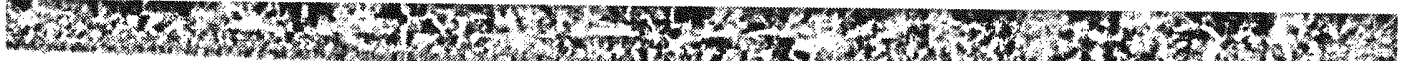

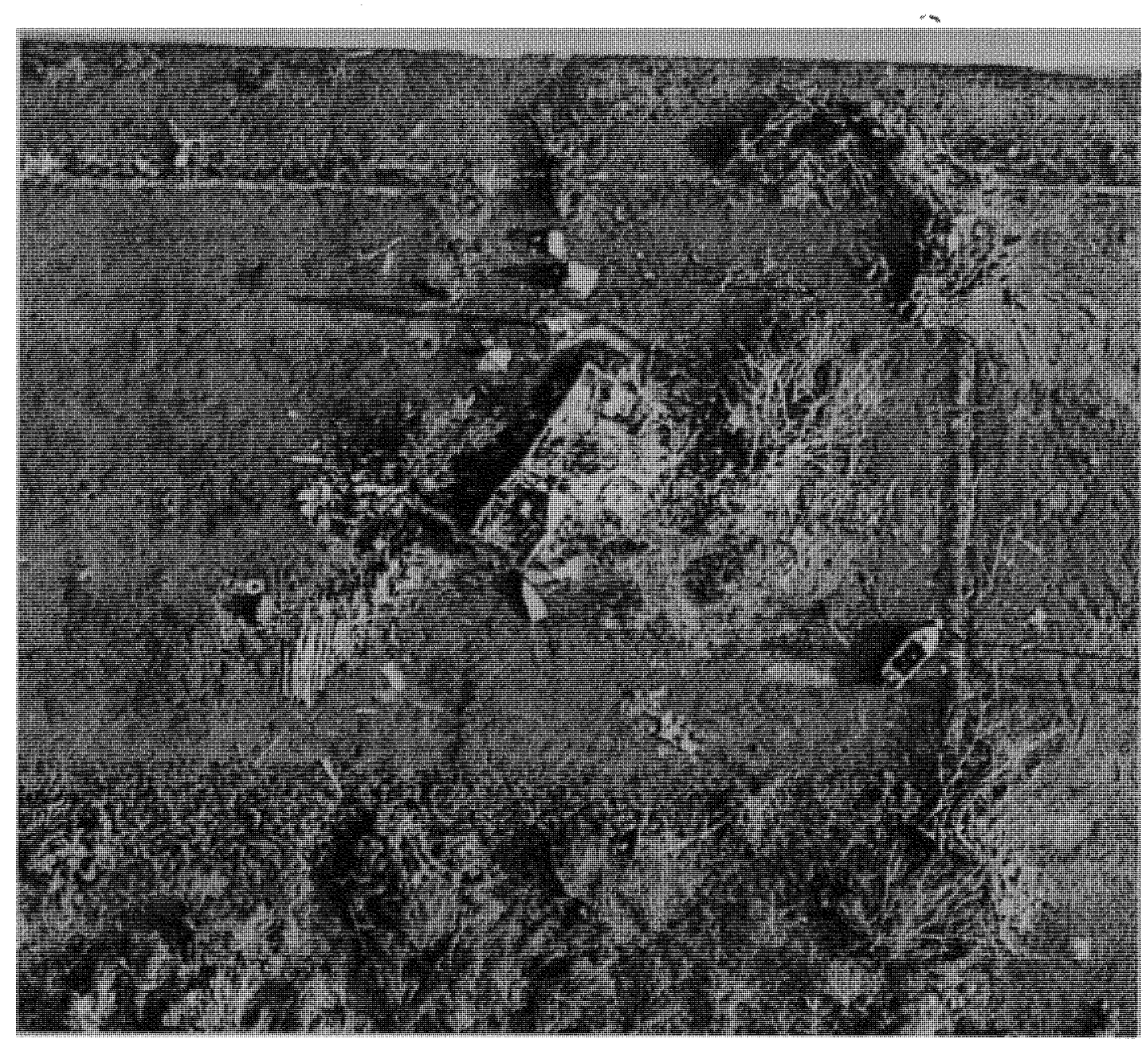

Figure 1.8. Collapsing of the roof system.

This figure shows an isolated single family home surrounded with small trees. The house has been severely damaged with the entire roof is reduced to rubble. Even the dry wall has been shattered. The foundation of the dry $w$ alls $w$ as $n$ ot so a dequate to r esist the wind velocity. The dry walls rely heavily on the roof system to provide lateral support. When the roof structure fails, the wood-frame dry walls may lack the strength by themselves to withstand sever wind loads. Numerous trees can be found around the house. 


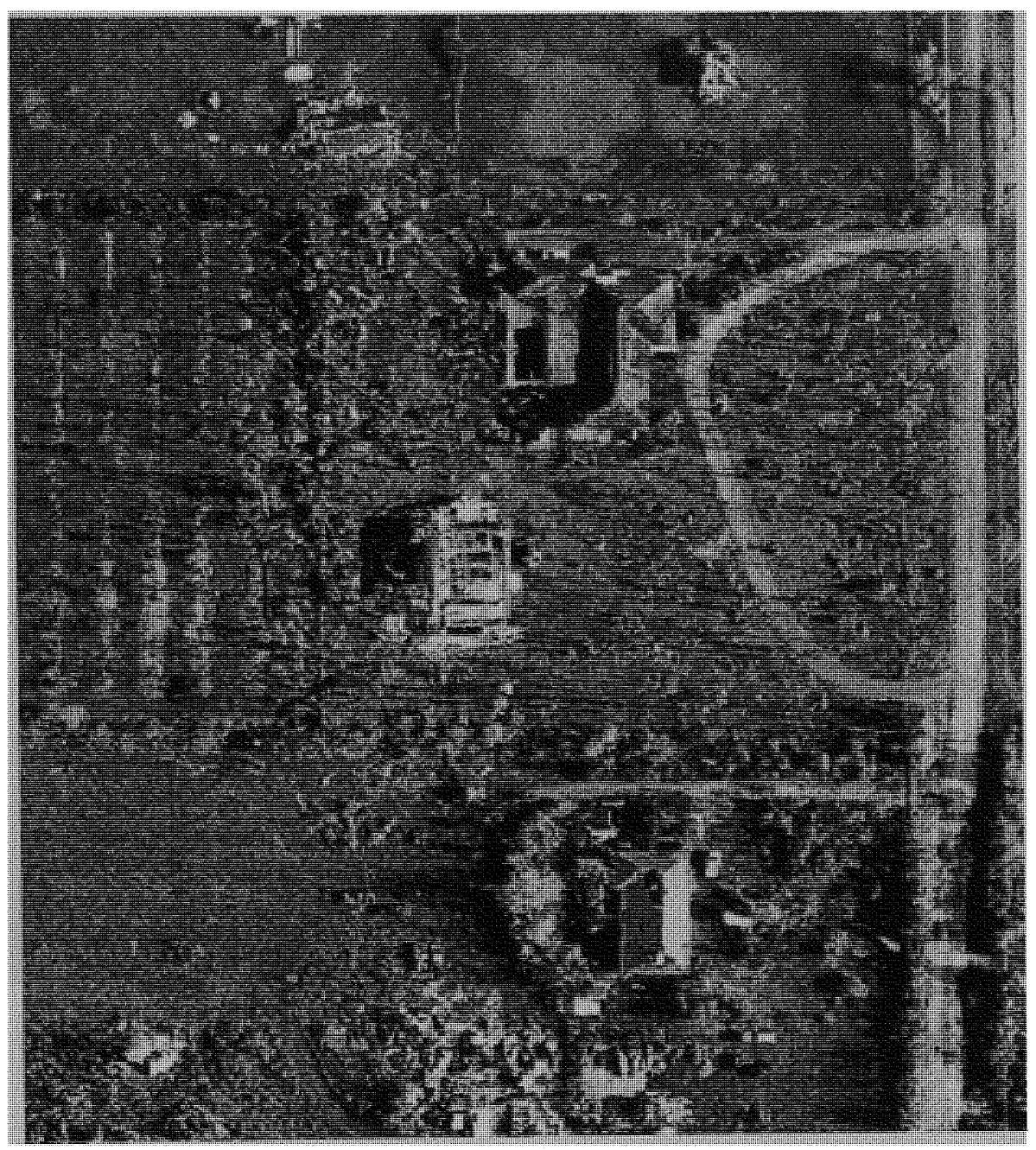

Figure 1.9. Roof lacked bracing support and ridge blocking.

This figure shows few scattered single-family homes. Some of the houses were badly damaged while others had minor damages. Major damage could be observed in the house having a roof with a gable end than the hip roof. In case of the gable end it got separated and there was inadequate connection between the wood roof framing. Also due to lack of bracing support and ridge blocking there was an inward collapse. Debris can be found surrounding these damaged houses. There were few small trees surrounding the houses, which could not provide enough protection to these houses. 


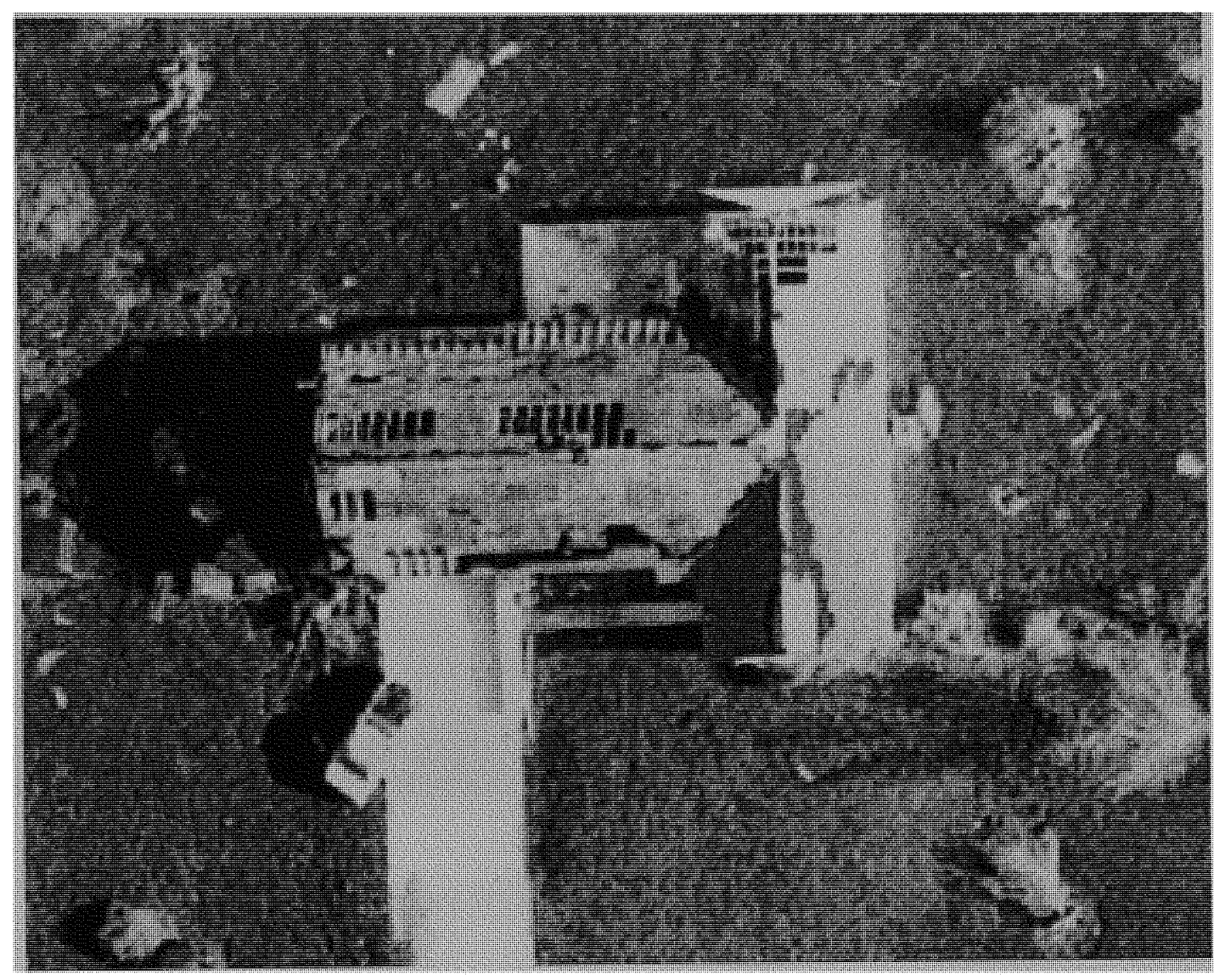

Figure 1.10. Blown roof cover and sheathing.

This figure shows an isolated single family home. The roof cover has been blown off. In some cases sheathing were missing and the wooden truss can be observed. The wooden truss was structurally very strong and hence there was no displacement and it was intact. Small amount of debris can be seen scattered around this house but they are not wind borne debris. One of the gable end got detached which might be due to inadequate connection between the wall and the truss. 


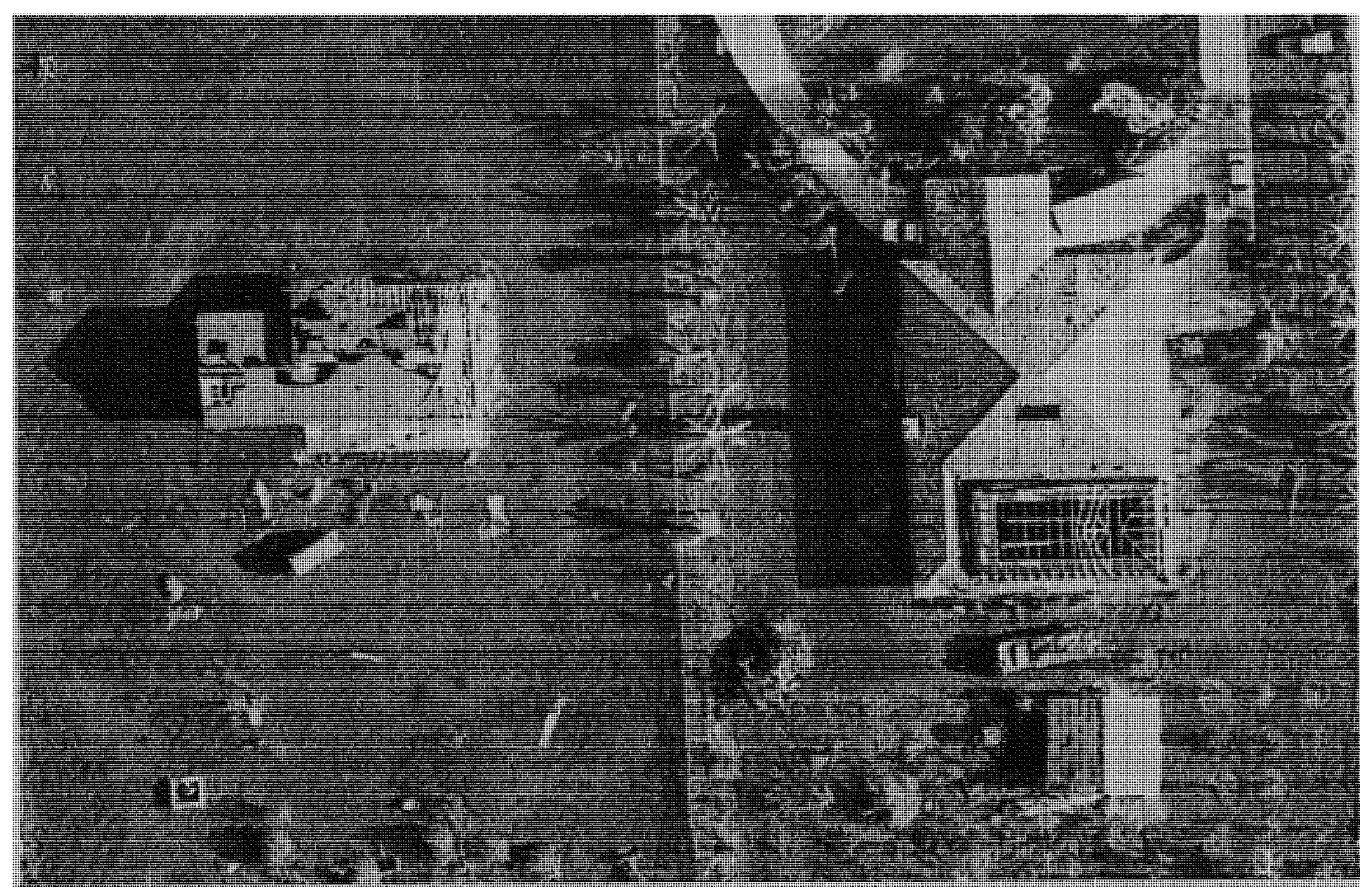

Figure 1.11. Destroyed gable-ends.

This is a typical example of single-family homes. The house having the differential roof elevations, part of the roof cover and the sheathing was blown off and the sheathing was exposed. The wooden trusses got inclined due to strong wind force. Similar is the case for the house in the left hand side. The roof of this house was partly damaged and one of the gable end was completely destroyed. The trusses fell into one another due to lack of secondary connection between the individual trusses. 


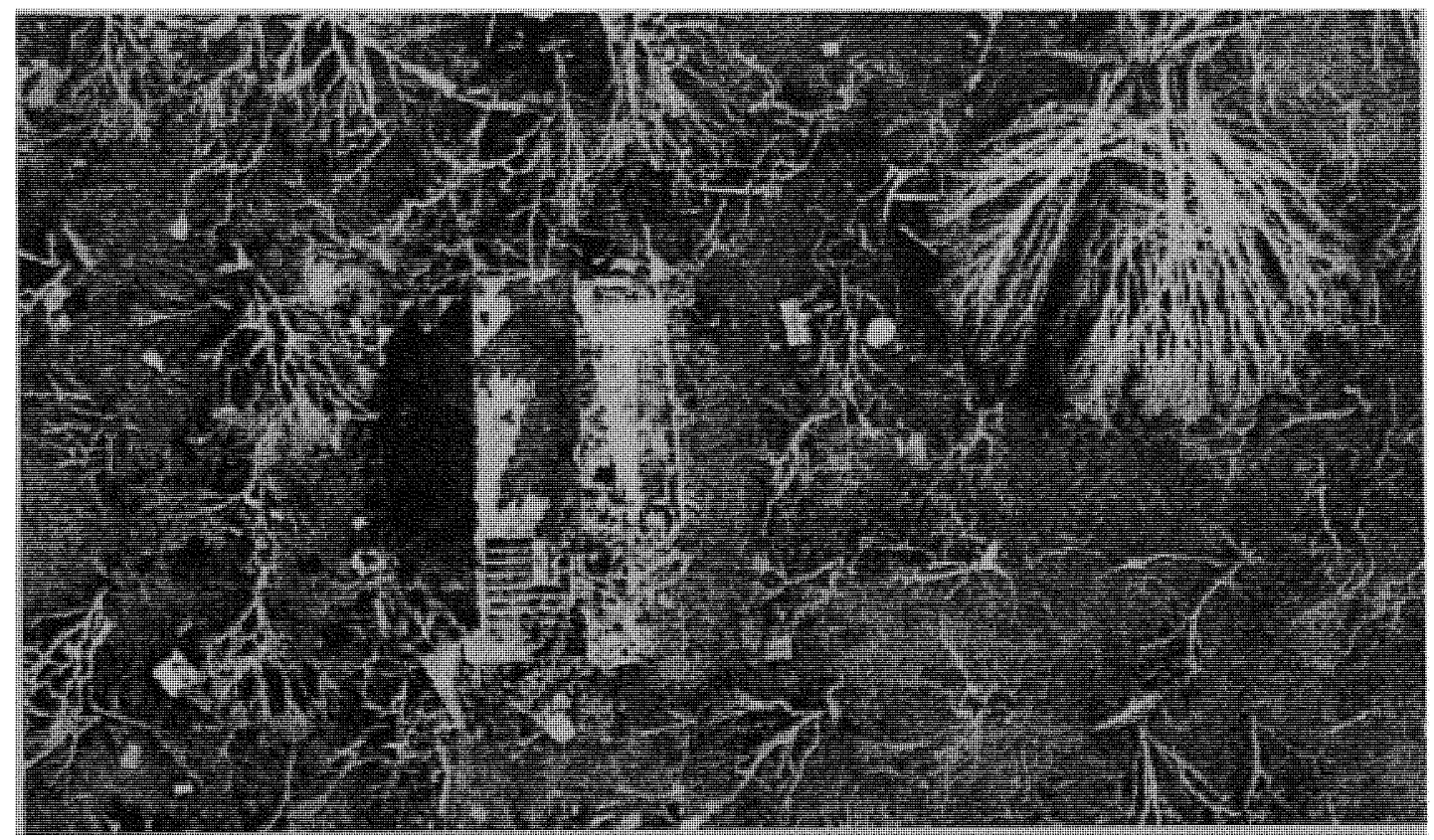

Figure 1.12. Exposing of truss skeleton.

This figure shows a single family home with $75 \%$ damage to the roof. Some portion of the house was damaged due to the trees surrounding the house. The front right hand corner was severely damaged. Even the walls have been extensively damaged as a result of which the gable end in the front is missing. Its is very usual that the truss in the corner portion was also destroyed. The missed sheathing exposed some portion of the truss, which has minor damages. Certain amount of the debris can be seen around this house. An over all damage of $80 \%$ is estimated. The wind was blowing south to north direction so the front portion was struck by the wind directly perpendicular to the gable end and hence major damage can be seen occurred in the front rather than the back portion. 


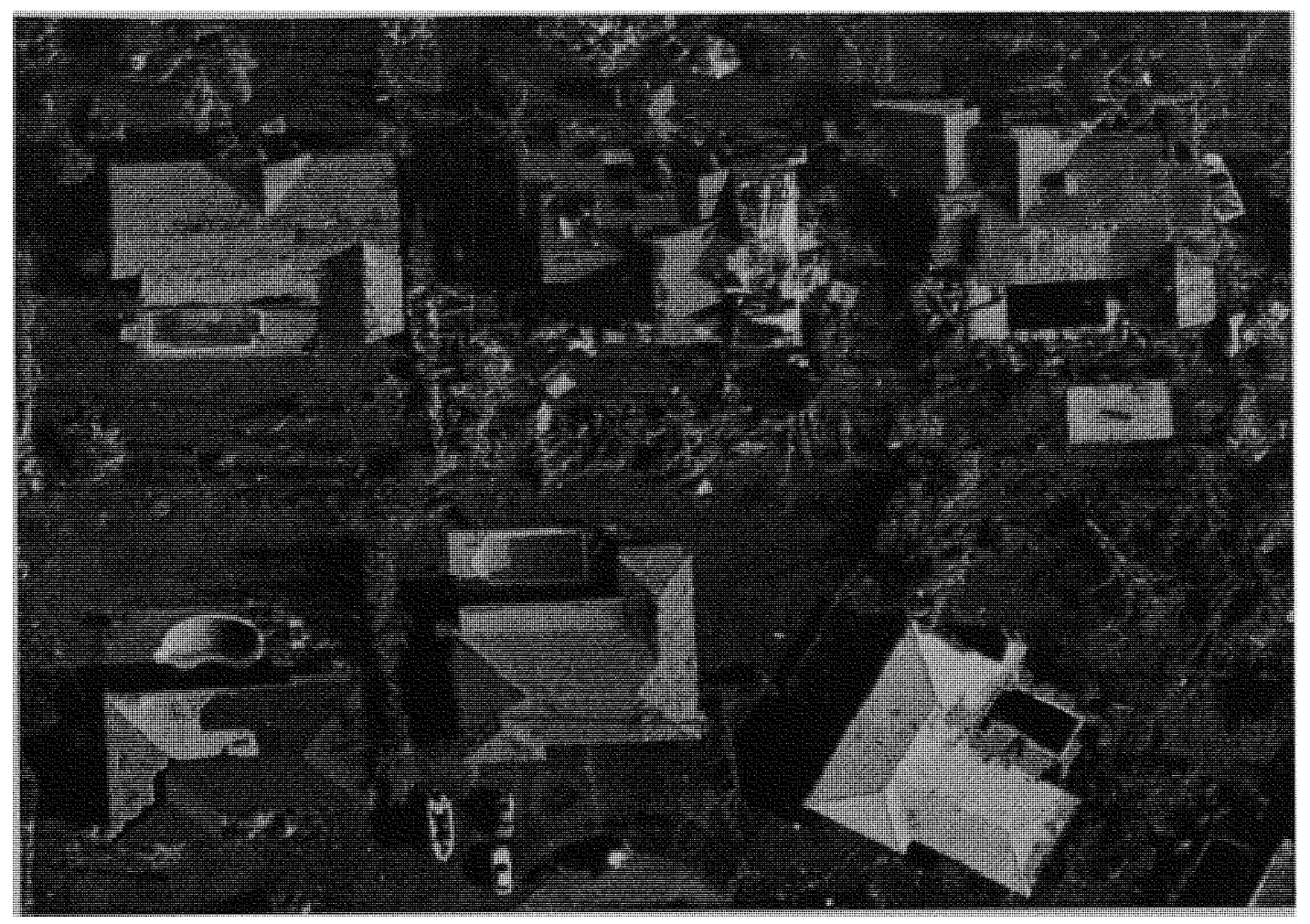

Figure 1.13. Curved wind path.

This figure shows clearly the wind path and destruction of the hoses along that path. The wind was blowing from south-east to north taking a curved path. In case of the first house the entire roof cover is missing hence there was $100 \%$ damage to the roof cover. In case of the house in the middle of the second row. An over all damage of $40 \%$ damage could be observed. The wind struck that house at an angle damaging one of the gable-end along $w$ ith some trusses on the right hand side. The roof cover and the sheathing got collapsed inside the house. Small amount of debris can be seen around the house. The wind blew from the gap between the two house and hence established a clear path to damage the middle house in the second row. 


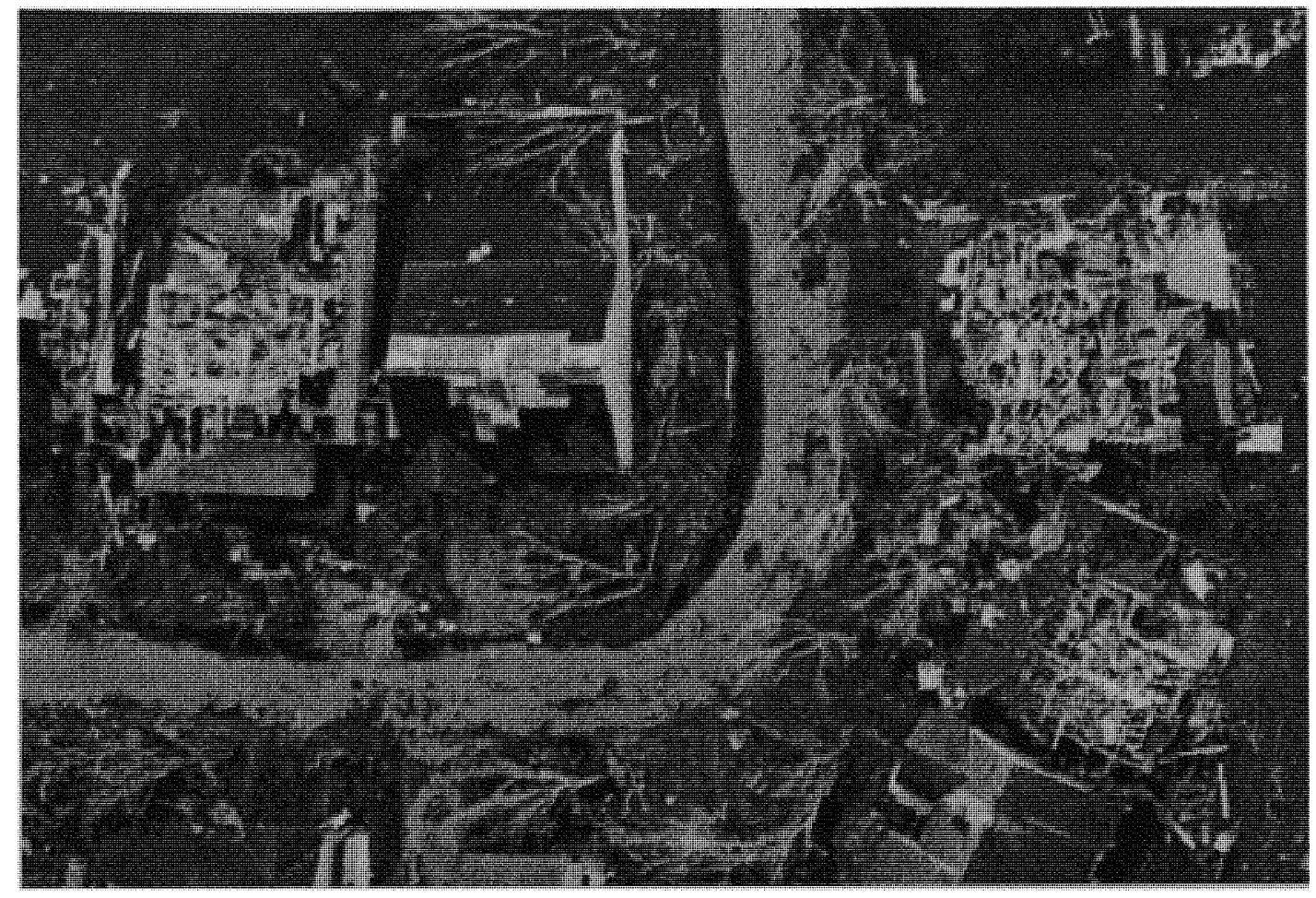

Figure 1.14. Overall damage of $100 \%$.

This figure consists of four houses, which has an overall roof damage $100 \%$. In these units, it shows that roof structures and the walls have been destroyed. It is predicted that there was a small tornado that went through these buildings as debris could be found at some far distance. The wind had blown from right to left. One of the houses that had very less roof damage the reason for that is the building is oriented differently and the wind had an aerodynamic path to destroy the roof system of the house just behind this house. 


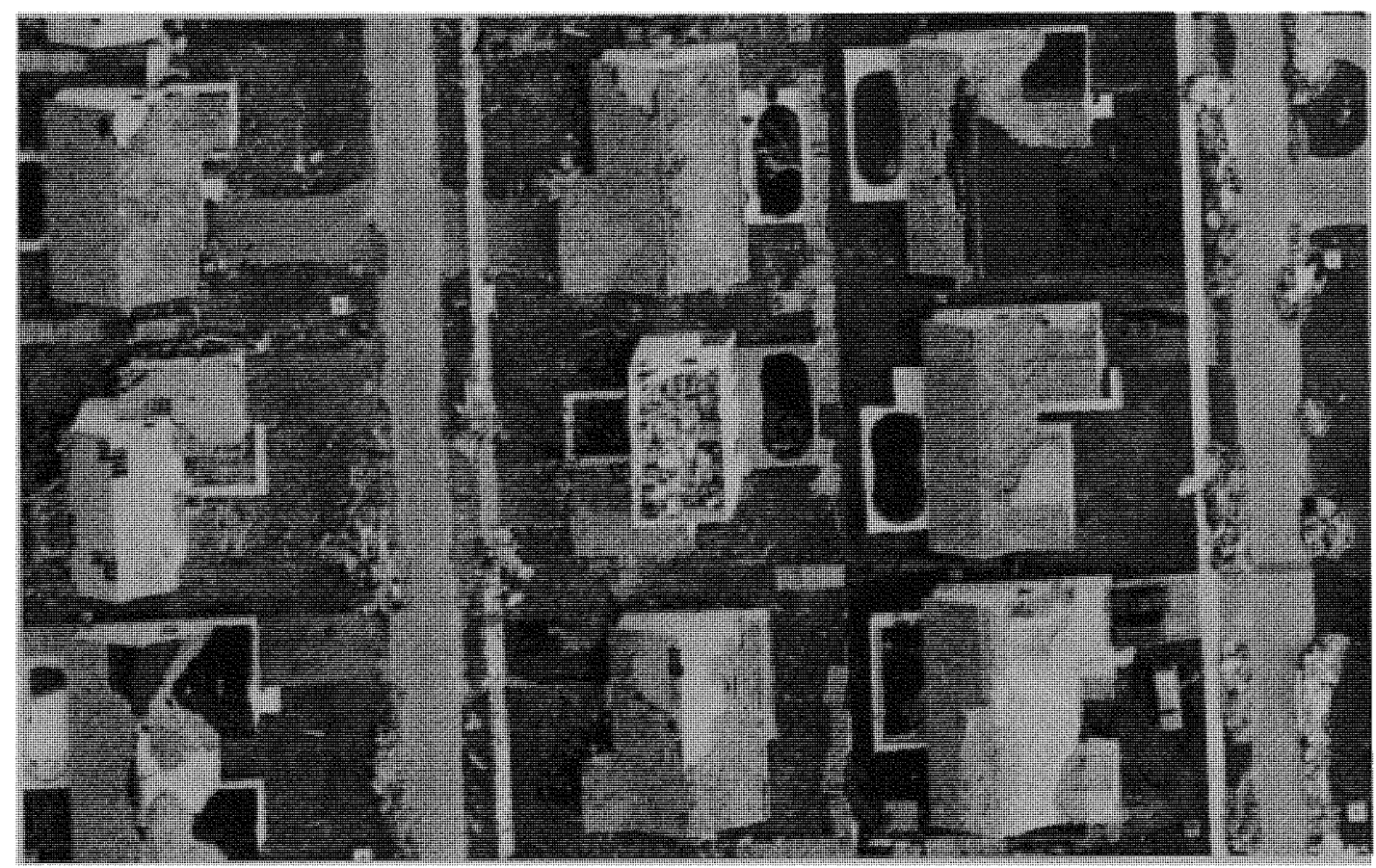

Figure 1.15. Inward collapse of roof trusses.

This figure shows that the house in the middle shows that the whole roof has gone. Most of the trusses are scattered within the house. As this picture shows, trusses did not blow from the house. The reason could be following: first, this house lost all its roof sheathings and the trusses were exposed to rain. Then the trusses became week all the roof framing collapsed. Second, the house had inadequate nailing and connection of the roof framing. Another point to be noted is that the adjacent houses were not so severely damaged which means that there was some inadequate bracing connection between the truss members and hence there was a collapse of the structure. 


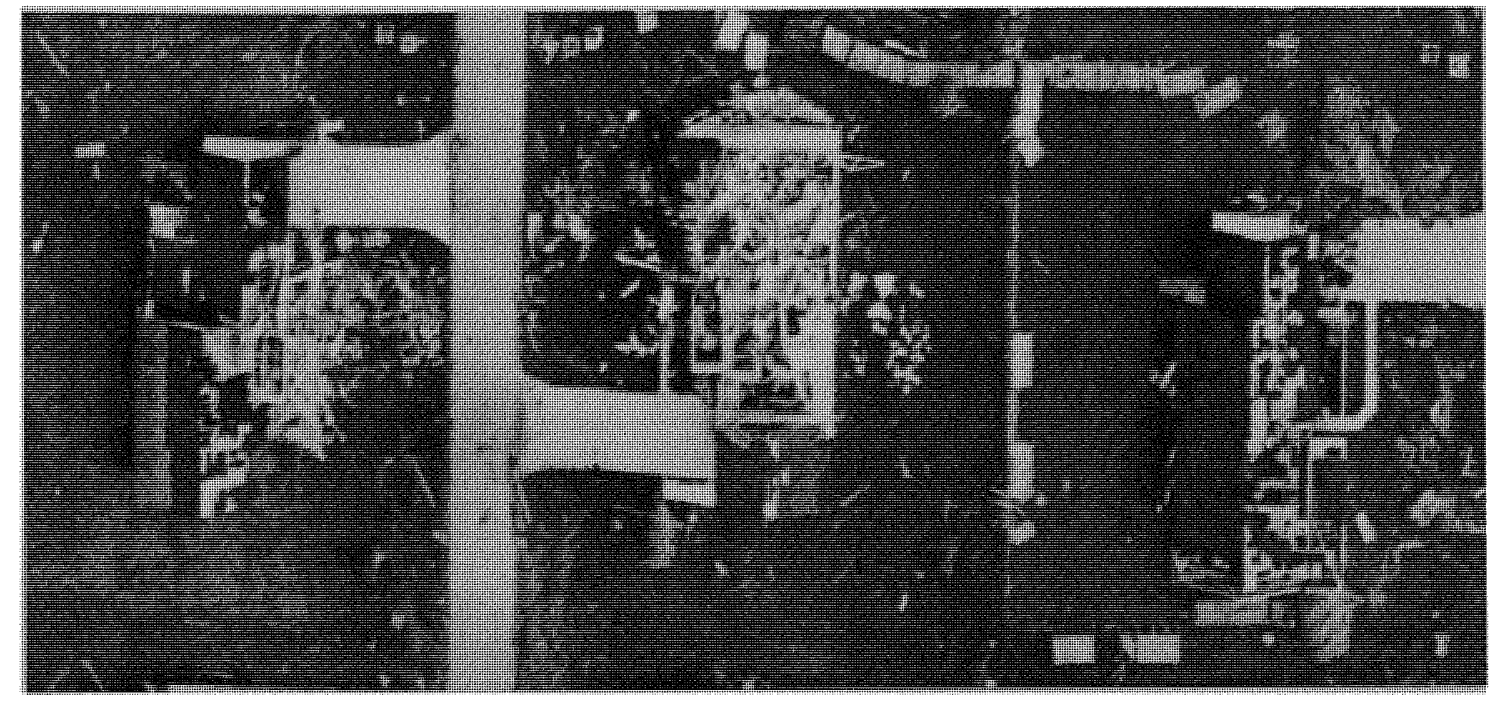

Figure 1.16. Debris damaged the adjacent house.

The above figure shows three single-family homes of which the middle house has been badly destroyed. The wind blew from east to west and striking the middle house damaging the entire roof frame. The over all roof damage is $100 \%$. Consequently debris from this middle house flew and fell on the building on the left hand side and damaging the r oof and the dry wall of the building. Any extension of the roof b eyond the w all surface elevates wind pressure on both the sheathing and framing systems at these locations. 


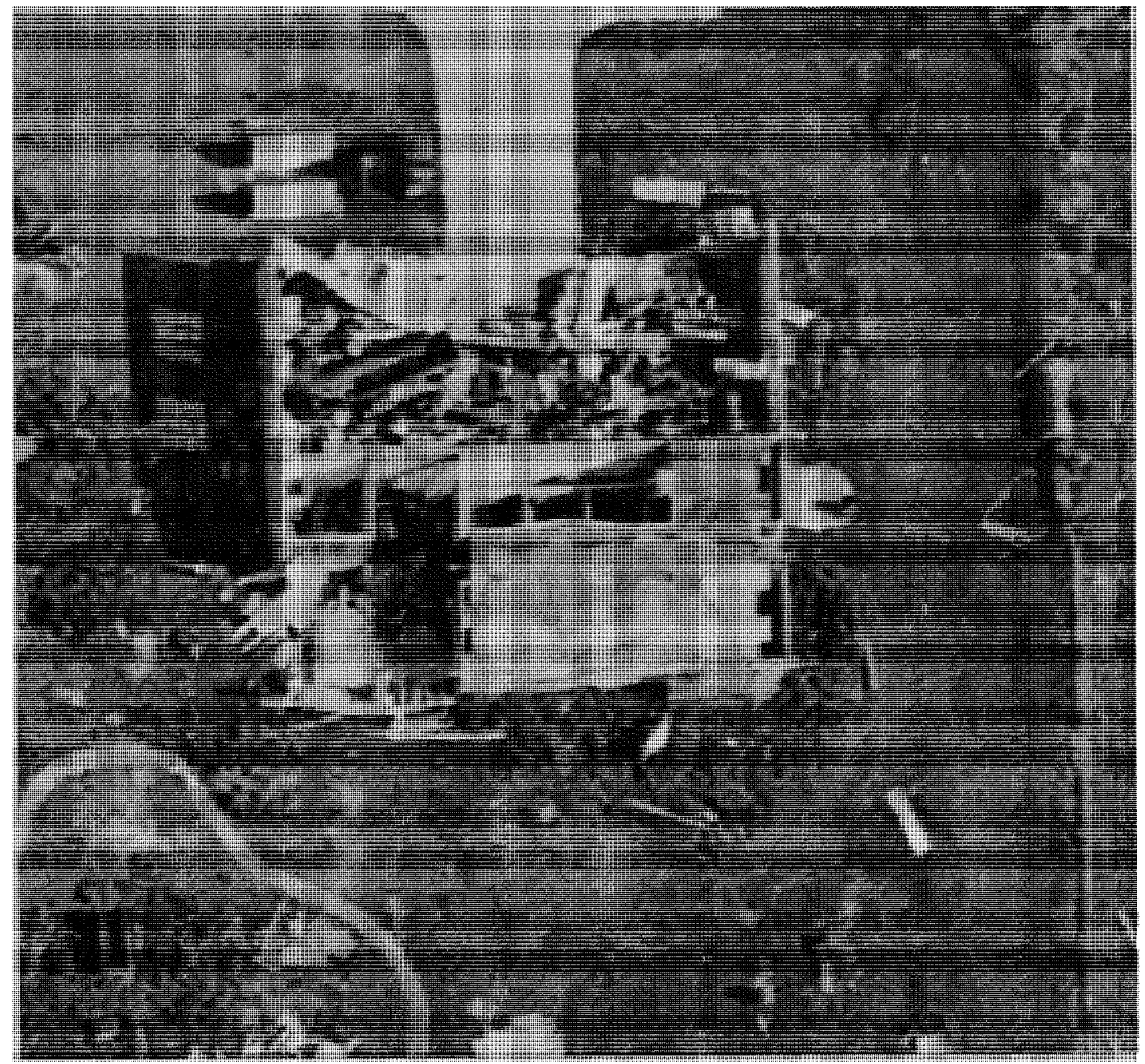

Figure 1.17. Weak foundation for exterior walls.

This figure shows a complete failure of the wood framing system including the dry walls. As seen in the above figure the exterior walls collapsed. The dry wall failure might be due to inadequate corner connection. The wind blew from north to south. The wind pressure was high enough to damage the dry wall and then the timber roof collapsed. All the debris can be found inside house. 


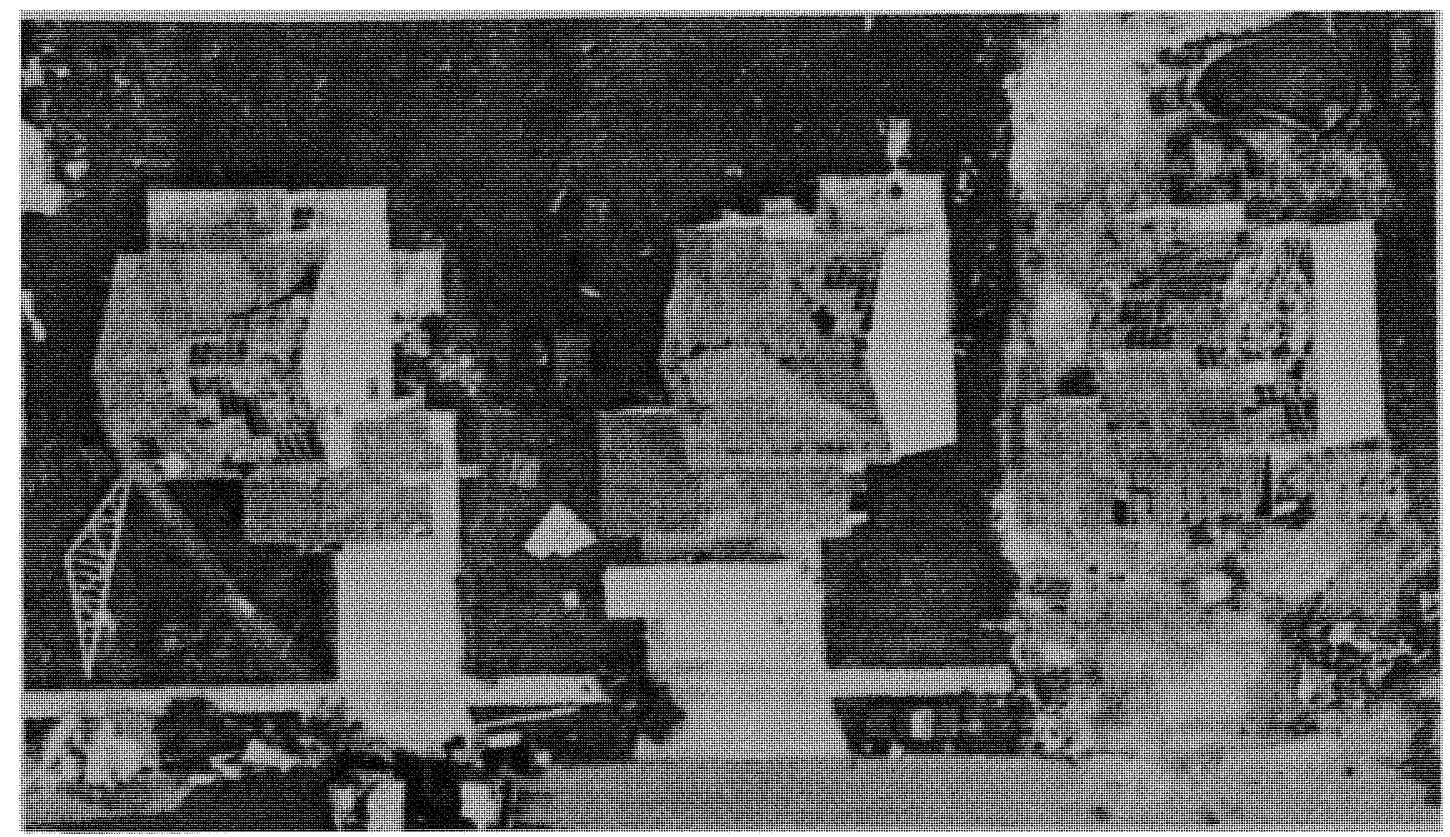

Figure 1.18. Comparative destruction of three single-family homes.

This figure gives comparative destruction of three single-family homes. The two houses on either end have major roof damage. Gable end failure is very prominent. The failure end seems attributable primarily to poor or nonexistent bracing between gable-ends and rest of the structure. B racing of the roof framing at the plane of the roof deck during construction and supplemental distribution of inward and outward forces into the roof "diaphragm" when gable-end walls are subjected to high winds. 


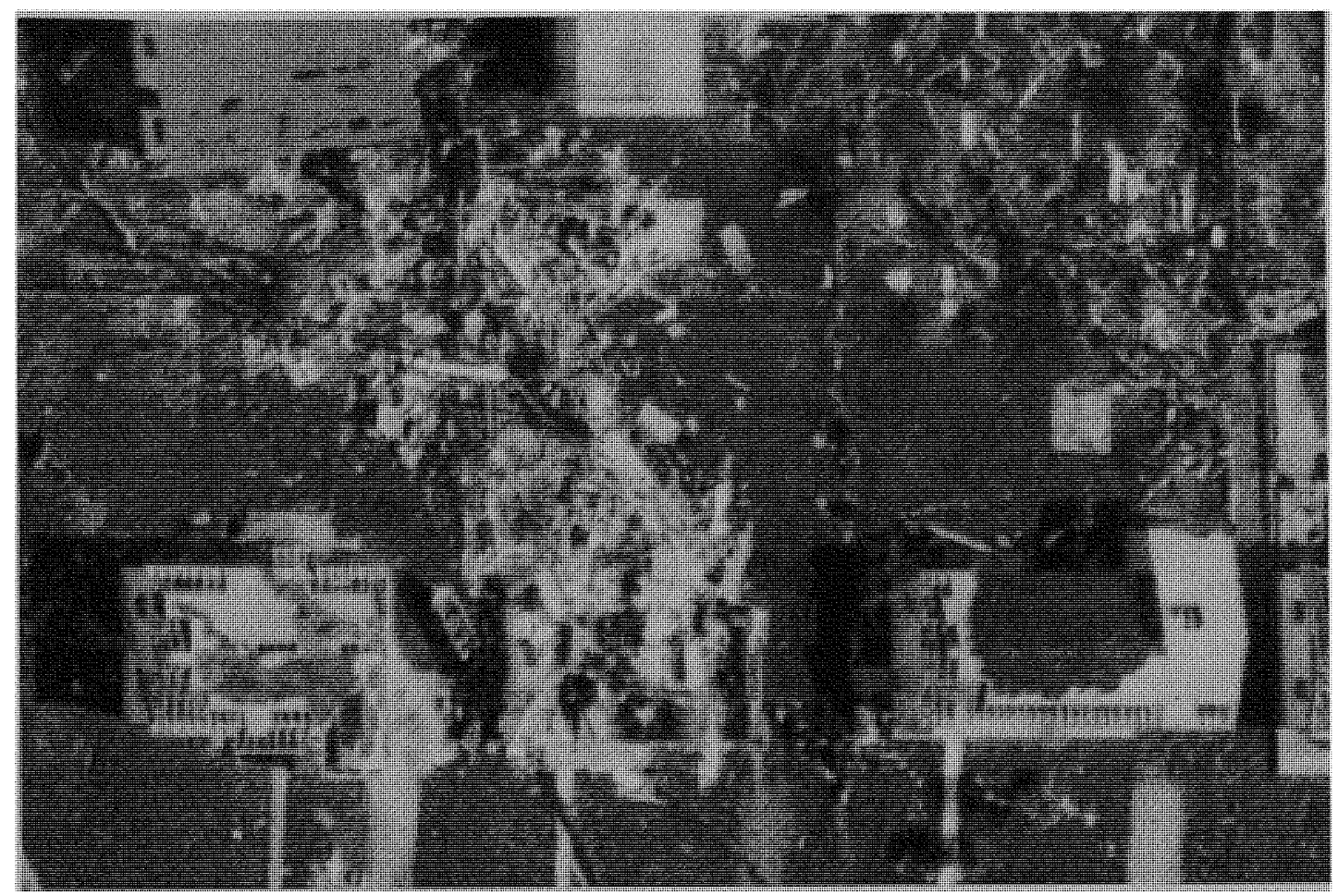

Figure 1.19. Insulation of the ceiling was saturated by rain.

This figure illustrates complete failure of the roof as well as the dry wall of the building in the middle. With two adjacent building partly damaged the over all damaged for the building in the middle is about $95 \%$. What might have happened was the insulation of the ceiling was saturated by rain. The loss of ceiling strength due to water saturation and the increased weight of the wet insulation caused widespread collapse of ceilings. The loss of the ceiling also contributed to gable-end wall failures due to diminished lateral support at the base of the gable-end walls. The failure of the walls might be due to improperly reinforced masonry walls or due to omission of reinforcement at the intersections or corners. 


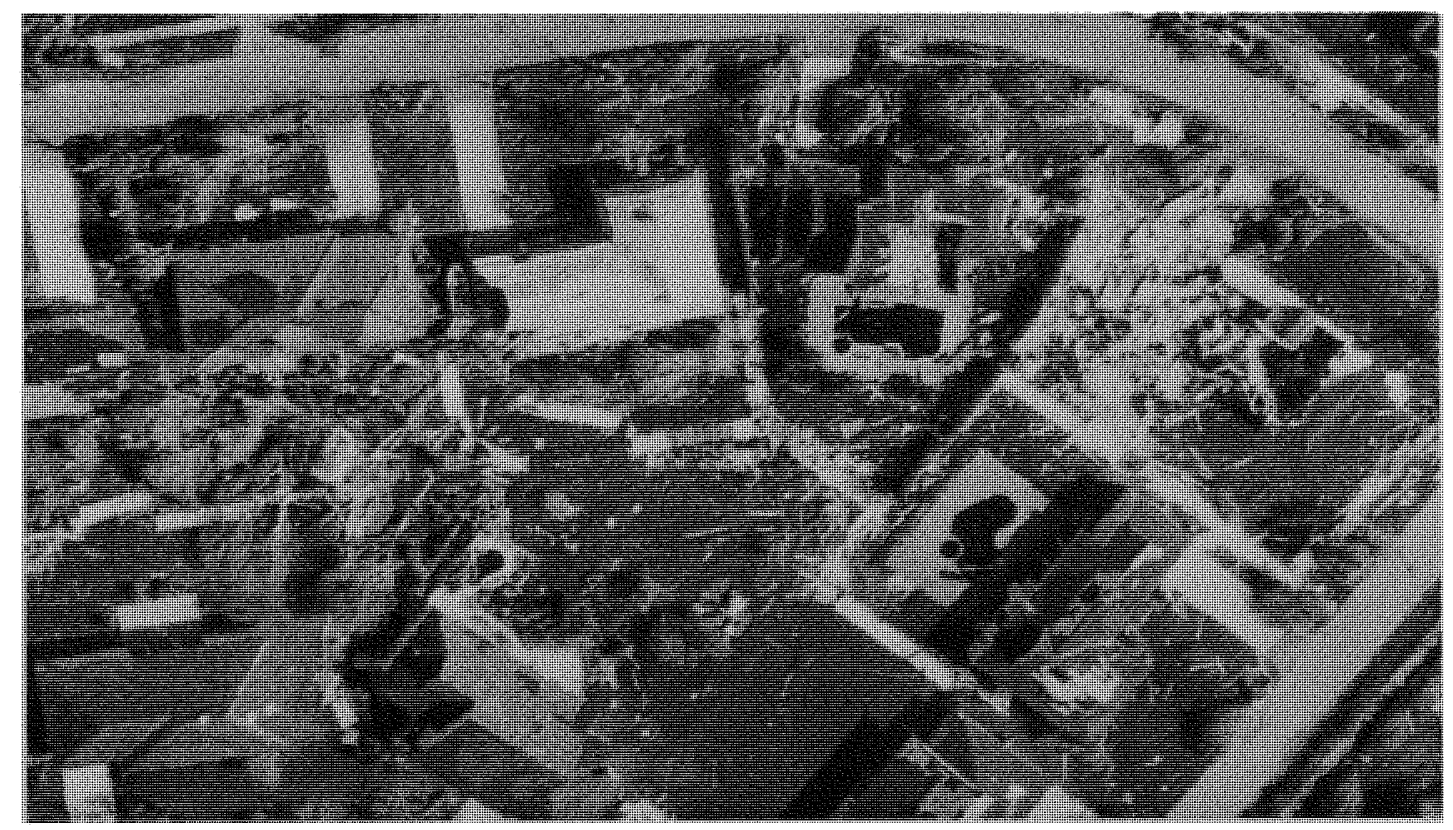

Figure 1.20. Failure occurred due to development of suction force.

This figure illustrates wind damage was caused by wrenching and bending forces imposed by gusting winds and the rapid increase in wind force as wind speed increases. With a doubling in wind speed the wind force on the structure increases four times. The wind struck the buildings produced pressures against the building on the windward side and the suction, which pulled the building on the leeward side. Failure occurred might be due to external pressure and suction on the wall combining to push and pull the building off its foundation. 


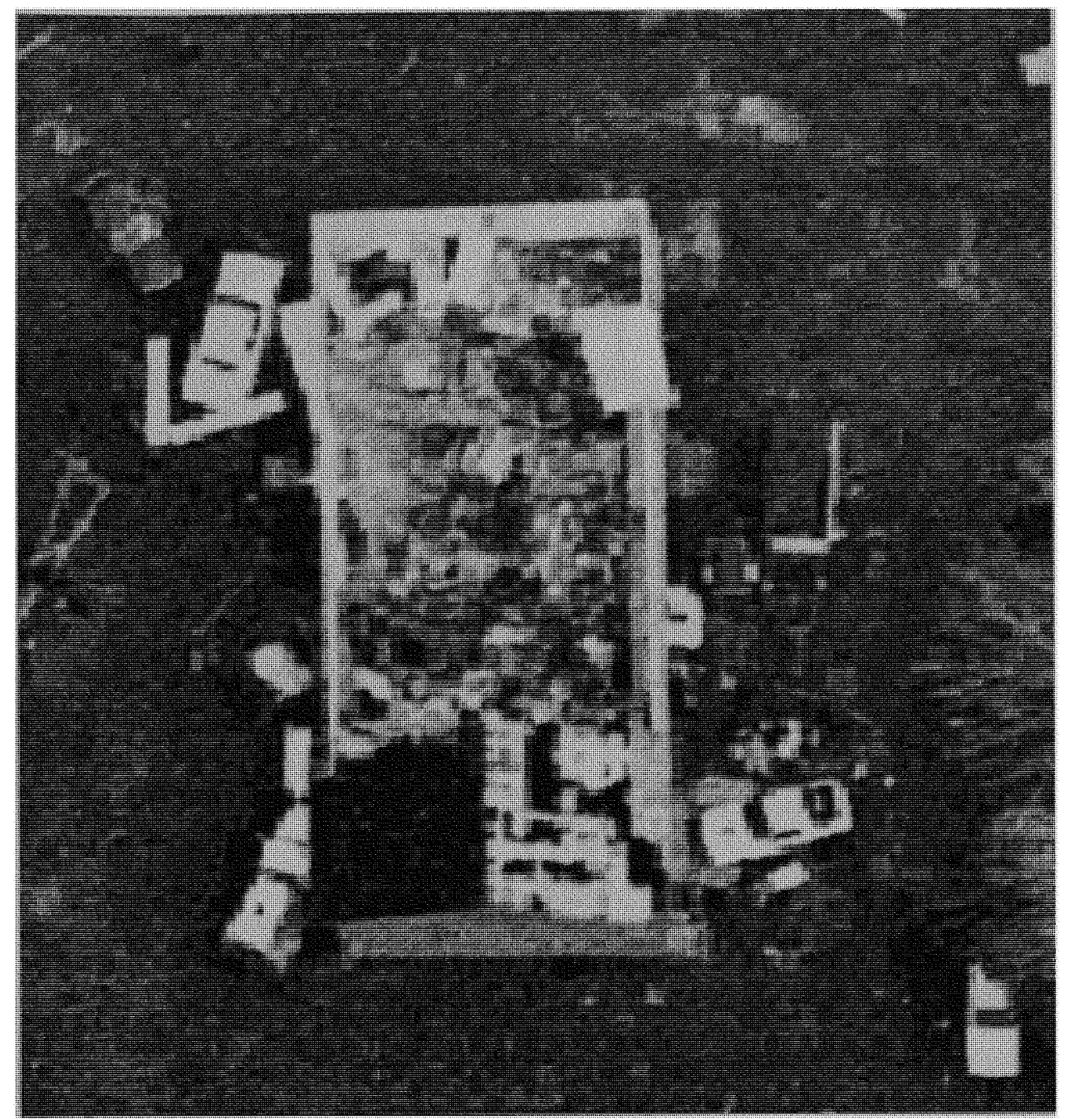

Figure 1.21. Damaged isolated house due to pressurization and depressurization.

Complete collapse of the roof structure is clearly visible along with some portion of the walls. The roof system failure was attributed to the use of lightweight roofing material. Some roofs remained partially intact but the damage to windows, doors and internal partitions was significant. The house stands isolated and the wind's path was clear enough to produce pressure and suction through the damaged doors and windows to pull down the roof structure. There is a 50\% destruction of the gable end. 


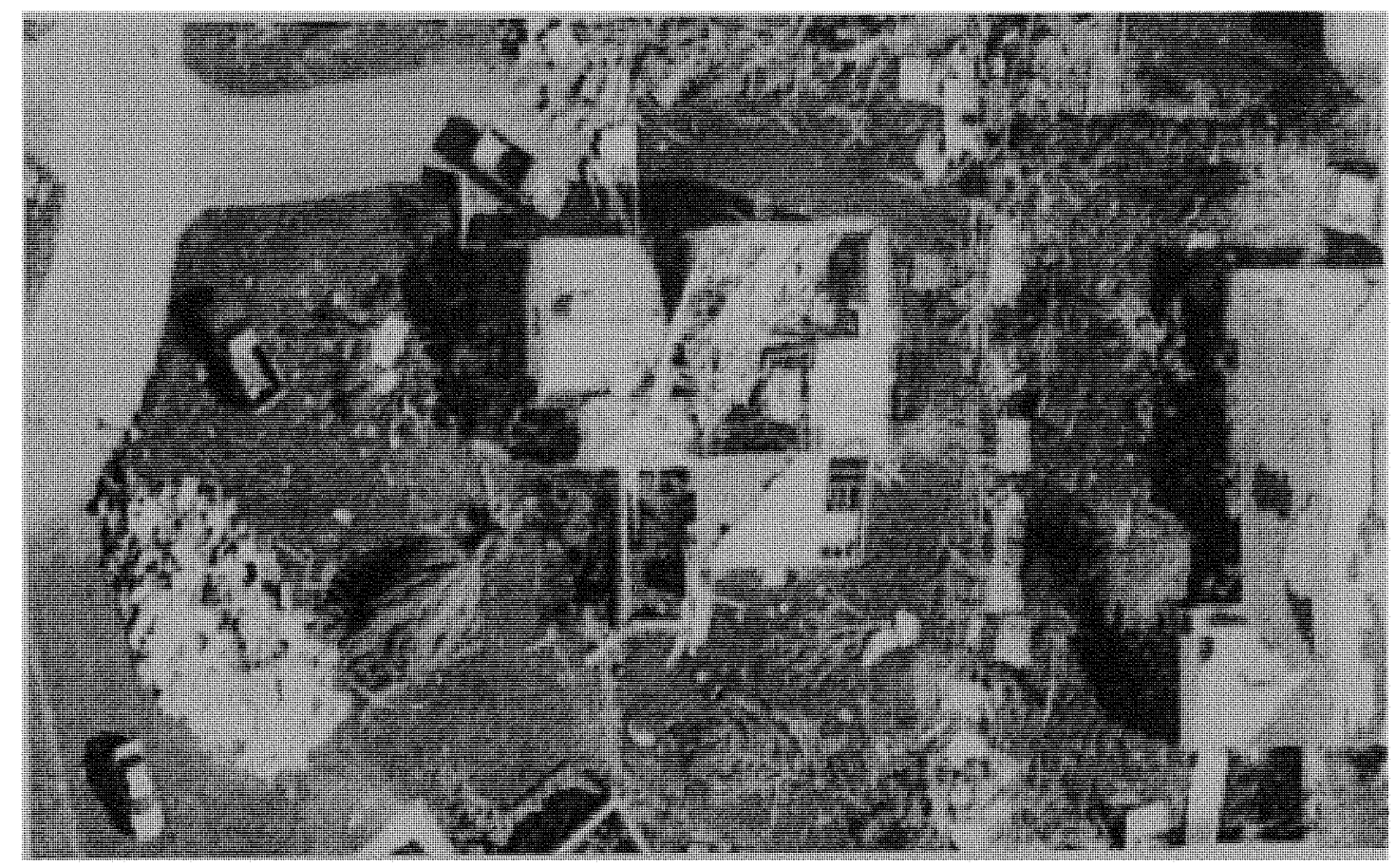

Figure 1.22. Wood-frame wall lacked strength due to roof failure.

This is an example of a two-story, wind damage house. The wood-frame second story of this house was stressed and crucial damage was the roof truss damage. When the roof structure fails, the wood-frame walls may lack the strength by themselves to withstand severe wind loads. Secondary lateral bracing should be evaluated, particularly for tall gable roofs on all types of homes. Rubble could be found surrounding this house. The wind direction was from east to west. 


\section{SINGLE FAMILY DUPLEX HOUSES}




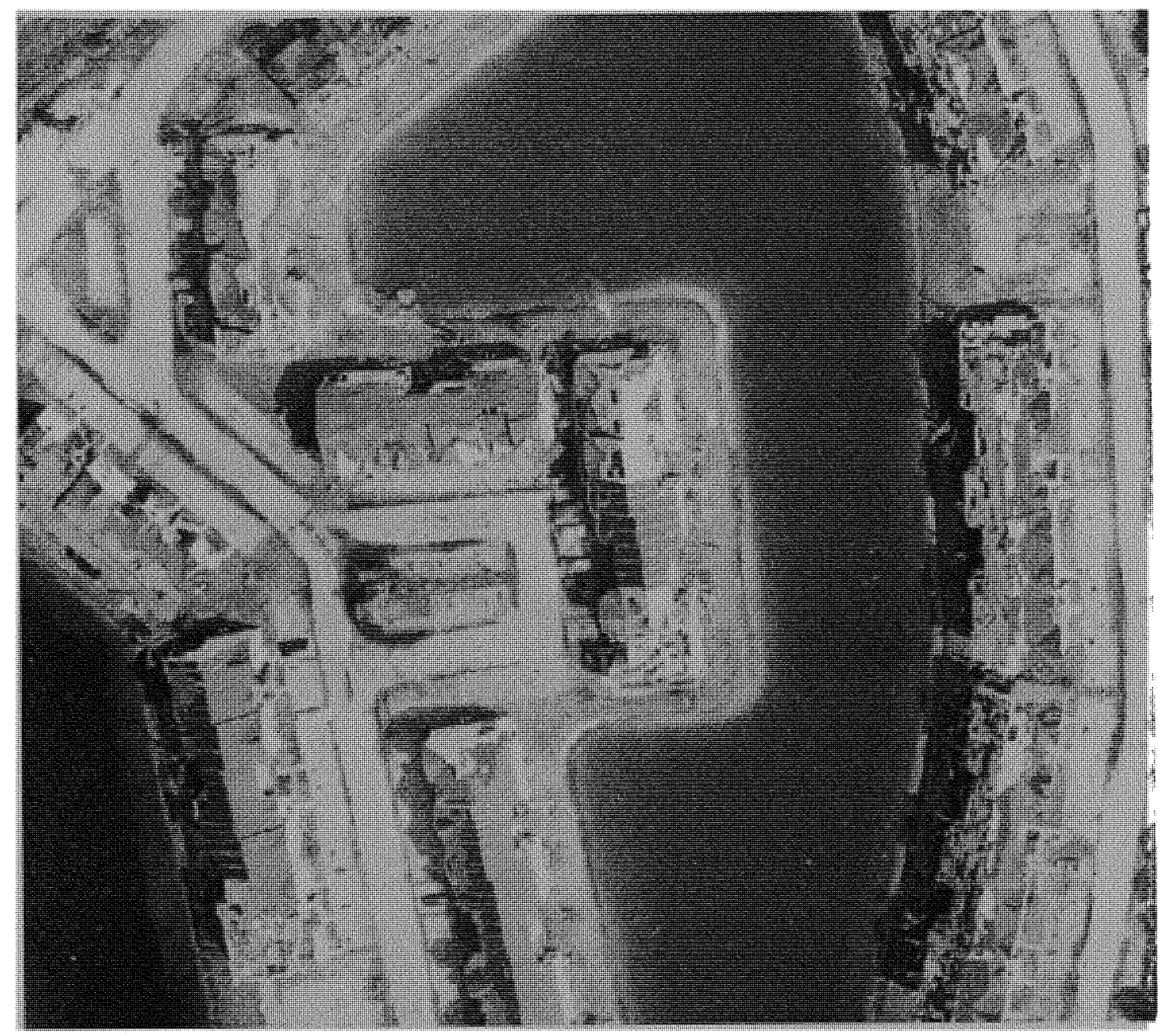

Figure 2.1. Clear wind path due to artificial lake.

The figure shows single family homes situated around the artificial lake. An overall damage $\mathrm{c}$ an be observed in these houses. There $\mathrm{h}$ as been no major roof $\mathrm{d}$ amage. The roofing system was intact. Major damages were the roof cover and sheathing damage. In some cases exposed trusses can be observed. The wind direction cannot be very accurately predicted, as there are no trees surrounding these houses. 


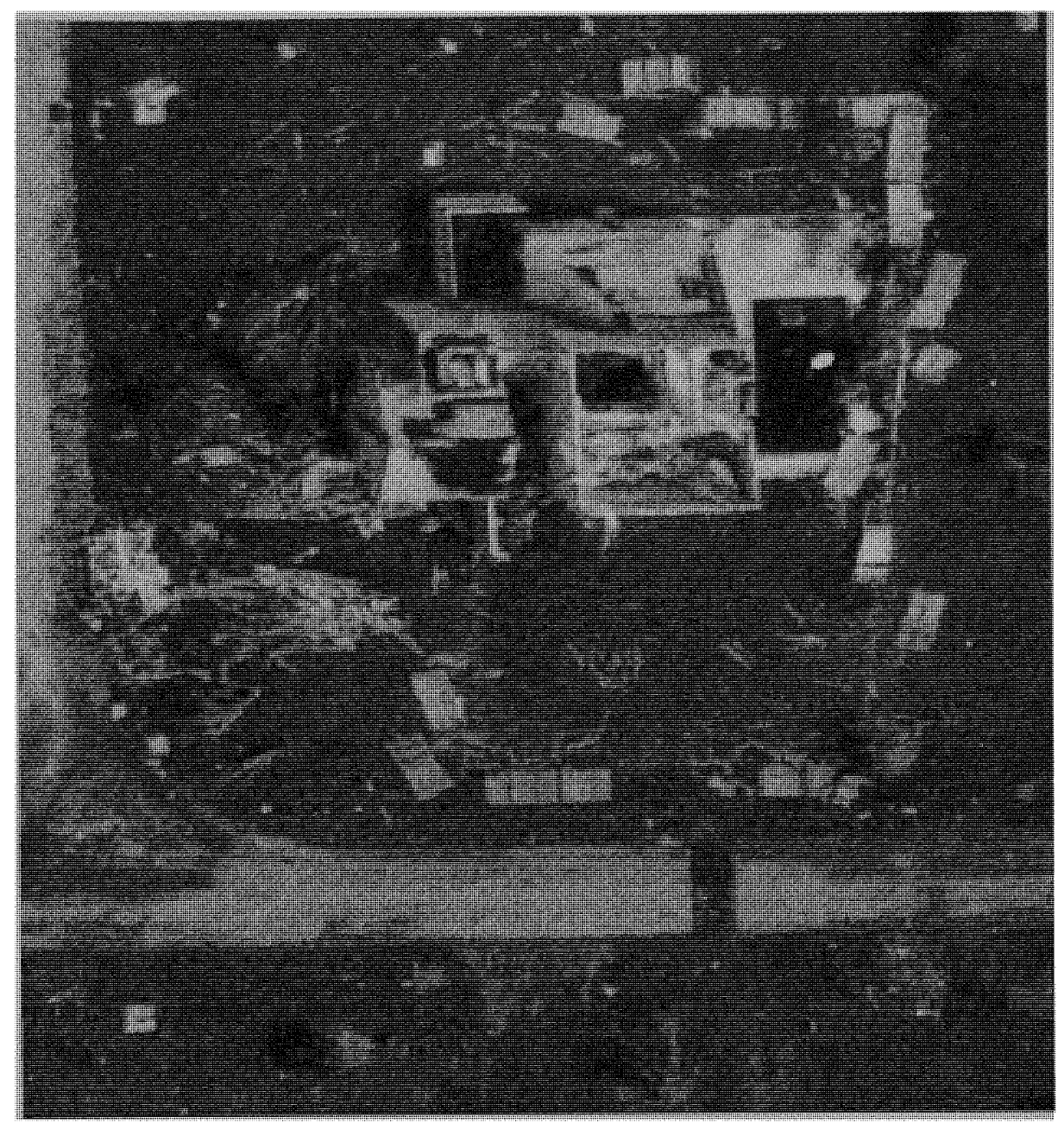

Figure 2.2. Collapse of roof truss.

The figure shows an isolated house, which has been badly damaged. The major damage is the roof sy stem. The entire r oof frame $w$ as not $v$ isible and d ebris $\mathrm{c}$ an be found all around this house as well as inside of this house. Some materials might have been collapsed inside the house. This house has differential elevations. There are no trees surrounding this house. Pieces of rafter, roof cover and gable end can be seen lying on the ground. A rough estimate of the wind direction can be made by considering the falling debris. The wind might have blown from north to south. 


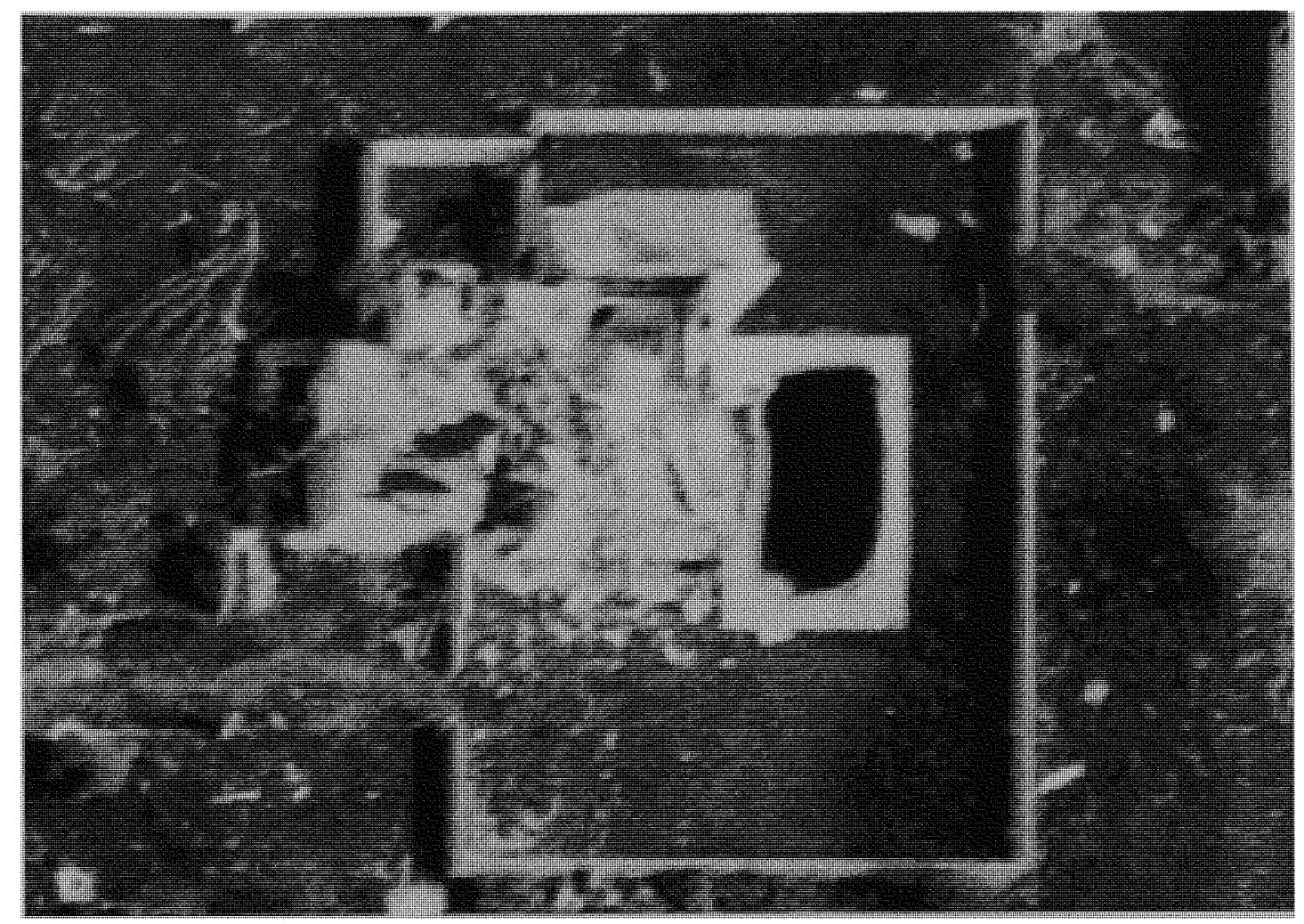

Figure 2.3. Isolated house with no barriers.

The figure shows a damaged isolated house. The roof cover, sheathing and ceiling drywall has been completely damaged. The wind direction can be clearly predicted from the damage and the trees. The wind direction is from north-east to south-west. The wind speed was so high that the entire roof cover was blown off. The trusses were also not structurally strong enough to resist the wind force. Moreover the house stood isolated and hence there were no barriers and hence major destruction. 


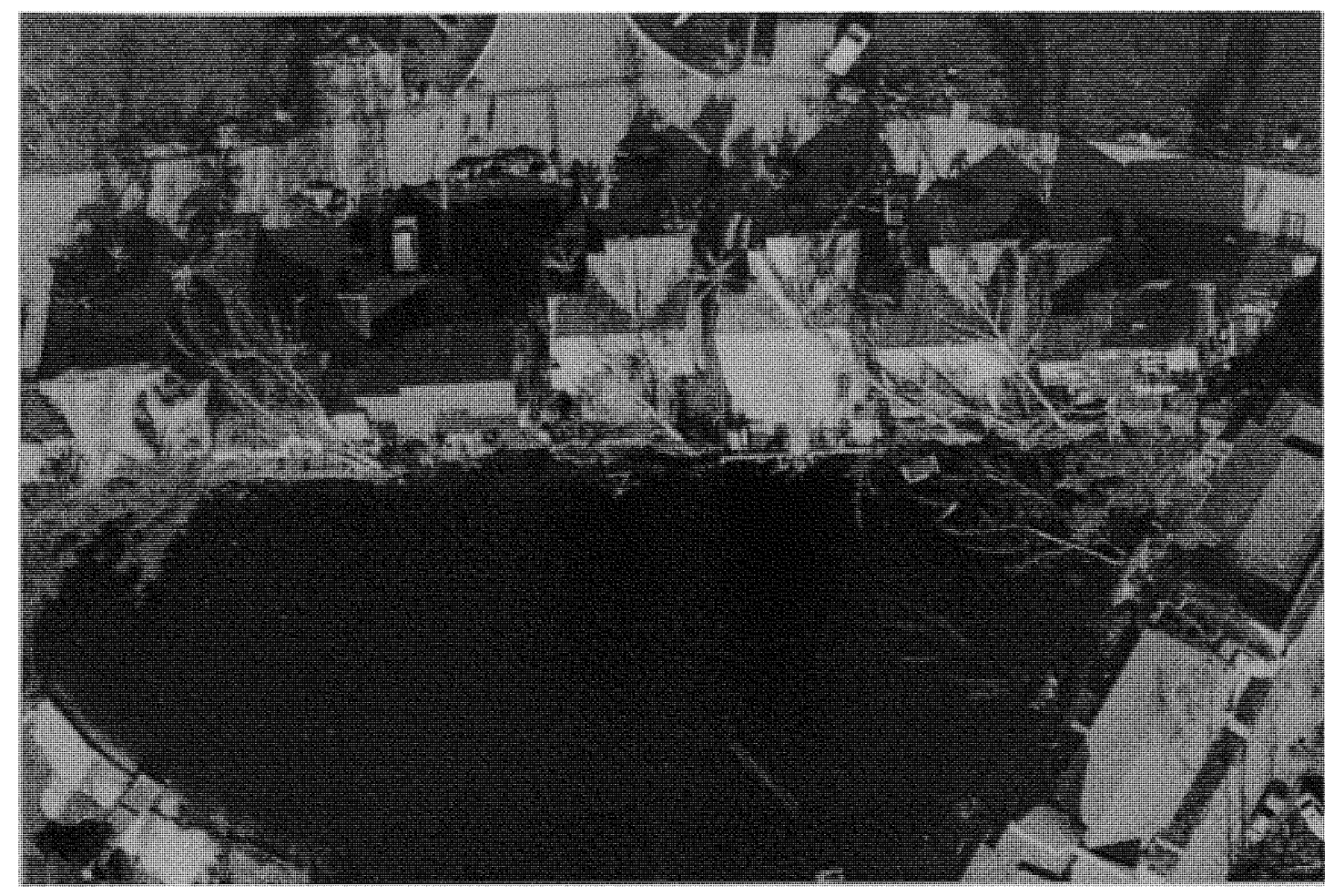

Figure 2.4. Damage due to fallen trees.

This figure shows rows of single-family house around an artificial lake. Some of these houses had roof cover damage due to fallen trees. The trees were so long they became unstable and fell on the roofs. In some cases there were $100 \%$ roof cover damage. The wind was blew from south to north. There was no major structural truss damage. Common performance problems affecting roof coverings included poor installation and inadequate material characteristics relative to the storm severity. 


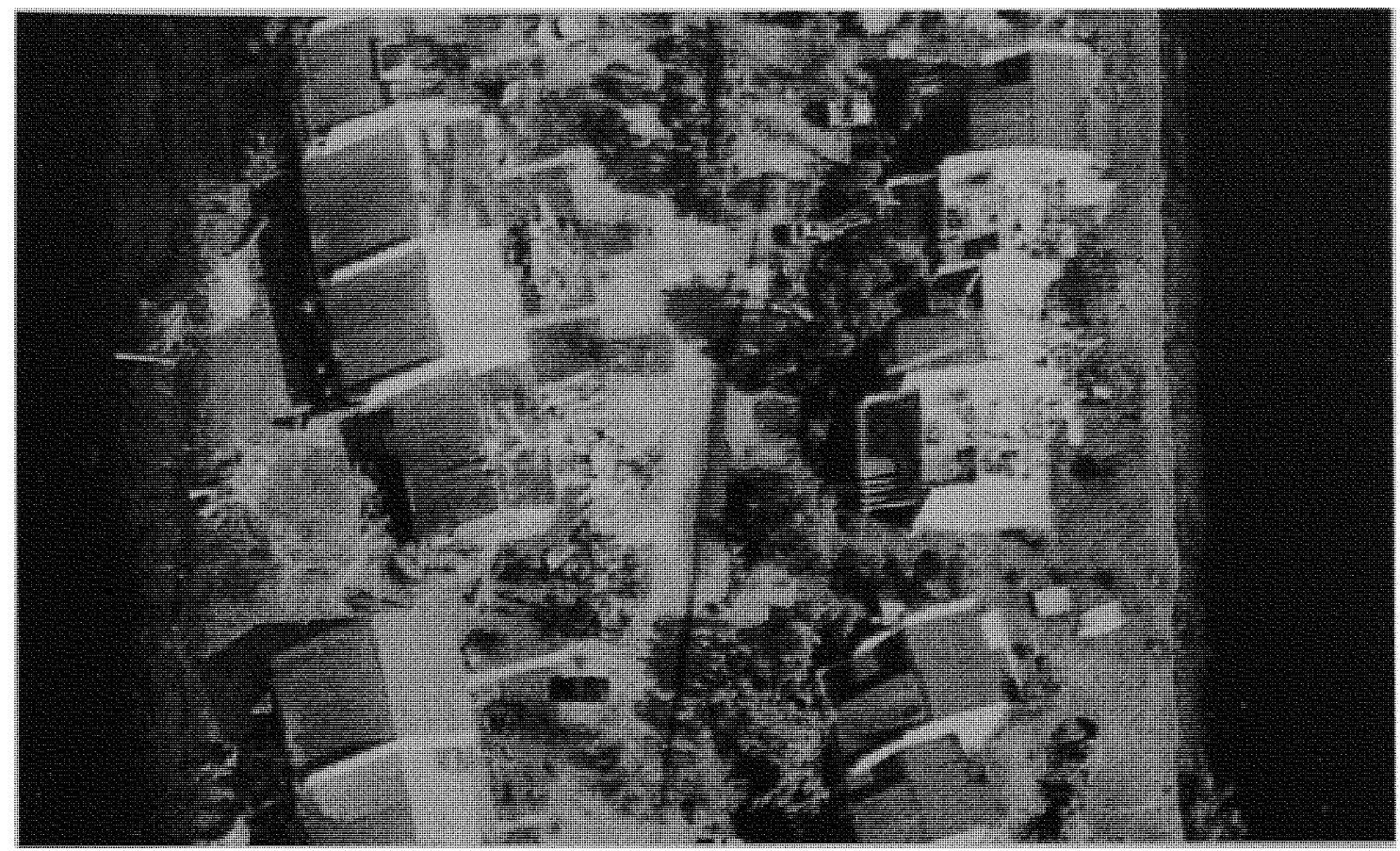

Figure 2.5. Collapsing of roof truss due to saturation load.

The figure shows two storied single-family homes situated near an artificial lake. Three buildings had an over all roof damage of $90 \%$. There is a severe loss of plywood sheathing indicating inadequate connections. Debris got collapsed inside the houses. In case of two buildings there is a structural damage to the roof frame might be due to lack of truss connections between them. The wind had blown from east to west and hence some minor damages could be observed in the houses on the left-hand side. 


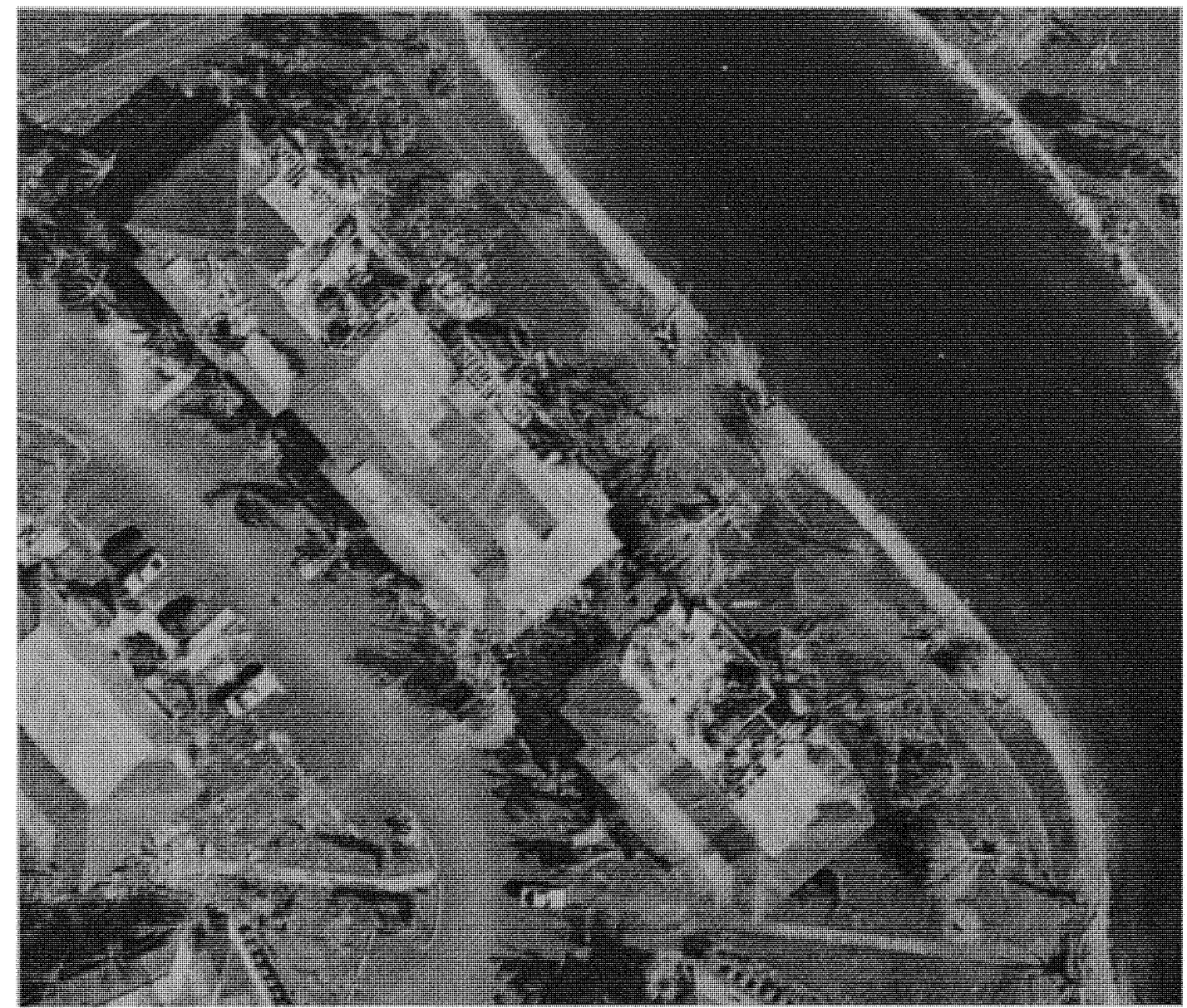

Figure 2.6. Aerodynamic hip roof.

This image shows two storied single-family homes around an artificial lake. The house consists of hip roof with partial roof damages in the two buildings as seen in the above figure. Hip roof is more efficient aerodynamically and therefore introduces lesser loads to the structure and its components. The corner failures in the wood-frame second storied might be due to improper connections of the top plates at the corner joints. 
3. MOBILE HOMES 


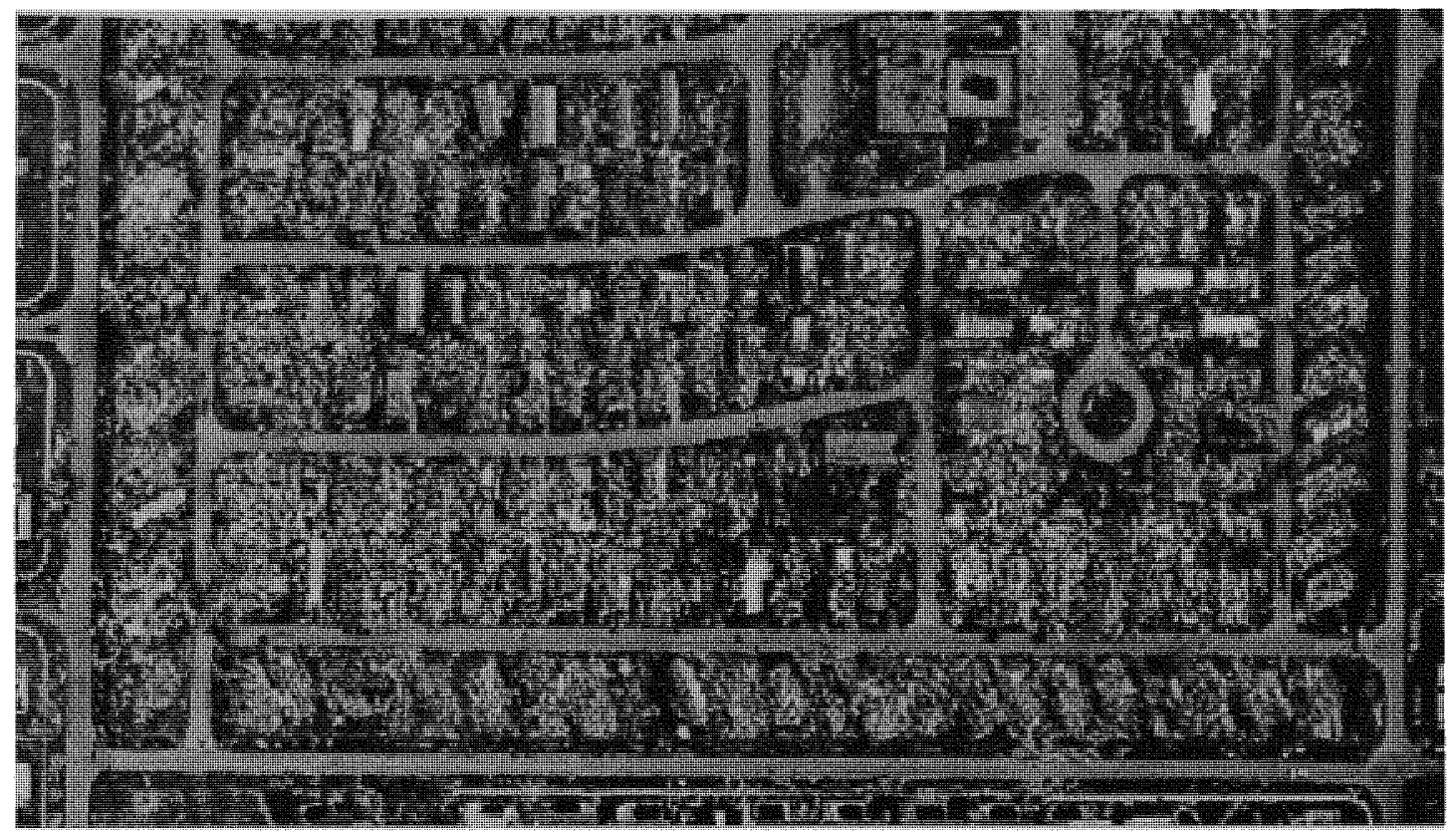

Figure 3.1. Severely racked exterior walls.

This figure indicates that more than $70 \%$ of the mobile homes have more than $60 \%$ roof cover damage. More than $70 \%$ of these houses have more than $50 \%$ damage to their sheathing. The main structure of roof such as trusses and gable-ends in this area show that more than $60 \%$ of these houses have more than $50 \%$ damage. It a ppears that the overall damage of homes is mostly contributed to the trusses and gable ends damage. In this figure, it shows that more than $50 \%$ of mobile homes have $100 \%$ roof damage; some structures are totally destroyed. 


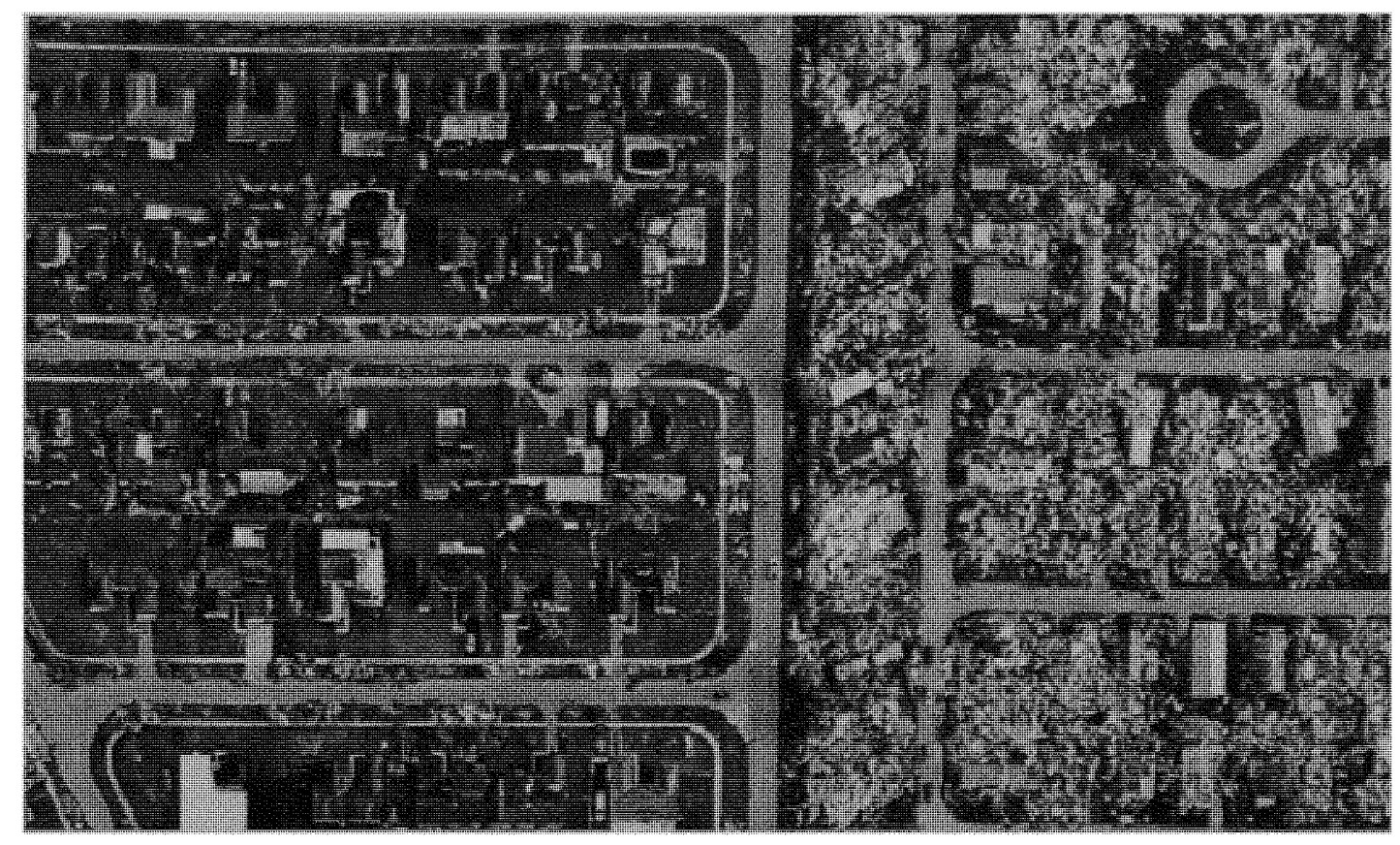

Figure 3.2. Comparison between single-family homes and mobile homes.

This figure clearly illustrates and compares the damage between single-family homes and mobile homes. In case of mobile homes more than $70 \%$ of the mobile homes have more than $50 \%$ roof cover damage. The over all damage to the mobile homes were about $90 \%$. Most of the mobile homes were reduced to rubbles. Whereas in case of single family homes there were less than $30 \%$ roof cover damage. All the roof covers of the townhouses have more than $10 \%$ damage in that particular area. The wind direction was from right to left. 


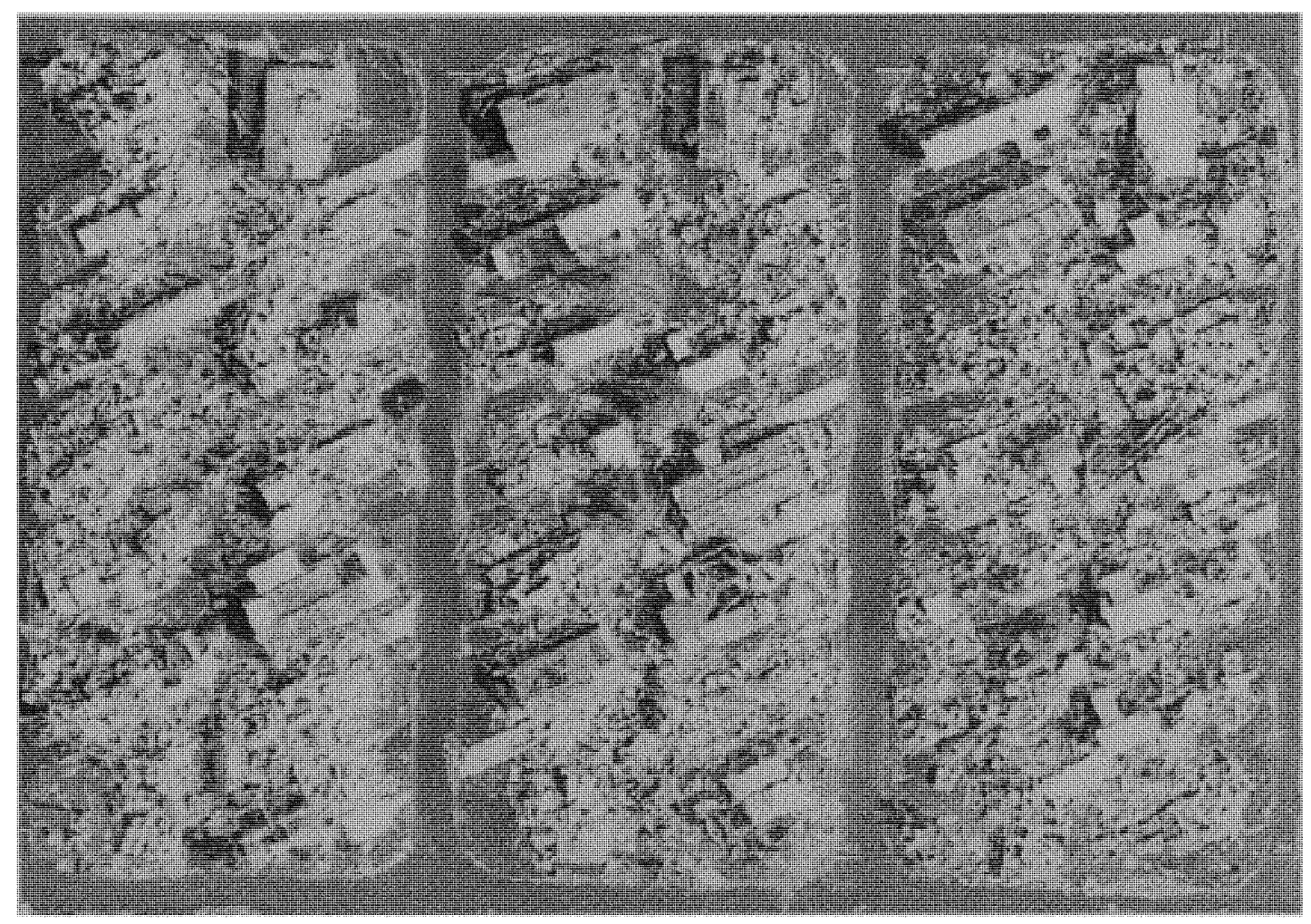

Figure 3.3. Tattered roof structure and faulty shear wall construction.

The figure illustrates $95 \% \mathrm{~d}$ amage to m obile homes. The d amage is so extensive that individual houses cannot be distinguished. In majority of cases the entire house collapsed. These houses have weak foundations and with slight wind pressure these houses became unstable and got reduced to rubbles. The were no trees surrounding the houses. As observed from the damage the wind direction was from north-east to southwest. In most cases the gable end was perpendicular to the wind direction and hence the structure got collapsed very easily. 
4. HIGH RISE RESIDENTIAL STRUCTURES 


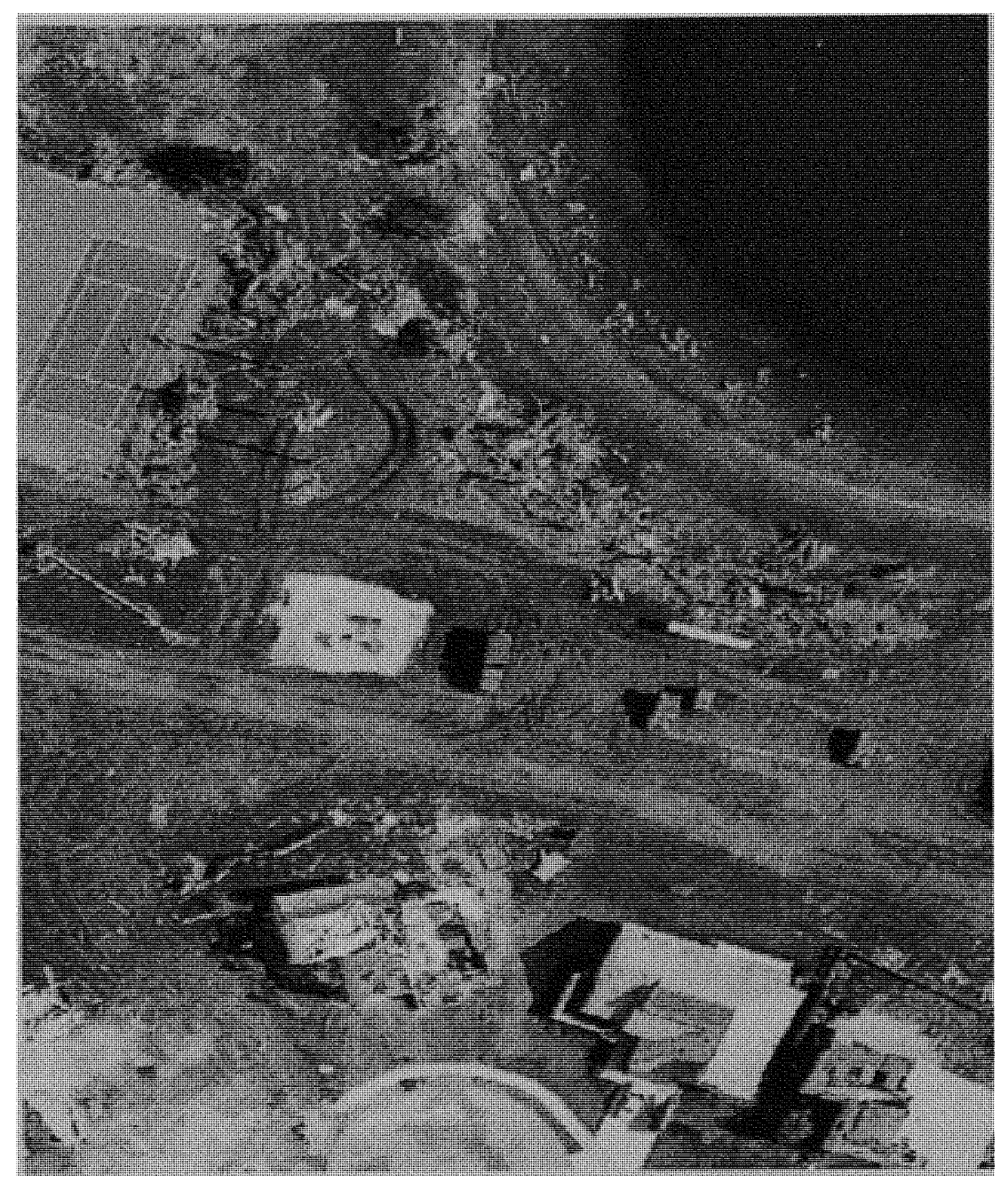

\section{Figure 4.1. Corner plot damage.}

This figure shows a typical picture of a corner house, which has been destroyed by storm surge. There has been major damage to the roof covering and the sheathing. Very little portion of the exposed truss can be observed. The roof framing was adequately strong enough to resist the wind force even though it was a corner house. The wind direction can also be predicted. The wind was blowing from south-west to north-east. The debris can be found around and near the lake. 


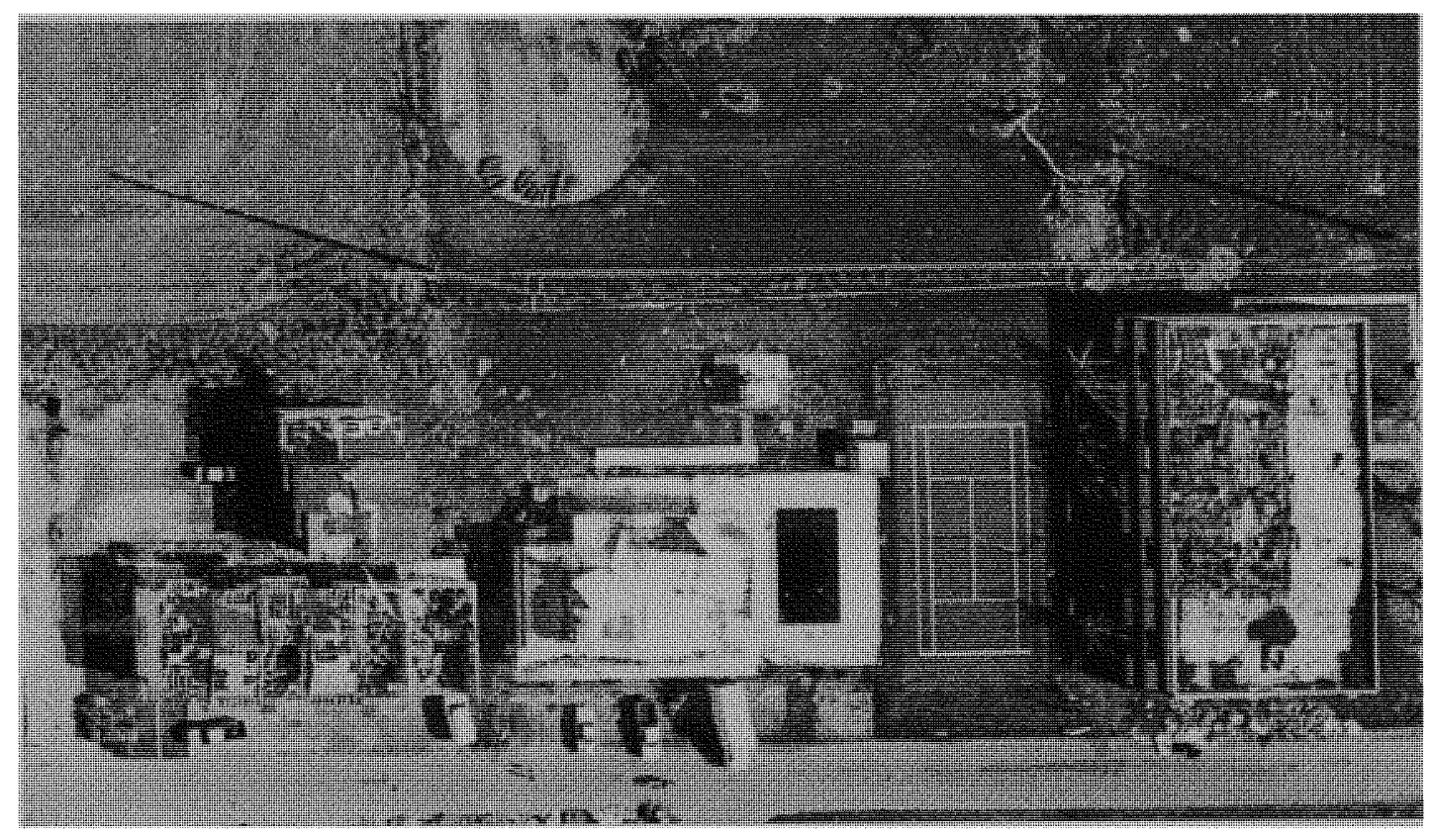

Figure 4.2. Strong anchorage between panels.

The figure shows damages in a clubhouse. Major damages are in roof cover and sheathing. In some places trusses can be seen but they are not structurally damaged. The anchorage between the panels was adequately strong enough and hence it could survive the wind force. The wind direction cannot be predicted accurately, although a rough guess can be made about the wind direction. The wind might have blown from north to south, this is evident from the fact that there was a fallen tree. 
5. TOWN HOUSE 


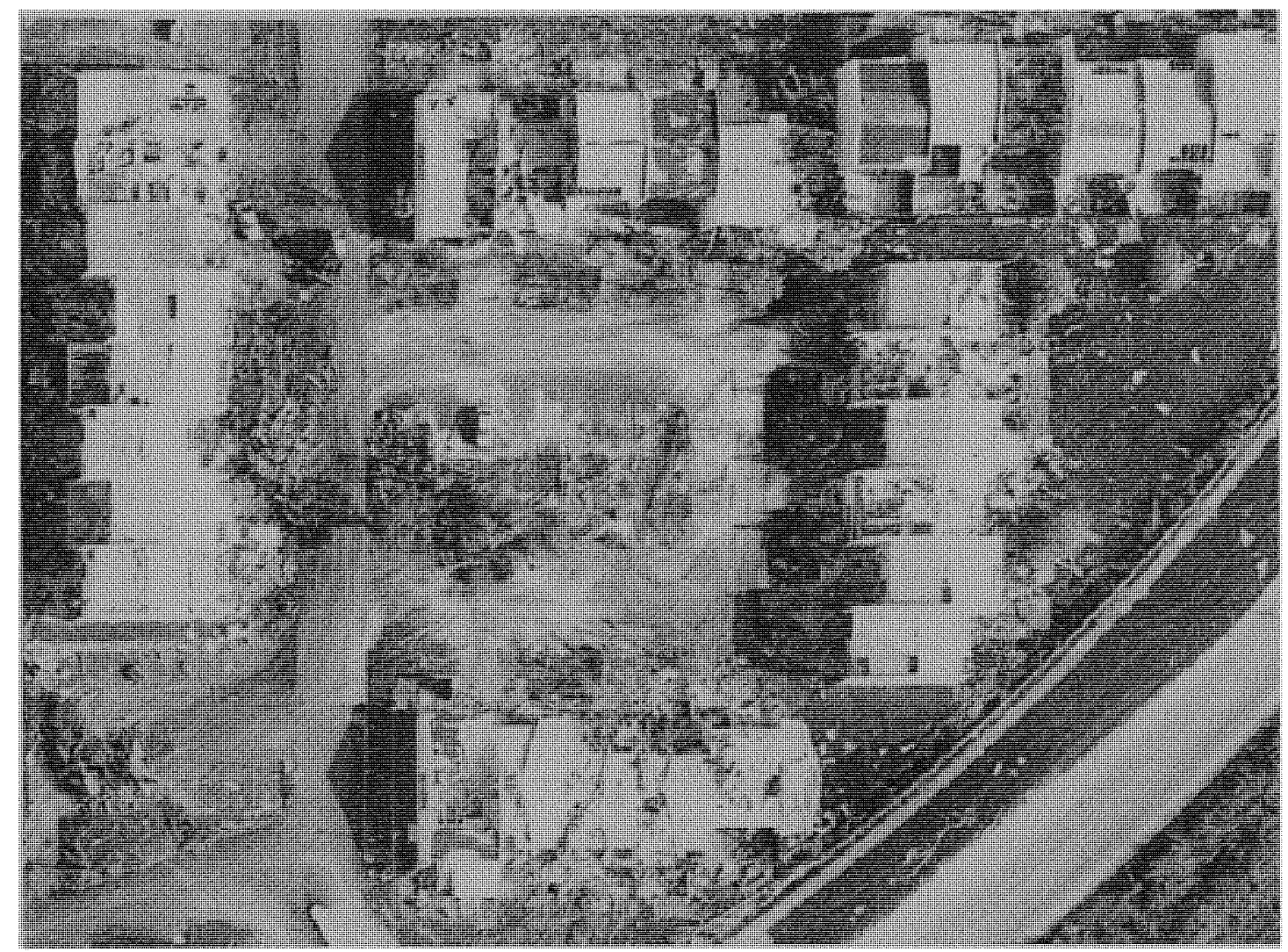

Figure 5.1. Improper connection between the roof and the exterior walls.

This figure shows s ingle-family homes, which a re a djoined $w$ ith no space in b etween except the corner homes. In between houses some houses are badly damaged with complete roof system failure. Collapse of roof structure within the houses can be observed. The failure might be due to lack of proper connection between the roof and the exterior walls and due to lack of a bond between the mortar and the tile. 


\section{PUBLIC BUILDINGS}

6. SCHOOL BUILDING 


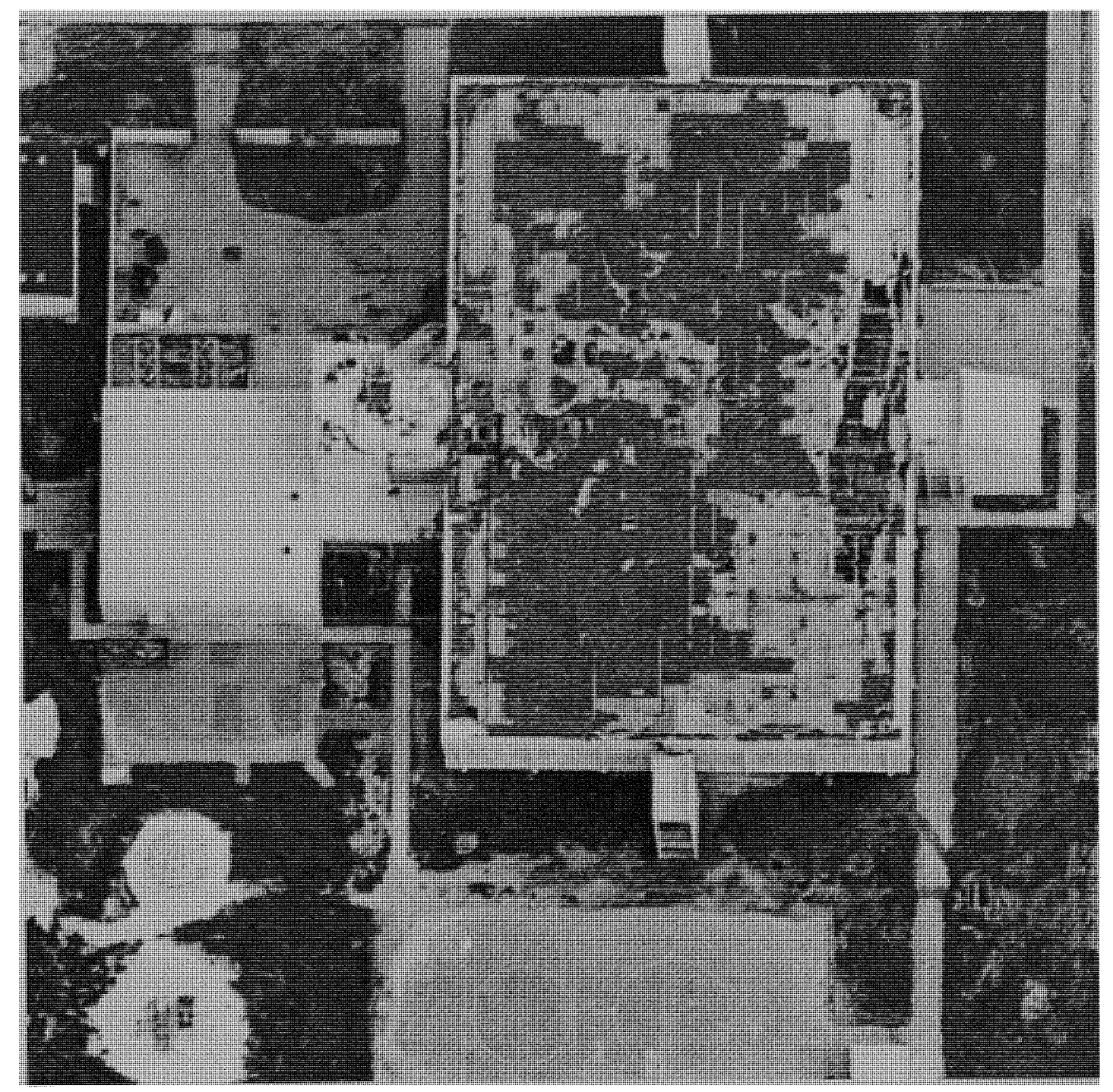

Figure 6.1. Minor damage to concrete roof.

The figure shows a school building, which has RCC roof covering and some portion of the roof, got damaged which exposed the steel reinforcement part. During a hurricane or cyclone only houses with RCC roofs have better resistance to damages. This is attributed to heavy dead weight of the roof system, which will effectively resist the excessive uplift forces caused by hurricane. $\mathrm{RCC}$ roofs can effectively resist potential damage initiation by wind-borne debris. 
7. SHOPPING CENTERS 


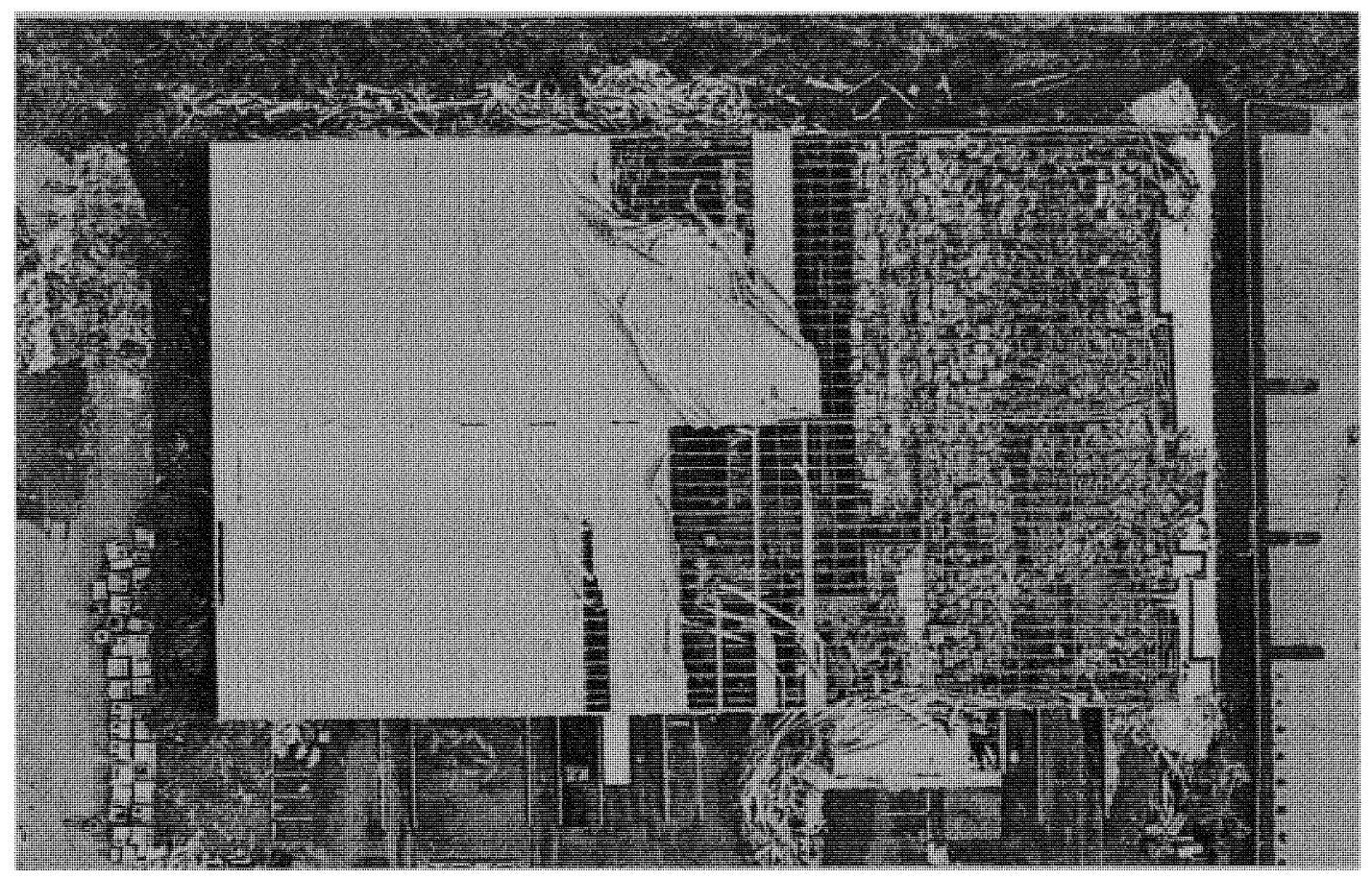

Figure 7.1. Blowing of roof cover sheets.

This figure illustrates a big shopping mall, which has major roof cover damage. In case of large shopping malls there are neither cover tiles nor sheathing. There is special roof cover material directly placed on the metal truss. The wind might have blown from east to west damaging the roof cover partially. Whereas the metal truss has not been damaged at all. In case of the extended porch bending and twisting of metal frame is observed. The porch metal truss could not withstand the storm surge. 
8. COMMERCIAL STRUCTURES 


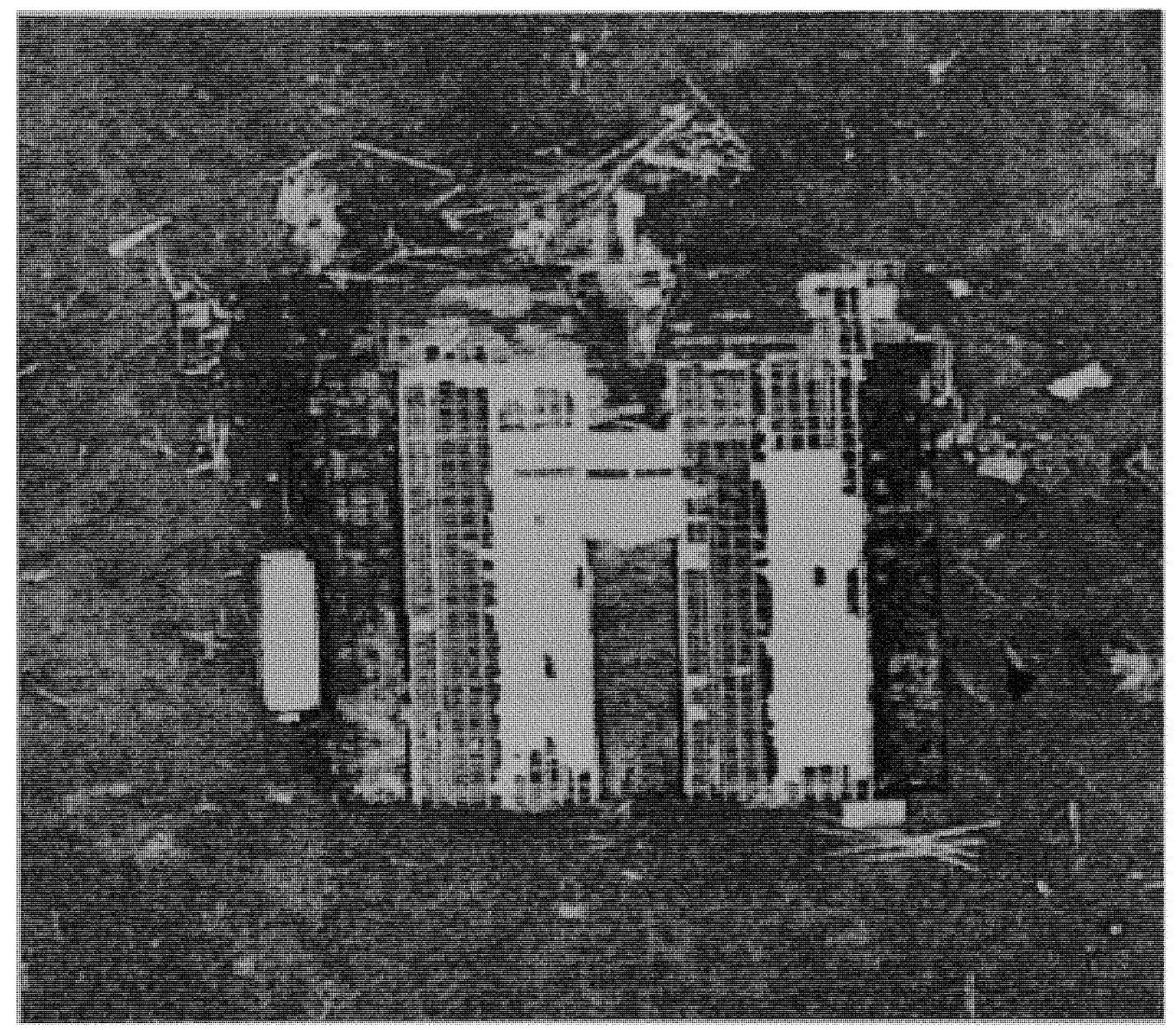

Figure 8.1. Roof cover damage.

In this figure major roof cover damage was observed. The entire roof cover was blown off by storm surge but some portion of the sheathing was intact. The roof cover was torn off because the material was not securely fastened together. There was no major structural damage to the trusses, which means the truss connection was adequately strong enough to resist the wind force. Sever loss of plywood roof sheathing, indicating inadequate connection. Secondary bracing appeared to be more important to taller roofs with larger gables. 


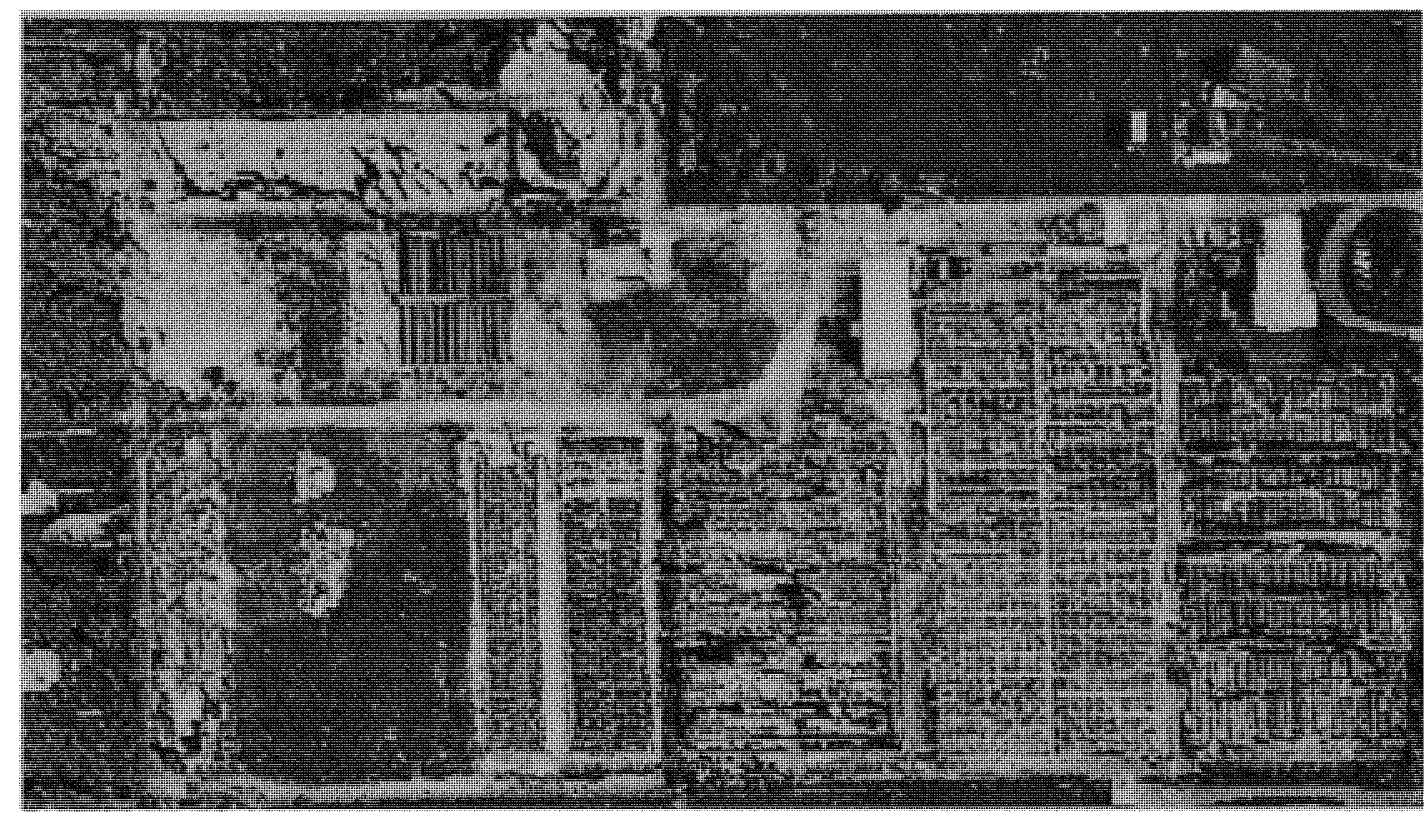

Figure 8.2. Major structural damage.

This image looks like a warehouse, which is severely damaged. The roof cover of the entire storehouse has been removed by strong wind force. Some structural damages of the truss can be observed. The wind damage cannot be predicted very accurately as there are no trees surrounding the warehouse. Even the concrete structure (i.e. the roof), which can be seen on the top left hand corner, did not survive the wind impact. Major cracks can be seen very clearly. 


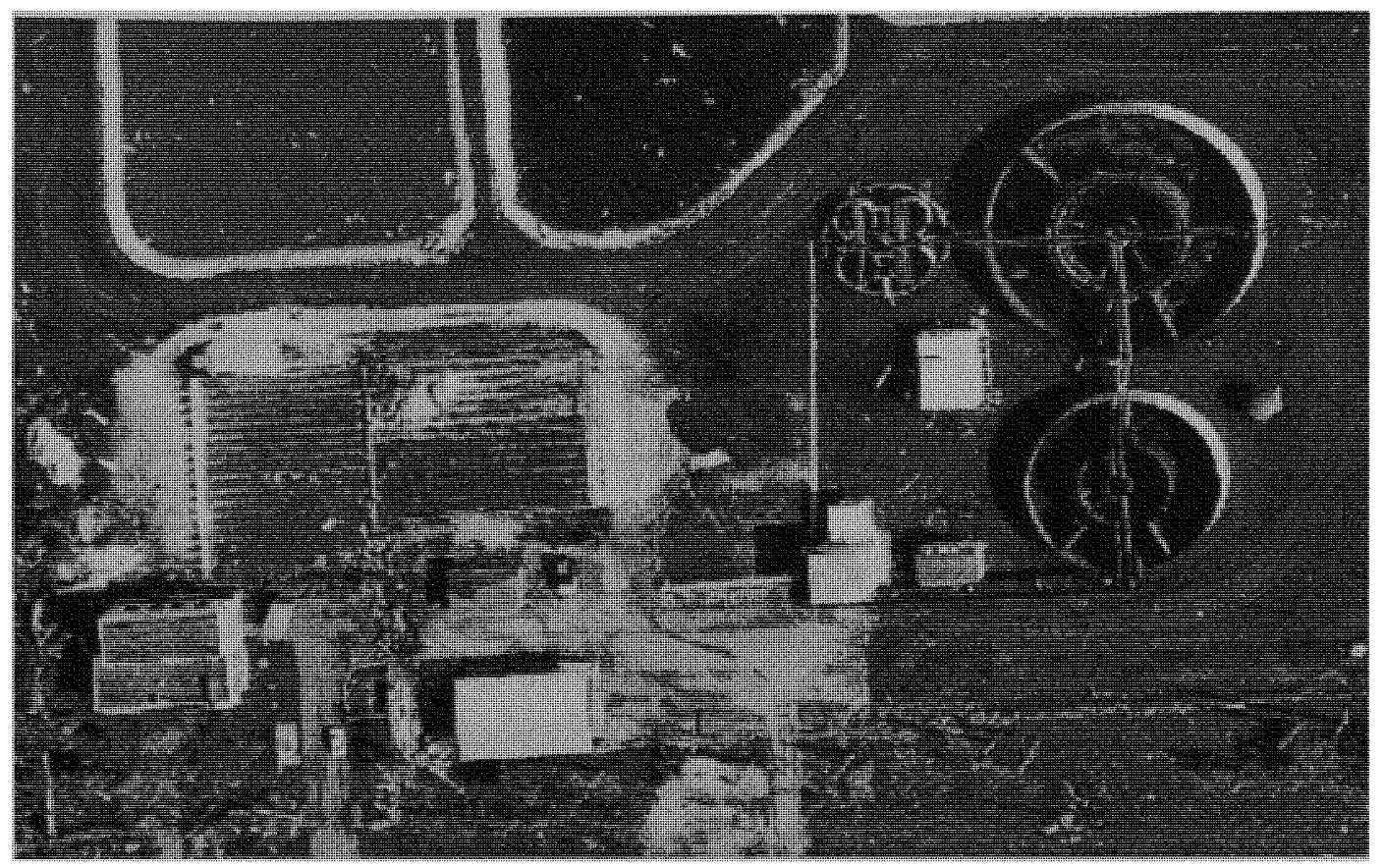

Figure 8.3. Damage to filter beds.

The figure shows a wastewater treatment plant. There has been no major damage to the overall structure as most of the construction was done with high strength concrete. Damage has been observed in a number of places around the building area and the filter beds. Wind direction cannot be predicted accurately with such minimum damages. 


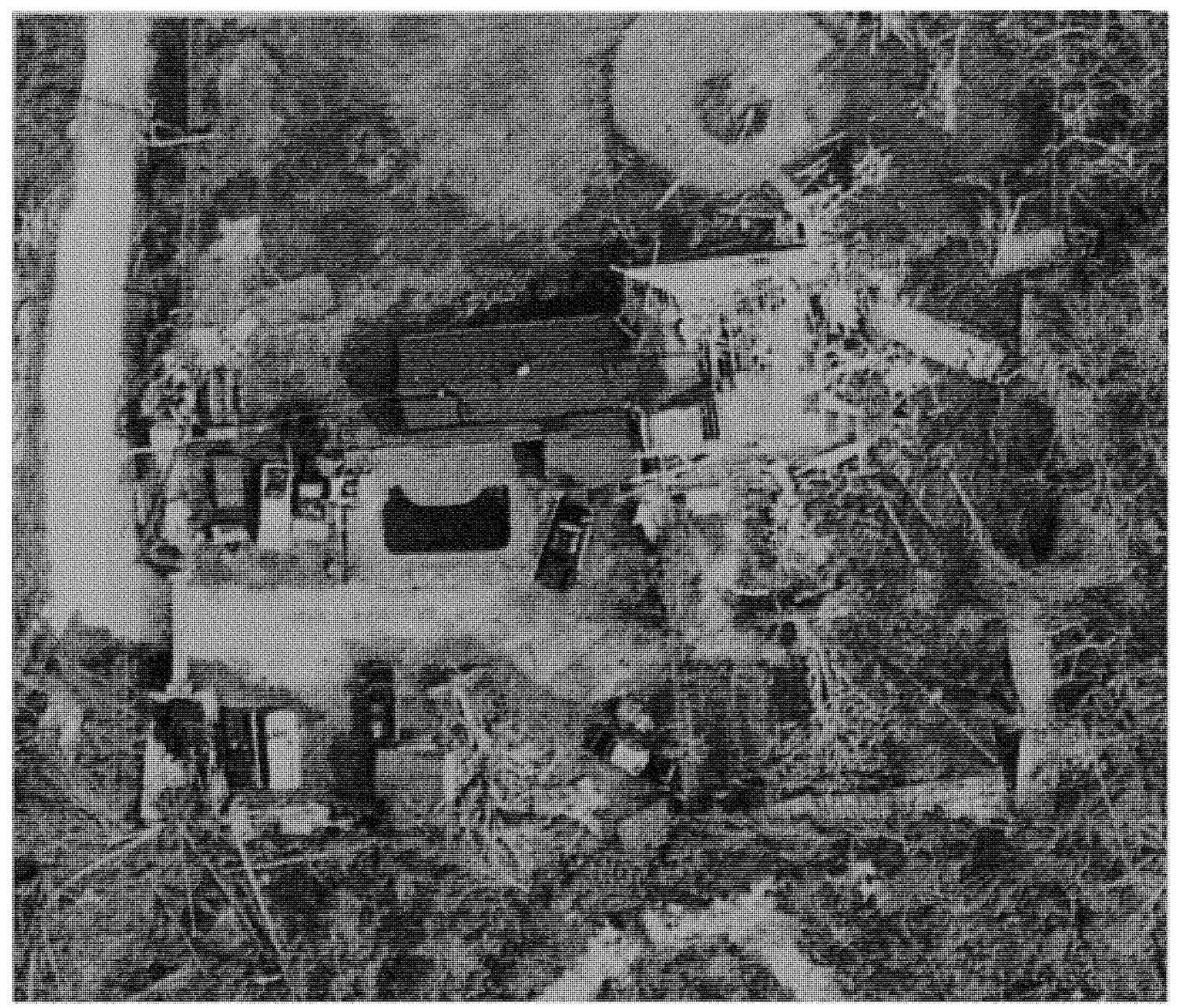

Figure 8.4. Upliftment due to strong wind force.

This figure shows major roof damage. The roof cover and the sheathing are completely missing. It appears that the wind direction was from east to west. It was evident from the fact that when the wind was blowing in this direction the east side of the house has been damaged more than the west side. The complete uplift was due to strong wind force blowing in north south direction. In such cases the house should have adequate bracing support and the ridge should be strong enough to avoid structural failure. 


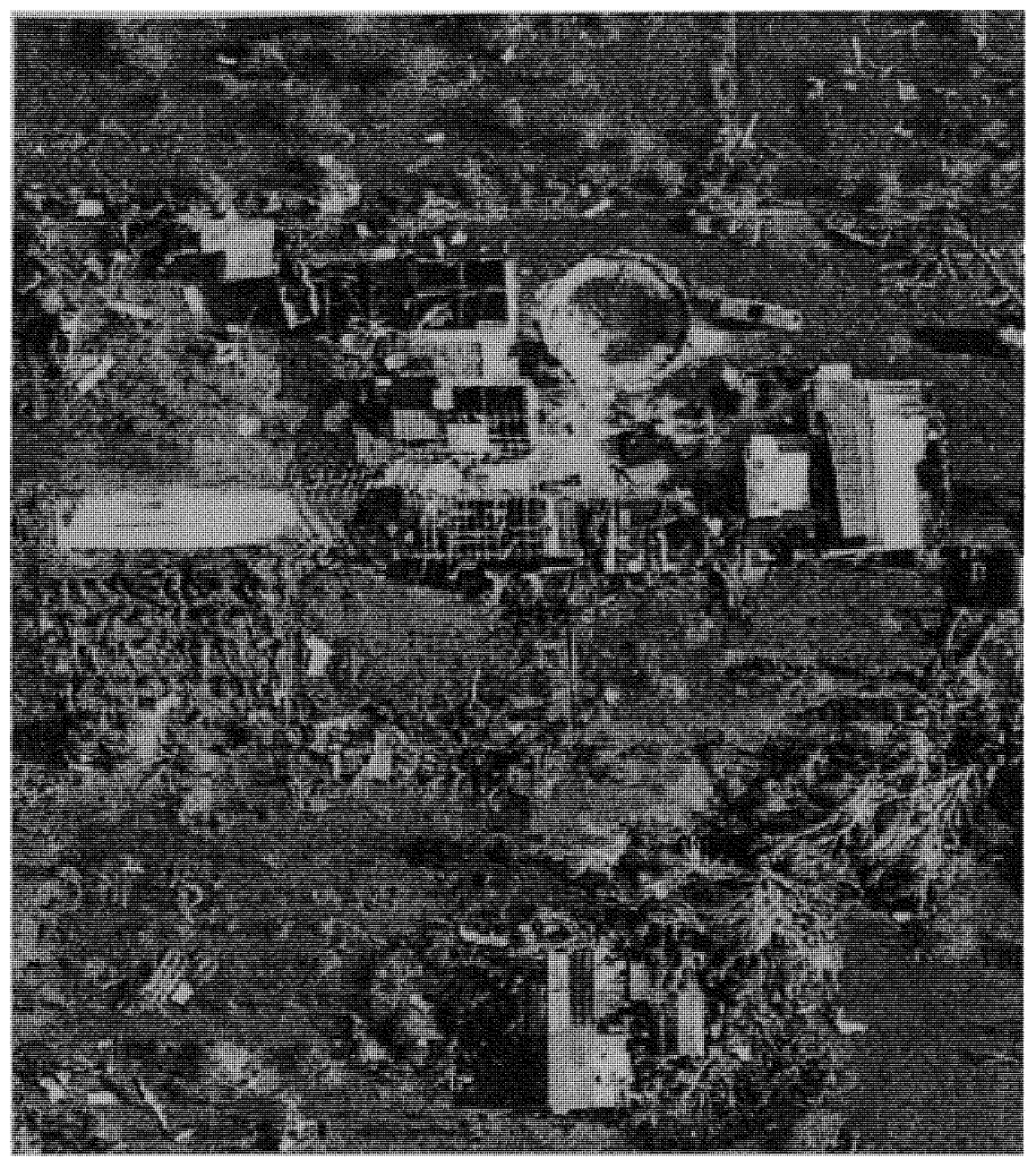

Figure 8.5. Sheathing blown, exposing the truss.

This figure shows destruction of numerous houses. For all the houses that can be seen in the picture the roof cover has been blown off. For one of the house the sheathing has been blown exposing the trusses. Small hanging trusses got itself detached from the main trusses and laid on the ground. Extensive amount of rubbles can be found scattered all around these house. The house where truss can be observed, the framing was intact and strong enough to resist the wind force. The wind direction can be predicted with accuracy, the wind was blowing from north-east to south-west taking a curved path. 


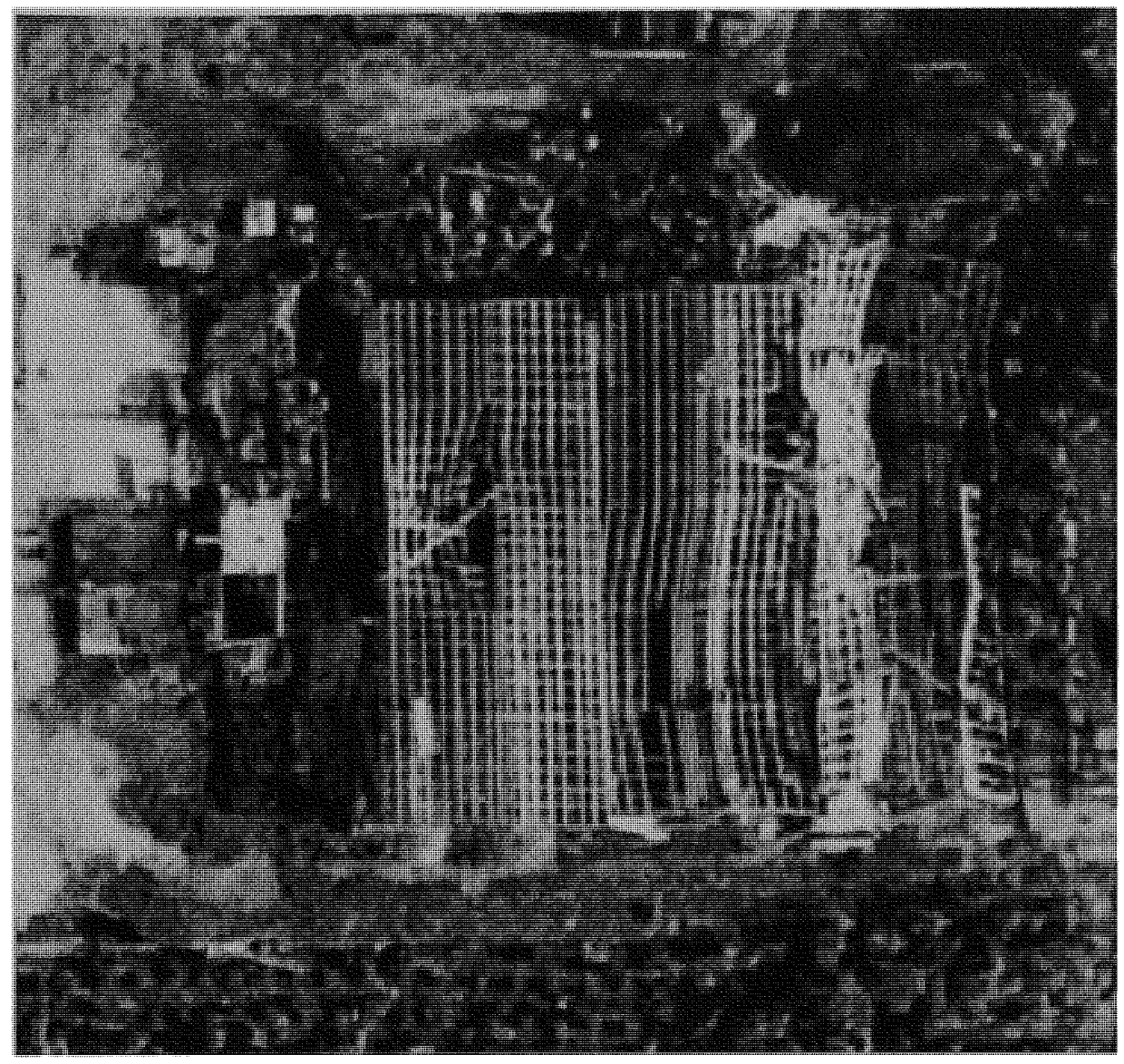

Figure 8.6. Dislocation of trusses.

This figure shows the entire roof cover and the sheathing has been blown off exposing the truss for both the buildings. In case of both the buildings the trusses were dislocated. Some portion of the truss is beyond repairable. The damage was caused mainly due to the strong wind force, as there were no major trees surrounding the buildings to create an obstruction to prevent damage to the building. The wind first hit the roof of the building on the right hand side and hence the truss acquired a curved shape. The wind was blowing from east to west. A portion of the truss got collapsed and lying on the ground. 


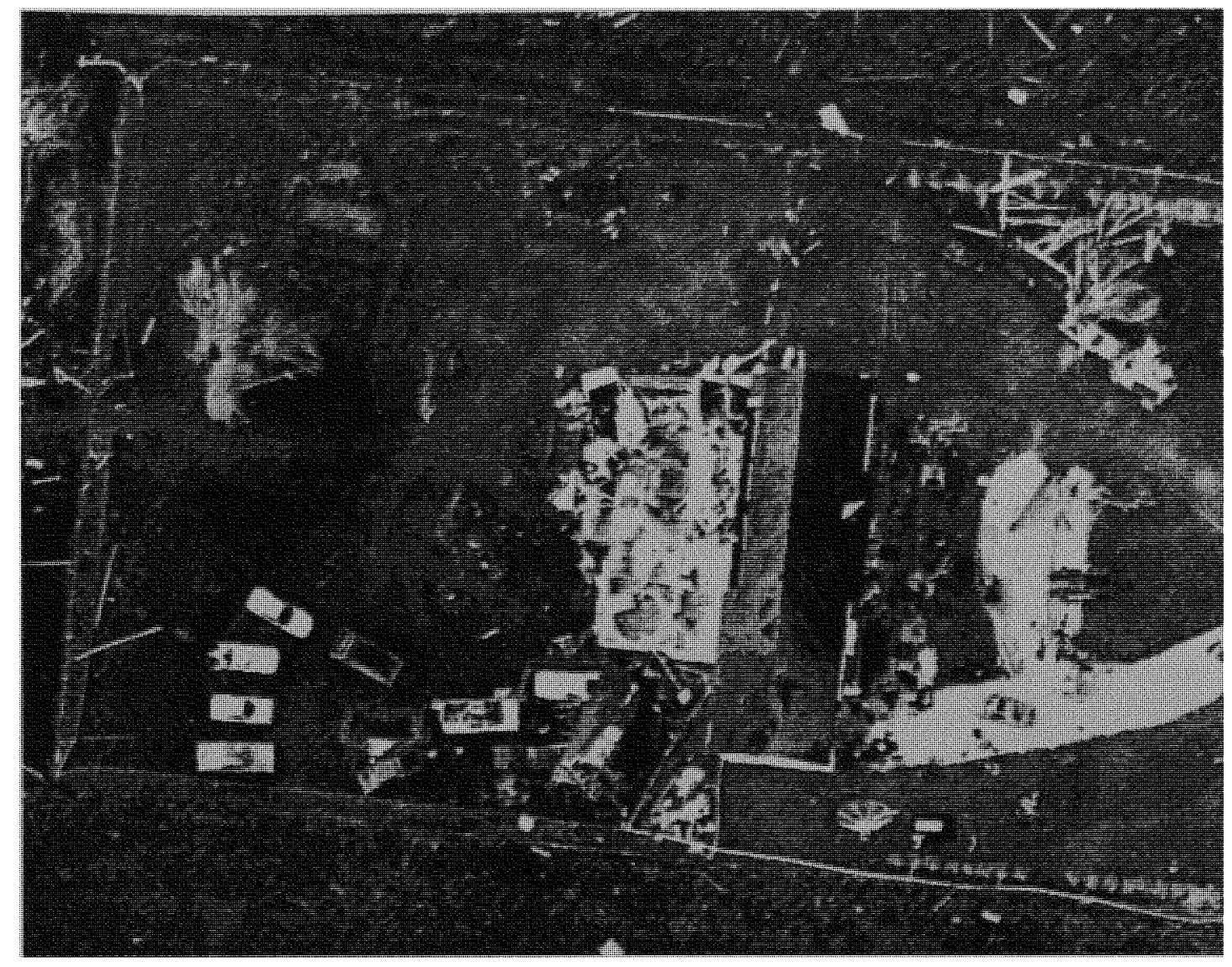

Figure 8.7. Collapsing of main roof structure.

The figure shows an extensive damage to the roof. There was a major structural damage to the roof framing system. The roof cover, sheathings, trusses and gable-ends were completely destroyed. The main roof structure got collapsed. The cause of the roof sheathing damage could be the fact that the overhang framing was not anchored to the roof system. The wind direction was difficult to predict. The wind force could also displace the cars parked in front of the building. 


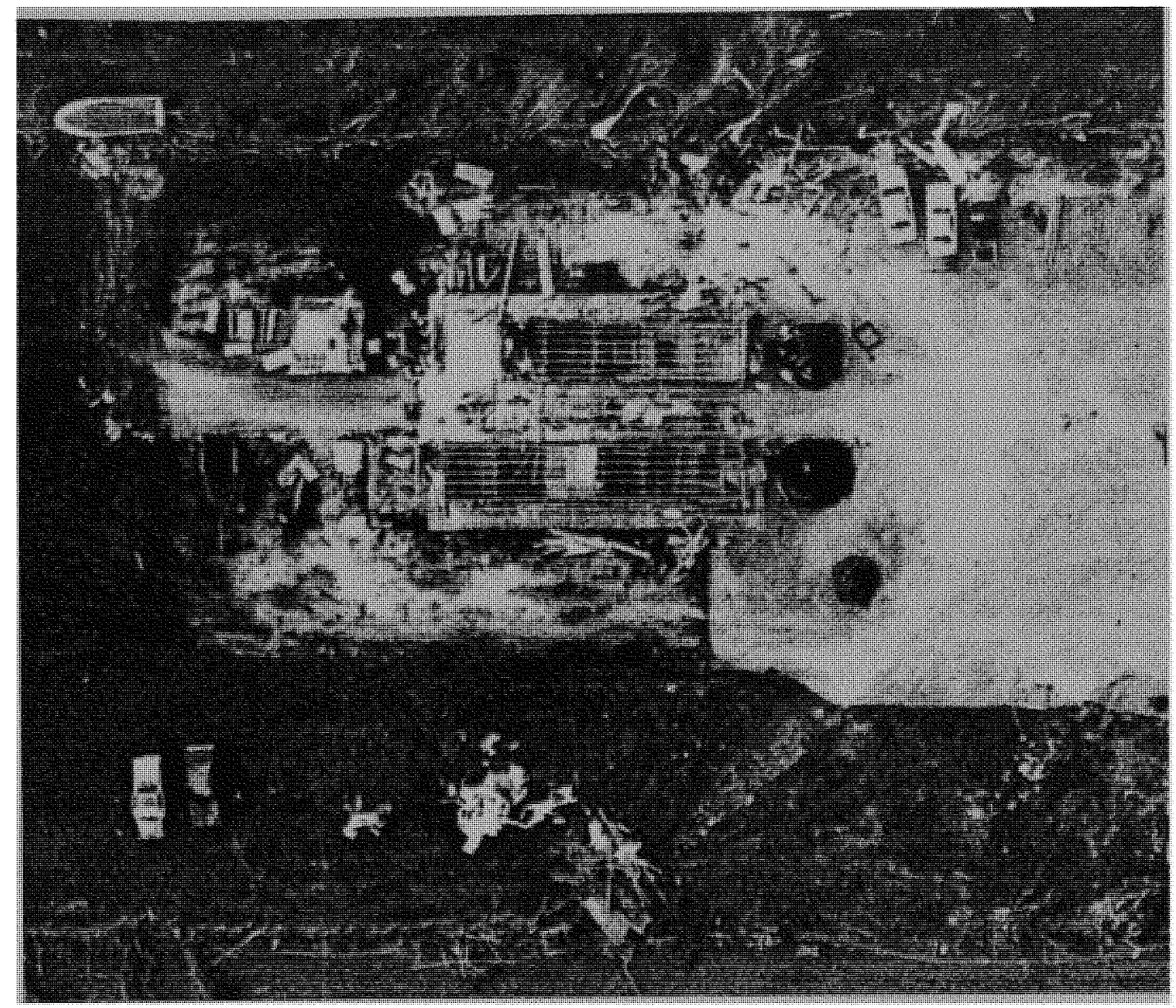

Figure 8.8. Inadequate binding material used.

This figure shows the wind's direct force on the roof. The roof cover and the sheathing are missing. It can be predicted that the wind direction was perpendicular to the gable end. The structural part of the roof was strong enough and hence there w as no major damage. The main structure was intact. Missing of the roof cover and sheathing might be due to inadequate binding between each other. By observing this image we can see that the gable-ends have no noticeable damage. 


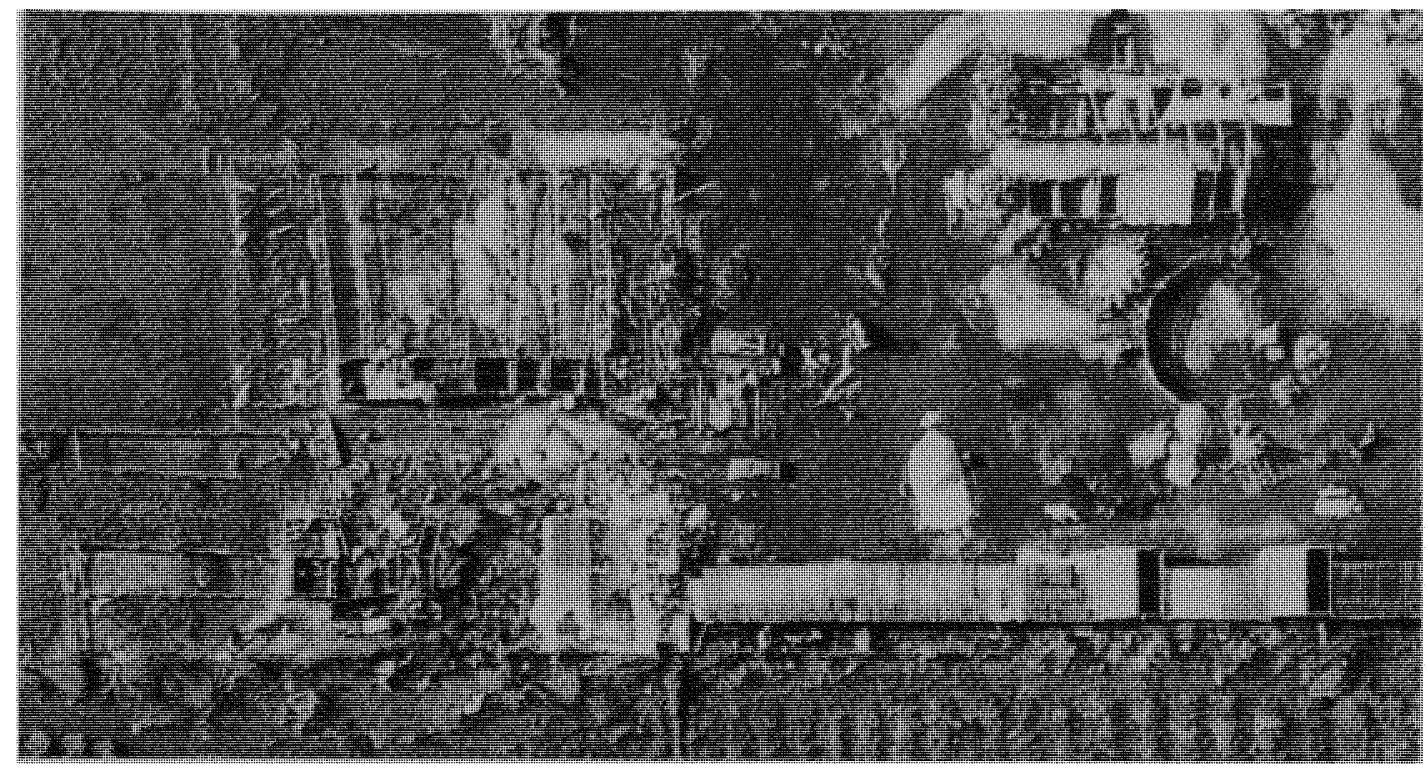

Figure 8.9. Weakening of trusses.

The figure shows that the whole roof is gone. Most of the trusses are scattered within the house. As this picture shows the trusses did not blow from the house but got dislocated. The reason could be the following: first, this house lost all its sheathings and the truss was exposed to rain. Then, the truss became weak and all the roof framing collapsed. Second, the house $\mathrm{m}$ ight have i nadequate $\mathrm{n}$ ailing and connection of the roof framing. Consequently, according to damage assessment criteria the overall damage in this house is $90 \%$. 


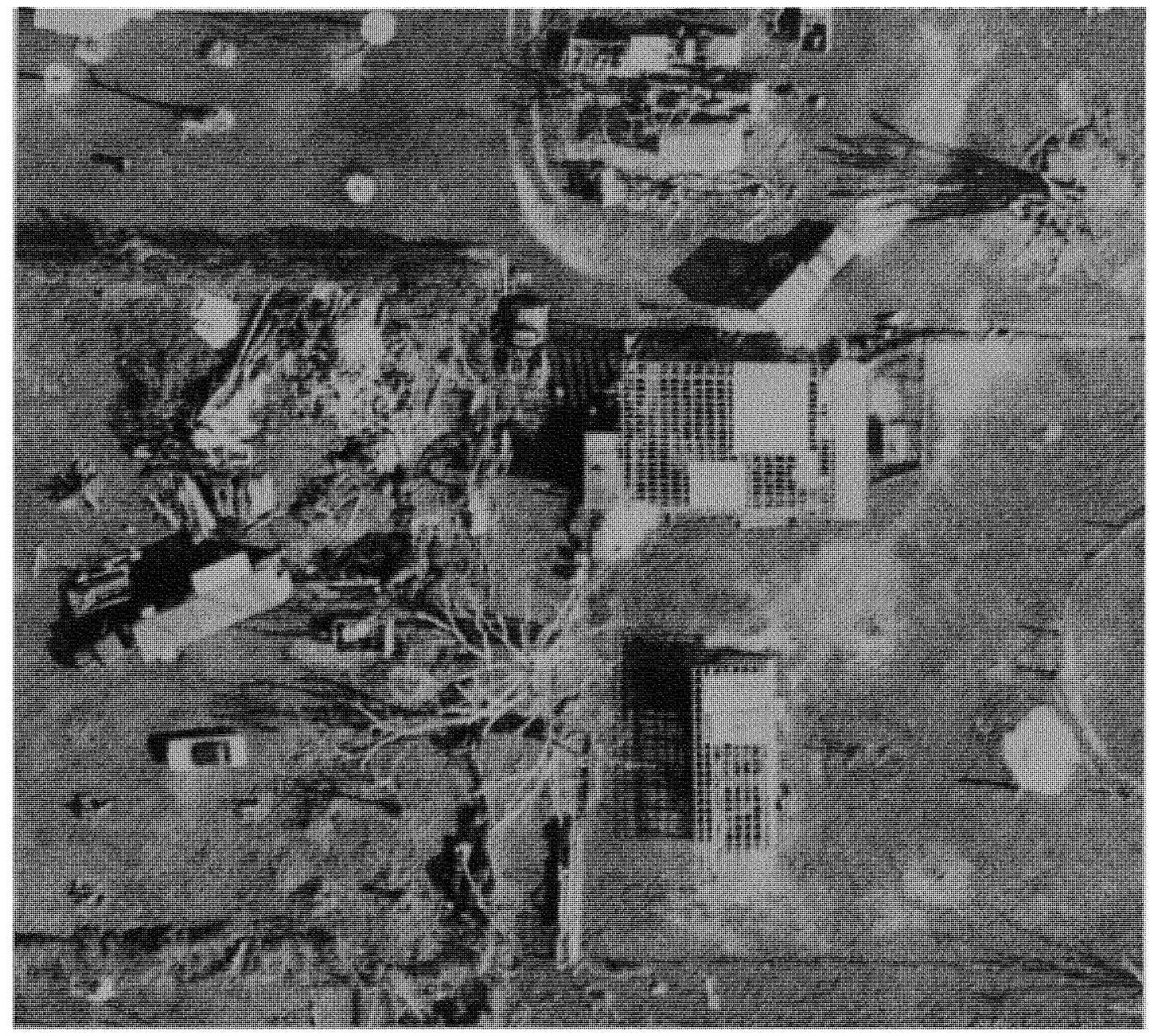

Figure 8.10. Strong bracing connections.

The figure shows that more than $70 \%$ of the roof covers are missing. More than $70 \%$ of the sheathing are also damaged. The trusses were intact without and structural damage. The bracing connection was adequately strong enough to resist the wind force. Wind borne debris can be found at some distance from the houses. The wind was blowing from east to west. This was evident from the accumulation of wind borne debris. 


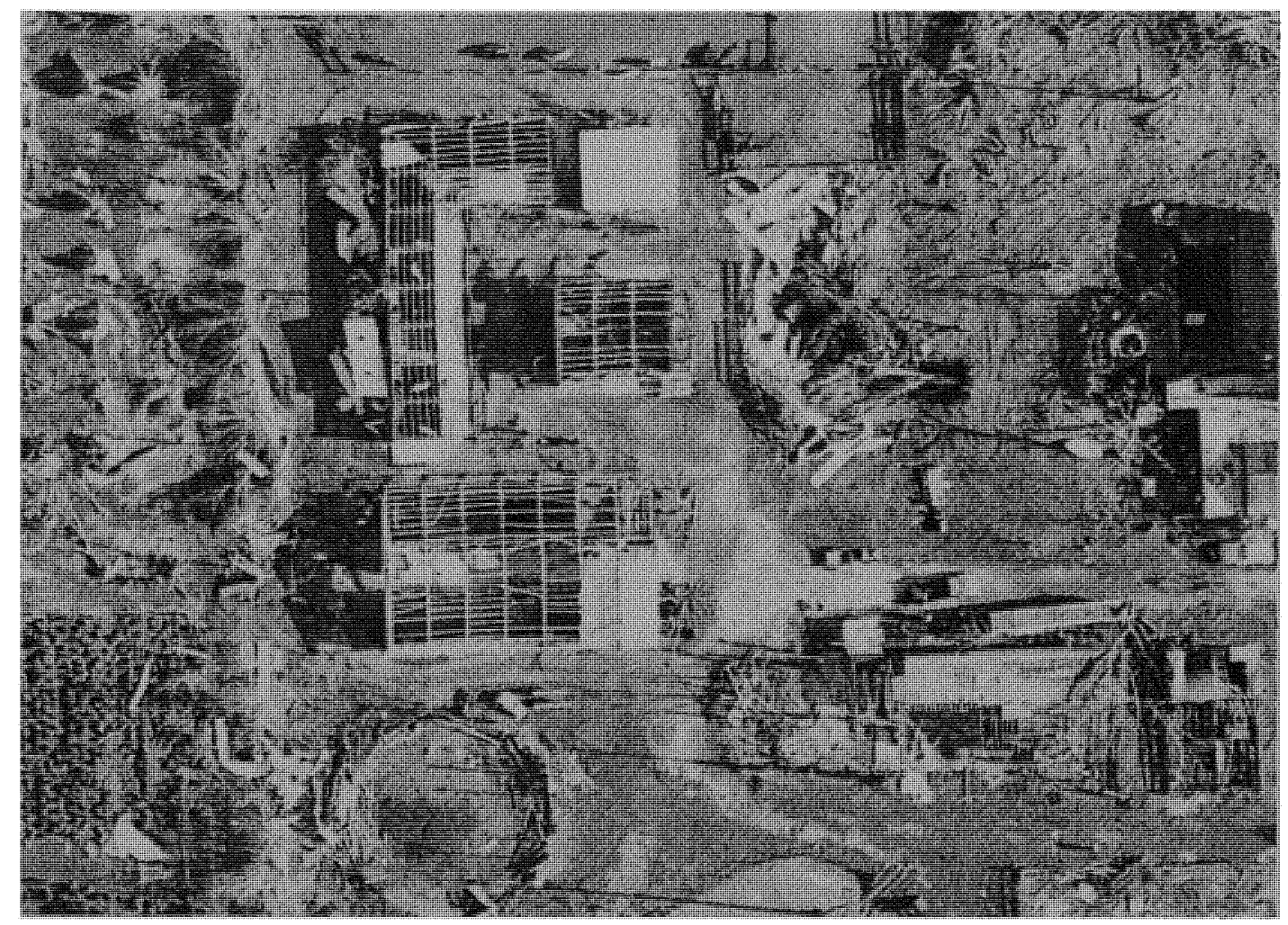

Figure 8.11. Missing roof covers and structural damages.

The figure shows $d$ amaged roofs. R oof cover and sheathing $h$ ave $b$ een missed and in some cases the wooden frame truss is also damaged. The cause of the damage was due to strong wind and inadequate connection between roof cover, sheathing and trusses. Only some portion of the truss was damaged. So truss damage can be about $20 \%$. One house that can be seen on the extreme right-hand side was hardly damaged which means that house did not fall in the path of the wind. 


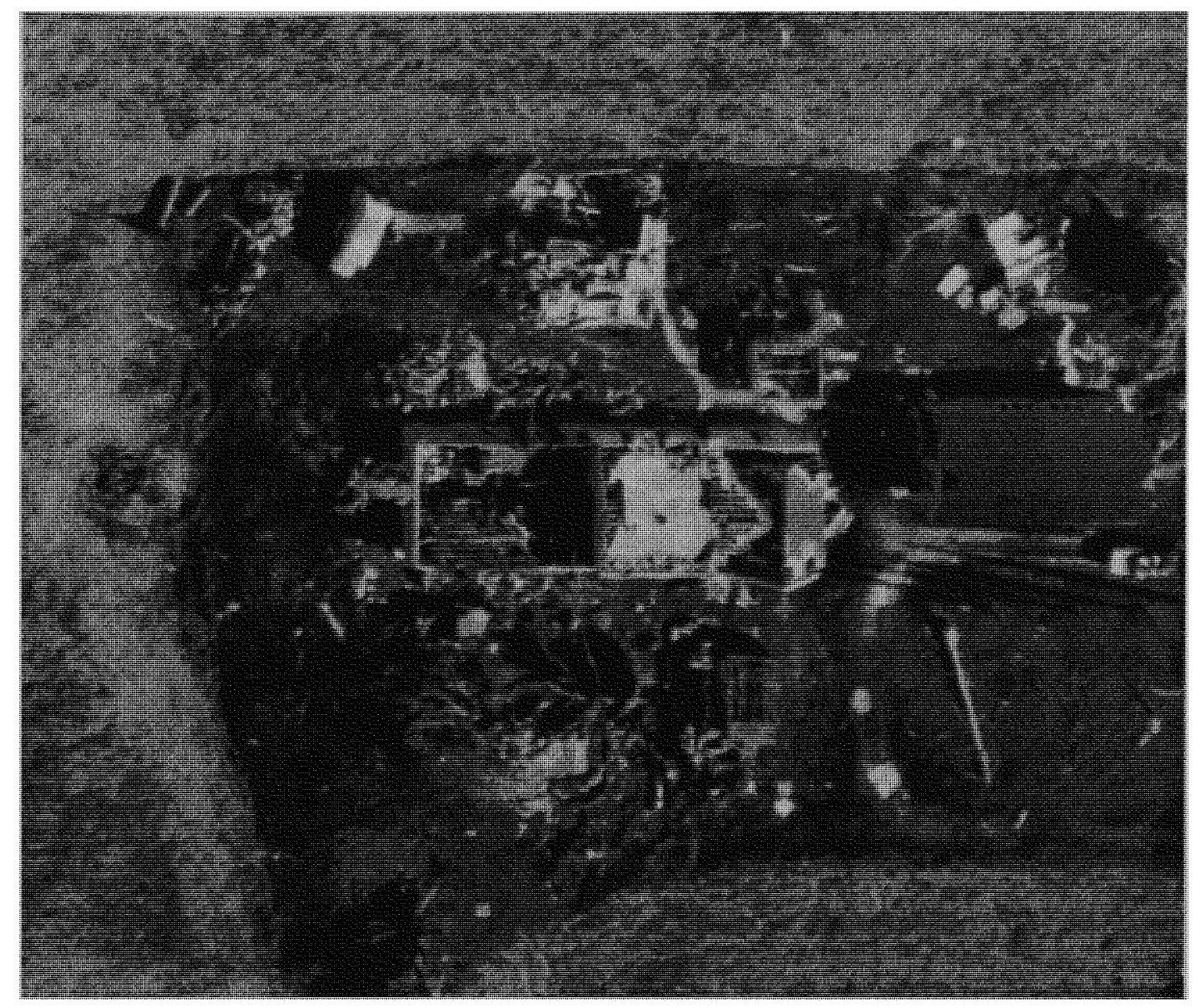

Figure 8.12. Collapsed trusses.

This image shows a house in which there was a roof cover damage of nearly $90 \%$. The entire truss has been collapsed. Only two king post trusses can be observed and one of the gable end on the right hand side feel on to the roof of the other building. The truss system got collapsed and the rubbles can be seen inside the house. On careful observation we see the house on the other side has also been damage extremely. There were no large trees to avoid the wind, which had blown from west to east. Debris can be seen some distance from the house, which indicates the strong wind velocity. 


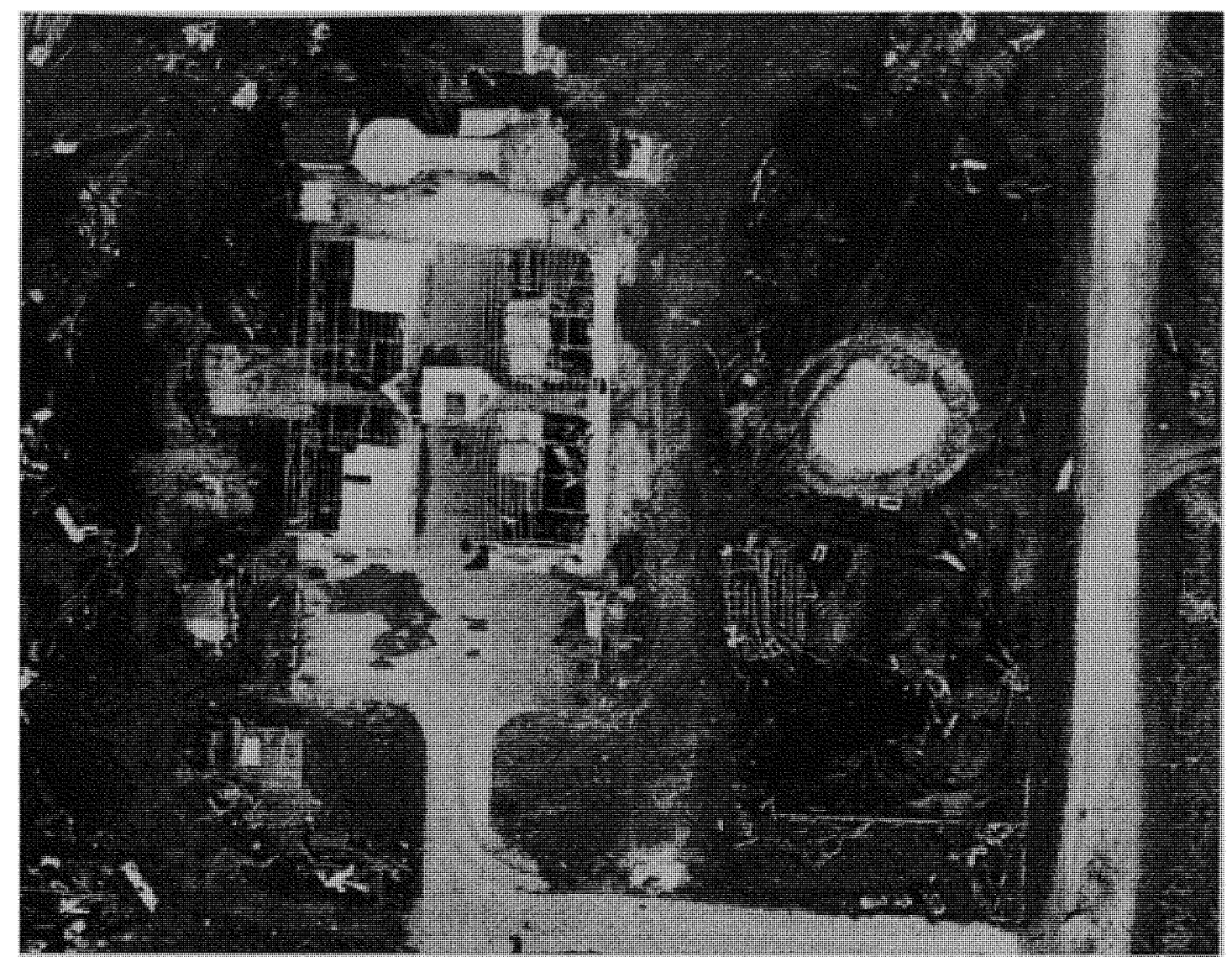

Figure 8.13. Severe loss of plywood sheathing.

In this figure major roof cover damage is been observed. The entire roof cover is blown off by storm surge but some portion of the sheathing is intact. The roof cover is torn off because the material was not securely fastened together. There is no major structural damage to the trusses, which means the truss connection was adequately strong enough to resist the wind force. Sever loss of plywood roof sheathing indicating inadequate connection. Secondary bracing appeared to be more important to taller roofs with larger gables. 


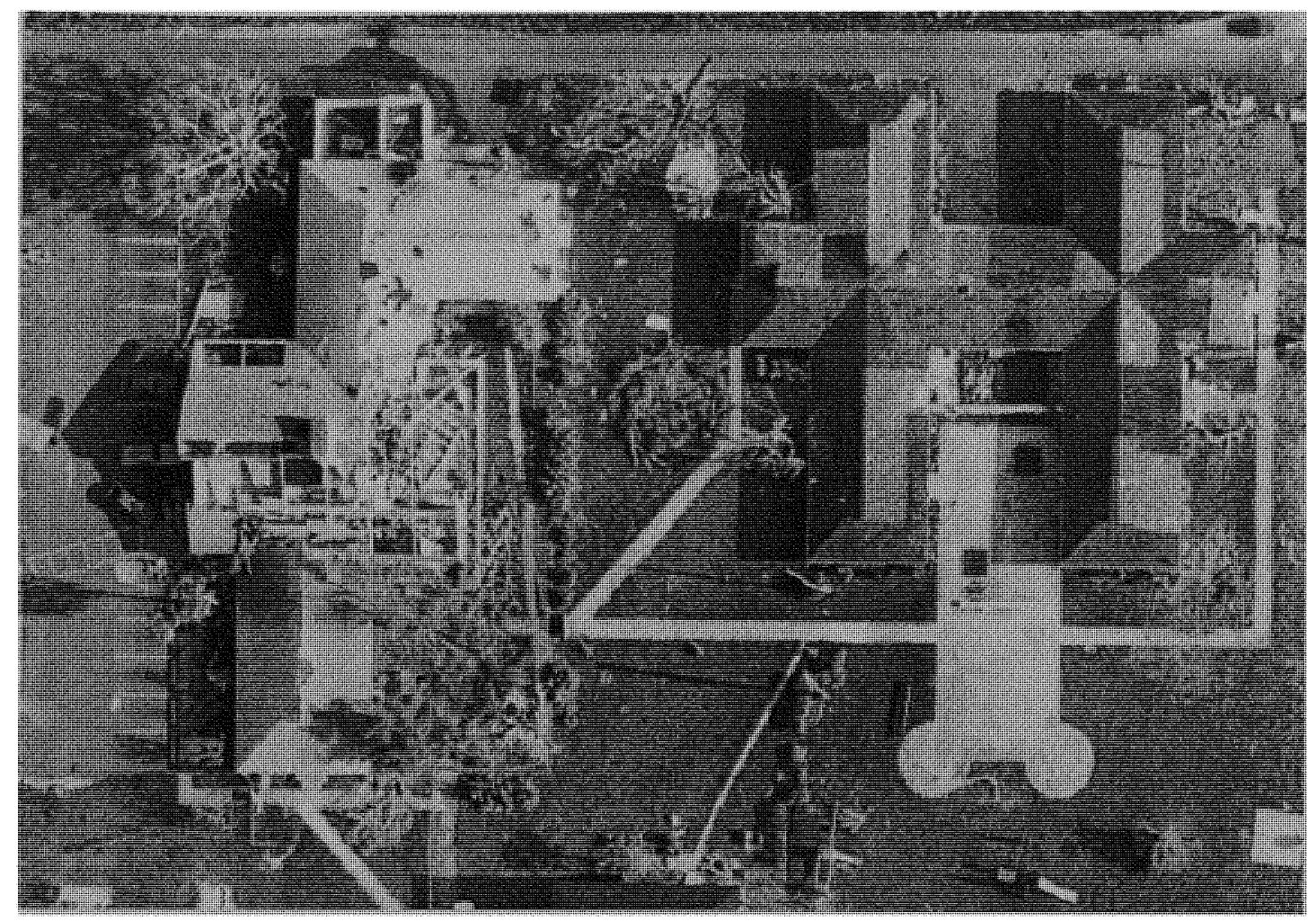

Figure 8.14. Damage to differential roofing system.

This figure shows two structures, which has differential roof system. The left side has a portion of damaged roof whereas the house on the right hand side has minor roof cover damage. This might have occurred due to improper connection between the roof and the exterior walls. Often rafters were attached by toenails to the top plate and in some cases hurricane clips attached the rafter to only the top plate rather than to the wall stud. 


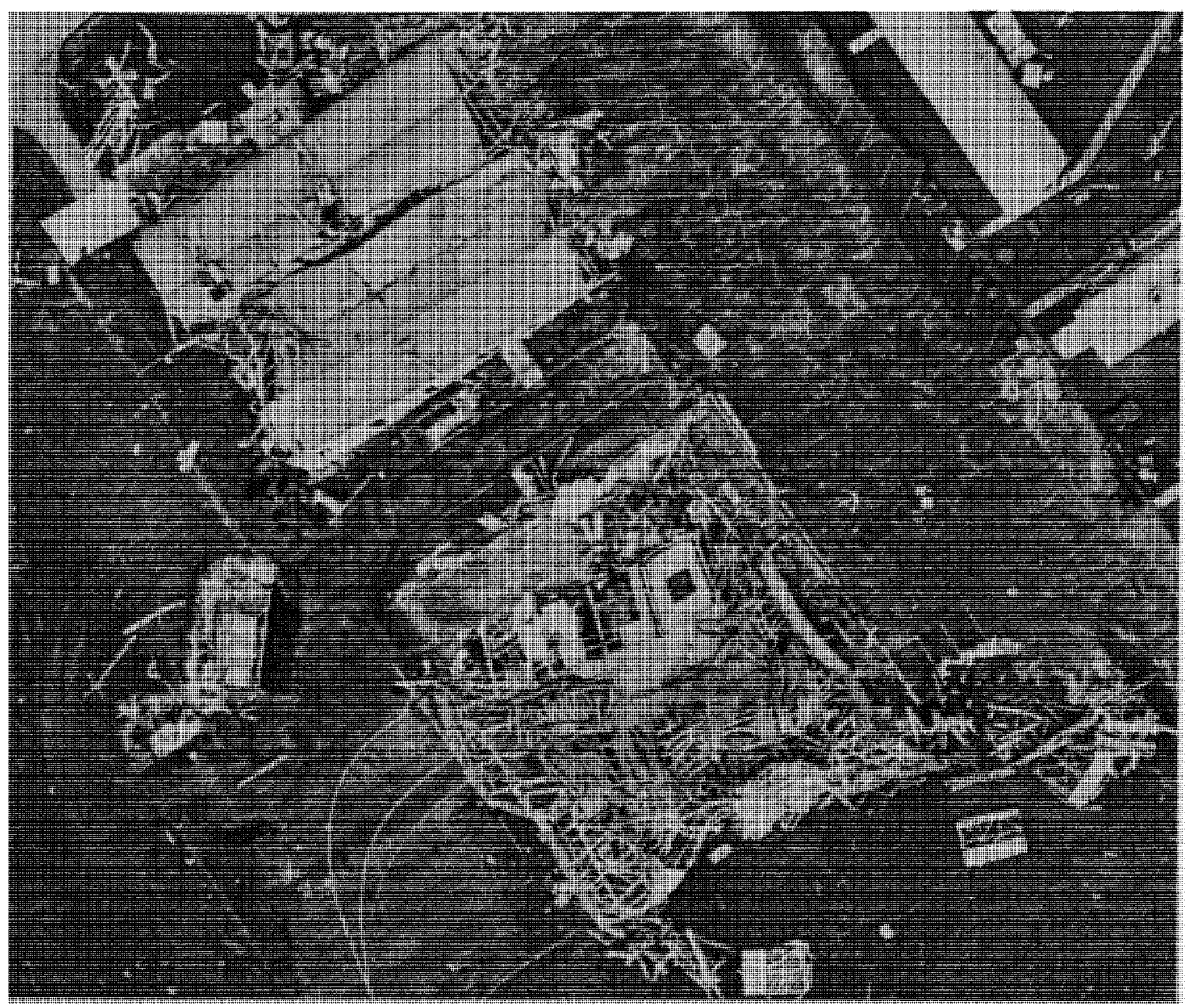

Figure 8.15. Loss of ceiling strength due to water saturation.

This figure shows complete destruction of the structure. Rains accompanying the wind can saturate the insulation and the ceiling. The loss of ceiling strength due to water saturated, and the increased weight of the wet insulation caused widespread collapse of ceilings. The loss of the ceiling a lso c ontributed to gable-end $w$ all failures d ue to the diminished lateral support at the base of the gable-end walls. Improperly reinforced masonry walls failed because of a combination of uplift and pressure forces. These forces combined to lift up the edge of the roof and bond beam, separating the bond beam from the rest of the roof system. 


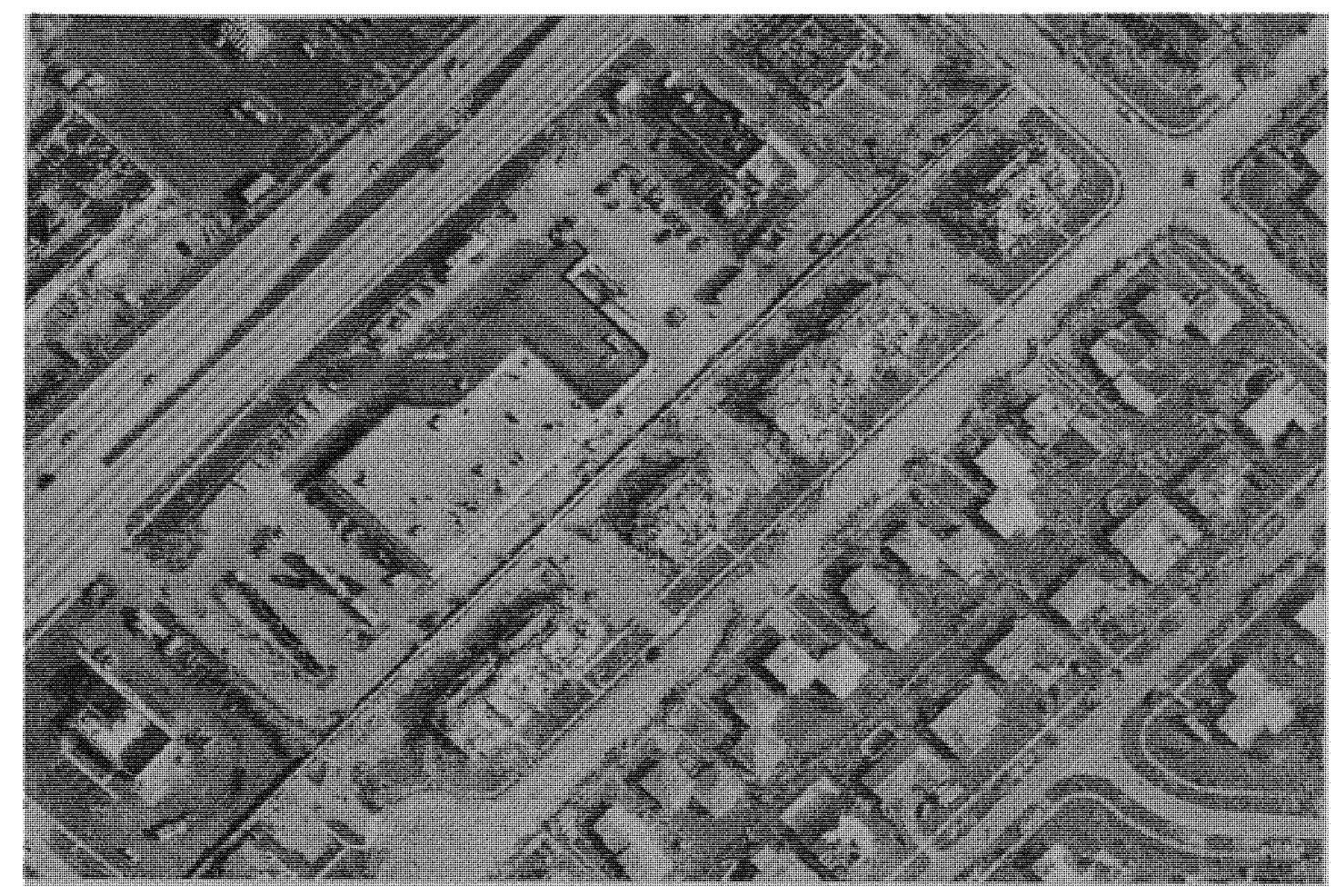

Figure 8.16. Lack of connection between roof cover and sheathing.

This image illustrates $80 \%$ roof cover damage in four major buildings, which have long roof span. The roof coverings might not be adequately attached, and corner and eaves regions of roofs were frequently damaged. Tile roofs, composed of either extruded concrete or clay, showed failures in both nailing and mortar connection. Clay tiles seemed more susceptible to damage from flying debris than concrete tiles. For steep roof systems, as seen above roof failure occurred at the ridge or gable ends where windinduced force were the highest. 


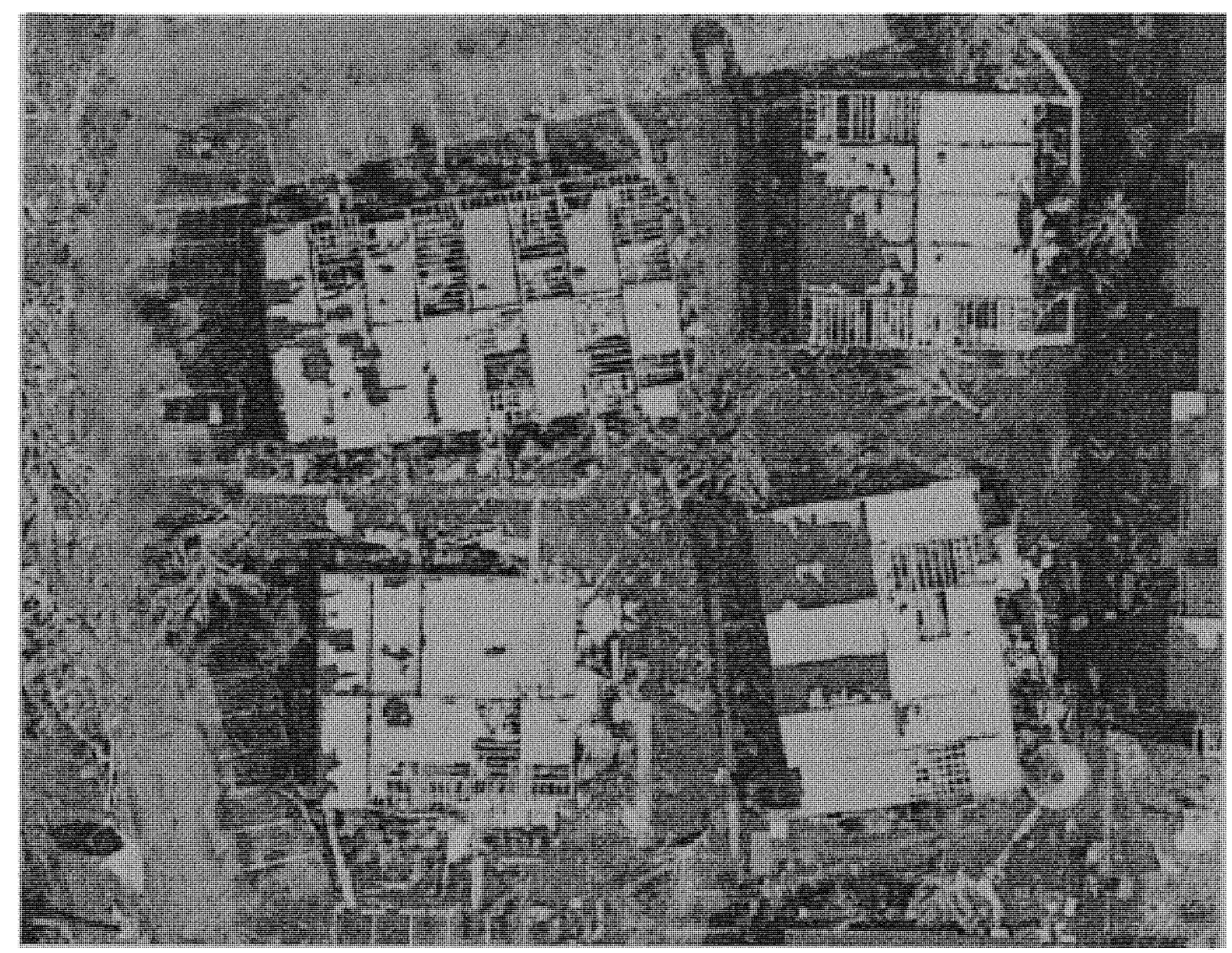

Figure 8.17. Upliftment of rake overhangs.

The figure above shows metal roof cover instead of tiles. The disadvantage of this type of roof cover is that when wind force is applied the entire metal portion is uplifted exposing the trusses. In some cases truss damage can also be observed. To avoid such type of uplift additional support of roof sheathing at overhang rake ends should be provided. Increased stiffness and strength of cantilevered roof systems to provide added resistance to wind uplift forces. Also by increasing the roof diaphragm shear capacity at the ends of the roof decking by creating a blocked roof diaphragm in these areas. These blocked areas have greater stiffness and shear load capacity and the blocking provides improved shear load transfer from gable-end wall framing. 


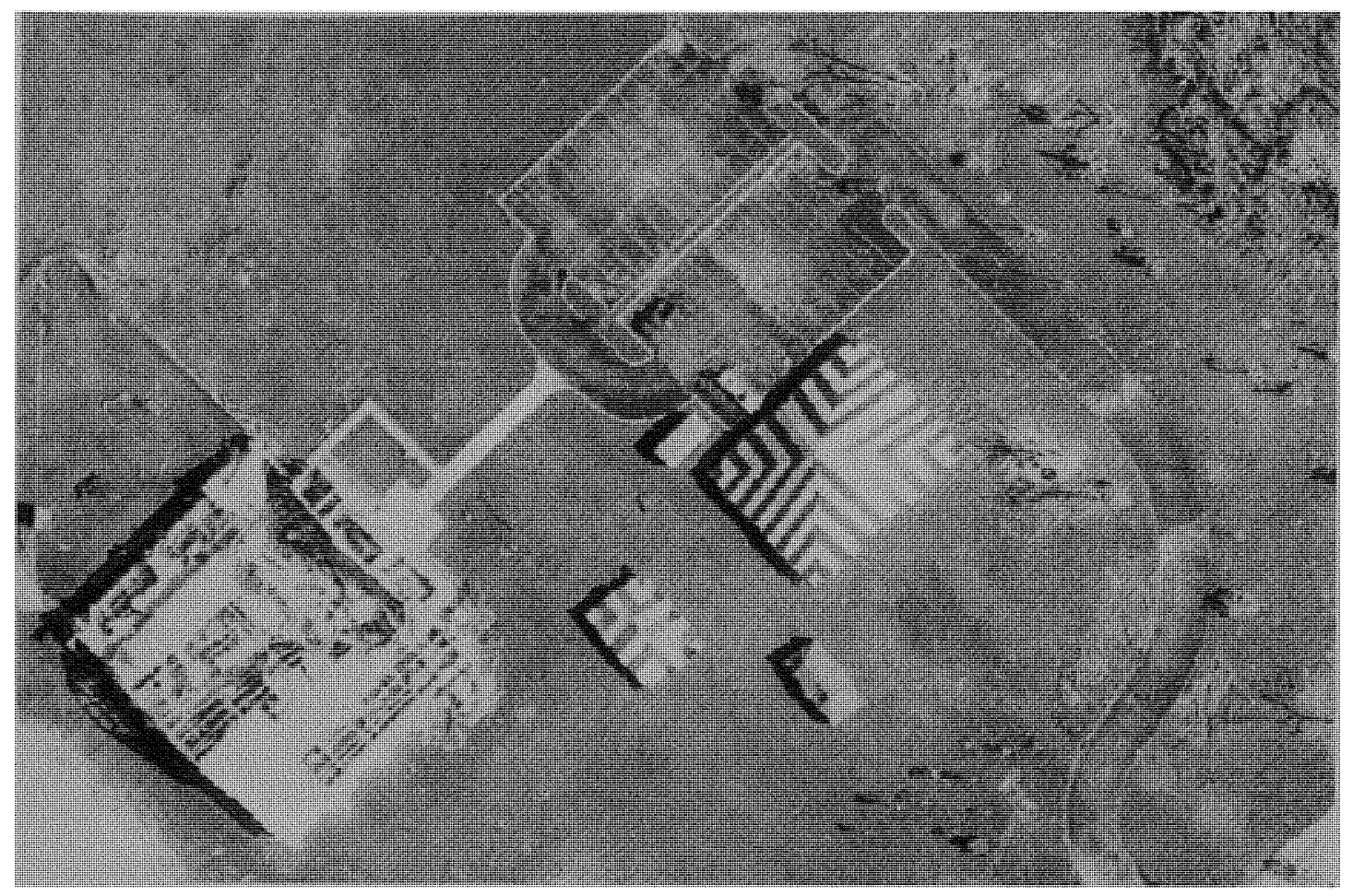

Figure 8.18. Breaching of the building envelope.

Complete failure of the middle portion of the roof is clearly visible. The truss got collapsed within the house. This might be due to breaching of the building envelope which eventually led to roofing removal, broken windows, collapsed doors and damage of to the exterior cladding. There was no damage to the gable end and hence it was intact due to $u$ sage of $p$ roper construction sy stem and foundation a nchorage. There w ere no other houses or trees surrounding this house, which could provide resistance to the wind to avoid such damages. 


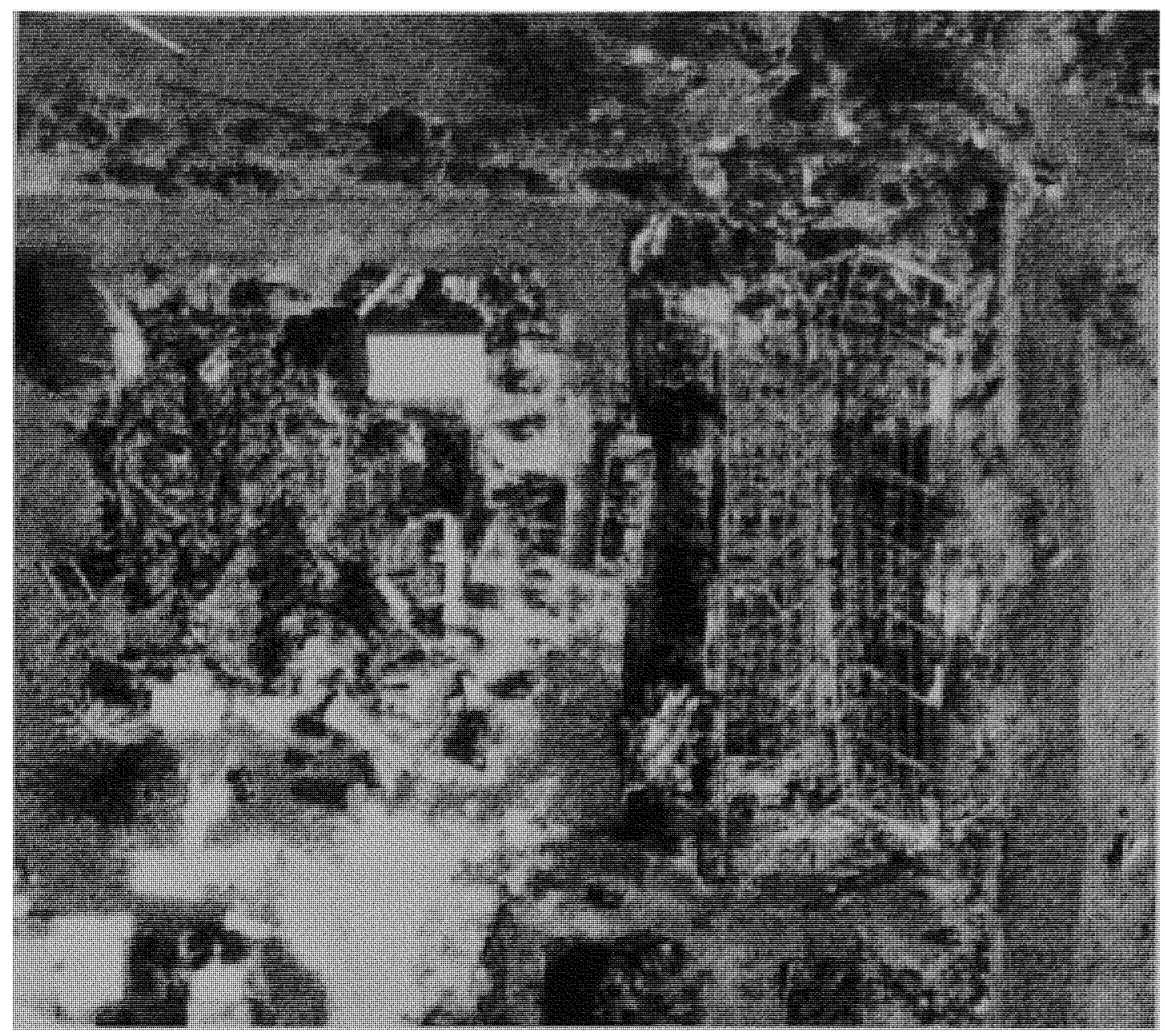

Figure 8.19. Curvature in the main rafter.

The figure shows $50 \%$ damage of the truss. There is $100 \% \mathrm{~d}$ amage to roof truss and sheathing. The main rafter got curved. $100 \%$ gable end destruction is visible. The building on the left-hand side was also destroyed extensively. Wind born debris can be found surrounding the left-hand side building. The entire roof covering and the sheathing was lost might be due to wind uplift force. 
9. INDUSTRIAL BUILDINGS 


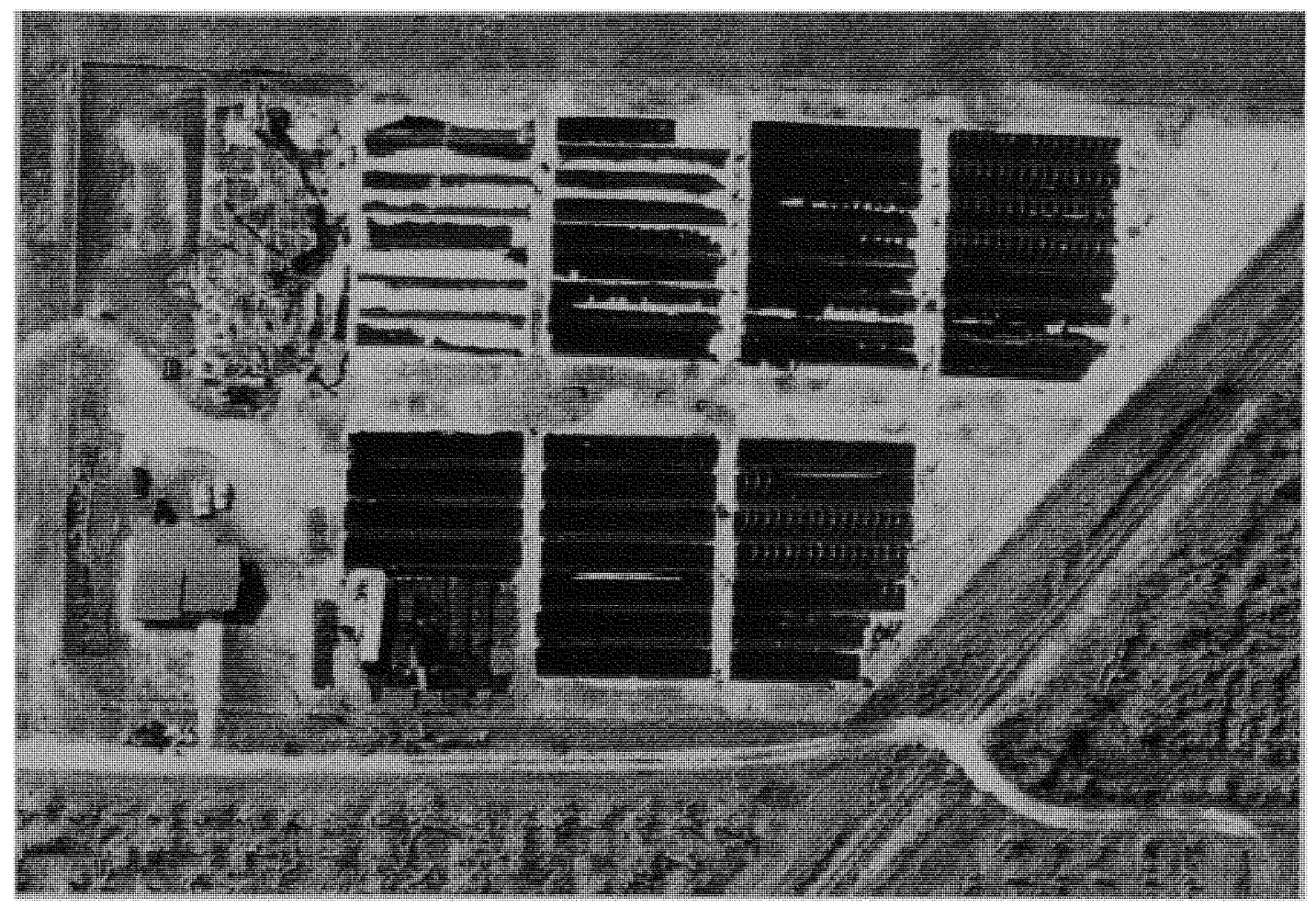

Figure 9.1. Progressive damage of roof cover.

The figure shows that it was some kind of a factory, which has been destroyed partly, that is damage was visible only on the left-hand side. As observed from the damage the factory has metal truss, which has been badly twisted, and bended resulting the truss damage as $100 \%$. It is very clear from the above destruction that the wind had blown from west to east as the extent of damage can be seen from more towards the left hand side and gradually reducing as it progresses. The roofing system of this factory was an $\mathrm{AC}$ sheet covering which failed due to improper connection. Progressive damage is very clear from the above figure. 


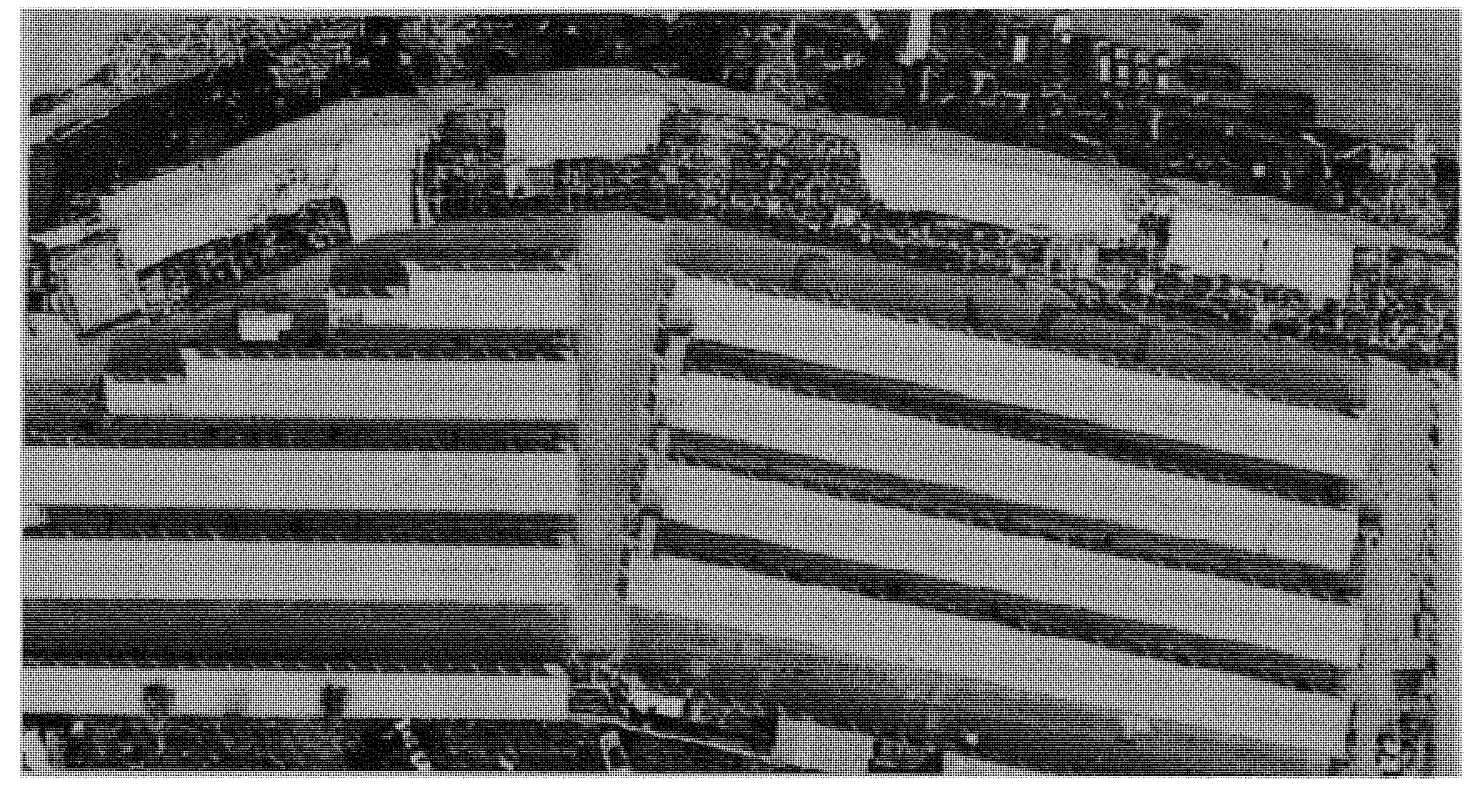

Figure 9.2. Peripheral damage.

This is an example of a small factory building with metal frame and AC sheet covering. Due to the strong hurricane wind force the $\mathrm{AC}$ sheet covering had been blown off and exposing the truss skeleton. Once the sheathing was lost, the building envelope was effectively breached. Wind pressure now exerted against the inside of the building leading to possible failure of the walls and against the underside of the remaining sections of the roof, increasing the likelihood that the remainder of the roof would be lost. 


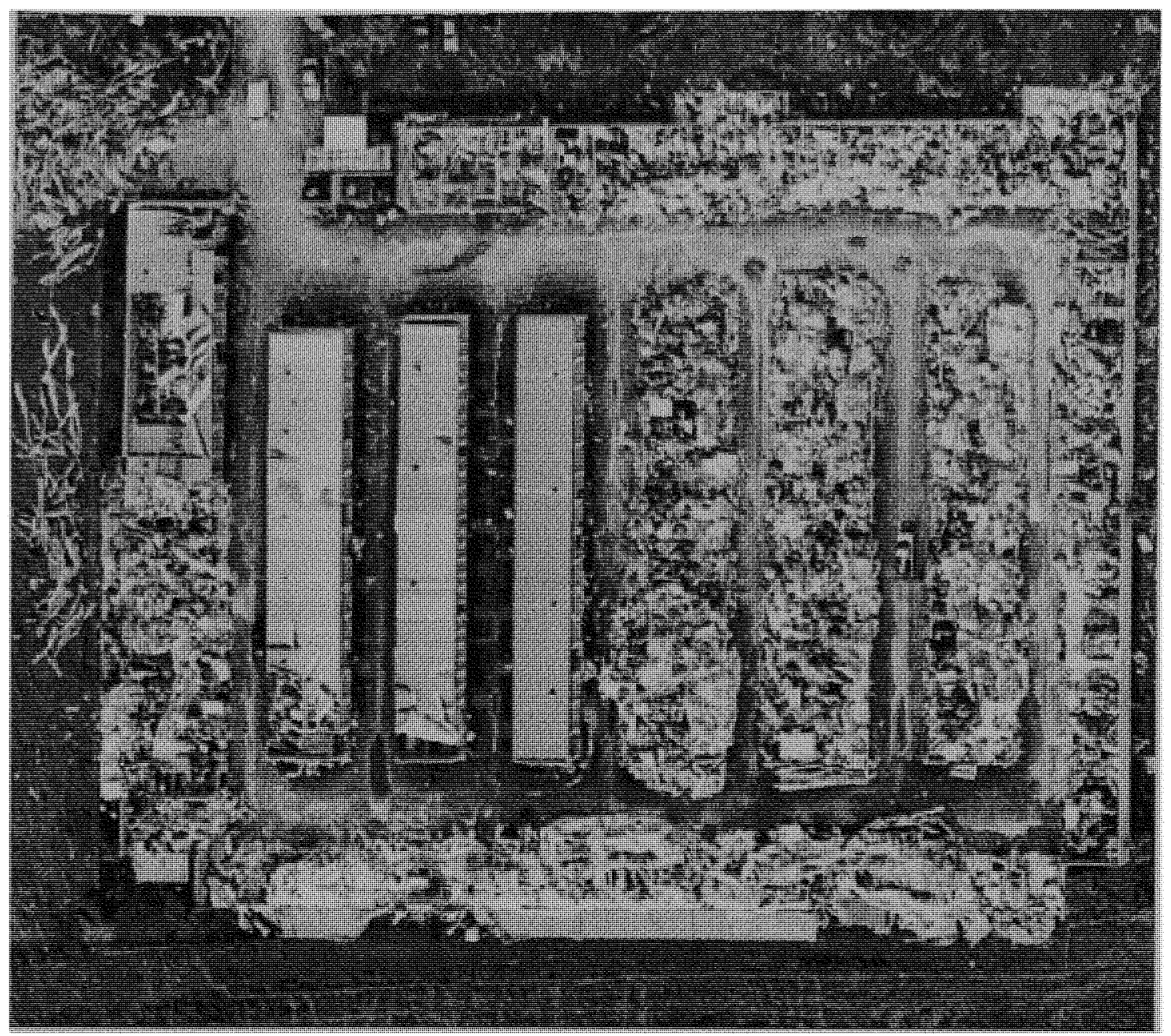

Figure 9.3. High upliftment pressure.

This is an illustration of a small-scale factory work shed that has been excessively damaged. In majority of the units the roof framing system collapsed. The wind direction was from south to north. The uplift pressure was high enough to lift the AC sheets that were placed on the roof frame. The structural failure of the roof framing may be due to design shortcomings such as inadequate fastening of $\mathrm{AC}$ sheets and insufficient anchoring. 
10. CONCRETE STRUCTURES 


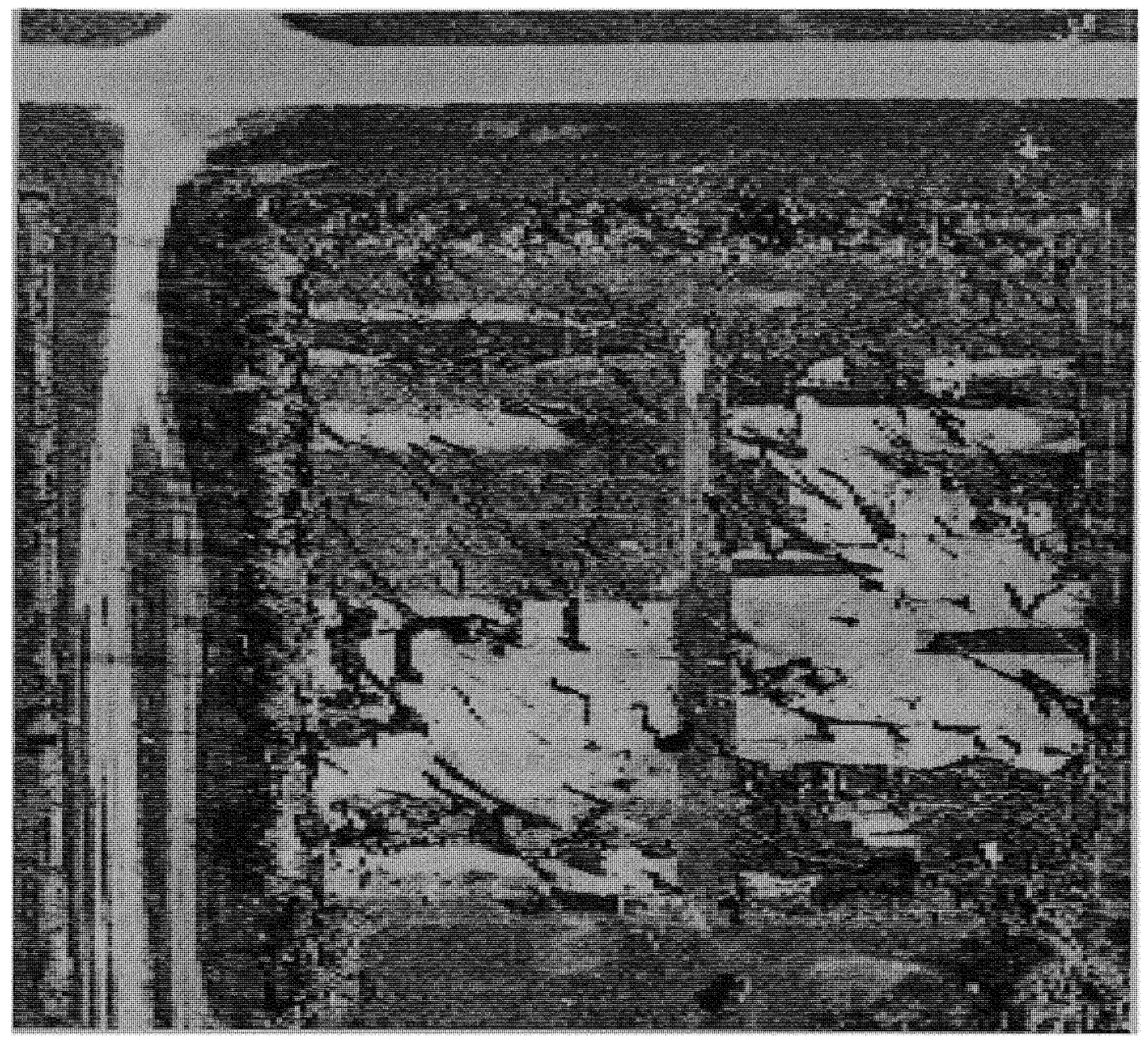

Figure 10.1. High wind velocity.

This figure shows houses with concrete roofs that have been damaged due to the wind impact. The wind velocity was so high that even concrete could not resist and large cracks could be seen on the concrete slab. Damage to the concrete structure might be due to lower grade of concrete, which lacked strength to withstand the wind impact. The exposed steel portion could be seen in the roofs of these structures. The damage to roof slab may in turn effect the walls of this building. 


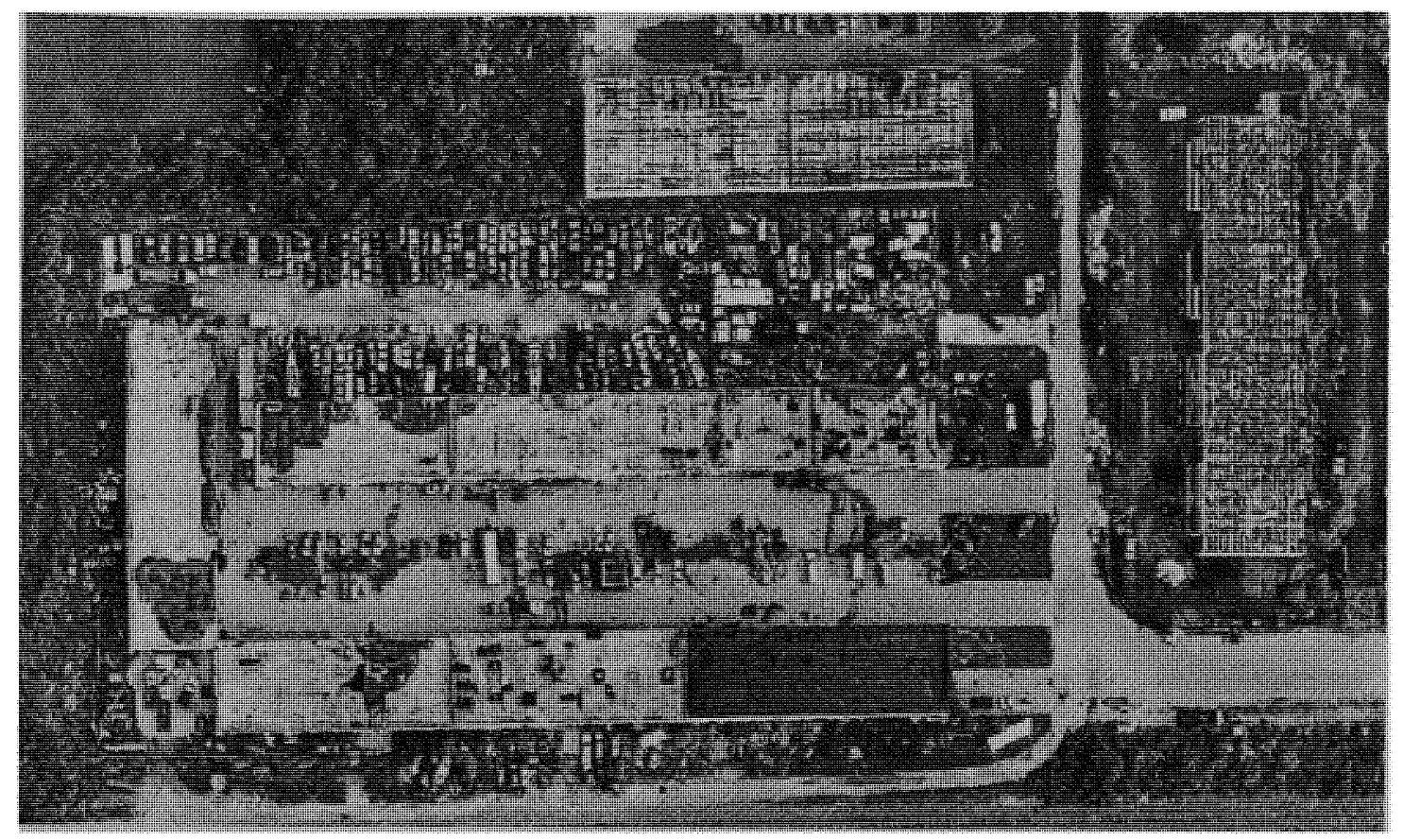

Figure 10.2. Collapsing of concrete roof.

This figure shows a huge building with concrete roofing. This building look like a shopping mall. Roof damage can be observed. It shows that even concrete cannot withstand the high wind impact. Generally the corner portion was mostly affected and the steel portion was exposed. Incase of the right side of the building the roof seemed to be collapsed. This may be due to the wind, which might have blown from east to west causing an impact to the dry wall, and hence the collapse was observed. Even vehicles parked got pusher to the left side by wind velocity. 


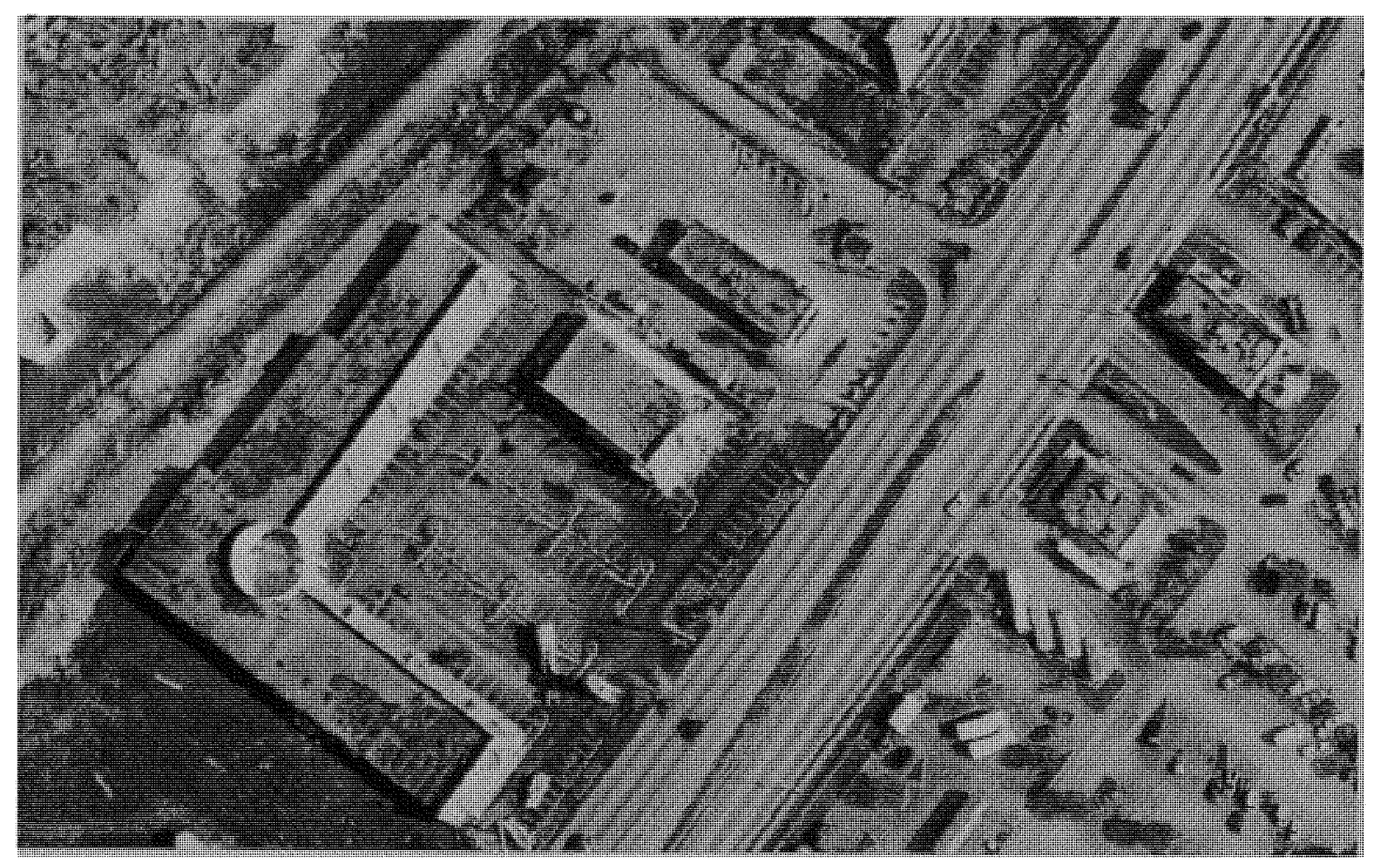

Figure 10.3. Usage of low-grade concrete.

This figure shows a small business center. This business center has concrete roofing system. The force of wind exposed the steel reinforcement part. As seen from the picture even the heavy vehicles were displaced. Some of the debris can be found lying along side of the building. High grade concrete must be used to counteract the wind impact. There were no major trees to function as a barrier and protect from the roof damage. 


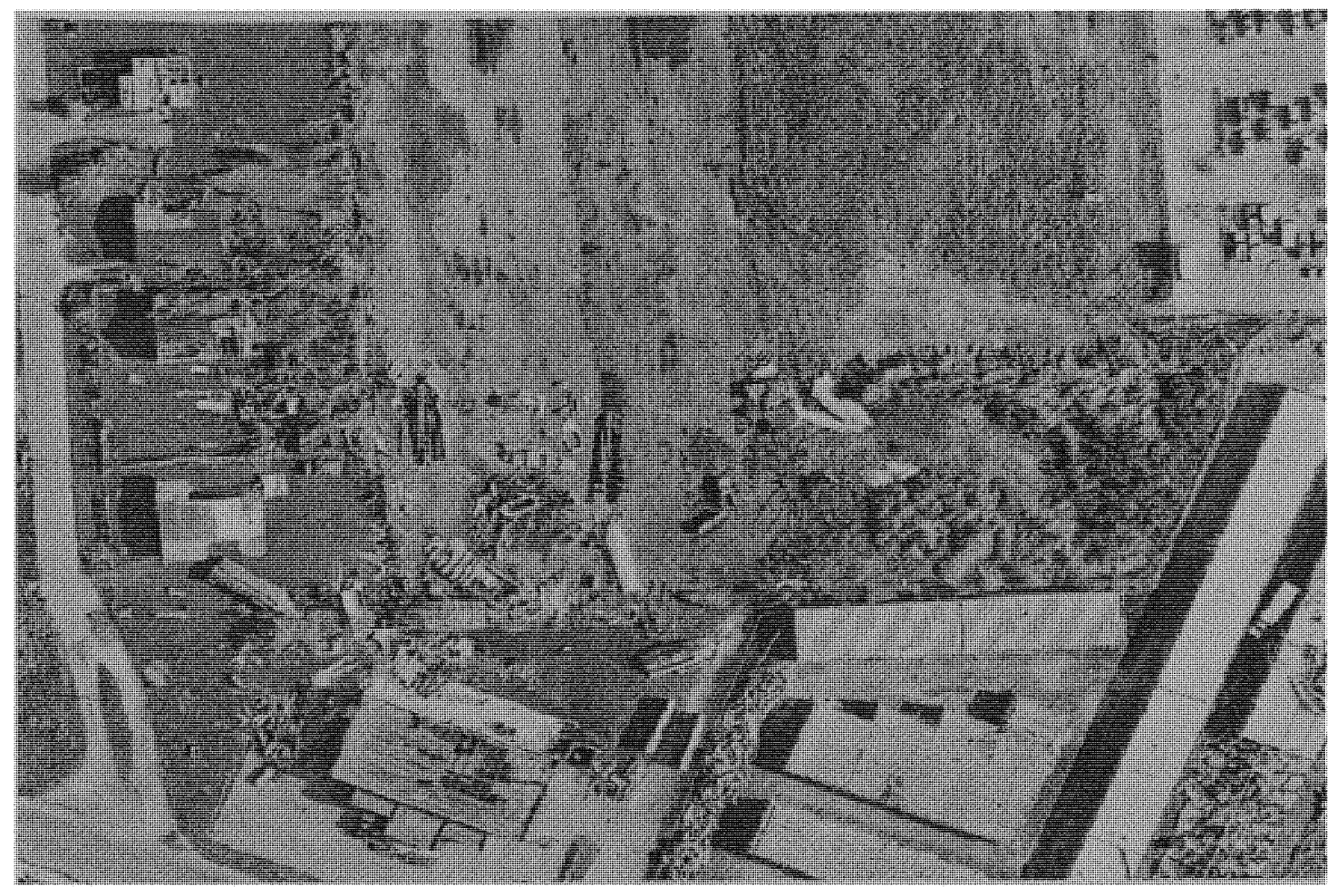

Figure 10.4. Composite construction: concrete and timber.

This figure shows that this area consist of composite concrete and timber roof truss structure. In case of concrete structure the steel part can be seen exposed. The area is scattered with debris with small boats turned upside down. The area had few homes and hence the wind got a clear path to destroy the structures. The observed failure in concrete structures was poor mortar joints between walls and slab, lack of tie beams, horizontal tie columns and tie anchors and misplaced or missing hurricane straps between walls and roof. 


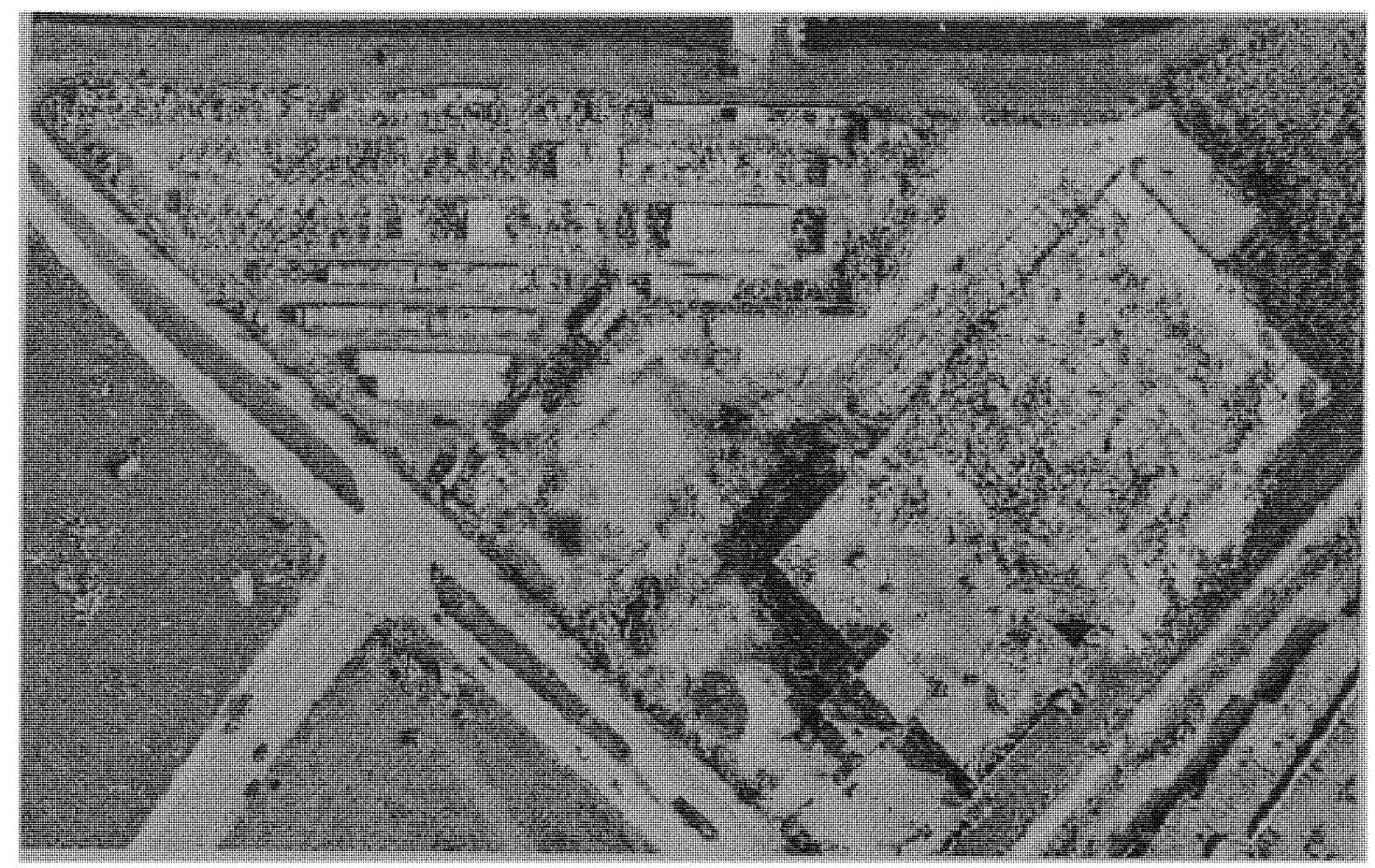

Figure 10.5. Omission of reinforcement bars at the intersection.

This figure shows some kind of workshop. The area is partly built with gable-end roofs and the other portion there is a concrete structure. In case of the gable-end roof it has metal roof covers instead of tiles. The wind stream generates uplift as it divides and flows around a structure. According to Bernoulli's principle, as the wind speeds up across the roof, the pressure drops, generating uplift. The roof, in effect, acts as an airfoil and a ttempts to take off from the remainder of the building. Failure of the $w$ alls $w$ as observed which might be due to the omission of reinforcement bars at the wall intersections or at corners. These intersections provided continuity of tie beam reinforcing. When this deficiency existed in combination with failure of the tie beam to roof connection, the wall collapsed. 


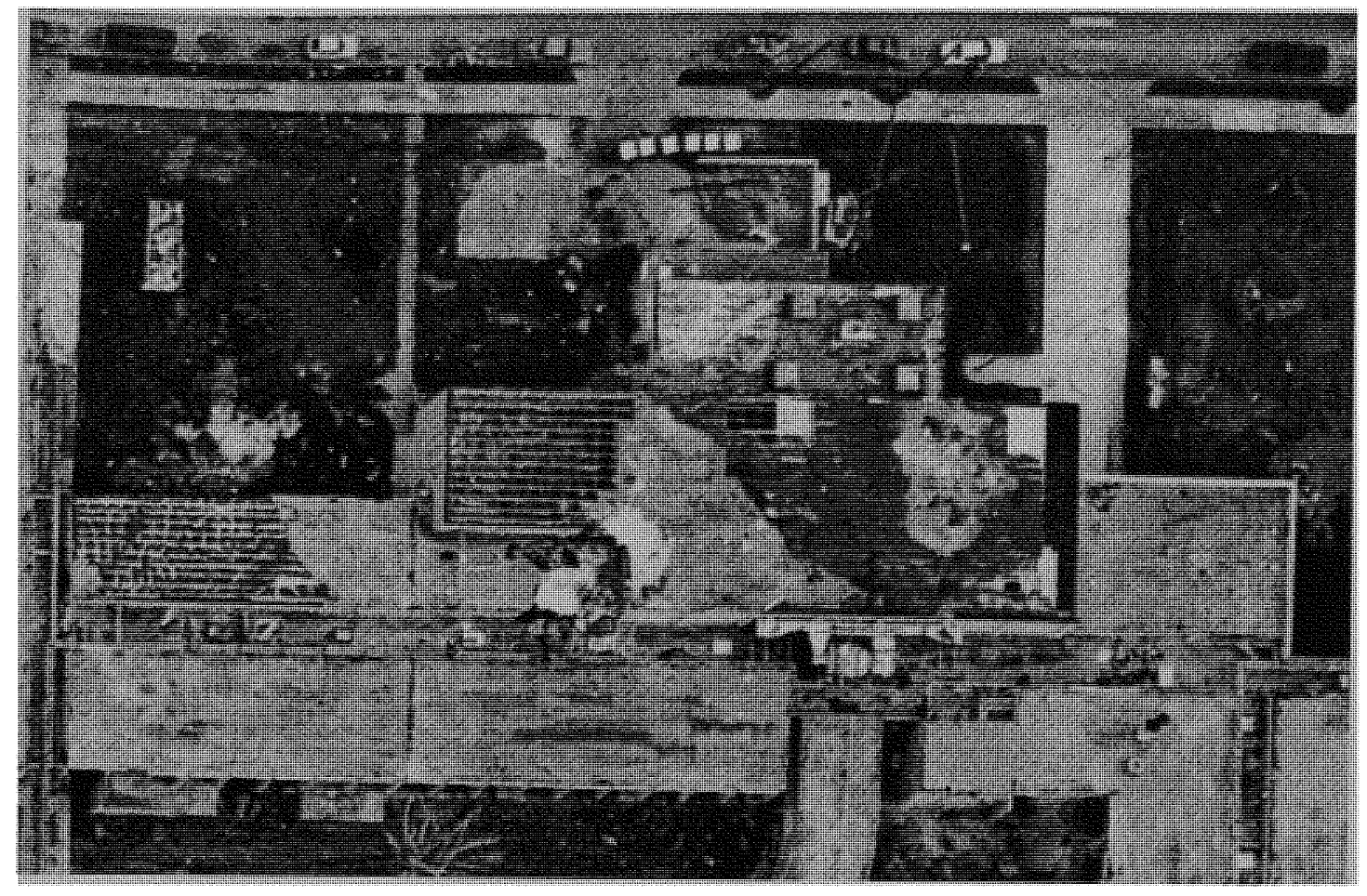

Figure 10.6. Multistoried RCC structure.

This is an example of a multistoried building, an RCC structure. The roof damage had exposed the steel reinforcement. The failure of the roof exposes the interior of the buildings to devastation and often contributes to the weakening and further collapse of the remaining structure. Usage of high strength reinforced steel and higher grade concrete should be to resist the wind pressure and avoid damages to important multistoried structure. 
11. WARE HOUSE 


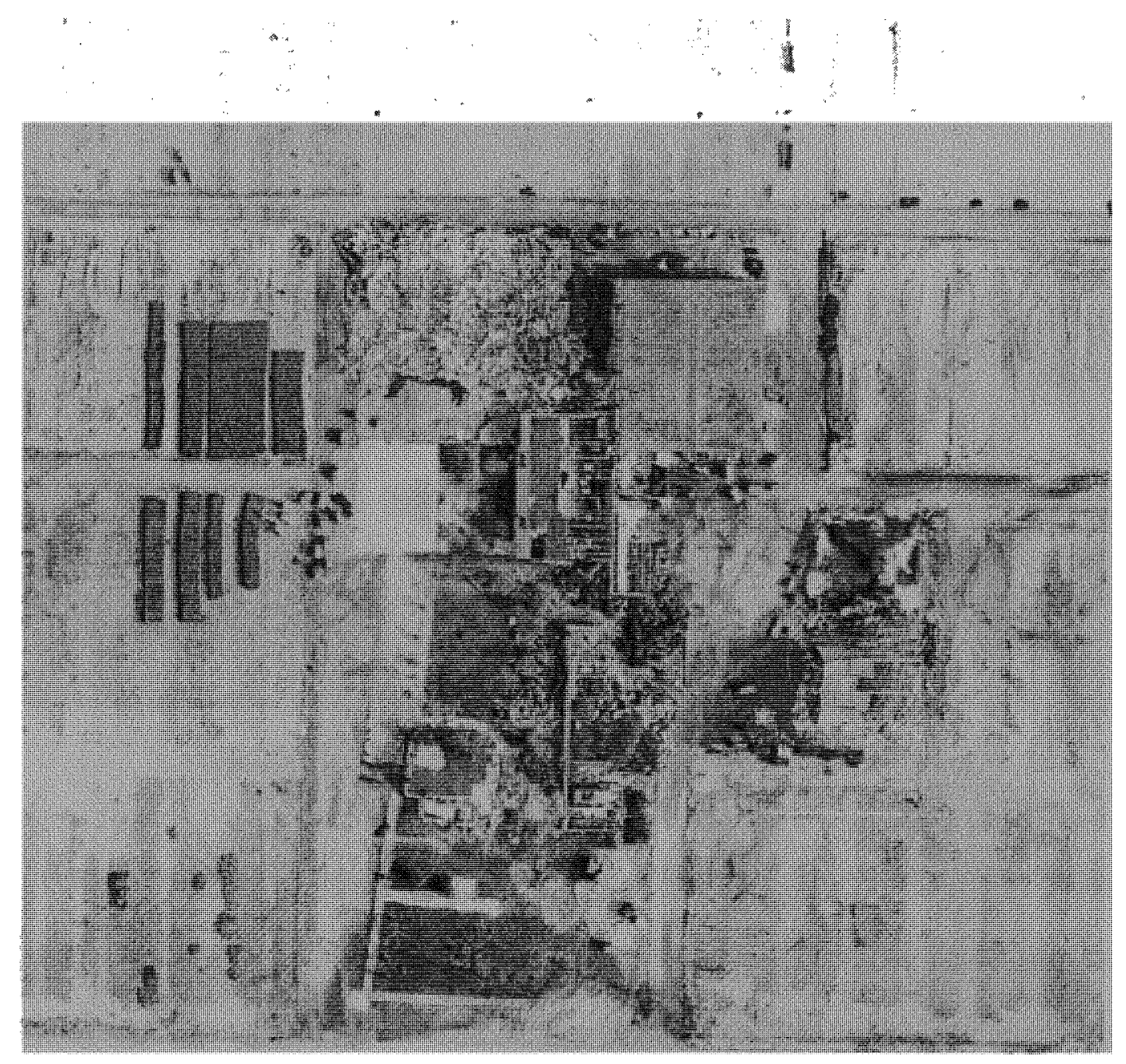

Figure 11.1. Clear wind path for isolated warehouse.

This image looks like a warehouse, which is badly damaged. The roof cover of this entire storehouse has been removed by strong wind force. Some structural damages of the truss can be observed. The wind damage cannot be predicted very accurately as there are no trees surrounding the warehouse. Even some the concrete structure (i.e. the roof) did not survive the wind impact. Major cracks can be seen very clearly. 


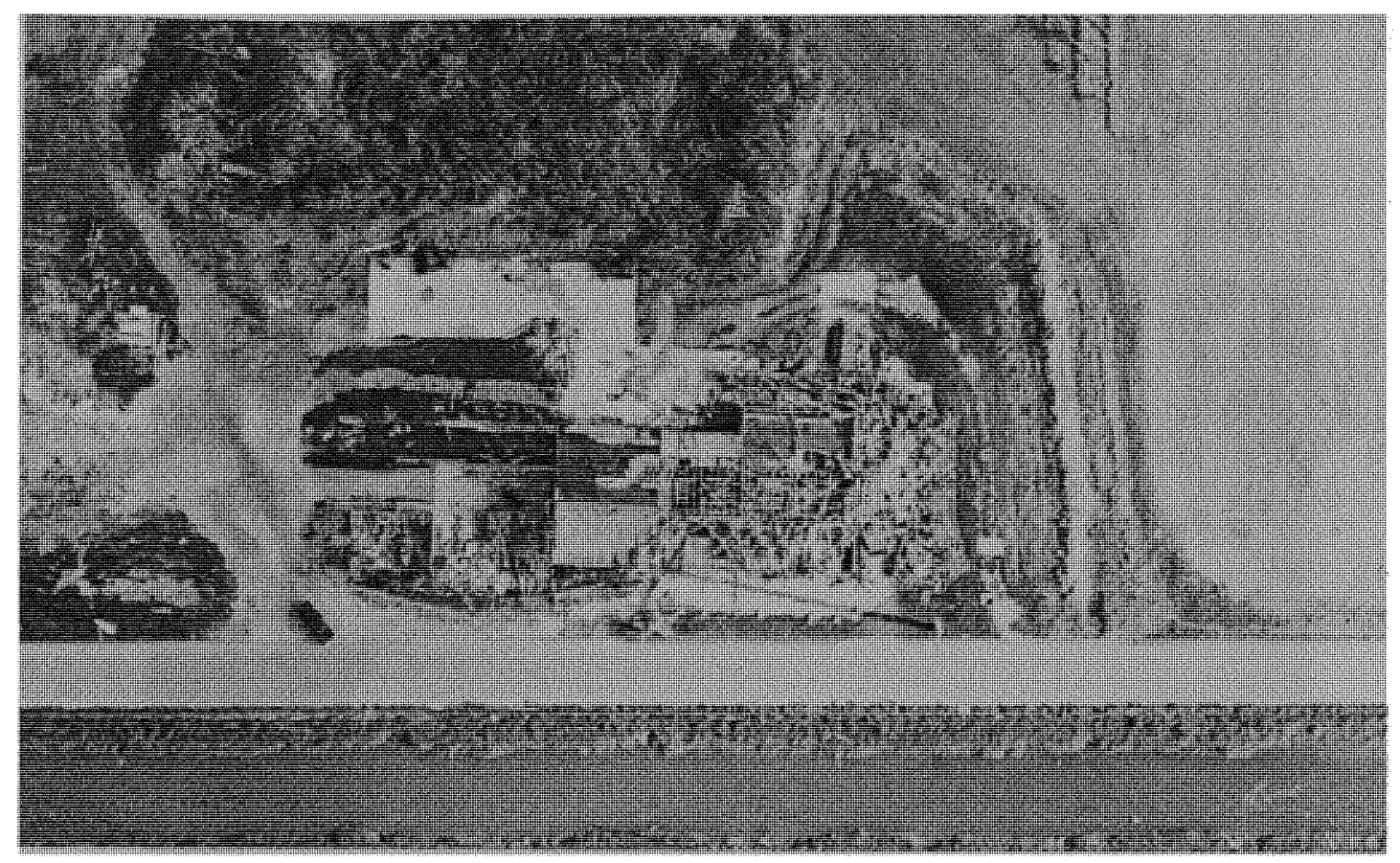

Figure 11.2. Instability caused due to loss of sheathing.

This is an example of an isolated structure standing in the middle of an agricultural field. There is $80 \%$ damage to the roof system and $50 \%$ damage to the gable end. Roof sheathing is a critical component that locks all other roof members together to form a structural system. Loss of roof sheathing led to instability and subsequent failure of the wood frame gable ends and trusses. The wood frame gable ends of roofs were especially failure-prone. 


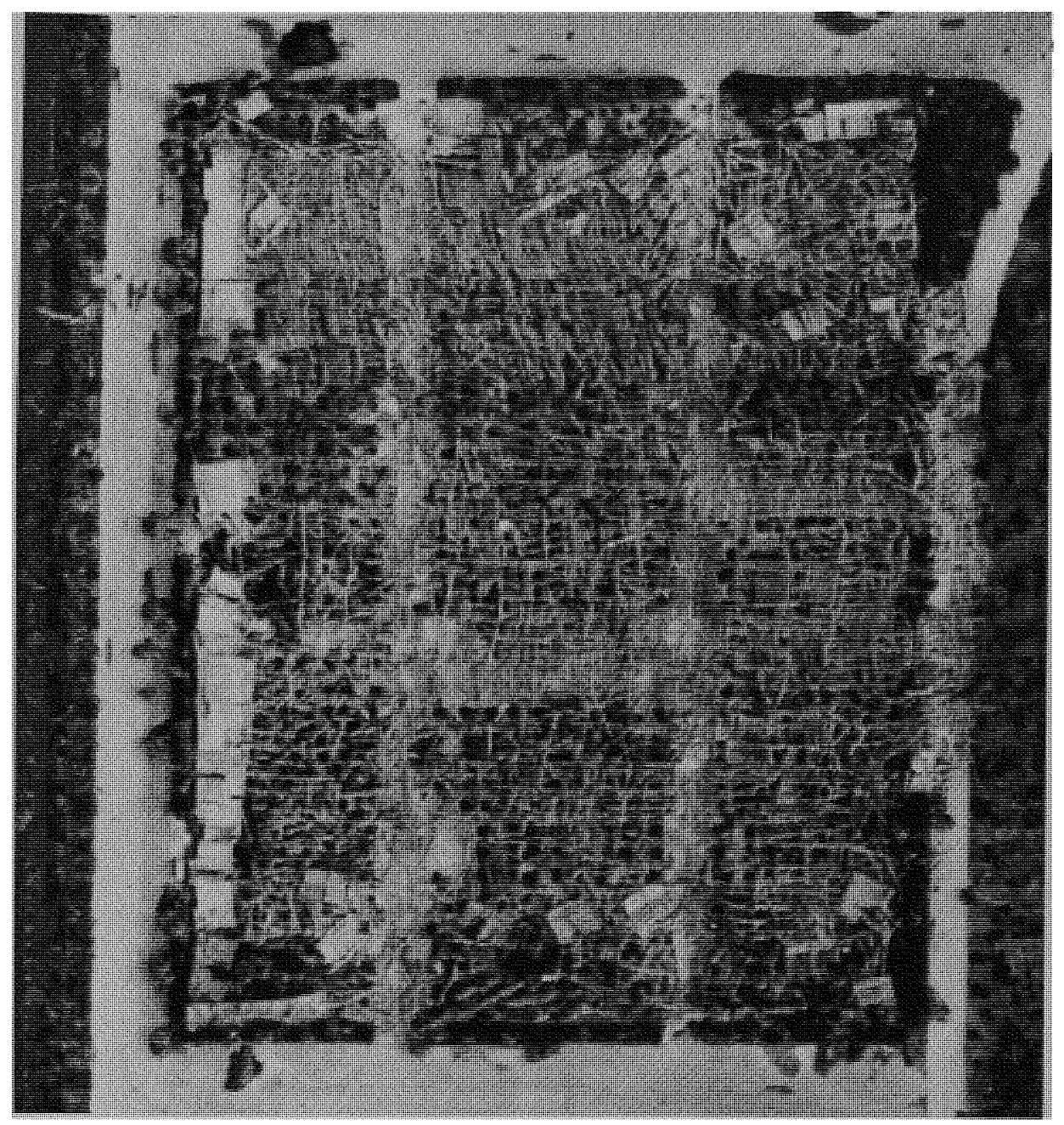

Figure 11.3. 100\% damage to roofing system.

The figure shows s ome kind of s torage h ouse w ith timber r oof truss, which $\mathrm{h}$ as b een completely damaged due to storm surge. The overall roof system damage is $100 \%$. The collapse of the roof truss might be due to inadequate stiffness from the siding materials that has been used and also might be due to lack of secondary bracing. Substantial improvement could be expected in wind resistance of wood-frame trusses by improved roof sheathing attachment, improved roof covering methods or materials and skill connections between the frames when the span increases. 
12. FARM STRUCTURES 


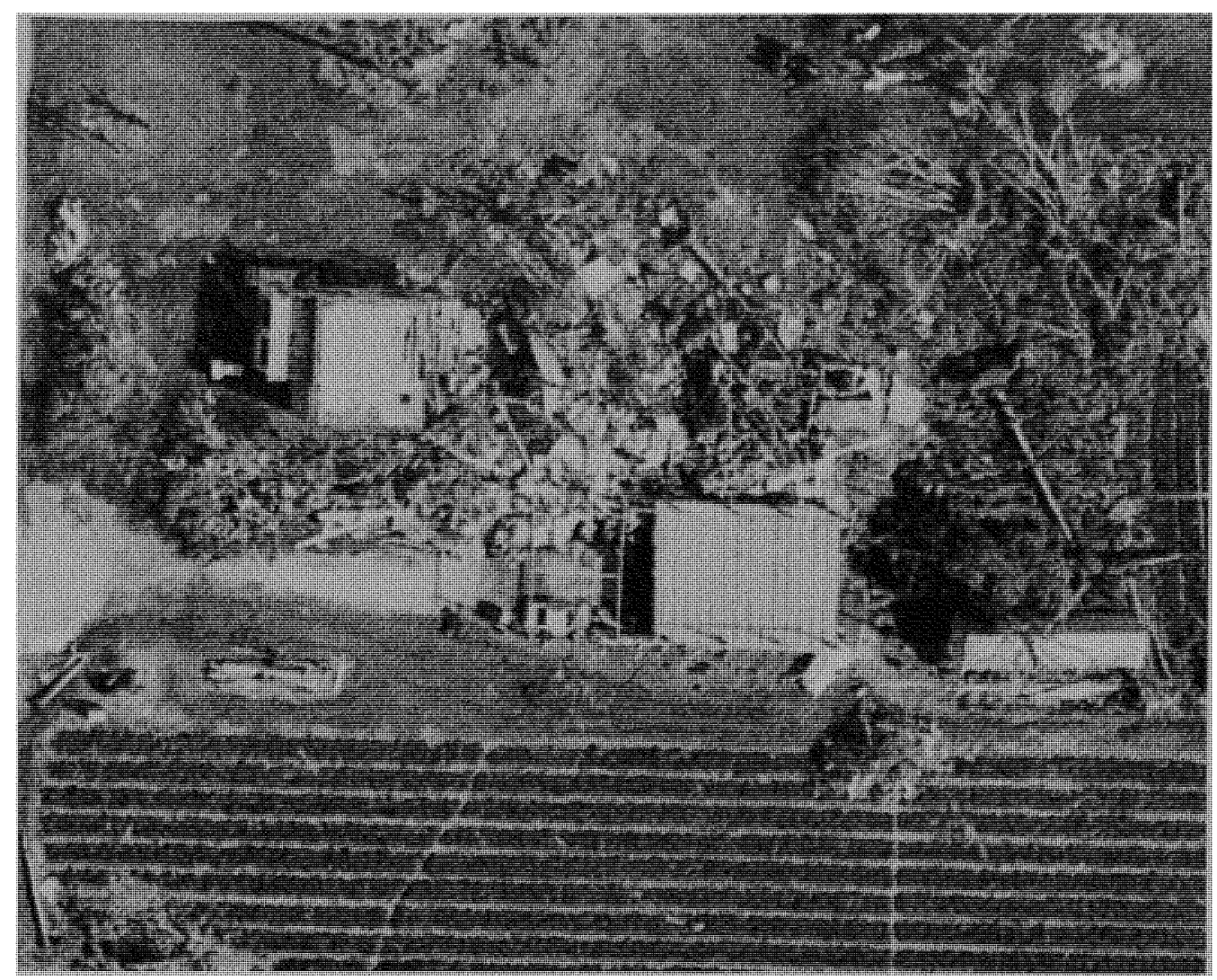

Figure 12.1. Damage due to wind borne debris.

The figure shows wind borne debris scattered all around the house. There were numerous trees and the wind direction $\mathrm{c}$ an $\mathrm{b}$ e very well predicted. The wind $\mathrm{w}$ as blowing from south-east to north-west. Uprooted trees can be seen in picture. 


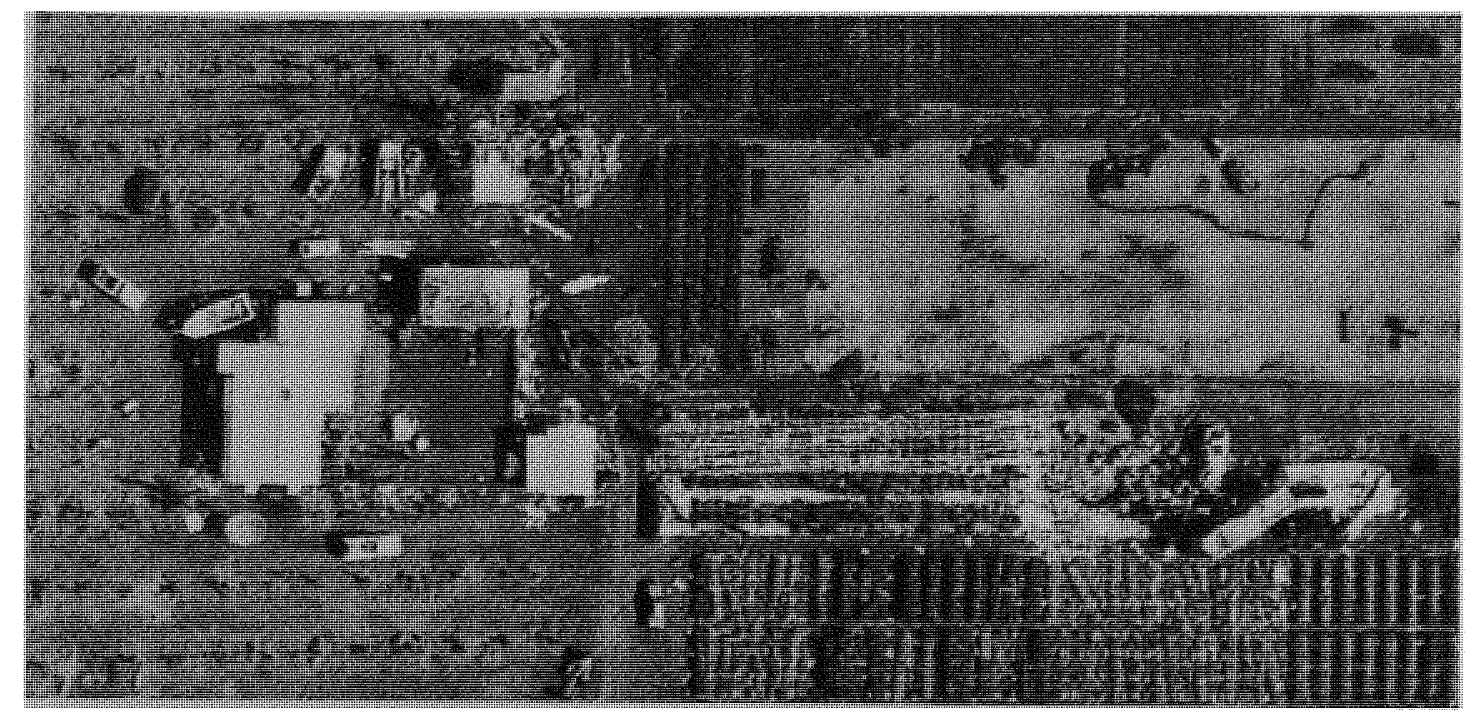

Figure 12.2. Large roof span.

The figure shows extensive damage of the house. The house might be some kind of storehouse. The roof cover, sheathing, trusses and the gable end have been badly damaged. The wooden framework was completely destroyed. The over all structure has collapsed. The wind direction cannot be predicted with the extent of damage. There are numerous small boats, which had been dislocated. Secondary bracing appeared to be more important to taller roofs with larger gables. 


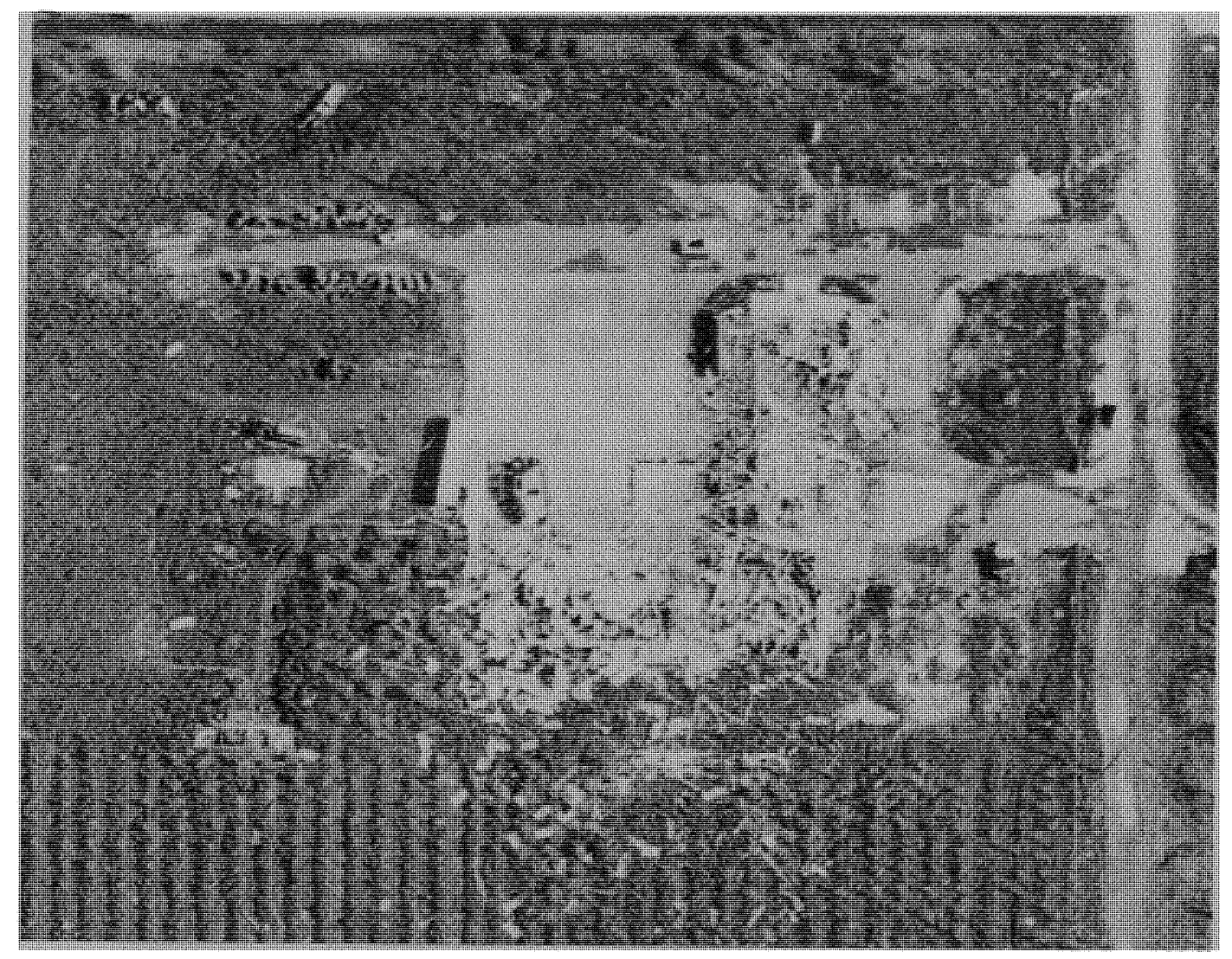

Figure 12.3. Insecurely fastened roof frames.

The figure shows a farm structure, which was situated, in the middle of the field without any kind of barrier. There are no houses or trees surrounding this house. The wind got an unobstructed path and it directly hit the house. The roof cover, sheathing was completely damaged. The roof framing (rafter) was completely destroyed. This shows that the frame wad not securely fastened with other members. The debris from this house was all around the as seen in the picture. The pieces of the rafter found scattered all around round the building. The house should have trees surrounding it to provide as a barrier against such strong winds. Trees could resist the wind force and such extensive damage would not have occurred. 


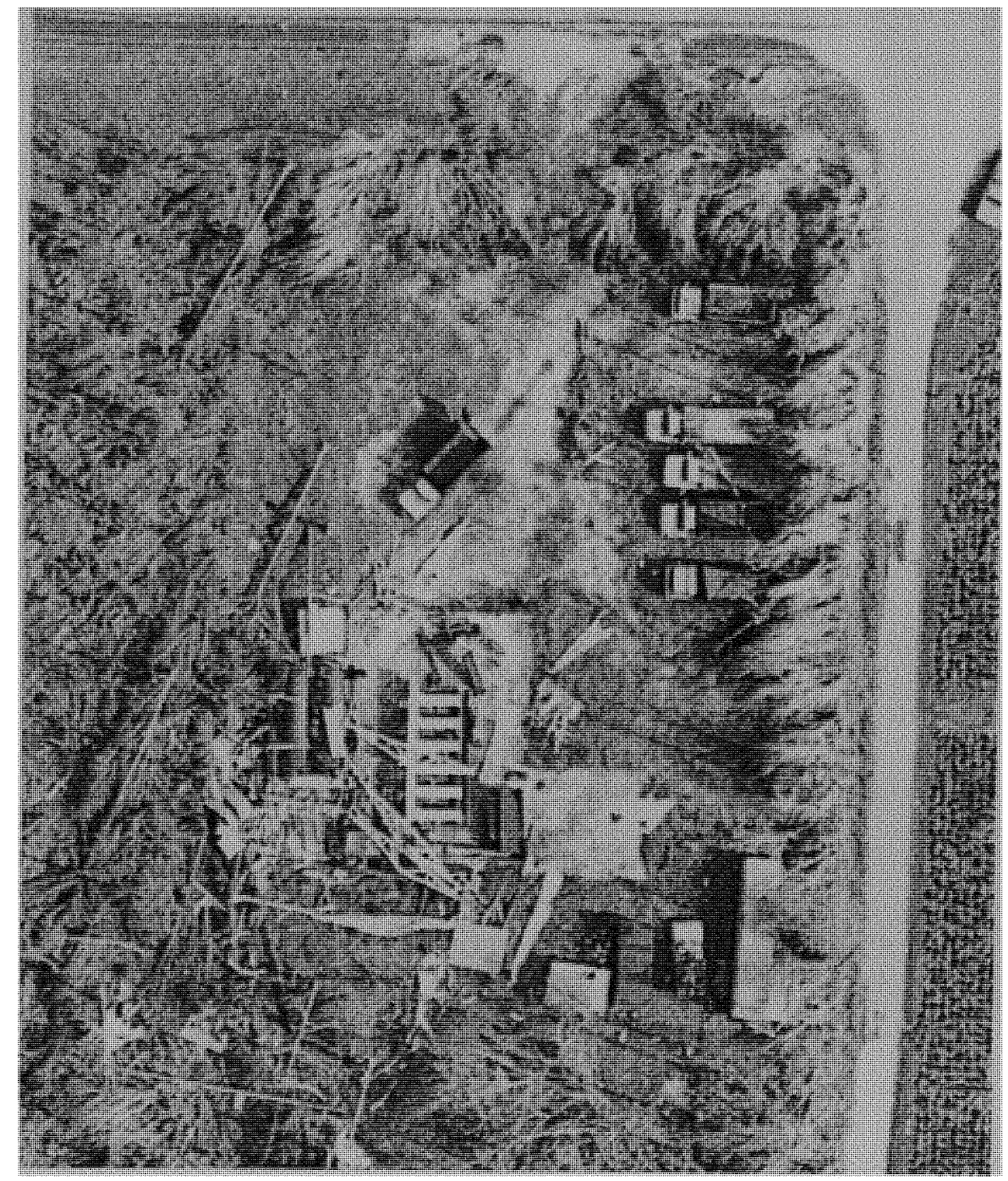

Figure 12.4. Accumulation of debris due to dislocation of trusses.

This figure shows a farm structure, which has been destroyed by hurricane. Major structural damages can be observed. The truss framework has been completely destroyed. The wind was blowing from east to west as seen from the bending of the trees. The accumulation of debris was due to dislocation of roof frame structure. The trees were located far from the house and the wind speed was extremely high and hence could not provide a major barrier to protect the house. 


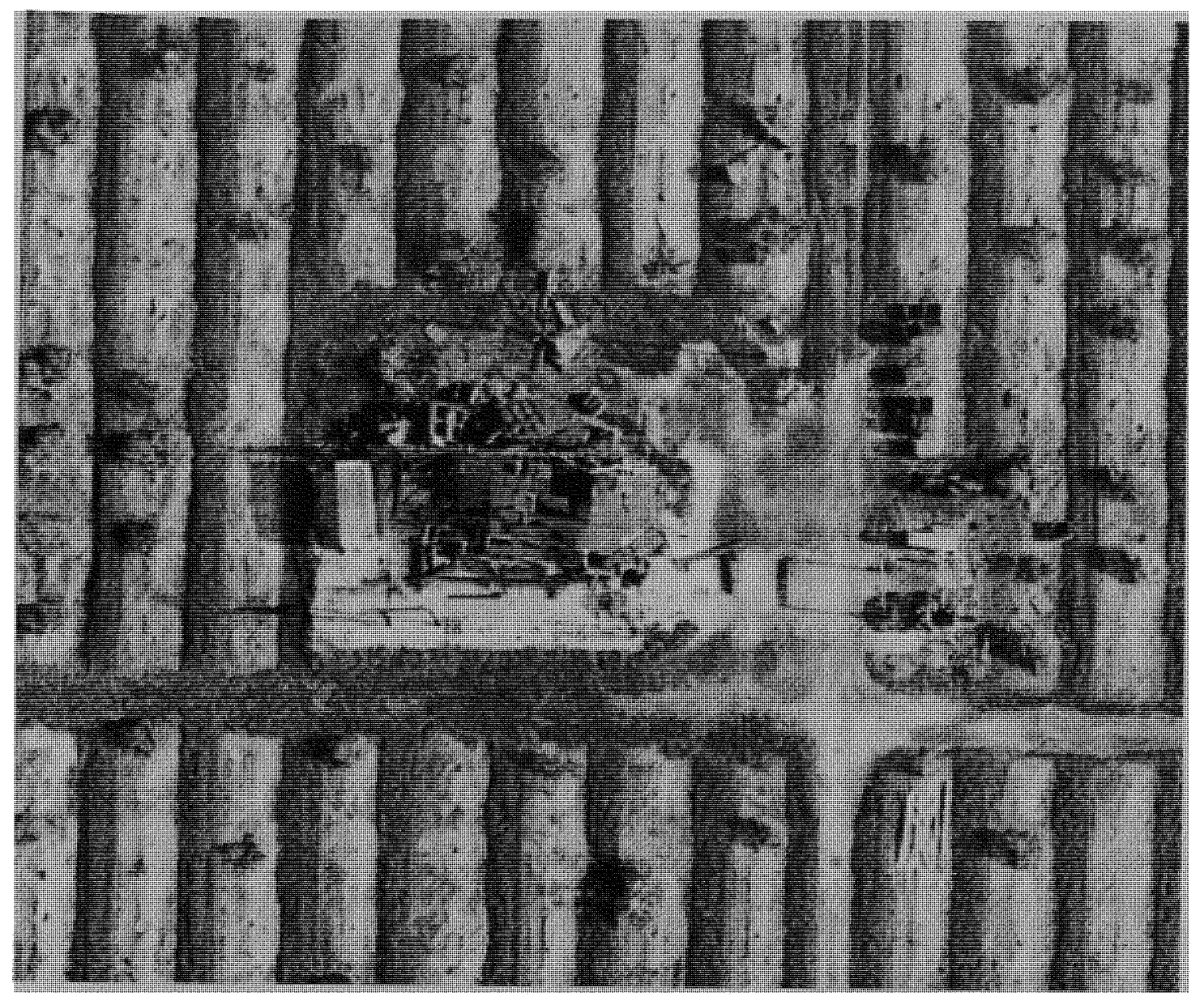

Figure 12.5. Unobstructed wind path.

The figure shows a damaged house standing in the middle of an agricultural field. It is seen in the figure that the entire roof has been blown off including the dry walls. Parts of trusses can be seen lying on the ground besides the building. There were no trees that could have obstructed the wind from being directly striking the building. As seen there is a major structural damage. The roof cover and the sheathing have been completely blown off. This may be due to inadequate tie up between the materials. The wind direction might have been from south to north as predicted from the fallen debris. 


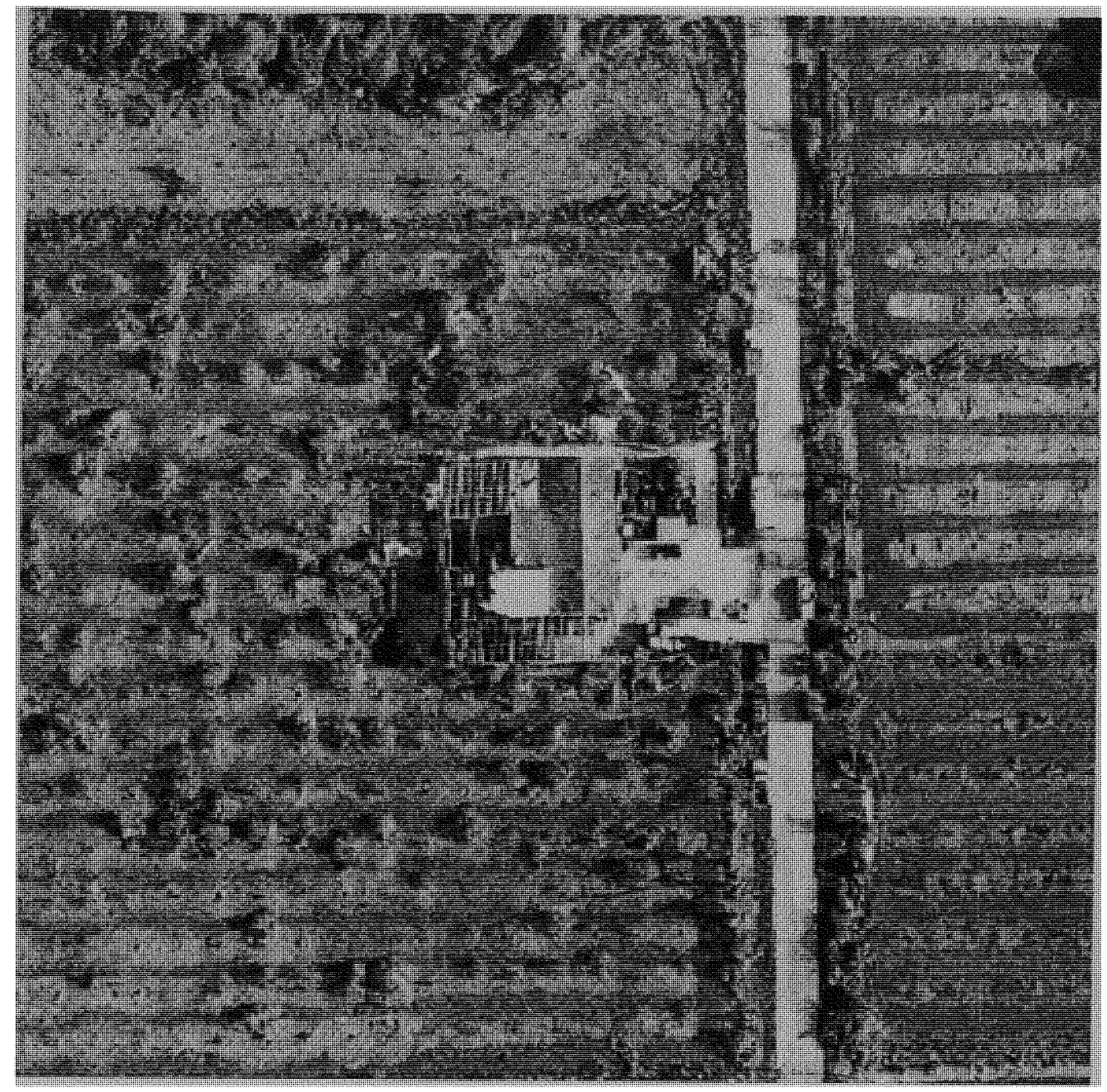

Figure 12.6. Damage to windward portion of the house.

This figure shows a house standing in the middle of the field. There were no major obstruction such as trees or other houses and the wind got a clear path to blow off the roof cover, the sheathing and even the truss was partly damaged. The failure of the truss might be due to lack of bracing and internal support. The wind direction might have been blown from west to east causing damage to the windward portion of the house. 


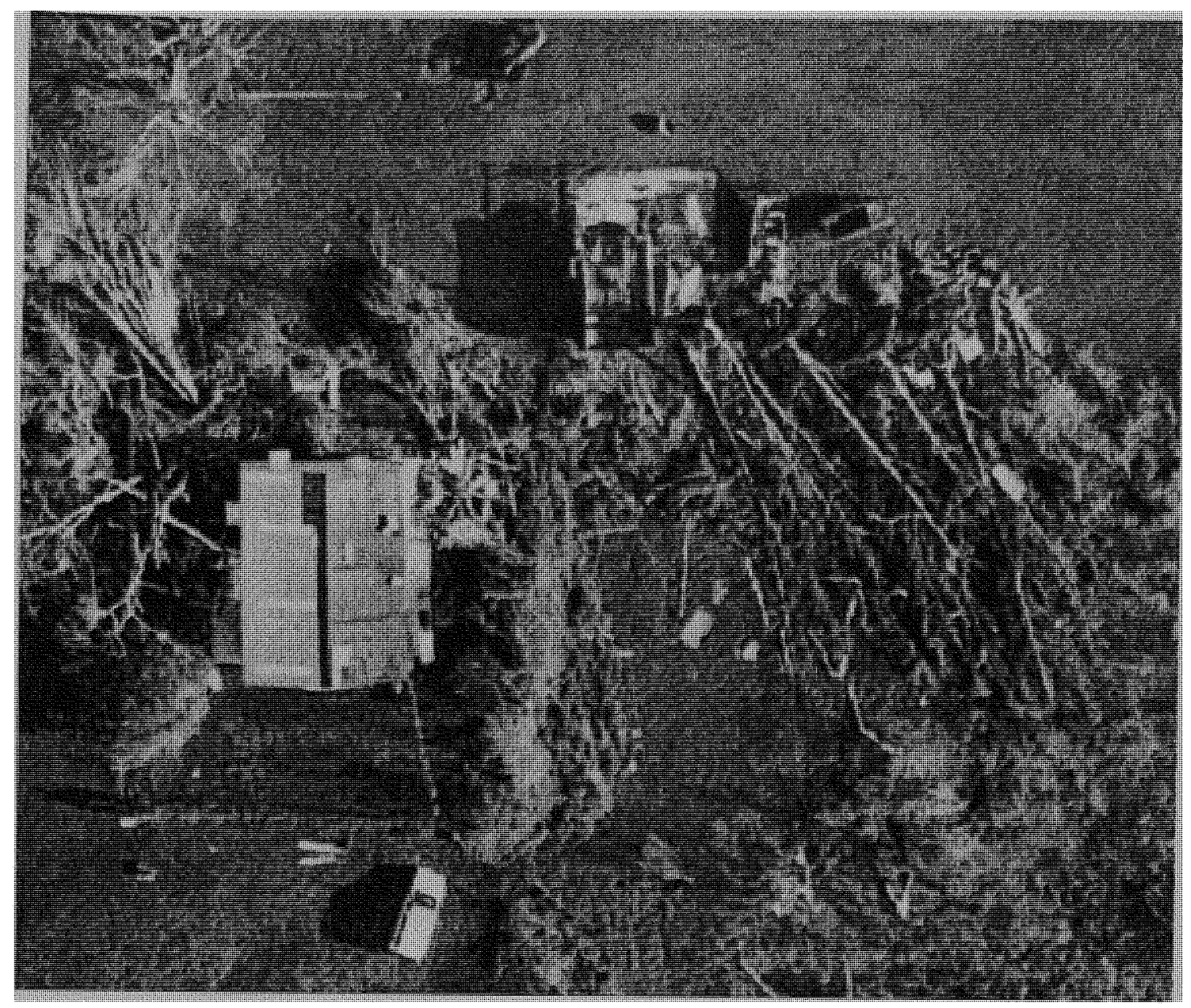

Figure 12.7. Damage due to fallen trees.

The figure shows farm structures, which was damaged due to falling of trees. Large trees were surrounding the house, which got uprooted due to strong wind force, and directly falling on the roof of the houses. Items commonly damaged were roof cover and sheathing and some cases dry walls were damaged. The wind direction can be predicted from falling of trees. It was blowing from south-east to north-west. 


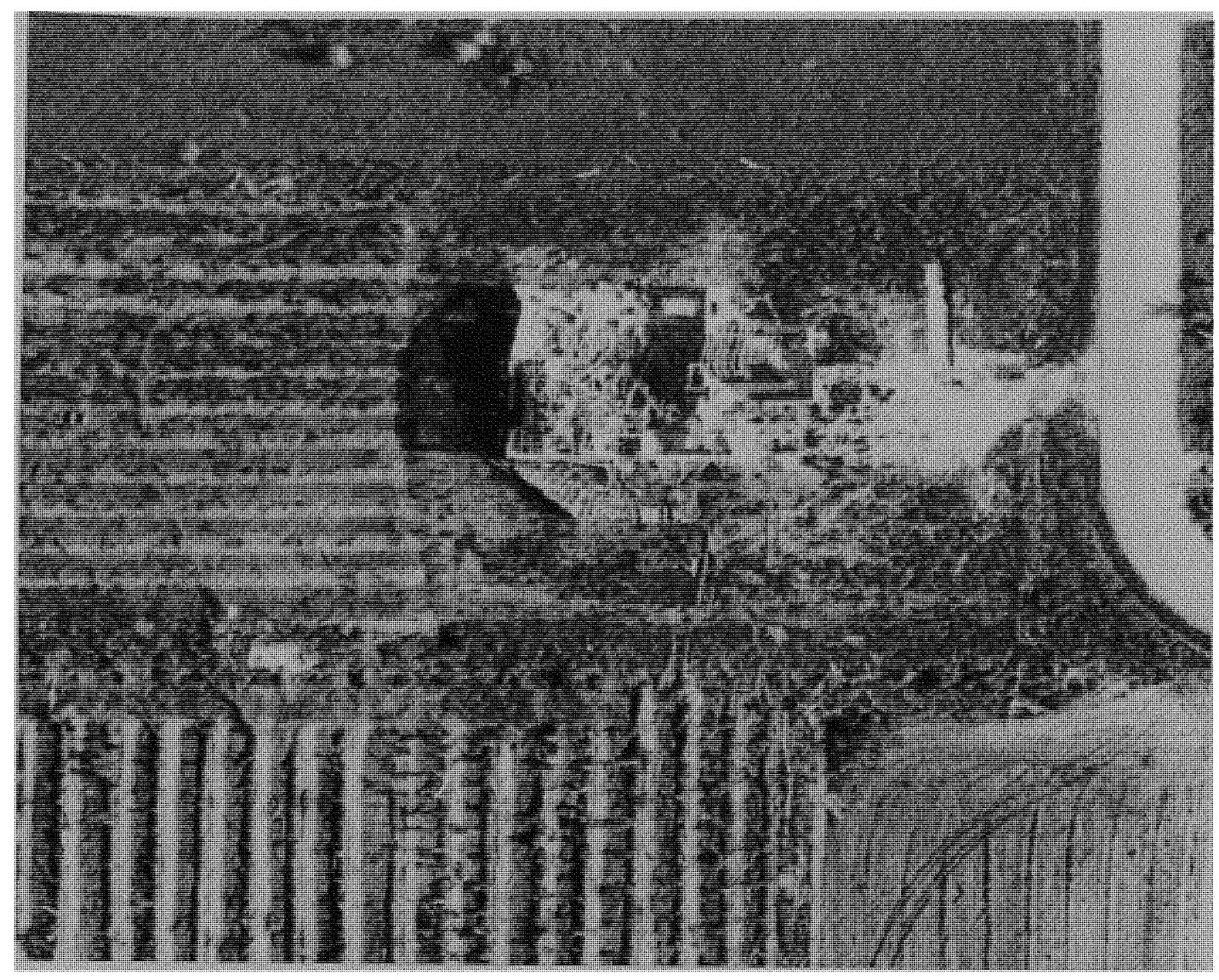

Figure 12.8. Damage due to lack of barrier surrounding the house.

This figure shows a typical example of an isolated house situated in the middle of the farmland. The house has been badly damaged with roof system completely destroyed. As seen the roof system collapsed inside the house. There was some debris on one side of the house. The major reason for such extensive damage was because there were no barriers such as trees or houses surrounding this house. The wind was blowing from west to east. 


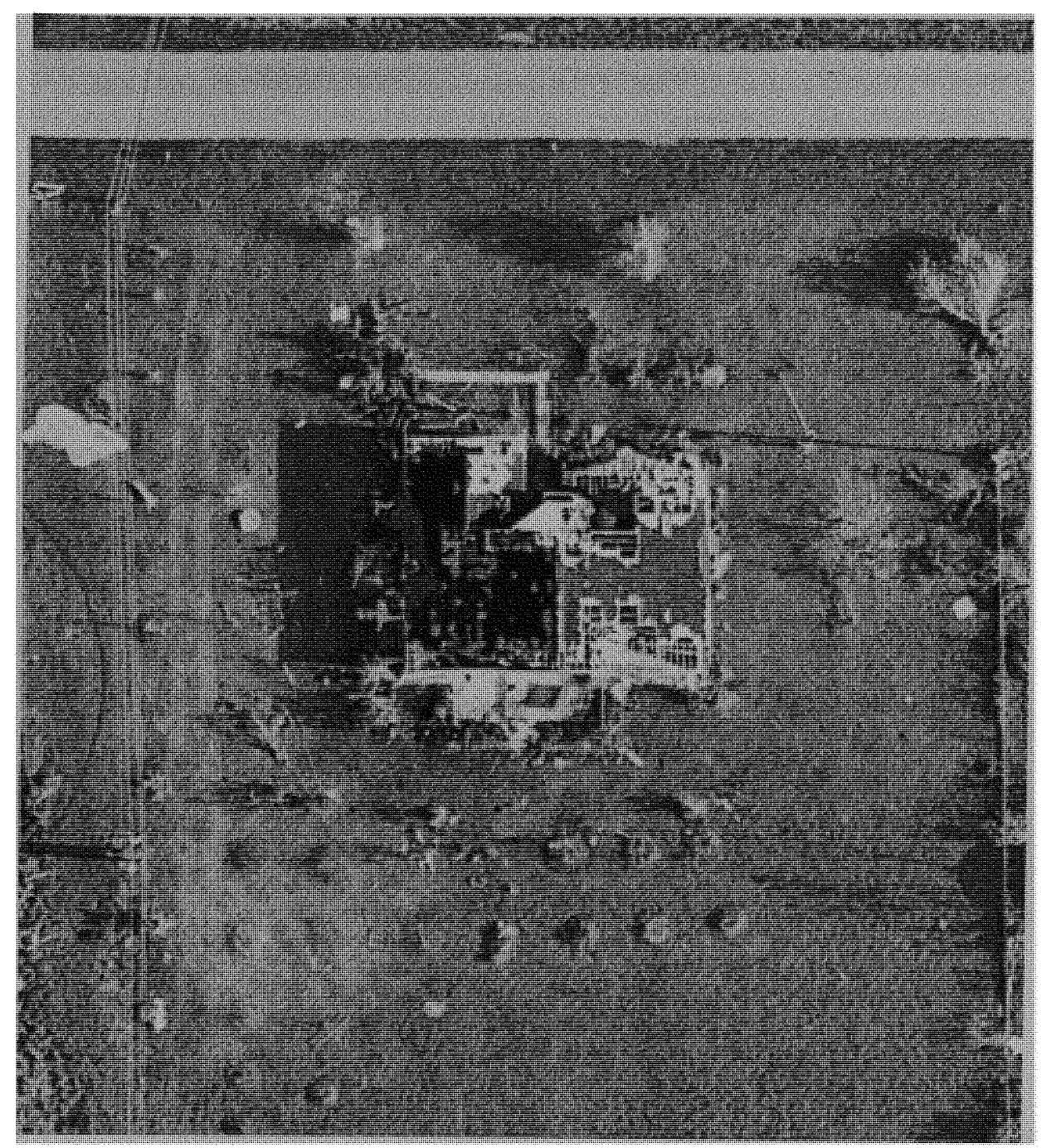

Figure 12.9. Structurally strong roof truss.

This figure shows a house with damages to the roof cover and sheathing. Minor damage has occurred to the roof truss. This indicates that the roof truss was structurally strong enough to resist the wind force. The roof cover and sheathing was blown due to lack of strength between them. The wind direction was difficult to predict from the damages, as there were no trees surrounding the house. 


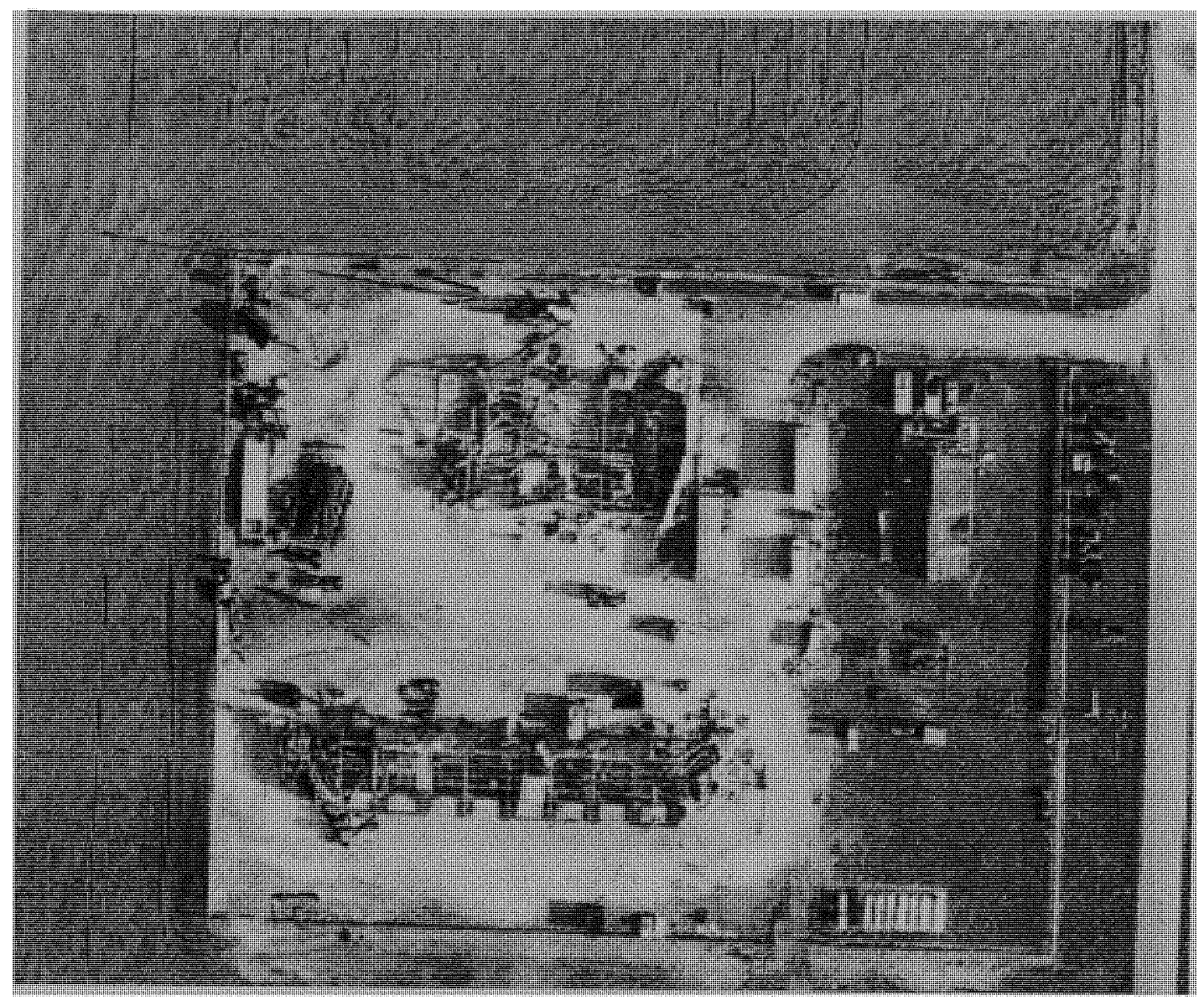

Figure 12.10. Severe structural damage.

This is a typical example of a warehouse, which has been extensively damaged by the wind force. There were sever structural damage and the whole of roof system has been collapsed. S heathing and roof cover $\mathrm{h}$ as $\mathrm{b}$ een $\mathrm{b}$ lown off including the gable end. The wind force was so high that debris cannot be found near or surrounding this building. The surrounding of this building lacked trees which might had protected this structure. The wind direction is difficult to predict. 


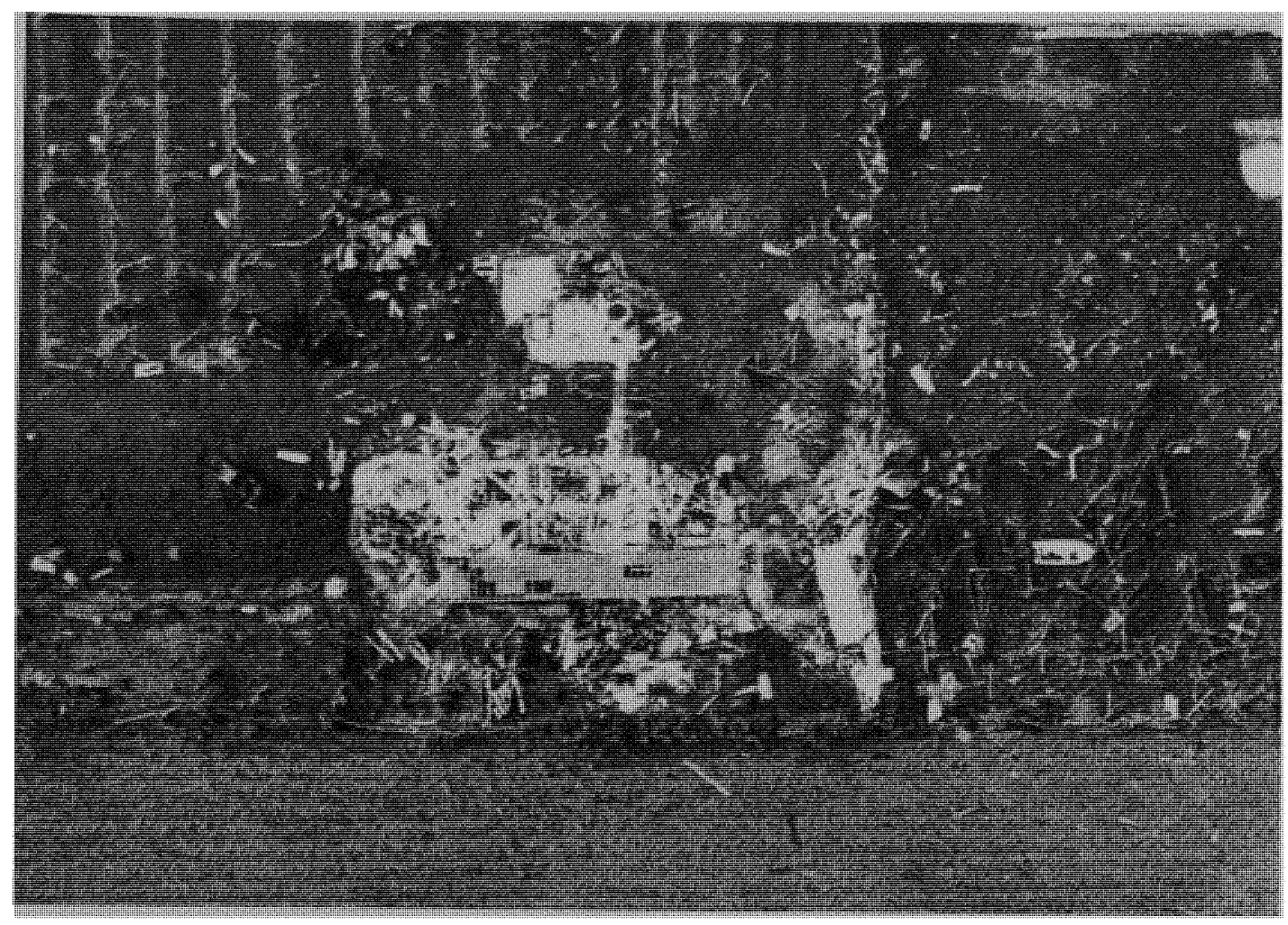

Figure 12.11. 80\% damage to roof structure.

The figure shows more than $80 \%$ of the roof structure is severely damaged. More than $70 \%$ of the right-hand side of this townhouse was totally destroyed. The exterior wall and the roof was ripped and peeled away by Hurricane Andrew. Only $20 \%$ of the roof covers, and the sheathings stay on the roof. Once the house lost the roof sheathings, all the interior properties were damaged by rain. Since the roof-structure on the right-hand side was gone, it was obvious to see that one of the gable-ends missing. Even the gable end on the left-hand side was missed. 
13. TRANSPORTATION VEHICLES 


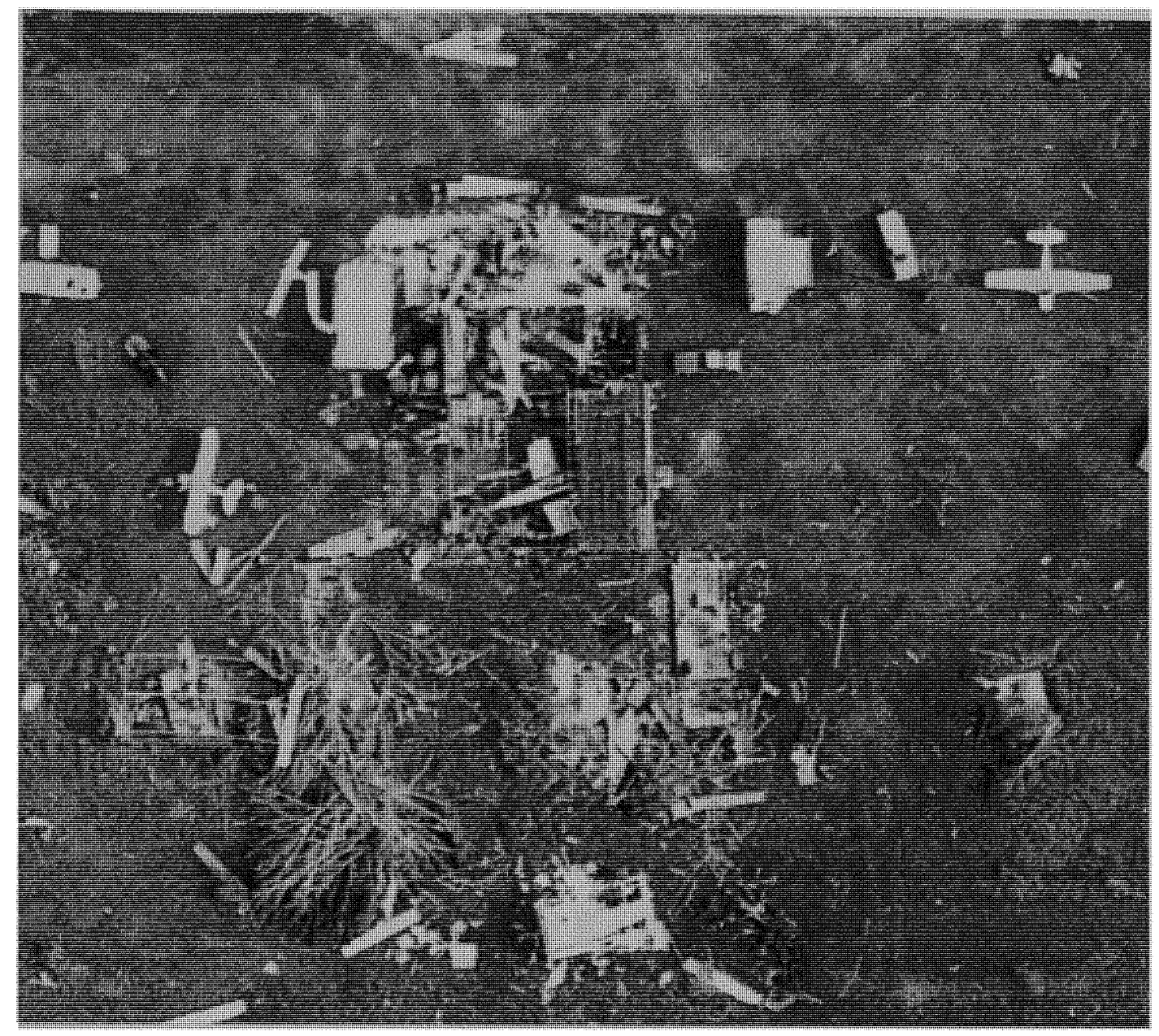

Figure 13.1. Destruction of hanger.

The figure shows some kind of small airfield or a hanger. We can see small aircrafts, some of which are damaged. There has been lot of accumulation of debris due to damages caused in the small establishment all around. The wind direction cannot be adequately predicted from the above figure. Normally hangers a re elevated and hence there has been major damage to the roof. Some structural failure can also be observed. In one place the entire frame is displaced and is lying on the ground. 


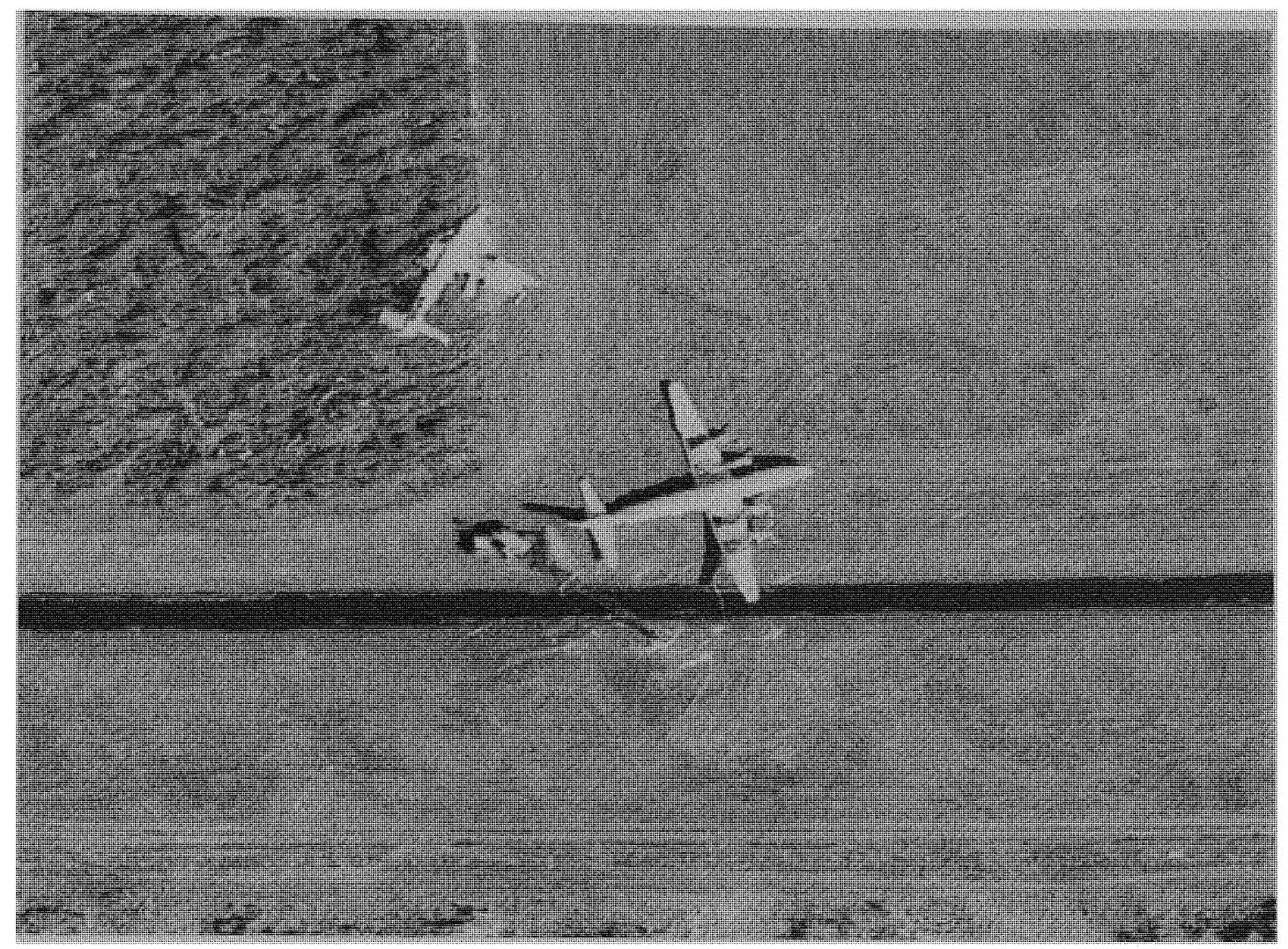

Figure 13.2. Dynamic objects cannot withstand the strong wind force.

The figure shows two small planes, which were grounded, might be due to the wind effect of the hurricane. It can be concluded that any dynamic object present during the hurricane may not withstand the impact and can lead to accidents as seen in the above figure. In these case it is believed that the wind pressure high enough to push the airplane down. The airplane fell in open field and hence there was no damage to life or to the property. 


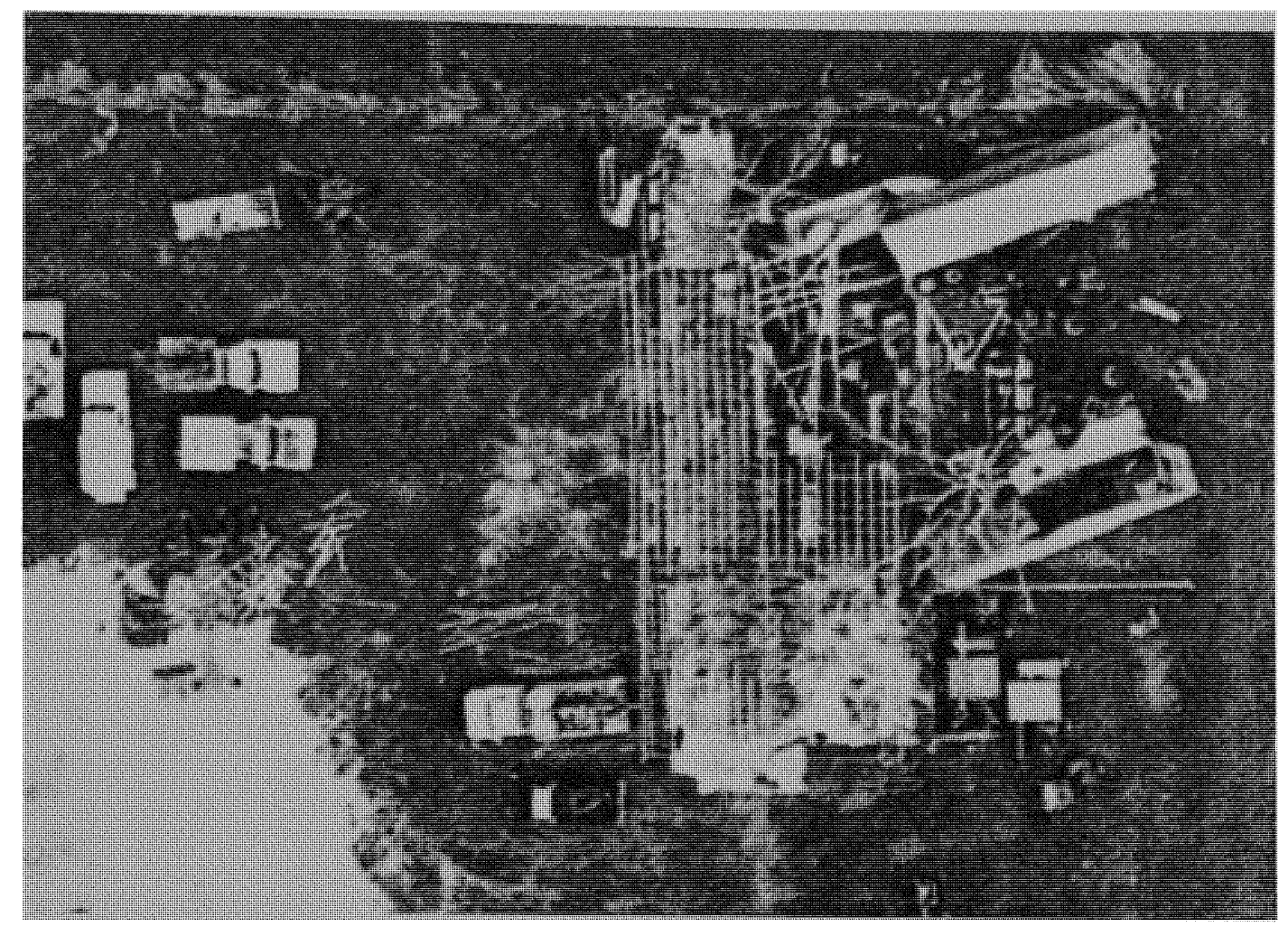

\section{Figure 13.3. Damage due to overturning of heavy vehicles.}

This figure illustrates major roof cover and sheathing damage. Once the sheathing was lost. The building envelope was effectively breached. Wind pressure was now exerted against the inside of the gable end-wall leading to possible failure. Once the wind managed to lift one layer of shingles tabs, the shingles acted as a sail, bending at the attachment and tearing it away. One of the major causes of the damage was due to overturning of the truck. In $\mathrm{c}$ ase of this $\mathrm{p}$ articular s tructure the roof $\mathrm{w}$ as s ubjected to wind forces from many directions. 
14. COMMUNICATION TOWERS 


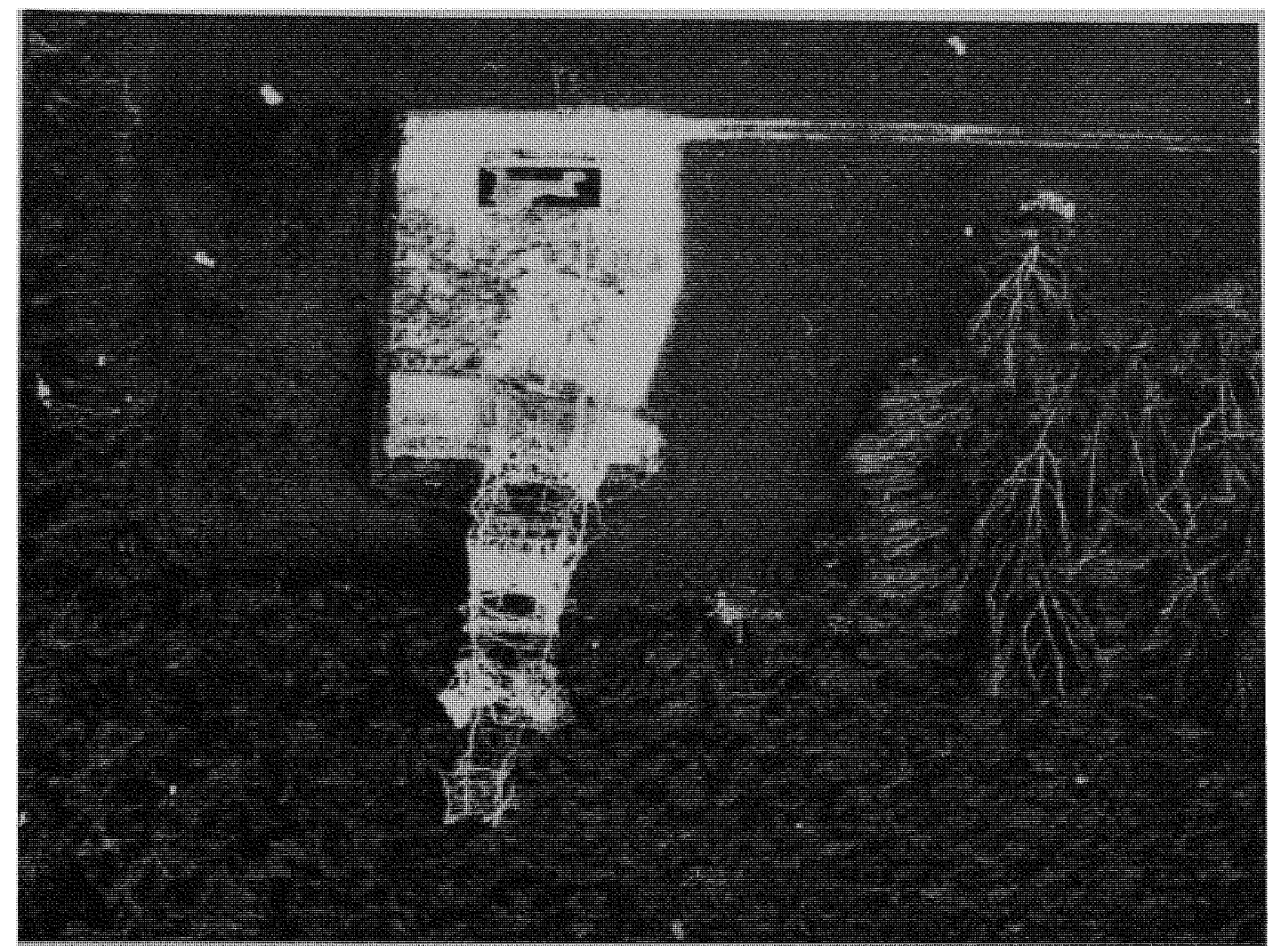

Figure 14.1. Dislocation of secondary steel bracings.

This figure shows a pylon, which has been uplifted and grounded by wind force. This huge structure might have a week foundation. Pylons are generally steel structure. Major structural damage of the steel section can be observed. Secondary steel bracings within the structure got dislocated and badly mutilated and got entangled within themselves. The wind might have blown from north to south. There were no residential or commercial establishment surrounding the damaged structure and hence there was no major loss of other property. The soil bearing capacity of the particular area should be estimated before placing the pylon and simultaneously wind pressure exerted on the pylon should be calculated. 